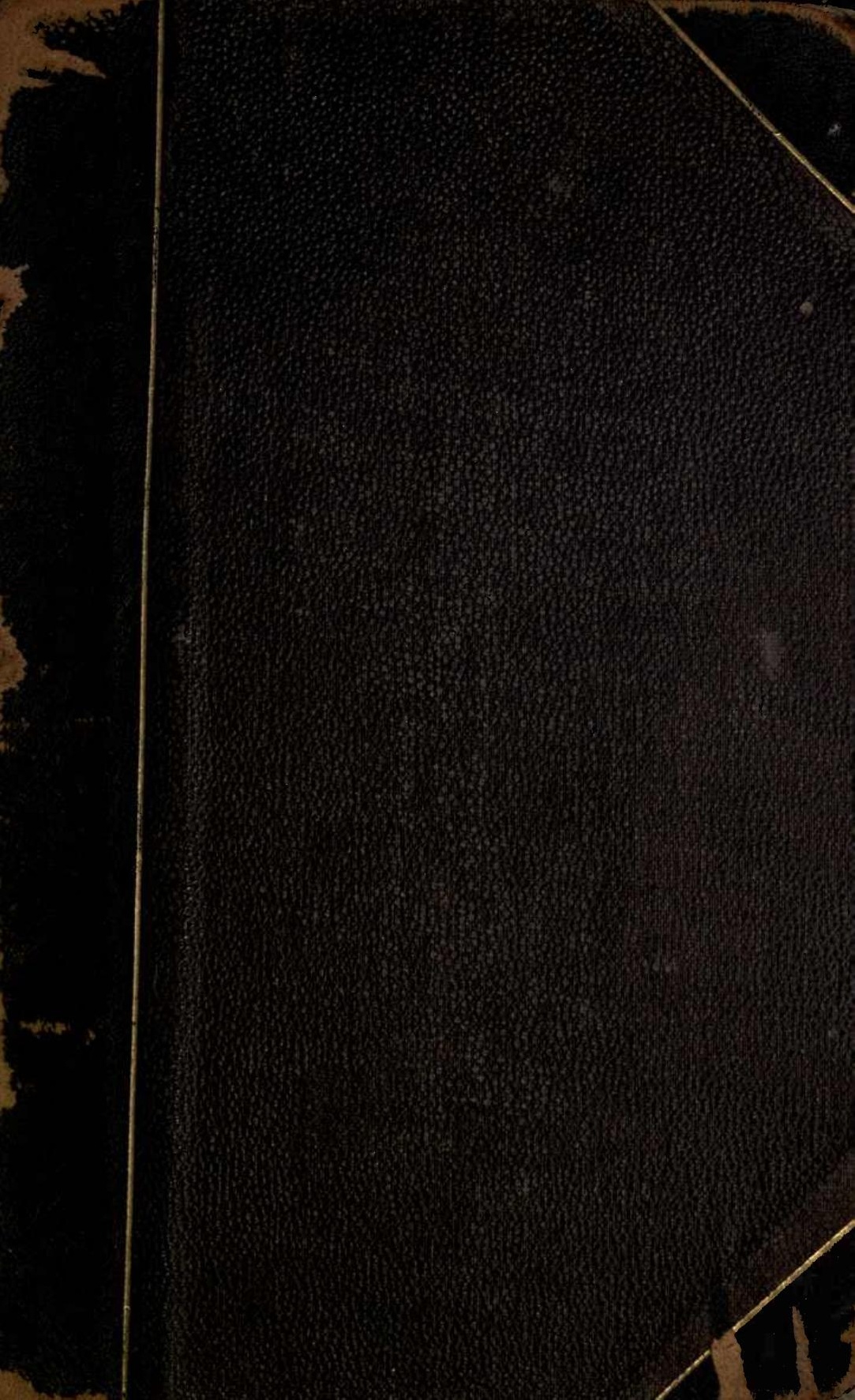




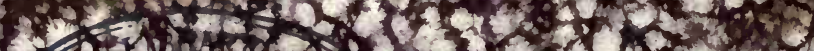

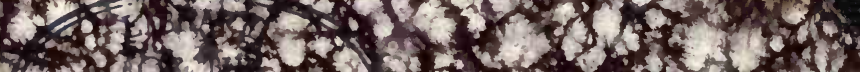

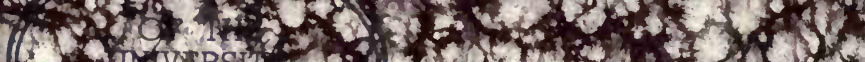

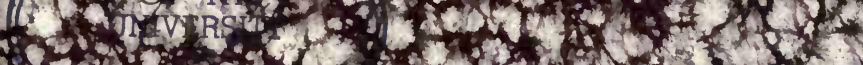

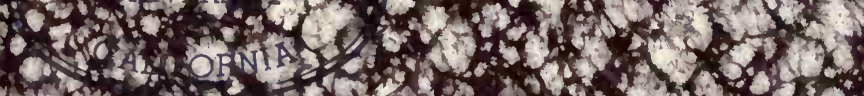

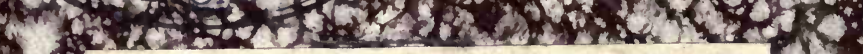
20

24.

6.

(1)

s.

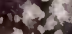

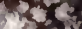

23

coses

की

It)

int?

(2)

6.04

$x^{2}+2$

If

neling

1.2.

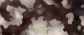

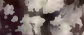

$2)^{2} 3$

N.

13

(3)

$37^{2}$

$x^{2}$

36 (3)

AGRIC.

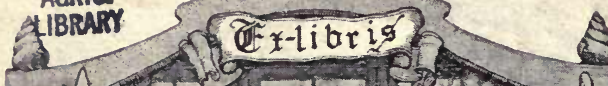
8

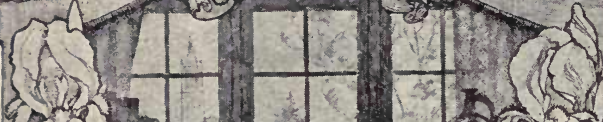

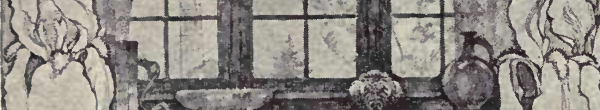

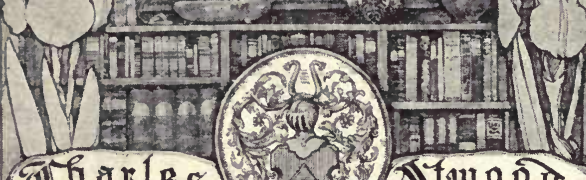

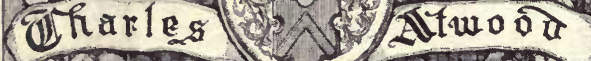

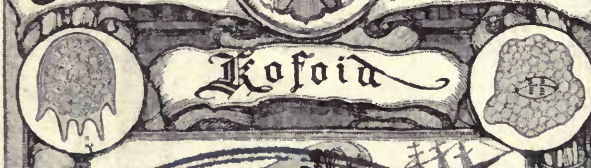

(r)

and is

1.8.

If $x$,

(2). 13

(x) 1313

20)

2 ?

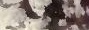

6.

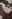

(3)

ares.

2. $\mathrm{M}=\mathrm{C}$

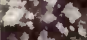

Sals

Hox.

*at 15

4.

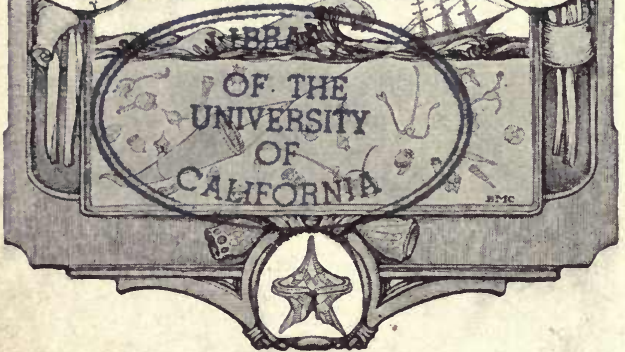

at

3.

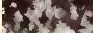

$+2$

i.

Nis 18 (1)

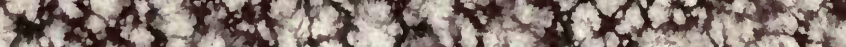

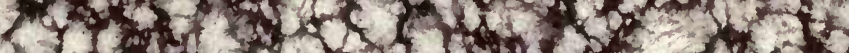

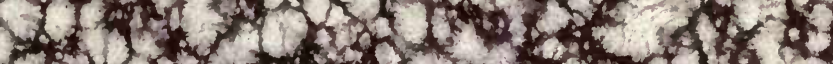

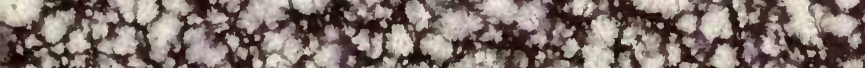

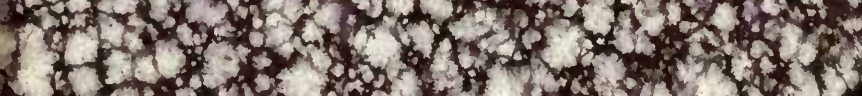

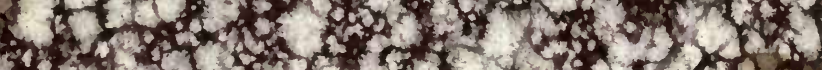




\section{$\gamma=$}

-

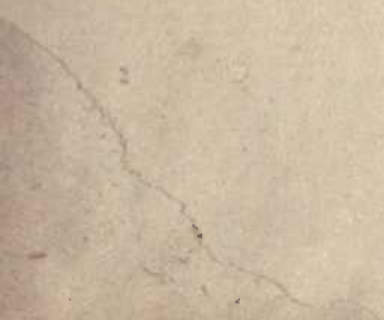






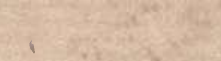

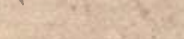

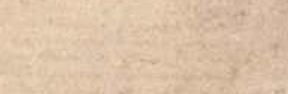

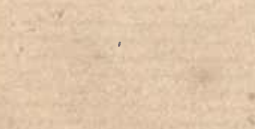

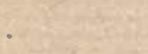

44

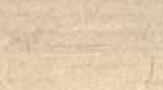

- 



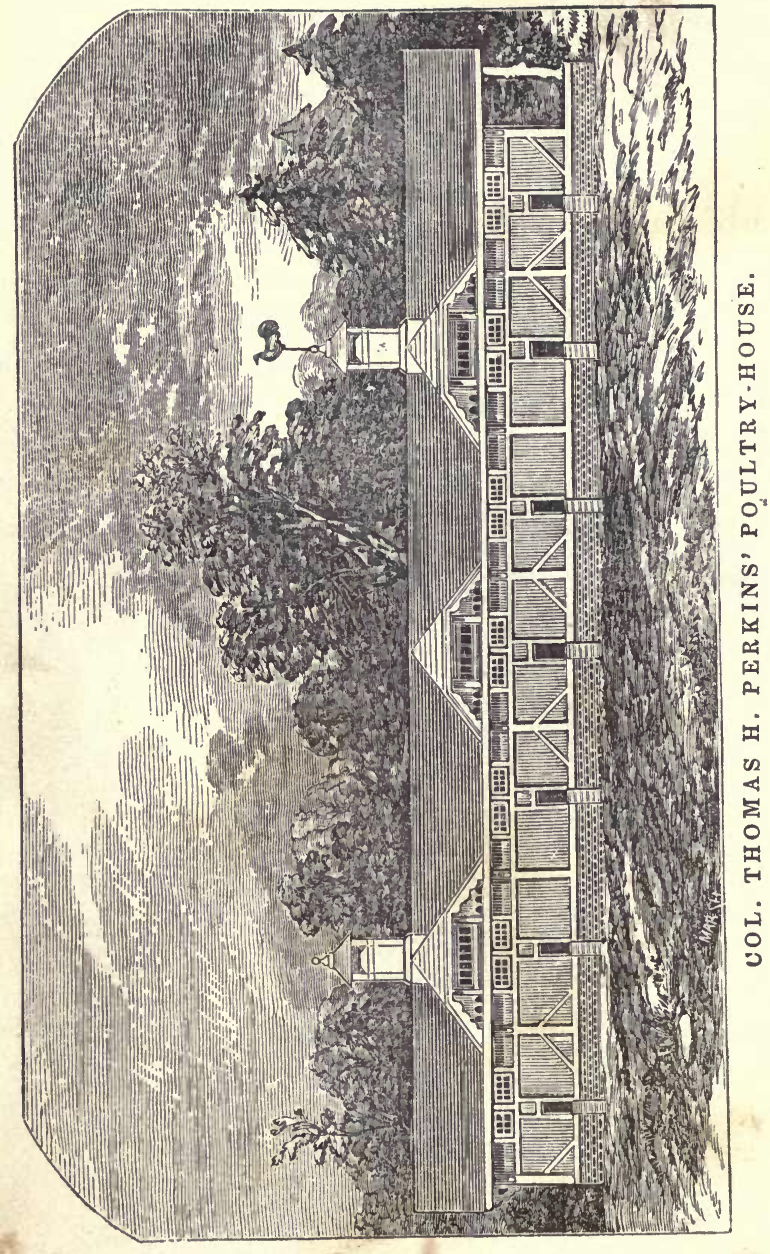




\title{
POULTRY BO0K:
}

A TREATISE ON

\section{BREEDING AND GENERAL MANAGEMENT}

\author{
OF \\ D 0 M E S T I C F $0 \mathrm{WLS}$;
}

WITH NUMEROUS

(1)riginal \$escriptions, and portraits from fife.

\section{BY JOHN C. BENNETT, M. D., PHYSICIAN AND SURGEON.}

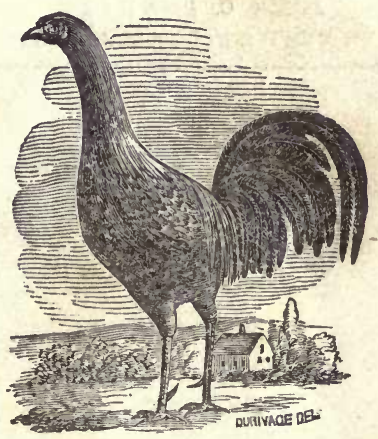

\section{BOS TON :}

- PHILLIPS, SAMPSON \& COMPANY. NEW YORK : CHARLES M. SAXTON. PHILADELPHIA : THOMAS, COWPERTHWAIT \& CO. BALTIMORE.: CUSHING \& BROTHER. CHARLESTON, S: C.: M'CARTER \& ALLEN. CINCINNATI : H. W. DERBY \& CO. BUFFALO: G. H. DERBY \& CO. 
Entered according to Act of Congress, in the year 1850, by JOHN C. BENNETT, In the Clerk's Office of the District Court of the District of Massachusetts.

New England Type and Stereotype Foundery, Boston.

WRIGHT AND HASTY, PRINTERS, 


\section{$15 F 487$ 1843}

MERIG. UBBRARY

\section{ADVERTISEMENT.}

Is presenting the Poultrx Boor to the public, the publishers take occasion to introduce the volume by a few preliminary remarks.

Dr. Bennett is favorably and extensively known as a practical breeder of fowls. To him is due the credit of originating the interest which is now felt in respect to poultry; and fanciers and breeders are already greatly indebted to his labors. Col. Jaques testifies that he was "the first to set in motion this laudable excitement ;" and Dr. Eben Wight speaks of him as "a pioneer in the cause." A treatise on Poultry, from such a source, we can, therefore, confidently commend to public favor, as adapted to the present state of information on the subject, and to practical and economical use.

No pains or expense has been spared in order to secure great accuracy, and to produce a beautiful volume. The engravings have been executed in the first style, by the best artists, and, in most cases, from original drawings. In no other work can be found so numerous and reliable portraits of fowls; and in accomplishing this, such an expense has been incurred as to cause the proprietors to copyright them. We are persuaded that the public patronage will show that we have accomplished our aim, in issuing a work which will be from henceforth of standard authority and permanent value.

PHILLIPS, SAMPSON \& COMPANY,

Publishers.

Boston, March, 1850. 


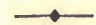

This work owes its origin to the request or advice of some of the most distinguished Poultry Breeders and Fanciers in this country. Among these may be mentioned, John Giles, Esq., of Providence, for many years a judge of the American Institute, and widely known as an importer and breeder of Fowls; James Pedder, Esq., editor of the Boston Cultivator, distinguished in Europe and America as authority in all matters of Rural Economy ; Wm. Buckminster, Esq., and Wm. J. Buckminster, Esq., editors of the Massachusetts Ploughman, names of celebrity in the same department ; and Edward P. Roberts, Esq., the popular editor of the American Farmer, of Baltimore.

The object which has been kept in view, in this publication, has been to furnish a full, authentic, and reliable work, adapted to meet the demand growing out of the interest recently manifested on the subject of Poultry. With the exception of the American Poulterer's Companion, it is believed that no other book, claiming authority, has appeared in this country. $\mathrm{Mr}$ Bement deserves a respectful mention of his labors, for they have been the means of diffusing much information and effecting desirable results. Until his book appeared, those interested in rearing domestic fowls were, of necessity, compelled to resort to the works of such foreign authors as might be accessible to them. Among them, Dickson and Richardson have been the most prominent, with the exception, perhaps, of Mowbray. These writers have done valuable service, and to them all their successors must be more or less indebted. They have amassed stores of information, collected from all available sources, and augmented by their original investigations. But, after all, a 
poultry-book adapted to our climate, and the present state of intelligence, is a desideratum.

To supply this deficiency has been attempted by the author; how successfully, remains to be seen. Every pains has been taken to collect important facts, and to digest in these pages whatever information could be obtained. All accessible authorities have been consulted, and such use has been made of available materials as would best subserve the purpose designed to be accomplished. To mention all the books which have been laid under contribution, would be only a pedantic display; but if any failure is discoverable in giving the requisite credit, it is undesigned. A vast mass of correspondence has furnished many original observations, which are of great value, and are not elsewhere to be found.

Special attention has been given to the description of the varieties of Fowls, and it will appear, on examination, that great labor has been expended on this department; and the author flatters himself that a remarkable degree of accuracy has been attained. A peculiar feature of this volume, also, is, the presentation of the portraits from life, which have been faithfully delineated, and engraved by eminent artists, and which possess an importance and value which will be readily appreciated. These have been produced with great care, and at a large expense, and will add to the fame of F. A. Durivage, Esq., from whose drawings they are taken, and are creditable to the burin of Messrs. Hartwell and Marsh, by whom they have been engraved.

In all matters pertaining to the Breeding and Management of Poultry, this book is designed to be a vade mecum, and the endeavor has been to present to the reader all that is necessary to be known on these subjects. In no other work. it is believed. can similar information be found.

In addition to the counsel and aid furnished by the distinguished gentlemen already mentioned, I gratefully avail myself of the opportunity of acknowledging my obligations to J. N. 
Bates, M. D., of Barre; W. S. Sanders, M. D., of Sturbridge ; S. E. Strong, M. D., of North Andover; H. L. Devereux, Esq., George E. White, Esq., and Mr. James M. Parker, of Boston. To George P. Burnham, Esq., the popular editor of the American Union, my particular acknowledgments are due, for many favors and valuable aid; and to J. J. Kerr, M. D., of Kensington, I am likewise greatly indebted for his acceptable correspondence and useful suggestions. To Rev. Robert B. Hall, of Plymouth, for valuable suggestions and assistance in arranging and perfecting the work, my acknowledgments are especially due. To Winslow Warren, M. D., Francis B. Brewer, M. D., William H. Spear, Esq., Dr. Frank A. Fuller, and Mr. George H. Jackson, all of Plymouth, I am also indebted for repeated favors, which have facilitated the progress of the work.

It is hoped that, prepared with such advantages, this book will serve to diffuse, more widely, reliable intelligence in respect to the very important subject of which it treats, and will prove a welcome acquisition to the libraries of practical men. It is not pretended that it is free from defects; but its imperfections, such as they are, must be attributed to other causes than negligence, or the absence of an honest design to furnish a manual of present interest and permanent utility. 


\section{CONTENTS.}

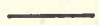

CHAPTER I. - INTRODUCTORY . . . . . . . . . . 13

CHAP. II. - ORIGIN OF THE DOMESTIC FOWL . . . . . . 19

CHAP. III. - VARIETIES OF DOMESTIC FOWL.

Chittagong Fowl ............. 26

Shanghae Fowl ................. 31

White Shanghae Fowl ........... 37

Cochin China Fowl . . . . . . . . . . 39

Cochin China Hen . . . . . . . . . . 40

Royal Cochin China Fowl . . . . . . . . . 45

Cochin Chinas of the Baylies! Importation ..... 48

Great Malay Fowl ............. . 51

Great Malay Hen ............ . . 52

Shakebag Fowl .............. 54

Common Malay Fowl . . . . . . . . . . 57

Great Java Fowl . . . . . . . . . . . . 58

Game Fowl - General Description . ....... 60

Wild Indian Game . . . . . . . . . . . 63

Spanish Game Fowl . . . . . . . . . 66

Yankee Game Fowl . . . . . . . . . . . 67

English Raven Fowl . . . . . . . . . . 68

Dorking Fowl - General Description . . . ....71

Fawn-colored Dorking ........... . 73

Plymouth Rock Fowl . . . . . . . . . . . 77

Guelderland Fowl ............ . . 81

Spanish Fowl ............ . . . . . . . . 83

Spanish Hen ............ . . 84

Blake's Spanish Fowl ......... 86

Bavarian Fowl . . . . . . . . . . 88

Polish Fowl . . . . . . . . . . 89

Spangled Hamburgh Fowl ......... . . . . 94

Silver Pheasant ........... . . . 90 
Page

Bolton Grays, or Creole Fowl . . . . . - . . . 97

Frizzled Fowl .. . . . . . . . . . . . 98

Dominique Fowl ................ 100

Bantam Fowl . . . . . . . . . . . . . . 101

African Bantam ............... 104

CHAP. IV. - THE TURKEY.

Origin of the Turkey .. . . . . . . . . . 105

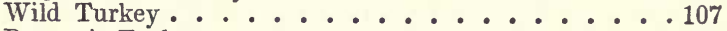

Domestic Turkey . . . . . . . . . . . . . 112

Guinea Fowl, or Pintado . . . . . . . . . 124

CHAP, V. - THE GOOSE.

General Description . . . . . . . . . . 126

African Goose . . . . . . . . . . • • . 129

Indian Mountain Goose . . . . . . . . . . 131

Poland Goose . . . . . . . . . . . . . . 133

Chinese Goose . . . . . . . . . . . . 134

Toulouse Goose . . . . . . . . . . . . 135

Bremen Goose .. . . . . . . . . . . . 137

CHAP. VI. - DUCKS.

Domestic Duck . . . . . . . . . . . 139

Aylesbury Duck . . . . . . . . . . . . 141

Rouen Duck . . . . . . . . . . . . . 142

Poland Duck . . . . . . . . . . . . . 143

Muscovy Duck . . . . . . . . . . . . 145

CHAP. VII. - PIGEONS.

General Description ............. 145

Carrier Pigeons ............... 148

CHAP. VIII. - FOOD OF POULTRY.

General Remarks .......... . ... . 150

Varieties of Food ............... 152

Different Sorts of Food ............. 161

Methods of Feeding Fowls ........... 171

CHAP. IX. - FATTENING OF FOWLS.

General Remarks ............... 176

Mascall's Mode of Fattening . . . . . . . . . 177

Markham's Mode of Fattening . . . . . . . . . 179

Bradley's Mode of Fattening . . . . . . . . . 179

Modern English Methods of Fattening . . . . . . 179 
CHAP. X. - SELECTION OF STOCK AND PAIRING. Page General Remarks ............ 185 Selections of a Good Cock . . . . . . . . 186 Choice of a Hen . . . . . . . . . . . 191

CHAP. XI. - ON BREEDING FOWLS . . . . . . . 193

CHAP. XII. - LAYING . . . . . . . . 206 Preservation of Eggs ............ . . 211 Weight and Value of Eggs . . . . . . . 215

CHAP. XIII. - INCUBATION . . . . . . . . . 218

First and Last Stages of Incubation . . . . . . . 222

Exclusion of the Chick . . . . . . . . . . . 223

Position of the Chick immediately before Hatching, and of the Situation of the Bill in the Act of Chipping the

Egg . . . . . . . . . . . 224 Food of the Chick . . . . . . . . . . 227

CHAP. XIV. - CAPONIZING . . . . . . . . 233

CHAP. XV.-POULTRY-HOUSES . . . . . . . . 239

The Royal Poultry-house . . . . . . . . 242

Lord Penrhyn's Poultry-house . . . . . . . . 243

Mr. England's Poultry-house .......... 244

Mr. Wakefield's Poultry-house . . . . . . . . 244

Col. Perkins' Poultry-house . . . . . . . . 245

Common Poultry-house .......... . 248

CHAP. XVI. - DISEASES OF POULTRY $\ldots . . . . .251$

I. Diseases of the Digestive Organs.

1. The Pip, or Gapes . . . . . . . . . 254

2. Indigestion . . . . . . . . 257

3. Costiveness . . . . . . . . . 258

4. Diarrhœa . . . . . . . . . . . 258

II. Diseases of the Respiratory Organs.

1. Obstructions of the Nostril . . . . . . 260

2. Asthma .................260

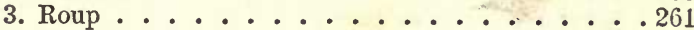

4. Consumption . . . . . . . . 263

III. Diseases of the Circulation.

1. Fever . . . . . . . . . 265

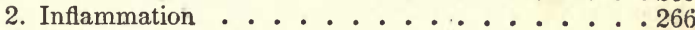

3. Rheumatism . . . . . . . . . 266

4. Gout ................... 267 
IV. Diseases of the Brain Page

1. Apoplexy . . . . . . . . . . 267

2. Melancholy and Moping ........ 269

V. Diseases of the Skin.

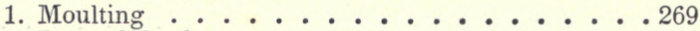

2. Loss of Feathers . . . . . . . . . 270

3. Vermin ............... 271

VI. Externai, Disorders.

1. Disease of the Rump Gland . . . . . . 272

2. Fractures and Dislocations . . . . . . 272

3. Wounds and Sores ............ 273

4. Vermin in Poultry-houses ...... 273

A P P E N DIX.

Exhibition of Poultry in the Public Garden, Nov. 15th and 16th, 1849 . . . . . . . . . 275

Constitution of the New England Society for the Improvement of Domestic Poultry . . . . . . . . 296

Letter from the Committee of Supervision of the Poultry Exhibition at the Public Garden, to Dr. Bennett . . . 303 Cochin Chinas and Shanghaes ....... . 304 Chittagong Fowl .......... 305 


\section{THE POULTR Y-B $00 \mathrm{~K}$.}

\section{CHAPTER I.}

\section{INTRODUCTORY.}

IT is only within a few years that attention has been turned to the subject of Poultry in a scientific or economical point of view. While all over the world poultry has ever been considered a delicate and favorite article of food, and in this country is universally esteemed a luxury, it seems surprising that information concerning the different breeds, the mode of rearing them, and other matters pertaining to the subject, should not have attracted greater notice.

In France, Egypt, and some other countries, poultry is used as a common and necessary article of food. The various sorts are raised around the dwellings of almost every peasant. It is said, on good authority, that in France a greater quantity of food is supplied for the tables of the wealthy from the poultryyard than from the shambles, and it is well known that, in Egypt, artificial means are commonly used for hatching and rearing chickens in vast numbers for common consumption. It is probable that in all warm countries poultry may be more readily raised than among us, and that it furnishes a sort of food best adapted to the inhabitants of more genial climes.

In England, of late years, there has been a growing disposition to investigate more thoroughly the nature and varieties of Domestic Fowls, in order to determine the economical import- 
ance of promoting their multiplication, and by the encouragement of the best sorts to add to the agricultural wealth of the country. A vast amount of scientific information has been accumulated, statistics have been accurately obtained, and such facts have been amassed in respect to the best methods of feeding and treatment, that poultry raising has been reduced to a system, precise in its details and efficient in its operation. The same spirit has recently been awakened in this country, and the labors of those who have become interested in this subject have brought to light many astonishing facts, and have given an impetus to further investigation which promises the best results. It is no longer universally true that fowls are raised without care, or with a perfect indifference as to their kind. The old notion, that fowls are an unprofitable stock to the farmer, is exploded, by force of the demonstrations which have been given that they may be made productive. The agricultural census has proved that the raising of poultry ranks high in value, as a branch of rural economy, and the astonishment created by its results has been succeeded by a more careful attention to the matter, as one in which the interests of a large class of men are involved. It is now generally acknowledged that, in proportion to the capital invested, the poultry-yard will, if properly managed, contribute its full quota to the aggregate profits of the farm.

The statistics on this subject are doubtless imperfect, but enough is known not only to excite wonder in the minds of those who have given no attention to it, but to prove beyond doubt that the value of poultry stock in the United States is a very important item of the national wealth. The table below exhibits the total valuation of poultry in the various states and

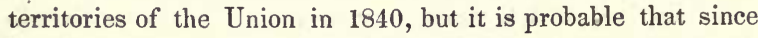
that time this valuation has nearly doubled. It is fair, at least, to estimate that, at the present time, the value of this stock, in 
the United States, is twenty millions of dollars. The statistics for 1840 are as follows :

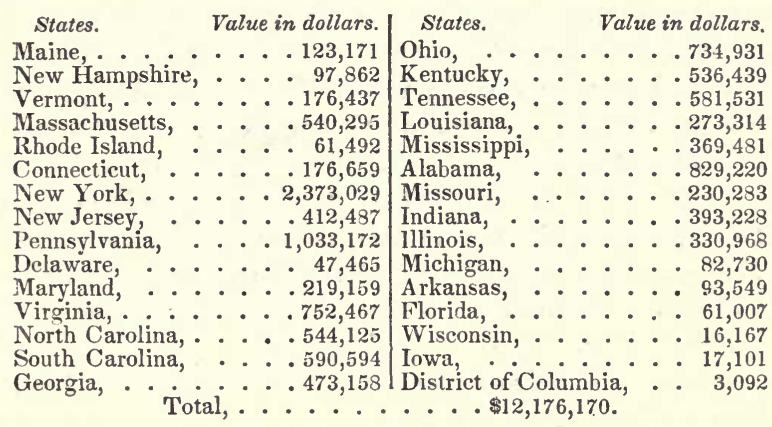

From this table it appears that the value of poultry in the single state of New York was $\$ 2,373,029$; which, on comparison with other tables procured by the same census, shows that this sum exceeds the value of the sheep raised in the same state, the entire value of her neat cattle, and is nearly five times the value of horses and mules raised within her borders.

It is estimated, from satisfactory returns, that the city of New York alone expends nearly a million and a half of dollars per annum in the purchase of eggs. A half million of eggs are consumed monthly, and the Astor House is said to require a supply of one thousand per day during five days in the week, and on Saturdays twenty-five hundred.

The amount of sales of eggs, in and around the Quiney Market, for 1848, was $1,129,735$ dozen, which, at 18 cents per dozen, (the lowest price paid $11 \frac{1}{2}$ cents, and the highest 30 cents per dozen, as proved by the average purchases of one of the largest dealer's books,) makes the amount paid for eggs to be $\$ 203,35230$. And from information already obtained from other egg merchants in the same city, the whole amount of 
sales will not fall much, if any, short of a million of dollars, for 1848. The average consumption of eggs at three of the hotels was more than 200 dozen each day, for the year 1848 .

The value of eggs brought from the Penobscot and Kennebec rivers, during the running season of the steamboats plying between Boston and those two rivers, was more than $\$ 350,000$ for that season.

In one day, from Cincinnati, Ohio, it is stated in one of the public journals, there were shipped 500 barrels, containing 47,000 dozen of eggs.। One dealer in the egg trade, at Philadelphia, sends to the New York market, daily, nearly 100 barrels of eggs.

It is stated in a Providence paper, that one small vessel has been employed for twenty-three years in the egg business between Westport, Mass., and that place ; that her trips were about twenty-five annually; and the number of eggs brought in each trip averaged 400 dozen. The grand total brought from that port, by this single vessel, in the term mentioned, was $3,450,000$, and the value of them was $\$ 35,500$.

These facts will serve to show the great value of one article of the produce of the poultry-yard, in our own markets. In England and France, however, the value of eggs is immense, as the following statistics will show; and it is to be regretted that here an approximate value only can be ascertained, on account of the difficulty of procuring statistics of later date, which, no doubt, would show a more astonishing array of figures.

The number of eggs imported into England, from various parts of the continent, in 1839 , was $83,745,723$, and the gross amount of duty received for the same was $£ 29,111$.

The importation of eggs from Ireland, in 1837, to Liverpool and Bristol alone, amounted in value to over $\$ 1,250,000$. "It appears," says McCulloch, "from official statements, 
that eggs imported from France into England amount to about $60,000,000$ a year." These are sold to the consumer for a sum not less than $\$ 1,065,000$.

"When we look," says McQueen, "at the immense number of eggs brought from Ireland, (50 tons of eggs, and 10 tons of live and dead poultry, having been shipped from Dublin alone in one day,) and 66,000,000 eggs imported from France to London alone, and this immense number a trifle certainly to what are produced in this country, (England,) we shall cease to wonder at the large capital $(£ 8,000,000)$ invested in poultry of all kinds. The quantity of eggs imported into Liverpool from Ireland, in 1832 , was 4097 crates, value $£ 81,940$ sterling; which, at sixpence per dozen, gives $3,297,600$ dozens of eggs, and the number $39,331,200$. In 1833 , the import had increased to 7,851 crates, or upwards of $70,000,000$. The number imported into Glasgow from Ireland, in 1835, by the custom-house entries, was 19,321 crates, which, at nine eggs to the pound, gives the number $17,459,568 . "$

"The quantity of eggs used annually in France exceeds," says one of the late journals, " $7,250,000,000$, of which enormous number Paris uses about 120,000,000."

In Bixio's Journal of Practical Agriculture and Gardening, for April, 1848, it is estimated that the whole valuation of eggs consumed and exported in France will amount to $\$ 57,000,000$. The value of eggs shipped from Dublin to Liverpool and London was more than $\$ 5,000,000$, for the year 1848 .

Our convenience to the London market, by the aid of steamers weekly, enables the farmer, through the egg merchant, to make sale of his surplus eggs in that quarter.

In the sale of poultry itself, it seems that large sums are also realized. The amount of sales of poultry at the Quincy Market, Boston, for the year 1848 , was $\$ 674,423$. The average sales of one dealer alone amounted to $\$ 1200$ per week, for the 
whole year. The amount of sales for the whole city of Boston, for the same year, (so far as obtained,) was over $\$ 1,000,000$.

No statement concerning the sales of poultry in the markets of New York, Philadelphia, and other large cities, has fallen under our observation; yet it is reasonable to suppose that the sales in these places have been in proportion to their wealth and population. If this is so, then we must estimate the amount paid for this article of food by millions, and when compared with other articles of consumption its importance will be seen.

In England and France, according to the few statistics subjoined, it appears that the amount of poultry consumed is immense, and of course the proceeds are very considerable.

The annual consumption of poultry and small game in the city of Paris usually amounts to $22,000,000$ pounds; and, according to Count Chasol, it is divided thus:- 931,000 pigeons, $1,289,000$ chickens, 549,000 turkeys, 238,000 geese, 131,000 partridges, 177,000 rabbits, and 174,000 ducks.

So long ago as December, 1793, the number of turkeys sent to London, by the stage-coaches from Norwich alone, amounted to upwards of 2500 , weighing nearly 14 tons.

The week preeeding Michaelmas day, 1830, 40 tons of poultry were sent from Bury St. Edmund's, Suffolk, to London, 30 of which were geese; and 16 tons of the latter were the property of Messrs. Flatt \& Walton, poulterers of Yostock and Repworth. Mr. Clarke, of Boston, transmitted to London, in December, 1833, the following quantity of poultry:-2400 geese and 800 turkeys ; Mr. Harris, poultry-man of Spalding, also killed and forwarded to Leadenhall market, 1150 geese, 500 turkeys, 200 ducks, and 30 dozen of fowls. - Mowbray.

France, in 1835 , had $\$ 73,000,000$ invested in poultry.

England, in 1840 , had $\$ 50,000,000$ invested in poultry.

United States, in 1840 , had $\$ 15,000,000$ invested in poultry.

Since that time, the numbers have, of course, largely increased. 
In all these calculations, we have spoken only of poultry proper, of the gallinaceous order, though custom and convenience have extended the term so as to embrace the pigeon, the duck, the goose, the guinea-hen, and the pea-fowl.

\section{CHAPTER II.}

\section{ORIGIN OF THE DOMESTIC FOWL.}

IN former times, naturalists, in treating of the domestic fowl, classed the cock species and the pheasant together, under the general head of Gallinaceous Fowls. The result of later researches has been, the discovery of sufficient reasons to determine the propriety of distinguishing them as distinct classes.

The cock tribe is used as a generic term, to include the whole family of domestic fowls; the name of the male, in this instance, furnishing an appellation sufficiently comprehensive and well recognized. The popular use is followed by zoologists, who have adopted the word "Gallinæ," from the Latin gallus, a cock, as the scientific designation of the race.

This genus of birds is characterized by having the crown of the head usually naked, and the skin raised in a fleshy protuberance, called a comb. This differs in form and size in the several varieties. The base of the lower mandible, or beak, is likewise furnished with fleshy, lobular appendages, called wattles. The tail is carried erect, and is composed of two planes folded together at acute angles. In the male, there is an elongation of the middle feathers of the tail, which causes them to fall gracefully over the others. The plumage of the male bird is characterized by considerable brilliancy and beauty, and that of the female is more modest, and comparatively dull. 
The tail-feathers of pheasants are noticeably different. They are long and vaulted, and the intermediate ones are longer than those of the side, and the cheeks are overspread with a multitude of very short feathers, exceedingly soft to the touch, and in appearance like velvet. The constitution of these birds seems to be delicate, and it is only by great care and caution that they can be induced to breed when domesticated. The cock tribe, on the contrary, is exceedingly hardy, and they endure changes of temperature and climate with comparative impunity. This fact appears by their existence in almost all the world, whether tropical, temperate, or frigid.

The Domestic Cock seems to have been known to man from a very early period. Of his real origin there is little definitely known, and even the time and manner of his introduction into Greece, or southern Europe, is invested with obscurity. But the cock has never been undistinguished among birds. In the days when Greece and Rome were in their glory, he occupied a conspicuous place in those public shows which amused the masses of the people. His praises have been sung in immortal verse by poets whose names, even now, are familiar to us as household words. His effigy was engraved, and is extant on various ancient medals and coins. He was dedicated to the service of the Deities, and was connected with the worship of Apollo, Mercury, Mars, and particularly Esculapius. To this god Socrates directed a cock to be sacrificed in those melancholy hours which immediately preceded his frightful death.

As a delicacy, the flesh of this bird was highly esteemed in ancient times, and figured conspicuously at the Roman banquets. Great care was used in the rearing and fattening of poultry for this purpose. From Rhodes and Delos the finest birds were procured, and a brisk traffic was kept up between these islands, and the purveyors for Roman epicureanism.

It is remarkable that a practice so barbarous as that of cock- 
fighting should have originated in classic times, and among the most polished and civilized people of antiquity. This practice is said to have been introduced into Britain by the Cusars, and to it we owe our introduction to the domestic fowl. In England, cock-fighting, for a long period, was considered peculiarly a royal pastime, and was exhibited as such in public assemblies on a scale of considerable grandeur and expense, until about a century since. A hundred years ago, it was a regular amusement at what is called Shrovetide, and was even allowed and promoted at the public schools; the master himself furnishing the boys, at his own expense, with the birds necessary for their brutal pleasure.

But the cock has not been called to suffering alone, in order to establish his consequence and respectability. To him was given the privilege of reclaiming St. Peter when he denied his Master. From time immemorial, his "shrill clarion" has " ushered in the morn," and in every farm-house he has served the purpose of time-keeper in the "witching hours of night." By popular superstition, he has been invested with the fearful power of dismissing the ghosts of the churchyard to their prison in the tombs. The ghost of Hamlet's father, about to make an important disclosure to his son, suddenly hears the crowing of the cock, on which he announces no less abruptly that he "snuffs the morning air," and vanishes to his dreary home. As Shakspeare so beautifully writes too, the office of cock-crowing is likewise at a certain season rendered still more important : -

"Some say that over against that season comes,

Wherein our Saviour's birth is celebrated, The bird of dawning singeth all night long; And then they say, no spirit walks abroad. The nights are wholesome - then, no planets strike, No fairy takes, nor witch has power to harm, So hallowed and so gracious is the time." 
It is, perhaps, impossible to pronounce with certainty as to the precise origin of the domestic cock. It is impossible positively to say to what species of the wild cock, known at present, we are to look for the primitive type. The date of the original domestication of the fowl is so remote that the most curious antiquary must despair of gratification, if he seeks to fix it. It is necessary, therefore, to turn attention to those races of poultry which manifest a truly feral type, and in them seek for the evidence of originality, and rest content in such approximate knowledge as we may obtain.

Many authors of respectability and learning have made the attempt to show that all the varieties of the domestic fowl, of which we now have knowledge, are derived from a single primitive stock. This is, perhaps, the general opinion; and it is not surprising that it should obtain currency, when fortified by the support of so many distinguished names. In fact, naturalists, in their desire for generalization, have always endearored to refer all races of animals to the fewest possible primitive types. But there are facts in regard to poultry which seem to render such a course in relation to them impracticable. Dampier saw wild hens at Puloncondar, Timor, and St. Jago. Sonnini describes wild cocks which he saw in the forests of South America. M. Temminck procured wild cocks from Java, Sumatra, and Ceylon. All these birds are affirmed to differ essentially, in character and appearance, from those found by Sonnerat in the Indies, from each other, and from all the then known domestic races. More recent investigations, based on a comparison of large collections of facts, are said to confirm these statements.

It has been confidently asserted that the domestic cock owes his origin to the Jungle fowl of India, but there seems to be but little evidence to justify this supposition. The difference between them is too great to allow their common descent. The 
Jungle fowl is less in size than the common dunghill cock; the comb and wattles are similar, but the naked parts of the head and neck are more considerable. The feathers differ in structure and aspect, and are longest on the lowest parts. The Jungle hen has the throat entirely covered with feathers, and is without either comb or wattles, which is a remarkable distinction from our domestic hens. And there is a peculiarity also in the feathers of the Jungle cock, which is irreconcilable with the idea of this variety being the original type of the race.

The most probable supposition is, that the varieties known to us may be referred to a few of the more remarkable fowls, as the progenitors of their several species. However great the analogies which exist in any case, we must remember that domestication has produced great effects as to the form of the body and its appendages. The constant and frequently careless crossing of one bird with another, and the promiscuous intercourse which takes place, changes of climate and variety of food and treatment, must greatly multiply the difficulties which exist in referring modern individuals to their primitive stock.

It may be safe to recognize the Gallus giganteus of zoologists, the great fowl of St. Jago and Sumatra, as the type of some of the larger varieties, such as the Spanish and the Paduan fowls, and those resembling them. To the Bankiva cock, probably, on the other hand, belong the smaller varieties, such as Bantams, the Turkish fowl, and the like.

In the opinion of Richardson, the reasons for supposing these birds to be the true originals of our domestic poultry are, -

"In the first place, the close resemblance subsisting between their females and our domestic hens.

2. The size of our domestic cock being intermediate between the two, and alternating in degree, sometimes inclining towards the one, and sometimes towards the other.

3. From the nature of their feathers and their general 
aspect, the form and distribution of their barbs being the same as our domestic fowls.

4. In these two birds do we alone find the females provided with a crest and small wattles, characteristics not to be niet with in any other wild species.

To the more diminutive Bankiva cock we are, on the other hand, indebted for the smaller varieties, improperly designated Bantams, and the so-called Turkish fowl. By crossing, peculiarities of climate, management, \&c., have been produced from these -

1. The cock with small crest and wattles, furnished also with a tuft of feathers, which some writers have supposed to be produced by the juices that ordinarily go to furnish nourishment for the comb taking another form, and developing themselves in the production of the tuft. These approximate most nearly to the original Sumatra stock, and we may recognize their domestic representative in the Hamburgh and Polish breeds.

2. The ordinary village cock, provided with comb and wattles, but no crest or tuft of feathers; this scems the intermediate variety.

3. Diminutive cocks, ordinarily known as Bantams, with, in some varieties, the tarsi and toes covered with feathers; but this is not invariably the case.

I should here describe the two races to which I have stated it as my opinion that we are indebted for our domestic varieties.

The wild cock, justly termed the 'Gallus giganteus,' and called by Marsden the 'St. Jago Fowl,' is frequently so tall as to be able to peck crumbs without difficulty from an ordinary dinner-table. The weight is usually from ten to thirteen or fourteen pounds. The comb of both cock and hen is large, crown shaped, often double, and sometimes, but not invariably, with a tufted crest of feathers, which occurs with the greatest frequency, and grows to the largest size, in the hen. The voice is 
strong and very harsh, and the young do not arrive at full plumage until more than half grown.

There was, some years ago, in the Edinburgh Museum of Natural History, and probably still is, a very fine specimen of the St. Jago fowl ; it was said to have been brought direct from Sumatra, and, in most respects, closely resembled the common large varieties of domestic cock. In this specimen the comb extended backwards in a line with the eyes; was thick, slightly raised, and rounded on the top, almost as if it had been cut; the throat bare, and furnished with two small wattles. The neck and throat hackles of a golden reddish color, some of them also springing before the bare space of the throat; the hackles about the rump, and base of the tail, pale reddish yellow, long and pendent; the centre of the back, and smaller wing coverts, of a deep chestnut brown, the feathers having the webs disunited; the tail very full, and of a glossy green color. The greater wing coverts of a glossy green, with the secondarics and quills of a faint golden yellow ; under parts of a deep, glossy, blackish green, with the base of the feathers a deep chestnut brown, occasionally interrupted, so as to produce a mottled appearance. This bird measured very nearly thirty inches in height, comb included, and, of course, allowance must be made for the shrinking of the skin; the living bird must have been upwards of thirty-two inches high.

The Bankiva fowl is a native of Java, and is characterized by a red, indented comb, red wattles, and ashy-gray legs and feet. The comb of the cock is scolloped, and the tail elevated a little above the rump, the feathers being disposed in the form of tiles or slates; the neck-feathers are gold color, long, dependent, and rounded at the tips; the head and neck are of a fawn color; the wing coverts a dusky brown and black; tail and belly, black. The color of the hen is a dusky ash-gray and yellow; her comb and wattles much smaller than those of the cock, and, 
with the exception of the long hackles, she has no feathers on her neck. These fowl are exceedingly wild, and inhabit the skirts of woods, forests, and other savage and unfrequented places. These Bankiva fowl are very like our Bantams, and, like those pretty little birds, are also occasionally to be seen feathered to the feet and toes."

\section{CHAPTER III.}

VARIETIES OF DOMESTIC FOWL.

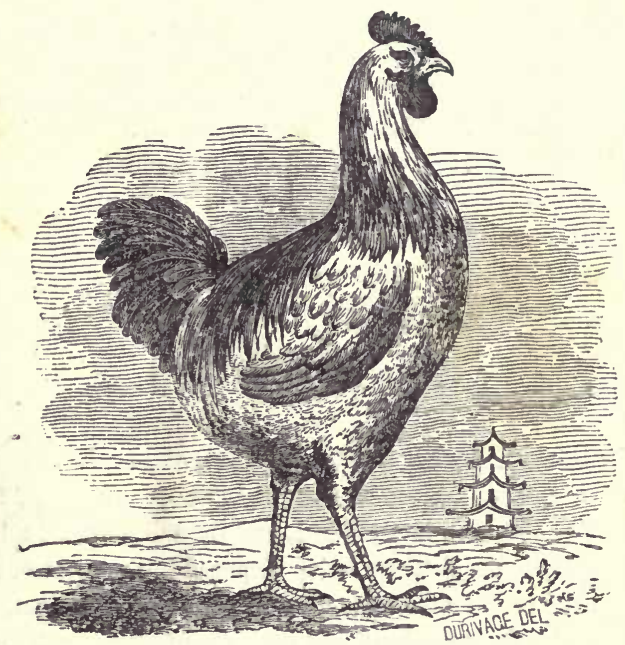

THE CHITTAGONG FOWL.

Turs fowl, so remarkable for size and beauty, is placed first among domestic varieties, as the true Gallus giganteus. The 
specimens from which the portraits here presented were taken are in possession of George P. Burnham, Esq., of Roxbury, and were obtained by him from Asa Rugg, Esq., of Kensington, near Philadelphia. They are, as near as may be, perfect samples of their kind; and excite astonishment and admiration in all fowl fanciers who behold them.

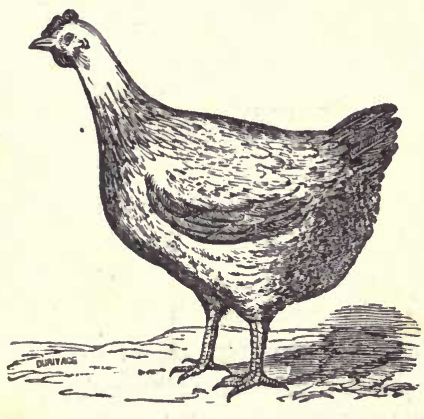

CHITTAGONG HEN.

Mr. Burnham furnishes the following description of these particular fowls, which is singularly accurate, and sufficiently ample.

" The Chittagong is a very superior bird, showy in plutmage, courageous, and exceedingly hardy. The color of mine is gray, generally, interspersed with lightish yellow and white feathers, upon the pullets. The rooster is gray body, the wings, hackles, back and rump-feathers a silvery yellow, tinted with stray light brown and white; the tail and breast are nearly black.

The legs of this fowl are of a reddish flesh color; the meat is delicately white, the combs large and single, wattles very full, wings good size. The legs are more or less feathered; the model is graceful, carriage proud and easy, action prompt and deternined." 
In correspondence with Mr. Rugg, the general characteristics of the breed are thus detailed: "The Gray Chittagong sometimes attains a great size; the tail is small, but more compressed than in some other varieties. The legs are whitish red, and usually feathered. The comb is single, serrated, with occasionally the slightest trace of a top-knot."

Mr. Rugg says, writing to Mr. Burnham :

"The samples of Chittagongs I send you have the largest blood in them of any variety of fowl with which I am acquainted." The above pair " were hatched on the 4th of June last, and are the best specimens I ever saw here or elsewhere, for their age. I had determined, under no circumstances, to part with them, but will do so, if you like my price. They are not yet six months old. The rooster weighs this day (Nov. 26, 1849) eight and a half pounds, strong ; the pullet seven and three quarter pounds. They are of a grayish color, both marked in every respect alike, with the single exception, that while the pullet is rather heavily feathered on the legs, the cockerel shows but few feathers below the thigh. The pullets will grow much larger, and are now about ready to lay, I judge. These fowls are considerably larger than any Cochin Chinas I have ever seen. This variety of Chittagong comes to maturity earlier than any of the large species ; and our breeders prefer thein generally, for both laying and other practical qualities. This pair of fowls, when fully grown, will weigh you, at the least, twenty-two pounds.

I have a cockerel fifteen months old, of this variety, and a hen about the same age, or a trifle older, which, if alive next March, and cared for properly meantime, I am certain will weigh twenty-two pounds. * * * I have a rooster of this species, also, seventeen months old, and a hen about three years of age, which, at the commencement of the laying season, next spring, I am sure will weigh twenty-five pounds! This is 
somewhat above the average, however. *** The skin and meat of these fowls is delicately white; which is different, you observe, from the yellow-legged and light yellowplumed Great Malay fowls, in the vicinity of New York; and which weigh, so far as I can judge from observation, about sixteen to eighteen pounds per pair, at full maturity." Such is the description furnished Mr. Burnham by the importer of his specimens of Chittagongs.

These fowls exceed in weight all known varieties. Mr. Rugg says, in a letter to the author, respecting his own stock, "Those from which I have been and still am breeding are rather heavier than the weight given; and although the stock has been in this country from six to ten years, I can distinctly trace the offspring to the original stock.'

Mr. Burnham says of the weight of the particular pair whose portraits are here given :

"The two fowls above shown were hatched on the 4th day of June, 1849, and are consequently seven months old, this present week. These are specimens of my breeding stock, and I weighed them on Saturday last, in presence of a member of the committee of the late fowl show. The rooster draws ten and a half pounds, the pullet weighs eight and a half pounds, strong. This being over nineteen pounds for a pair of last summer's chickens, I think I may safely ask, 'Can it be beat?",

The parents of these fowls, now in possession of Mr. Rugg, who is, beyond dispute, one of the best fowl breeders in America, weigh, when in condition, the cock, fourteen pounds, and the hen, thirteen pounds and four ounces. I procured from this stock three fowls, which are now owned by Mr. Joseph A. Sampson, of Duxbury, of the following weights and ages. The cock, which was a last May chick, weighs nine and a half 
pounds ; one hen, two years old, ten pounds; and another hen, of the same age, eight and a half pounds.

Mr. Burnham says of his fowls :

"For their age, the above speeimens of Chittagongs are the largest and finest I ever yet met with. I have known the ' Great Malay' species a good while, and have seen them near New York and around Philadelphia, where, at twelve to fifteen months old, they would draw fourteen to sixteen pounds per pair ; but I never yet saw a pair of fowls, of any breed, which, at less than seven months old, would weigh nineteen pounds - save those which are delineated in the above engraving."

On the whole it may be observed that the Chittagong breed are the largest in the world - the pullets usually weighing from eight to nine pounds when they begin to lay, and the cockerels from nine to ten pounds, at the same age. They do not lay as many eggs in a year as smaller hens, but they lay as many pounds of eggs as most of the best breeds.

Mr. Rugg says, in a letter:- "I am aware that with some the idea is that the Cochin China is an elephant among fowls, and so it is eompared with its inferiors; but by no means so when eompared with the Chittagong." Heretofore, most persons have confounded this splendid breed with the Great Malay; but on eareful comparison, the points of difference will be found to be important. There is less offal ; the flesh is finer, although the size is greatly increased; and their fecundity is greater, and the offspring arrive earlier at maturity, than in the eommon Malay variety.

There is also a red variety of the Chittagong, which is rather smaller. Mr. Rugg describes them as follows: "The red or yellow variety of Chittagongs have legs sometimes yellow and sometimes blue; the latter eolor, perhaps, from some mixture with the dark variety; the wings and tails are short Some- 
times there is a rose-colored comb, and a top-knot, through crossing. The variety may weigh sixteen or eighteen pounds per pair, as ordinarily bred. The eggs are large and rich, but not very abundant, and they do not hatch remarkably well."

There is also a dark red variety, the hens yellow or brown, with single serrated comb, and no top-knot; legs heavily feathered, the feathers black and the legs yellow. The cock is black in the breast and on the thighs.

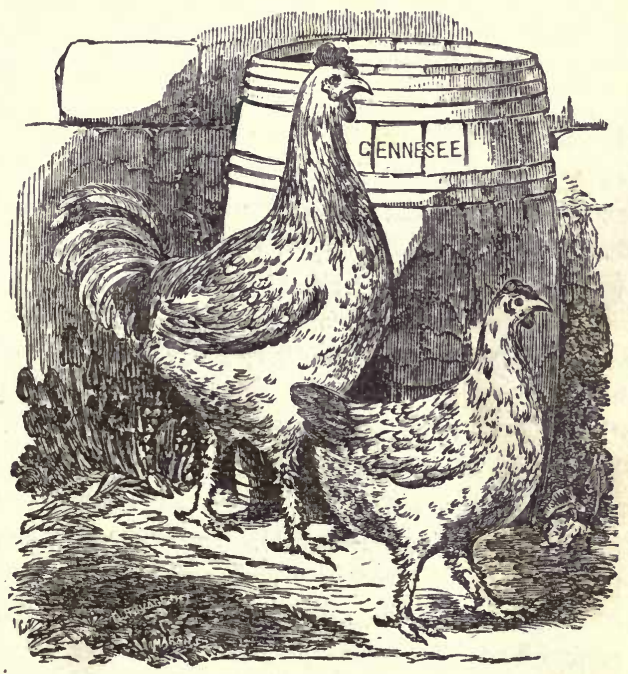

THE SHANGHAE FOWL.

There are two varieties of the Shanghae fowl, which may be distinguished as the Yellow (including the brown buff and the 
fawn-colored) and the White. The Yellow Shanghaes were imported from the city of Shanghae, in China, (whence their name,) by Captain R. B. Forbes, in 1848. I procured, at an early period, some of the most pure of this noble breed. In general shape and appearance they resemble the Cochin China fowl, though they have greater depth of quarter, and less depth of breast, and are of a lighter color. Their legs are uniformly large, usually of a bright red and yellow or white mixture, sometimes flesh-colored, and very heavily feathered. Their general plumage is of a bright yellow or gold color, variegated with dark brown and red. The tail is short comparatively ; the body is well formed; the wings small and high up on the sides; the gait proud and showy ; the legs, when young, rather lengthy for beauty ; the head full sized ; comb single, straight and serrated; and the feathers rather fine and downy, than otherwise. There is very little disposition among them to quarrel : the hens are excellent nurses, the roosters good "protectors," and thus far they have been found hardy and healthy generally.

The perfect uniformity in size in all chickens of the same age of this breed, prove them beyond doubt to be a distinct race, and they are among the most healthy, hardy, and rapid-growing chickens I have ever seen. Out of fifty odd chickens of this breed, not one of them has faltered this season.

The variety of domestic fowl which the above engraving represents, is, in my estimation, one of the very best known in America at the present time, all things considered. The rooster and pullet above delineated show a pair selected from the breeding stock of G. P. Burnham, Roxbury, Mass., and the artist has produced a lifelike representation of them. The above pair are from a brood hatched in early May last; the crower will ow weigh over eight and a half pounds, the pullet six and a half. They are out of the famous Forbes importation of Shanghae fowls. They grow to a large size, - the parents of the 
above pair, at maturity, weighing over eightcen pounds. As will be observed in the engraving, this variety is heavily feathered upon the legs.

The drawing gives a very correct idea of all the yellow varieties, - of the model, plumage, comparative size, and general carriage of all these birds, - than which there are none better in America, for goodness of disposition, for laying properties, for table use, or for early maturity. The roosters, when fully grown, will stand upright, as shown in the engraving - the head about on a line with the height of a flour barrel.

I am informed by Mr. T. Ames, of Marshfield, that one of his neighbors, Mr. Phillips, has a pullet of this breed, which laid a hundred and twenty eggs in a hundred and twenty-five days, then stopped six days, then laid sixteen eggs more, and stopped four days, and is now laying; and that he (Mr. Ames) has one that has done equally well. Mine have not equalled this, though they have done exceedingly well. Their eggs are rather lighter colored than those of the Cochin China breed. The pullets commence laying when from five to seven months old.

Mr. Burnham makes the following judicious remarks, in the Massachusetts Ploughman, in respect to the confusion so extremely prevalent in regard to the peculiarities of this breed. "I am confident that these fowls are confounded with the 'Cochin Chinas,' and I think that scveral persons who have this same stock now call it by that name. We have not had this variety in America long enough, nor is the distinction sufficiently well known, I imagine, generally, to determine between the real Shanghae and the Cochin Chinas we have here, and more commonly known by this last name. I make the distinction on the ground that all my imported Shanghaes (and I have three different varieties, from different sources) are hcavily feathered upon the legs. 
My 'Cochin China' fowls - which I consider possess all the good points that any specimens, classed under that name, do - have no feathers on the legs. The Shanghaes came from the mountains in the extreme north of China, fifteen hundred miles up the coast. The Cochin China originates in a country of that name, in a more southern latitude.

Now it seems to me that Nature may have provided the Shanghae fowl with feathers upon the legs and feet, as a protection, comparatively; for the country they inhabit is much colder than the other, and vice versa.

I may be in error, but such is my opinion, based upon the fact that wherever I have found fowls imported directly from either the north or the south, the above-named distinction actually exists; though many farmers and poulterers declare, spite of 'feathers or no feathers,' that their fowls are 'Cochin Chinas' or 'Shanghaes' - just as they please. In some instances, I find that a decision on this point depends entirely upon which particular kind you want to buy!

There are but very few, if any, bona fide Shanghae fowls now for sale, in this region. Scores and hundreds of Shanghaes (so called) are offered every week; but this breed is altogether too rare, and the real 'Simon pure' will readily bring too high a price at private sale, for these birds to be very common at this time. The coming year. there will be more of them ; and, to the farmer, the poulterer, the fancier, or the breeder, I consider this fowl (in its purity) to be one of the most economical and most profitable of all the known large breeds."

I have seen some fowls imported directly from Oahu, Hawaii, (Sandwich Islands,) by Captain C. W. Gelett, of Kingston, a part of which are a cross of the Shanghae with the native Oahu fowl, and a part pure Shanghaes. The Shanghae rooster will weigh about twelve pounds, or a little over; and the hen about seven and a half. They are very perfect bloods. This cross 
of the Shanghaes with the Oahus are rather smaller, shorter legged, and lighter colored, than the original Shanghaes, but most excellent layers. I am in possèssion of some stock of this excellent breed, which I obtained from S. A. Drake, Esq., of Fiskdale, of which the following portrait is an exact resemblance, drawn from the life, by Mr. Durivage. His weight is nine pounds and a half.

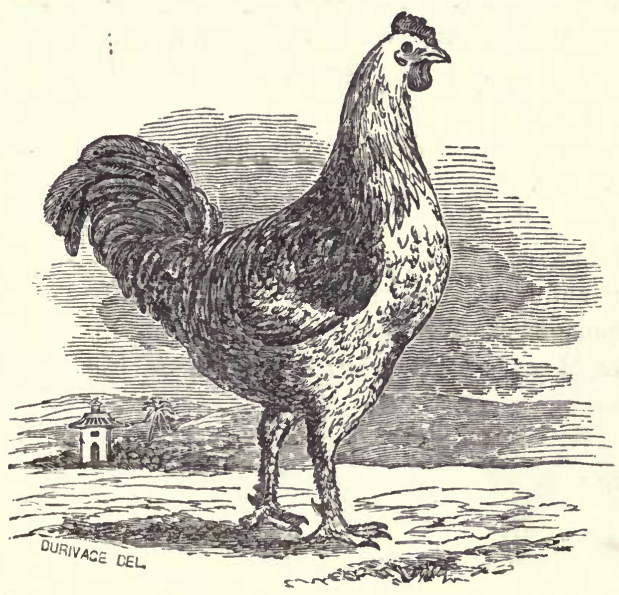

SHANGHAE FOWL.

This fowl was imported by the Rev. Mr. Brown, a missionary to China, from whom Mr. Drake obtained it, and in relation to which he says :

"Those Shanghae fowls were imported by a friend of mine, Mr. Brown, who resided in China some ten years. He told me that he had an opportunity to select the best breed of fowls in that country, to which he had access, and that the natives prized those which he brought home above all other breeds. 
Mr. Brown was a missionary and teacher in China, and had an advantage over most others. It is about three years since he returned. Mr. Brown, together with the three Chinese young men, (who came to this country with him,) dined with me last summer, and looked at my fowls, and said they still retained all of their distinet marks and peculiarities. And that the blood was as good as any that they ever saw in China."

Mr. Buckminster says:-_"This variety seemed to prevail at the late exhibition. We saw some of them sold at thirteen dollars a pair, and have been told that some were sold for eighteen dollars a pair. Ten dollars were repeatedly refused for a large hen owned in Newton, the breed of which is not known to us.

Among the Shanghae fowls we saw none that pleased us better than some from the stock of Dr. Bennett, of Plymouth. One pair of these is on the farm of the editor of the Ploughman, at Framingham. The rooster is nearly six months old, and the pair would not be sold for any of the prices paid and mentioned." 


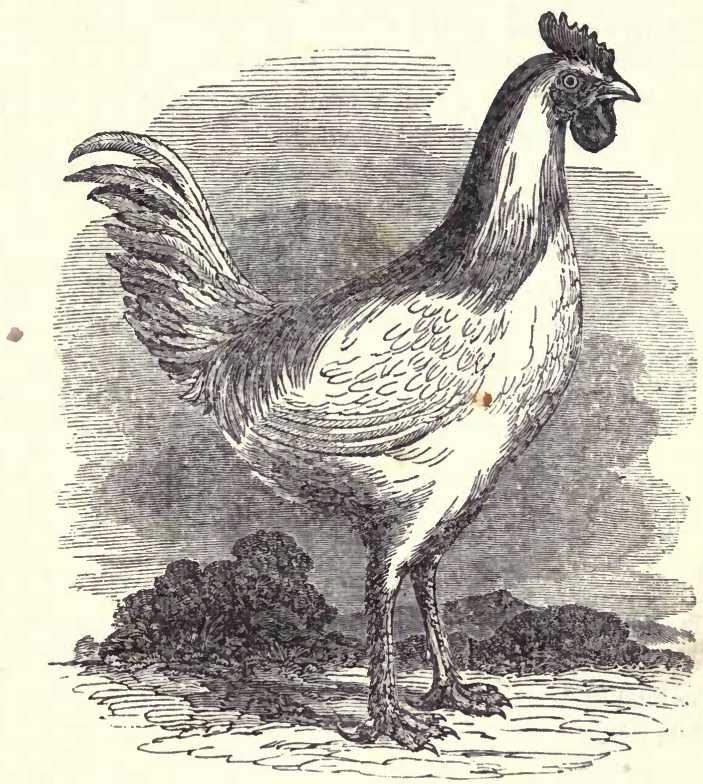

WHITE SHANGHAE FOWL.

Mr. George E. White, of the firm of Parker \& White, Boston, a well-known fowl fancier, who has a fine stock of the White Shanghae, has obligingly furnished me with a drawing from which the plate has been engraved, with the following communication, which gives a suitable description of the birds :

"I send you enclosed a drawing of one of my White Shanghae fowls - a cock hatched about the 25th of June, which weighs now seven pounds and three quarters, and, as he is 
growing rapidly and has a fine form, promises to be one of the largest of his kind. He has therefore been selected to breed from during the present year. The pullets, which were hatched earlier, weigh from five and a quarter to six and a quarter pounds, and appear to be still growing.

They are all quite heavily feathered on their large yellow legs, giving a rich finish to their general appearance, which is cleanly and beautiful. They lay as many eggs as any fowls that I have ever kept, and are good nurses to their young broods. The parents of this stock were imported by my friend, Mr. Osborne, of Lynn, who still has them in his possession.

It will not, perhaps, be out of place to say, that, notwithstanding the popular opinion, that a white fowl is more delicate than a colored one, I have found the White Shanghaes very hardy.

Very respectfully yours, Geo. E. White."

Mr. White obtained these fowls from Thomas Thorpe, Esq., of West Cambridge. They are the most beautiful specimens of the kind in America, and commanded universal admiration at the late fair.

These fowls partake of all the characteristics of the Yellow Shanghaes, with the exception of color. Mr. Spooner, of Plymouth, has some of this breed, obtained from the stock of Mr. N. C. Day, of Leominster. They are large and beantiful.

Mr. Giles, of Providence, writes me that he has the same stock, brought direct from the city of Shanghae, by Captain Palmer, and speaks of them in the highest terms. 


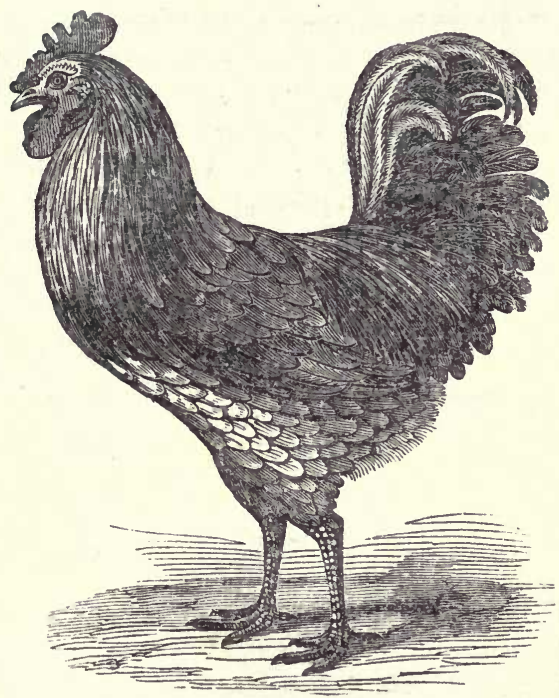

THE COCHIN CHINA FOWL.

" This gigantic bird," says Richardson, " has been only very recently introduced into Great Britain, and it is to that royal patroness of poultry fanciers, the nature-loving Victoria, that we owe its addition to our stock of domestic fowls. Two fine specimens of the Cochin China fowl, but rather aged, were sent over by her Majesty to the cattle-show of the Royal Dublin Society, April, 1846, and were subsequently presented to the Lord Lieutenant of Ireland, Lord Heytesbury.

The breed have since become comparatively well known, and are now kept by several private persons and breeders; amongst whom may be mentioned the well-known M. Du Gué. 
This variety of fowl so far surpasses, both in size and power, all that we have ever yet seen in the shape of poultry, as to have led many persons not conversant with zoology, on first viewing them, to refer them to the family of Bustards. They are, however, genuine poultry. Their general color is rich, glossy brown, deep bay; on the breast is a marking of a blackish color, and of the shape of a horse-shoe; the comb is of a medium size, serrated, but not deeply so, and the wattles are double. Besides their size, however, these fowl possess

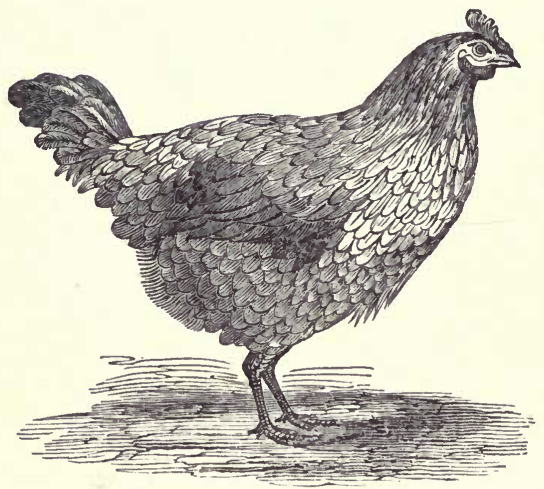

COCHIN CHINA HEN.

other distinctive characteristics, among which the most striking is that the wing is jointed, so that the posterior half can, at pleasure, be doubled up, and brought forward between the anterior half and the body. The birds can do this at pleasure, and the appearance the manœuvre imparts to their form has procured for them the title of ' ostrich fowl.' The flesh is white and delicate. The eggs laid by the hen of this variety are large, of a chocolate color, and possess a very delicate flavor. 
They are very prolific, frequently laying two, and occasionally three eggs on the same day, and within a few moments of each other. An anonymous writer in the Gardeners' Chronicle calls this statement of mine in question. I now beg to refer, as my authorities, to the Right Hon. Mr. Shaw, the Recorder of Dublin, to her Majesty's poultry-keeper, Mr. Walters, and to Mr. Nolan, of Dublin. One of the hens, 'Bessy,' exhibited by her Majesty, laid 94 eggs in 103 days."

In a letter recently received from Mr. Giles, of Providence, he pleasantly says :- "I hope you will succeed in procuring a pair of those fowls that will lay two or three eggs a day; they must be invaluable. This appears to be an age of wonders. I should not be surprised to hear of a breed being found that will lay golden eggs, but I should be surprised to see the eggs." The reader may be sure that neither he nor Mr. Giles will be gratified, unless such a breed shall be discovered in California.

But this marvellous laying is not the only wonder that is reputed of the royal fowls. The writer in the London Illustrated News, from which the above description is taken, has fallen into an error, which has been pointed out by Mr. Rugg, and the correction will be now subjoined in the words of his letter. It is necessary to premise, however, that the confident and ignorant assertions, made in several quarters, that there is none of the pure Cochin China breed in this country, are entirely without foundation. Mr. Rugg possesses fowls of the identical breed, and it will be seen that his are in fact superior to those possessed by her Majesty.

Mr. Rugg says:- "There is a discrepancy between the portraits and the letter press in the description of the queen's fowls. The reverse feathers, and the folding up of the last joint of the wing, are not made distinctly to appear; nor could they be otherwise displayed, from the nature of the case. In mine, 
the wing outwardly looks as it does in the cuts; and yet, it, on examination, is found tucked or folded up and forward, cxposing more than in any other breed the thigh and side of the fowl. When young, before the tail begins to appear, which is not until the fowl is about four months old, the wings lie folded on the back, and subsequently they fall lower down. The feathers on the back of the neck do not, in reality, run the contrary way, though to a casual observer, such as, in all probability, was the person who wrote the description of the queen's fowls, there is something peculiar in the arrangement where the hackles and the back feathers meet; yet nothing to justify the assertion 'turned upwards.' The hackles and lower feathers do not, in meeting, form so smooth a finish as in other fowls, and perhaps this gave rise to the error ' turned upwards.' The Jago cock, as seen in Mr. Dickson's book, appears to have the feathers on the upper part of the neck and back of the head ' turned upwards,' and this fowl may have been confounded, for the moment, with the Cochin China. I am constrained to regard the writer in error in that particular, especially as he would be more likely to err than the artist who contradicts him in the portrait."

Of the purity of blood of Mr. Rugg's stock there can be no question, as they were imported by him, through Mr. Taylor, of New York, in the ship Huntress, in May 1847, direct from Cochin China. Mr. Rugg states that his fowls are sufficiently well portrayed in the pictures of the queen's fowls, and differ in no respect, except in having the legs heavily feathered, which is regarded by him as an unimportant circumstance, which will not be observed, after they have been in the country a few years.

Mr. Rugg sought of the importer such information as he had in reference to his original stock; and the information thus derived, together with his own experience, will now be de- 
tailed : - "Mr. Taylor writes that the original pair, in consequence of being so long from the earth, were sickly when they arrived. He turned them out, and the hen, from May to October, laid forty-eight eggs, and hatched out twice. From the forty-eight eggs he raised forty chickens. The last hatching was in October; twelve came out, and ten were raised through the winter. This is noted to show, that though from an extreme south-eastern climate, they are sufficiently hardy for our winters. He says that the imported cock was a peculiar red and yellowish Dominique, and the hen a bay or reddishbrown; also that the young cocks and pullets are uniformly like their parents, varying only in shade of color. This accords precisely with my own experience, and I have been familiar with the breed for more than two years.

These characteristics of plumage never fail. The legs of both sexes are of reddish-yellow, sometimes, especially in the cocks, decidedly red, - more so than in any other variety. The combs are single, serrated, and of good size in the cocks, moderate in the hens; thin wattles; no top-knots; legs very heavily feathered; bones not large, and consequently but little offal ; wings very small, and when young, carried on the back. but subsequently let down a little; tail, not appearing till between the fourth and fifth month, short. well supported, not much compressed, measuring some five inches laterally behind, near the root, and no long weeping feathers. This is regarded as somewhat characteristic, as well as its being of a darker color than the general plumage. In the female the tail is not so short and stumpy as in the Shanghae, nor quite so well supported as in the Cochin cock. As regards the form of the wing, which some make characteristic, it is unquestionably folded up more than in most other East India breeds, but not so as to be placed back at the butt of the wing, as represented in the portrait of Victoria's fowls. 
So far as my observation goes, the best specimens of the varieties of south-eastern fowls have, in a good degree, the same peculiarities of wing, perhaps owing to crossing previously or subsequently to importation, or because they are all from a common stock.

Size. - There is considerable disproportion, as is the case with all thorough-bred fowls, between the size of the cocks and the hens. I have a choice cock, above the ordinary average, which, when full grown and in condition, will weigh down some thirteen or fourteen pounds. I have also a few pullets, equally as pure blood, but which will not exceed nine pounds. A fair average weight, for fowls of this variety, as usually bred by farmers, might be set down at from seventeen to twenty pounds per pair.

When the London Illustrated News appeared, containing portraits of the queen's variety, I was surprised to find her poultry-keeper, or more probably some penny-a-liner, stumping on the fact that she had pullets that weighed seven pounds; while at the same time I had hens which weighed over eleven pounds, and several pullets over eight pounds! I make the fowl, so far as I take an interest in poultry, my Magnus Apollo, and $I$ have every reason to be satisfied with it. If I desired to raise the largest kind of fowls, I know of none I would prefer to Chittagong hens and Cochin China cocks. From the product of such, capons might be produced 'as is capons.' "' 
ROYAL COCHIN CHINA FOWL.

\section{BURNHAM'S IMPORTATION.}

On a careful comparison of the preceding plates of the Queen's fowls with the description taken from Richardson, a wide discrepancy will be noticed. The engravings are rather pictures than portraits, and are altogether inferior to those in Mr. Bement's book. It is with peculiar satisfaction, therefore, that I am able to adorn this book with the beautiful original portraits which are here presented. They are drawn from life by Mr. Durivage, and engraved by Mr. Marsh, artists of acknowledged ability and accuracy. This representation of $\mathrm{Mr}$. Burnham's fowls is believed to be the only correct delineation of the species extant, and I flatter myself will henceforth be deemed the standard of comparison. Mr. Burnham's importation is the best of any of the Cochin China race which have been brought to this country ; and it will be seen, by the accompanying letter, that Mr. Nolan's stock, from which they are derived, took the premium at one of the agricultural fairs in England, while standing at the side of her Majesty's fowls.

Mr. Burnham, in a late letter to the author, says of the Royal Cochin Chinas: "The nearest thing to them that I have seen is your Wild Indian fowl." There can be little doubt that this importation contains some of the fine blood of this breed, (the Wild Indian Game,) which greatly enhances its superiority. In the preceding article, it is stated that the Royal fowls are derived from a mixture of the Chittagongs and Shanghaes; yet those imported into England undoubtedly participate in the blood of the Wild Indian Game. This is indicated distinctly by the shape of the head and neck, and corroborated by the fact that English writers pronounce them to be " game," when speaking of their habits and prowess. These facts prove the Queen's fowls and Mr. Burnham's to be different from what are commonly called Cochin Chinas, which are 


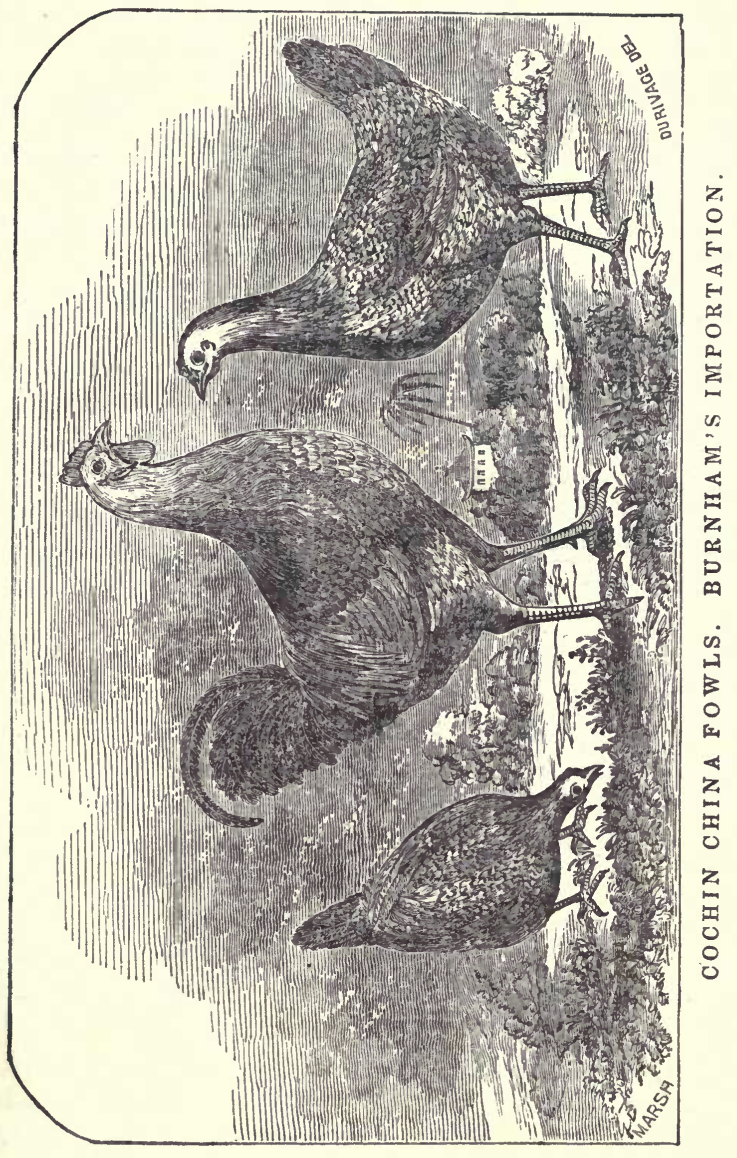


the mere cross of the Chittagongs and Shanghaes. Mr. Burnham thus fully and accurately describes the remarkable fowls here portrayed, under date of Feb. 4th, 1850 :-

"The importation consists of six fowls, - two roosters and four pullets. They are all last summer's chickens, and from different families. They were bred by J. Joseph Nolan, Esq., of Dublin, who says, in a brief note to me: ' $\mathrm{I}$ am able to forward you some choice specimens of Cochin Chinas; but cannot send you any as old as those you ordered. The pullets will soon be laying, however, and the cocks, I think, will astonish your neighbors, for weight.' The cocks are very promising in size. The color of one is brown and red ; the other is red and black. The plumage is beautiful, both in the roosters and the pullets. The color of three of the latter is generally a yellowish brown, with black-tipped feathers; the fourth is a deeper brown. The legs are free from feathers, except a slight show on one of the roosters, and vary in color from a brownish yellow to dark brown. The form of the pullets is unlike any fowls I have ever seen, though there is some general resemblance to the pure Dorking. They stand higher on the leg, however. The bodies are symmetrical, but long; the tail is also longer than that of the Shanghaes, and is very thin and tapering, from the rump outwards. The head of my fowls is quite small, the comb very small, and there are but slight signs of wattles, as yet, on the pullets. The neck is long and serpent-like; the eye, extremely large and brilliant; the chest is full, and the breadth of back is very great. The wing is full sized, and when upon the roost, one end laps over that of the other wing, transversely ; an extra joint on the outer extremity of the wing* enables the bird to sit in this manner. The frames of these fowls are ample, and the plumage lays closely to the body. They weighed, on the average, at starting from Ireland, about eight pounds each. I have weighed thein again to-day, and the two best pullets draw eight pounds and two ounces each, and the cock eight pounds and twelve ounces. The stock out of which these birds came is said to be the best in England; and I learned from Mr. Nolan, that his specimens took the premium at a late fair, at the side of the Queen's fowls. You will not fail to observe, from the drawing, that these fowls are most unlike the figures of her Majesty's in Richardson. A reference to the original picture, in the London Illustrated News, copied by Mr. Bement, will, however, show a strong resemblance between the two; indeed, the figure in the foreground is a very fair portrait of my birds."

Some surpassingly beautiful samples of these fowls, from Mr. Nolan's stock, have, likewise, just been imported by Mr. Joseph A. Sampson, of Duxbury, and Mr. George E. White, of Melrose.

$$
\text { * I have no faith in the extra joint. - Autror. }
$$




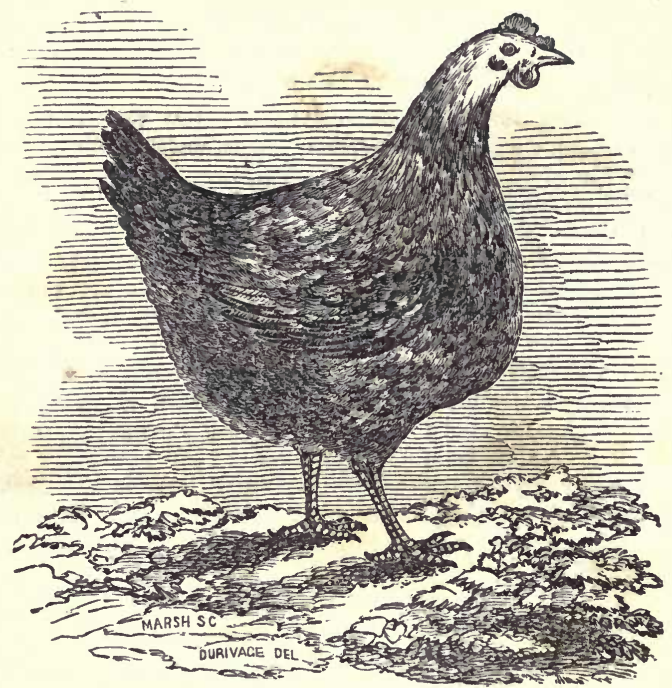

COCHIN CHINAS OF THE BAYLIES IMPORTATION.

One pair of these fowls was imported by Alfred Baylies, M. D., of Taunton, (through his nephew,) in July 1846, direct from Cochin China, and placed in the hands of Mr. E. Howard, of Raynham, for breeding. I procured a cockerel of Dr. Baylies, and a pullet of Mr. Howard, in 1847, from which my stock were produced. The portrait is taken from a fowl reared by Mr. Howard. At one year old, the cockerel weighed eight pounds and twclve ounces, and the pullet, six pounds and five ounces. She layed twenty-four eggs at her first litter ; I then set her, and before she drove off her chickens, she laid twentythree eggs more. Her mother layed eighty-four eggs, from the last day of March to the 14th of August, 1847. They are 
no more expensive to keep than the common hens, while they are about twice as large, better layers, less destructive to gardens, more docile and tractable, and very tender of their young. Their meat is fine and highly flavored. They usually commence laying at from six to seven months old. Their eggs are of a reddish or mahogany color, and of delicious flavor. They are very large, and Mr. Howard writes me that a pair of last year's chickens, in his neighborhood, now weigh eighteen and a half pounds. The plumage of these fowls is exceedingly rich and variegated, - usually brown or yellow: the cockerels are generally red. Their wings and tails are very short; their legs are very large, and of a yellow, blue, green, or whitish color, and frequently lightly, and sometimes heavily feathered; for depth of breast and quarter they excel most other fowls, and they are healthy, quiet, and much attached to home. The skin of the Cochin China, when young, is of a light pinkish color, as seen in its partially denuded state, near the butt of the wing; this, however, becomes paler with age, and fades into an ivory or yellowish white.

The difference between the Baylies importation and the Royal fowls is first observed in the size. The Royal fowls are one third larger, but those of the Baylies importation have the finest flesh. Both varieties undoubtedly proceeded from the Eame original stock, namely, a mixture of the Chittagong and Shanghaess. The royal breed, probably, is derived from the Gray Chittagong and Yellow Shanghae, and the other from the Red Chittagong and the Shanghae. Many of the Forbes importation of Shanghaes were not true to their names, but were really Cochin Chinas, of the Royal breed. Specimens of these may be found in possession of Messrs. Hyde, Alden, and others. The fowls of the Baylies importation have darker plumage, generally, than the Royal fowls, which is to be attributed to their different parentage on the Chittagong side. 
At the late fowl fair, good specimens of these fowls were exhibited by Francis Alden, of Dedham; S. and G. Hyde, of Newton; C. B. Marsh, of West Roxbury; Theodore Drew, of Plymouth, and others. Mr. Wm. Buckminster, editor of the Massachusetts Ploughman, says, in a notice of the show, in a late number of his paper :

"The Cochin China breed of fowls, introduced here by Dr. Bennett, of Plymouth, and others, took the lead - at least, so far as weight and portly appearance are concerned."

This breed is excellent to cross with the common fowl, and the half-bloods are much earlier fit for the market than full bloods.

I have seen the China fowl, from Canton, and a cross of the Great Malay with the Bucks County fowl, sold in the Boston market for pure Cochin China fowls, to persons who were not judges.

It may be well to add, that the London Illustrated News has fallen into another serious error in respect to the Royal fowls, in saying that " the cock is game, to the last degree, capable of killing the most powerful game cock in a few minutes." This is impossible, on account of their size and shape. The welltrained game cock would leap them in battle, and vanquish them by his superior agility and the dexterous use of the spur or gaff. None of the heavier fowls could live but a short time, if pitted with the best sorts of game fowls. 


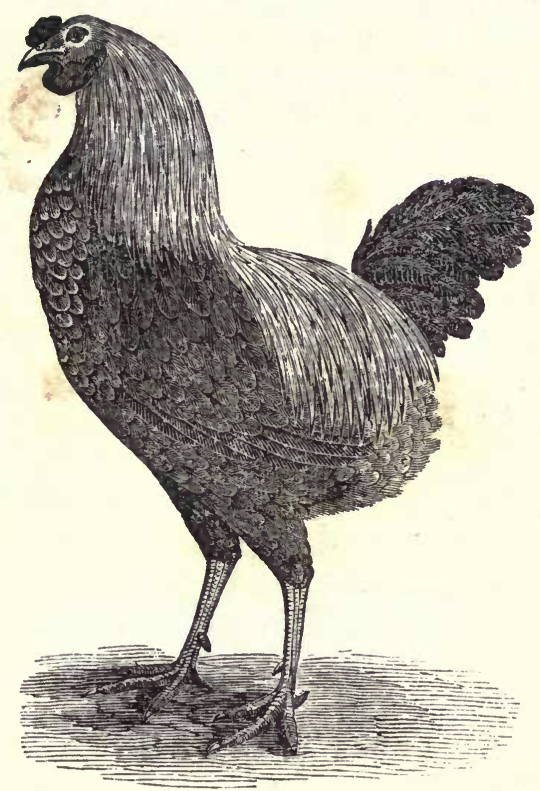

THE GREAT MALAY FOWL.

"The Malay fowl has, as its name implies, been brought, originally, from the peninsula of that name, at the southern point of the continent of Asia. He stands very high on the legs, is long-necked, serpent-headed, and is in color usually a dark brown, streaked with yellow, - sometimes, however, white His form and appearance are grand and striking in the extreme, and he is no small embellishment to the poultry-yard. This fowl is also frequently, but erroneously, called the Chittngong 
The Malay fowl, however, that were originally imported into these countries, were by no means such birds as I could recommend to the notice of the breeder, their size possessing too much offal, as neck, legs, and thighs, and the flesh, moreover, being dark-colored and oily. Another variety - that

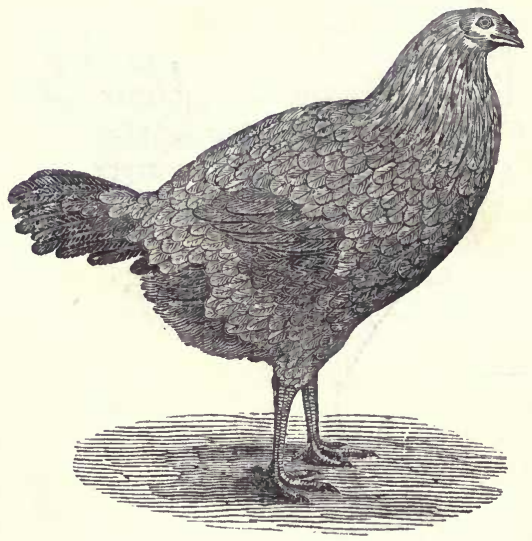

GRAT MALAY HEN.

represented by the cut - has been since introduced, which is well worthy of our attention. As a cross, this Malay has, indeed, proved a most valuable addition to our poultry-yard. the cross-breed possessing all the hardiness of our native domestic fowl, with the gigantic size of the foreign stock. Since the introduction of this variety, the export trade in poultry, both living and dead, has considerably increased; indeed, without introduction of fresh blood, as with all breeding stock that are bred in and in, fowl will become puny and degenerate." - Richardson. 
"These fowls have remarkably long legs, and large bones. Their flesh is, however, exceedingly well flavored, when they have been properly fattened; and their eggs, which are very large, are so rich, that two of them are equal to three of those of ordinary fowls. The color of the feathers is black, or very dark brown, streaked with yellow, and the legs are very large and coarse. The fowls are so tall that they can reach to a great height as they stand on the ground; and, as they have great power, and remarkably strong beaks, they are rather formidable antagonists, when offended. The cock has also a very loud and harsh crow. They are said to be bad sitters; but this is not always the case, as in some places in Yorkshire no other kinds of fowl have been kept for many years. It is said that a cross-breed between the Malay and the common fowl produces a breed very superior to either of its progenitors." - Dickson. 


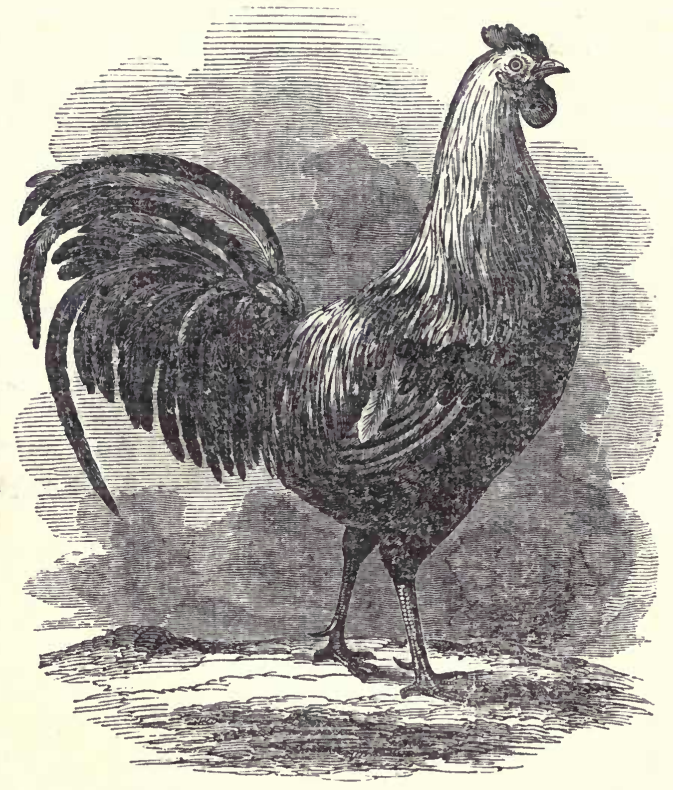

THE SHAKEBAG FOWL.

This fowl has so many points of affinity with the Malay tribe, that there can be no impropriety in associating it with them. It is more beautiful than most of the variety, the plumage of the cock being extremely brilliant and gaudy.

The fowls delineated here were imported by Mr. John L. Tucker, of the Tremont House, Boston, and were drawn from the birds in possession of Mr. James S. Parker, of the Samoset House, Plymouth. A glance at the portraits will show that 
they are magnificent birds. They are exceedingly rare in this country, this being the only importation of which I have knowledge. The average weight is from eight to fourteen pounds. The hens are good layers, and the eggs have every mark of the East Indian origin of the race, being dark-colored and largeyolked. The cocks are remarkable for their prowess.

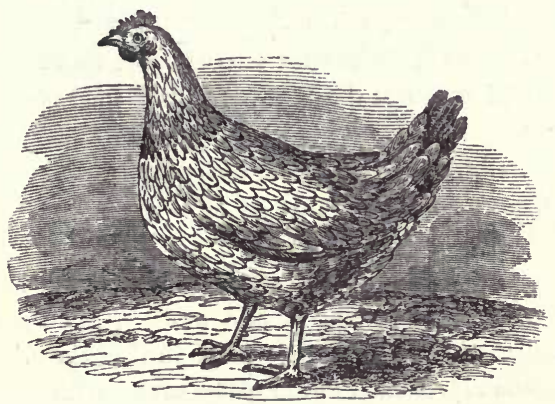

SHAKEBAG HEN.

Richardson says: "A good many years ago, there used to be a variety of fowl much in request in England, called the 'Shakebag,' or the 'Duke of Leeds' fowl,' his grace, of that name, about sixty or seventy years ago, having been a great amateur breeder of them. These fowl were as large as the Malays, but differed from them in the superior whiteness and tenderness of their flesh, as also in their very superior fighting abilities. Mowbray thus writes of one in his possession' The only one I ever possessed was a red one, in 1784, weighing about ten pounds, which was provided for me, at the price of one guinea, by Goff, the dealer, who then lived upon Holborn Hill, in London, and who, at the end of two years, received him back at half a guinea, having allowed me, in the 
interim, three shillings and sixpence each for such thoroughbred cock chickens as I chose to send him. At that period, the real "Duke of Leeds' fowl" had become very scarce, which induced the dealers to put Shakebag cocks to Malay hens, by that means keeping up the original standard size, but entirely sacrificing the color and delicate flavor of the flesh.' The name of this fowl seems to have arisen from the old practice of cock-fighting, when the fancy used to challenge all comers having their cocks concealed in a bag; and the tremendous size and power of the Duke of Leeds' fowl proving so far superior to all competitors, thus usually insuring conquest, and eventually obtaining for it the name, par excellence, of shakebag, since corrupted into shackbag."

Mr. Dickson adds: - "This fowl, which was formerly in very high repute, is said to have been as large and as finely flavored as a turkey; and though now rarely met with, it is still to be found in some poultry-yards in Berkshire."

The fowls represented in the plates may be thus described: - The plumage of the male is brilliant in the extreme, being of a bright red and glossy yellow, beautifully blended, and shaded with black, so as to present a most beautiful and captivating appearance. The hackles of the rump are long and drooping, and of a golden-reddish color. The comb and wattles are large and single; legs large, yellow, and destitute of feathers; tail long and drooping, with rich and glossy plumage. The gait is lively and majestic; in a word, it is the handsomest of any of the large breeds, and should be classed with the best varieties. The hens are of a bright yellow and glossy brown, good layers, good nurses, and very domestic. The eggs are rather large, well-flavored, and of a pale-reddish color. Their flesh is very fine, for so large a fowl. 


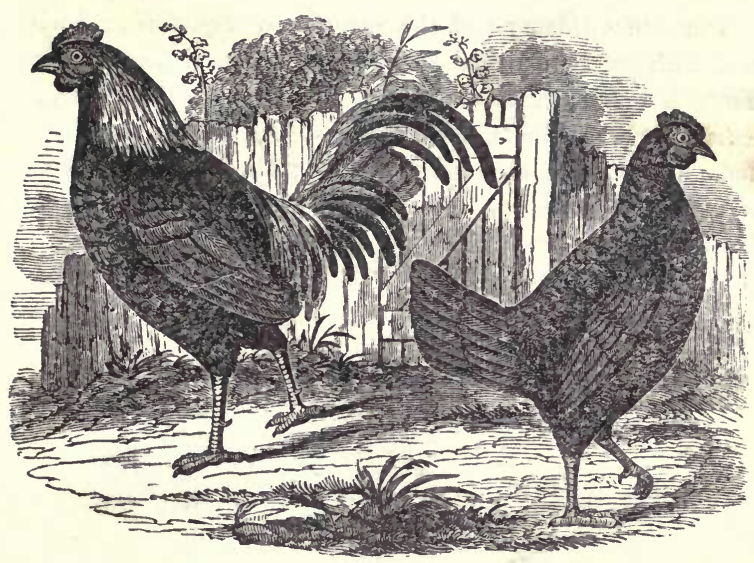

COMMON MALAY FOWL.

This plate is a representation of the common Malay fowl Amongst the best varieties of this breed recognized in this country, are the Jersey Blues, the Bucks County, and Boobies.

The Jersey Blues have all the characteristics of the East India fowls, and originated, probably, in some of the islands of the eastern Archipelago. They have diminished in size by neglect and careless breeding. 'Their average weight is not more than from eleven to thirteen pounds per pair. Mr. Rugg says, that where the imported stock has not been allowed to degenerate, he has known, in a single instance, caponized fowls of this variety to weigh twenty-five pounds a pair. This is regarded as a very good practical fowl in New Jersey, where it has been introduced; and the farmers there set a value upon It equivalent to that which the Dorking bears in England. The Jersey Blue is an extremely beautiful fowl, of fine plumage and graceful carriage; is a good layer, fine fleshed, and altogethér a profitable bird. 
The Bucks County and the Booby are unprofitable fowls; and, with what are called Malay fowls in the vicinity of New York, are degenerate varieties. A writer in the American Agriculturist pertinently remarks :- "As a fancy fowl, or to make up a variety, they are very well ; but can never become of great utility, except to cross with the common or the game fowl, to the farmer."

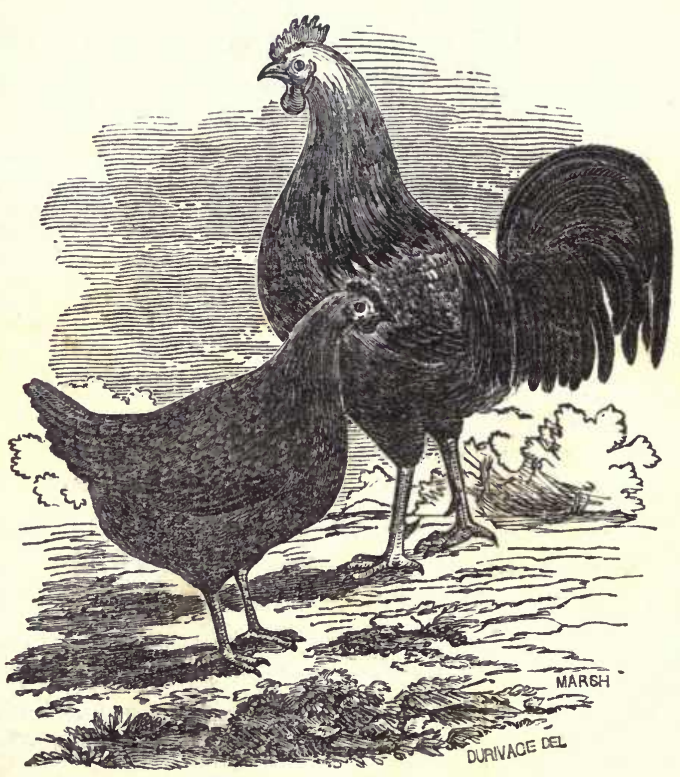

THE GREAT JAVA FOWL.

The Great Java fowl is seldom seen in this country in its purity; excellent specimens, however, may be seen at $\mathrm{Mr}$. 
*'harles Burton's, Plymouth, or at Mr. E. T. Packard's, East Bridgewater, which he purchased in New York as "Malays." The pair is now one year old, and the cock weighs ten pounds, the pullet nine pounds and a quarter. These, like all other pure Java fowls, are of a black or dark auburn color, with very large black legs, single comb and wattles. They are good layers, and their eggs are very large and well-flavored. 'Their gait is slow and majestic. They are, in fact, amongst the most valuable fowls in the country, and are frequently described in the books as "Spanish fowls," than which nothing is more erroneous. They are as distinctly an original breed as the pure-blooded Great Malay, and possess about the same qualities as to excellence, but falling rather short of them as to beauty. This, however, is a matter of taste, and some consider the pure Java superior to all other large fowls, so far as beauty is concerned. Their plumage is decidedly rich.

Mr. C. N. Bement, a distinguished breeder, and writer on the subject of poultry, says of this fowl:

"This is a singular breed, which partakes of the common fowl and the India fowl, peculiar to the island of Java, where they are seldom reared but for fighting; and are said to be so furious, that they sometimes fight together till the death of one or the other separates them. According to Willoughby, it carries its tail nearly like the turkey. The Sieur Feurnier informs us, that one of this species was kept in Paris; it has, according to him, neither comb nor wattles; the head is smooth, like that of a pheasant. This fowl is very high on its legs ; its tail is long and pointed, and the feathers of unequal length ; and, in general, the color of the feathers is auburn, like the vulture. It is generally supposed the English game cock originated in, or is a cross of, this variety." The above quotation is descriptive of the Wild Indian Game, and not of the Java, except in color. 
The portraits at the head of this article are from life, taken from fowls in possession of Mr. Sidney Packard, of East Bridgewater, and are excellent specimens of the race.

\section{THE GAME FOWL.}

No satisfactory information seems to be accessible by which to pronounce with certainty on the origin of the game breeds. The probability, however, is, that these fowls, like other of the choicest varieties, are natives of India. It is certain that in India an original race of game fowls exists, at the present day, bearing all the peculiar characteristics of the species, in full perfection. In India, as is well known, the natives are infected with a passion for cock-fighting. For this barbarous amusement, these fowls are carefully bred, and the finest birds become articles of great value. In Sumatra, the inhabitants are so much addicted to the cruel sport to which these fowls are devoted, that it is said, on good authority, that instances have occurred of men staking not only their property on the issue of a fight, but even their wives and children! The Chinese also are prone to this miscalled sport ; and, indeed, it is a common practice among all the Indian countries professing the Mussulman creed.

In ancient times, the most civilized nations numbered cockfighting amongst their public amusements; and the Romans, who were a sanguinary people, especially delighted in it. By them it was probably introduced into Britain, at the invasion of Julius Cæsar; and the date of the origin of the game fowl, in that country, may be most reasonably referred to the same period, though some writers assert that it should be fixed at an earlier era. 
The earliest record of cock-fighting in England is in the time of Fitzstephen, who wrote the life of Thomas à Becket, in the reign of Henry II., about the year 1100. Since that time, the history of English manners has been disgraced, until a late date, by the recognition of cock-fighting as a national pastime. Hogarth has a plate representing a blood of the day engaging in the diversion of the cock-pit; and not a century since, "the cock-pit" was a place as well known in London as any other fashionable resort. In the family of the Earls of Derby there has long been a renowned breed of game fowls, and it has been an hereditary boast, that none of them have ever "proved craven." Mowbray, one of the standard authors on poultry, apologizes for the custom, though now it would be difficult to find any to defend him.

"Philanthropists," he says, " are in the habit of declaiming much against the practice of cock-pit battles; but, on reflection, the cruelty of that sport will be found among the least, wherein the feelings of animals are concerned, since fighting, in the game cock, is a natural and irresistible passion, and can never take place against his will; and those that engage in regular combat upon the arena would do so voluntarily, and with equal ardor, did they meet in the desert."

In this country, if this cruel practice ever obtained to any extent, it must now be spoken of as among things that have been. It is only in Mexico and the South American republics that it is tolerated on this continent.

In Mr. Richardson's opinion, in which every one will concur, -

"The game fowl is one of the most gracefully-formed and most beautifully-colored of our domestic breeds of poultry ; and in its form, aspect, and that extraordinary courage which characterizes its natural disposition, exhibits all that either the naturalist or the sportsman would at once recognize as the beau 
ideal of high blood - embodying, in short, all the most indubitable characteristics of gallinaceous aristocracy.

The game fowl is somewhat inferior in size to other breeds, and in his shape he approximates more closely to the elegance and lightness of form usually characteristic of a pure and uncontaminated race. Amongst poultry, he is what the Arabian is amongst horses, the high-bred short-horn amongst cattle, and the fleet greyhound amongst the canine race.

The flesh of the game fowl is beautifully white, as well as tender and delicate. The hens are excellent layers, and although the eggs are somewhat under the average size, they are not to be surpassed in excellence of flavor. Such being the character of this variety of fowl, it would, doubtless, be much more extensively cultivated than it is, were it not for the difficulty attending the rearing of the young ; their pugnacity being such, that a brood is scarcely feathered before at least one half is killed or blinded by fighting."

There are many reasons, however, why the attempt should be made to rear the most desirable varieties; and, with proper care, most of the difficulties which are apprehended may be avoided. It is exceedingly desirable to perpetuate the race, not for the gross abuse of which mention has been made, but for uses the most important and valuable. As a cross with other breeds, they are invaluable, in improving the flavor of the flesh, which is an invariable consequence. The plumage of all fowls related to them is increased in brilliancy; they are, withal, very prolific, and the eggs are always enriched.

Four of the best varieties will now be described. 


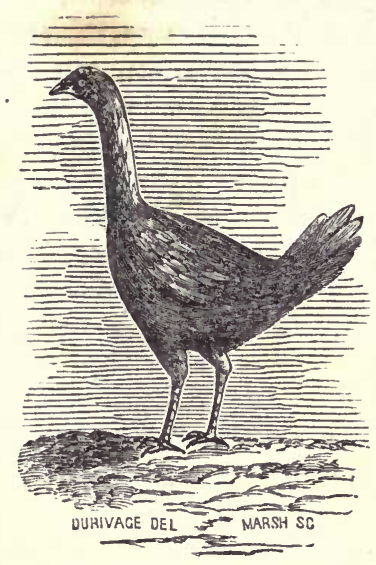

THE WILD INDIAN GAME.

The best, if not the only specimen of this remarkable fowl, in the country, is in my possession. The above plate is an exact portrait, taken from life, of a hen of this breed, imported from Calcutta, by Mr. Robert Estes, a great game-breeder, of East Abington. If it were not too sounding a title, this fowl might be denominated, the Great Indian War Hen. Her mate, the cockerel, died on the passage over.

This is the pure Indian game fowl, and is one of the most singular of the race. A gentleman who has been in Calcutta recognized this hen at once as the "Calcutta Game fowl," or "Wild Indian fowl." She has a long neck, like a wild goose ; has neither comb nor wattles; is of a dark, glossy green color ; has a very short fan tail; is lofty in her carriage, trim built, and wild in her general appearance, and has very large and long yellow legs, spotted with blue. She weighs five pounds 
and three quarters, but is so very compactly built, that good judges frequently estimate her only at about four pounds. This is conclusive evidence of her extraordinary fine quality.

When this bird was first described by me, I represented her as rather a poor layer, and as an incorrigible sitter. Further experience, however, enables me to state that as a layer she is equal to other fowls of the game variety. She has proved to be remarkable for her tenacity of purpose, and steady perseverance in whatever she undertakes. When she lays, she lays daily, and seems to devote her energies to this duty; if disposed to sit, she cannot be diverted from her object. The person who had charge of her last season says that he placed her in a barrel partly filled with water, for two weeks, during the daytime, in order to overcome her desire to incubate, removing her to the roost every evening, and at the end of this term, he was obliged to let her go to her nest.

This hen shows a plumage of remarkable beauty, being covered with feathers as brilliant as the long tail-feathers of the game cock; and the variety unquestionably stands at the head of the game race. When pitted with a perfect Spanish game fowl she was easily victorious, and I have seen no other fowl, as yet, that can stand before her in battle.

The wild fowls of India are generally peaceable with their acquaintances, but never suffer strangers to show fight without whipping them. They are superior to the common game fowl for fighting, when aroused; and this hen, the morning after I obtained her of Mr. Estes, whipped twenty-seven of my largest fowls, hens and cocks, one after another, without stopping.

The eggs produced by this hen are remarkable in their appearance. The color is white, tinged with yellow; and at one end, they are sometimes spotted like a bird's egg. The size is large.

In the following letter from Mr. Stoddard, will be found 
additional testimony to the good laying qualities of this particular fowl, and valuable information respecting the male bird, which was unfortunately lost.

\section{To Dr. Bennetr. - Sir :-}

"Hanover, 10th Aug., 1849.

In the last number of the Boston Cultivator, I noticed an article written by yourself, in which you described the famous India hen, imported by Mr. Estes; and having procured her for him, I read the article with no small degree of interest. I was somewhat disappointed in your statement in regard to her laying qualities, having anticipated otherwise, from the fact of her having layed a full litter on the passage home, commencing when five days from Rio Janeiro, and only missing three days, in a litter of thirteen, while the ship was in violent motion, in a gale of wind. The rooster, her mate, died on the passage, which I very much regretted, as I believe there is nothing like him in this country. He stood as high as a large turkey, and would weigh at least twelve pounds ; his plumage being of a reddish cast, interspersed with spots of glossy green, with a very small comb, and no wattles, with a bill unlike any other fowl, except the hen. I used every exertion in my power, on ship-board, to save his life, but to no purpose; I much wish you could have had him, with your numerous other varieties. I purchased these fowls to fulfil a promise made to Mr. Estes, when I left home, to procure him a pair of rare fowls on my return, paying $\$ 3.50$ for them, when I could have purchased others at one quarter that price. With regard to her fighting qualities, I may say, she whipped a flock of twenty-three hens and two roosters on the morning after I arrived at my father's house in this town, immediately on being let out from the coop in which she had been brought from the ship at New Bedford; and this she did without stopping. 


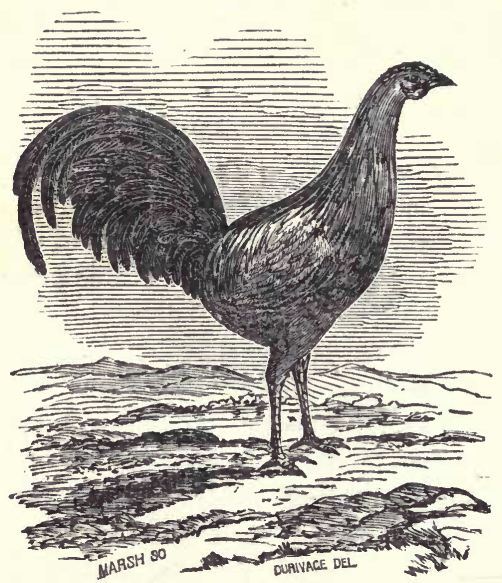

THE SPANISH GAME FOWL.

The fowl represented in this plate is drawn from life, from a bird belonging to Mr. O. M. Stacey, of Lynn. This specimen was deemed the handsomest of its kind exhibited at the late fowl fair, and the author has never seen so fine a.fowl of the kind. A glance at the portrait will show how perfect is the symmetry and how noble is the bearing of this splendid creature.

The cock weighs five and a quarter pounds, and the hen, his mate, three pounds and fourteen ounces.

This is the kind called the English fowl by Buffon and the French writers; it is more slender in the body, the neck, the bill, and the legs, than the other sorts, and the colors, particularly of the cock, are very bright and showy. The flesh is white, tender and delicate, and on this account marketable. The plumage is very beautiful - a clear, dark red, very bright, 
extending from the back to the extremities, while the breast is beautifully black. The upper convex side of the wing is equally red and black, and the whole of the tail-feathers black. The beak is black, and the legs are black also. The eyes resemble jet beads, very full and brilliant, and the whole contour of the head gives a most ferocious expression.

The flesh of this fowl is remarkably fine; the eggs are small, and extremely delicate.

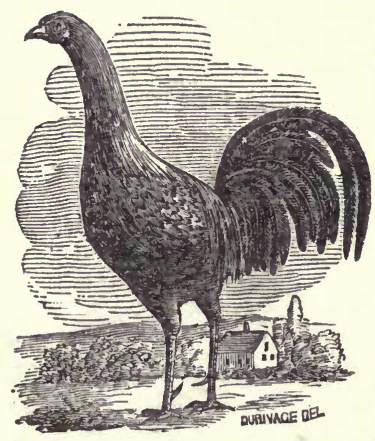

THE YANKEE GAME FOWL.

This portrait is also taken from life, from an excellent specimen of this breed, which I have denominated the Yankee Game. This fowl was originally produced by a cross between the Plymouth Rock and Indian Game hen. But a few only have been produced from this mixture. I have since bred, and shall continue to breed, this race, from the cock and hen described in the preceding articles; that is to say, from the Spanish cock of Mr. Stacey, and the Wild Indian hen of Mr. Estes. 
This variety combines the great strength and size of the Wild Indian Game hen, and the sprightliness and beauty of the Spanish Game, and thus partakes of the general characteristics of the two best kinds of game fowl. For loftiness of carriage, hauteur, compactness of form, healthiness, neatness, sprightliness, and general beauty, this sort are unrivalled; and so far as fine flesh and captivating appearance are concerned, they are undoubtedly the best breed in America.

No other fowl with which I am acquainted is more desirable to introduce into the poultry-yard for breeding purposes. If associated with different varieties, the flesh of the offspring will infallibly be improved, and the flavor of the eggs will become more exquisite. Improvement in plumage and beauty of form will also be a necessary consequence.

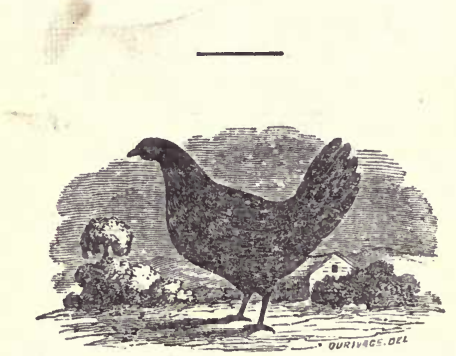

THE ENGLISH RAVEN FOWL.

This portrait represents a fowl from the stock of A. V. Poindexter, Esq., of Concord, N. H, formerly a breeder of reputation at the South. These beautiful fowls are "as black as a raven," and much more glossy ; in fact, their plumage is exceedingly brilliant. They are perfectly black, feathers, legs, comb, and all, (in fact, they have scarcely any comb or wattles,) excepting occasionally a few red feathers on the cocks. Heads, 
very small; tails, extremely large. They are a species of the "Game," and their flesh, therefore, is very fine and well flavored. They are the best layers of all the "Game Fowl," and their eggs are rich and savory. In size they are medium, and in form most symmetrical. They may be classed with the most valuable fowls. The pure bloods are very rare. I have but few.

The fowl represented above is in my possession, and is a great favorite, not only on account of its real worth, but of its ornamental appearance. The weight is about the same as that of the Spanish Game.

The following information, derived from Mr. Dickson's book, may not be without practical use to those who have or esteem other varieties of game fowls:

"Sportsmen who breed game cocks for fighting have numerous named varieties, such as piles, black-reds, silver-breasted ducks, birchin ducks, dark grays, mealy grays, blacks, spangles, furnaces, pole-cats, cuckoos, gingers, duns, red duns, smoky duns, among all of which, according to Sketchley, good birds may be found ; but he thinks the following eight are superior to any others, namely, dark reds, dark black-breasted reds, dark black-breasted birchin ducks, dark black-breasted berry birchins, silver black-breasted duck-wing grays, clear mealy grays, dark blark-breasted grays, and red duns.

The Mealy Gray, which may be ranked next in value to the true dark gray, originated from the black and mealy white, and has been the produce selected from those whose feathers were nearest to the mealy white, slightly tinged and shaded with black. These have been bred in and in, and established the mealy gray ; and from those of darker varieties have nearly all our grays originated. The hen's color will, in general, prevail wonderfully more than the cock's. 
The Tame Birchin Black-breasted Duck has been originally bred from the black-breasted red, the yellow birchin, and the gray duck-wing hens. The feather of the birchin duck is a gray hackle, tinged with black above and black beneath, the ground yellow, with a general shade of the dark birchin through, and clear black-breasted, with yellow legs and beak. No cocks exhibit a longer period of unfaded health than the true black-breasted birchin ducks, and their reputation stands high in the opinion of sportsmen.

The Piles have originated from a variety of crosses, which have constituted the many shades we find in this numerous class. There is a strain in these cocks which eminently distinguishes them.

The sorts which Sketchley mentions as inferior, most probably from injudicious crossing, are, the pheasant-breasted red, the large spot-breasted red, the blotch-breasted red, the turkeybreasted gray, the large marble-breasted gray, the large spotbreasted gray, the shady-breasted birchin duck, the streakybreasted birchin duck, and the marble-breasted birchin duck.

Among the list of imperfections, he enumerates ' flat-sided and then generally deep-keeled, short-legged, thin thighs, crooked or indented breast, short thin neck, imperfect eye, duck and short footed, and unhealthful.' "' 


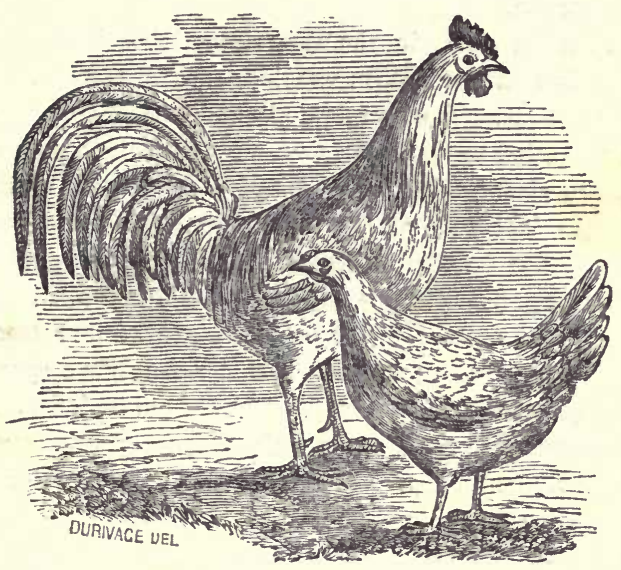

THE DORKING FOWL.

ThE fowls here represented are accurate likenesses from life, from stock imported by John Giles, Esq., of Providence. This stock was selected personally by Mr. Giles, in the town of Dorking, in Surrey, England, and are undeniably the best specimens of that breed ever imported into this country. Their color is a perfect white, without any shade whatever. The legs are white, and they have five toes, which marks are invariable characteristics of a pure breed. These particular fowls are now in the possession of Mr. Stephen Perkins, of Plymouth, who has the reputation of being a very careful breeder. Mr. Giles says that fowls of this breed average from six to eight pounds each.

Dr. Eben Wight, of Boston, imported some of the fowls in the year 1839, and though he bas since bred them " in and in," 
they have not degenerated, and his stock yet sustains an excellent reputation.

L. F. Allen says, in the American Agriculturist, "The Dorking is a fine large bird, weighing, when at maturity, five to eight pounds. They are large-bodied, and of better proportions, according to their size, than any breed I have yet seen; their bodies being very long, full, and well fleshed in the breast and other valuable parts. They are short-legged, thickly feathered, with fine delicate heads, both double and single combs, and a shining, beautiful plumage. The color of their legs is white, or flesh-colored, having five instead of four toes, the fifth being apparently superfluous, and rising like a spur from the same root as the heel toe in the common varieties. This is a distinguishing mark of the variety. They are most excellent layers, good and steady sitters, and kind, careful nurses. They are the capon fowl of England, and are bred in great quantities for the luxurious tables of the wealthy classes in the counties about London."

Specimens of this variety have also been imported by Messrs. A. B. Allen, of Buffalo, F. Rotch, of Otsego, and Chapman, of New York.

Mr. Allen, of Buffalo, was the first importer of the Speckled Dorking, this and the White being the only pure varieties in the country ; the others are hybrids, but nevertheless of excellent quality. These latter varieties are usually denominated improved Dorkings, and sometimes the Sussex breed; and they are considered by many an improvement on the original Dorking ; but, in my opinion, they are not equal to the pure White Dorking of the Giles importation, especially in regard to fineness of flesh. They are usually, however, a larger and heavier fowl.

The hybrids above referred to will now be described. 


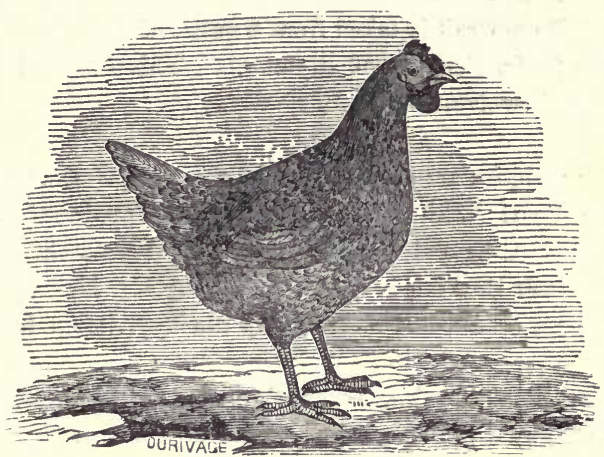

THE FA WN-COLORED DORKING.

This is really a misnomer, the fowl commonly bearing this name being a cross between the White Dorking and the Fawncolored Turkish fowl. The original imported hen, from which this cross was made, is in possession of Pierce B. Fagen, M. D., of Fort des Moines, Iowa. 'Though there has been some variation heretofore in the plumage; and the color of the leg, and the absence of the fifth toe, I shall hereafter breed them with uniform plumage, white legs, and five toes.

They are of lofty carriage, handsome and healthy. The males of this breed weigh from eight to nine pounds, and the females from six to seven pounds, and they come to maturity early for so large a fowl. Their tails are shorter than other Dorkings. Their flesh is fine, and their eggs rich, and darker than those of other Dorkings. From the latter part of February to about the 20th of June, my Fawn-colored Dorking hen laid 118 eggs, missing only three days in the time. 
I regard this as one of the best varieties of fowls known, as the size is increased without diminishing the fineness of the flesh. The portrait is taken from a pullet of this year, in possession of Mr. Perkins, of Plymouth. This bird weighs five pounds and twelve ounces.

Other varieties are called Dappled, Mottled, Cuckoo-colored, and the Pearl White, which variety was produced by $\mathrm{Mr}$. William Gooding and John Washburn, of Plymouth.

The Black Dorking is thus described by Mr. N. C. Day, of Lunenburg, Mass., but undoubtedly the appellation is a misnomer :

"The Black Dorkings were brought to this town a few years ago, by a young man, who presented them to his friends living in this place. The person who brought them is now in California ; but he stated to me that 'they came from Philadelphia,' and I have no doubt of the fact, as I have never seen or heard of any in New England. The family who have kept them here have valued them very high, and would rather kill them than sell them at a reasonable price; and the neighbors were not very anxious to obtain them, saying that they were ' too large a breed.' The family above referred to have since broken up housekeeping and removed from town, and I have purchased their entire stock, and also every one in the neighborhood of this breed that is of pure blood; and from one year's experience with them, I find their qualities as follows, as nearly as I am able to describe them:- Their bodies are of a large size, with the usual proportions of the race, and of a jet black color. The neck-feathers of some of the cocks are tinged with a bright gold color, and those of some of the hens bear a silvery complexion. Their combs are usually double, and very short, though sometimes cupped, rosed, or single, with wattles small, 
and they are usually very red about the head. Their tails are rather shorter and broader than most others of the race, and they feather rather slowly. Their legs are short and black, with five toes on each foot, the bottom of which is sometimes yellow. The two back toes are very distinct, starting from the foot separately, and there is frequently a part of an extra toe between the two. This breed commence laying when very young, and are the greatest layers, during winter, I ever had. Their eggs are of a large size, and hatch well ; they are perfectly hardy, as their color indicates, and for the product I consider them among the most valuable of the Dorking race."

It should be remembered that all pure Dorkings are compactly formed, and have rose combs, long tails, white legs, and five toes upon each foot ; and even the hybrids, when perfected, have these uniform characteristics : but it by no means follows that every five-toed fowl is a Dorking. Many, and I believe most, that are sold as Dorkings, are spurious, and a disgrace to $t\}$ Dorking race. 


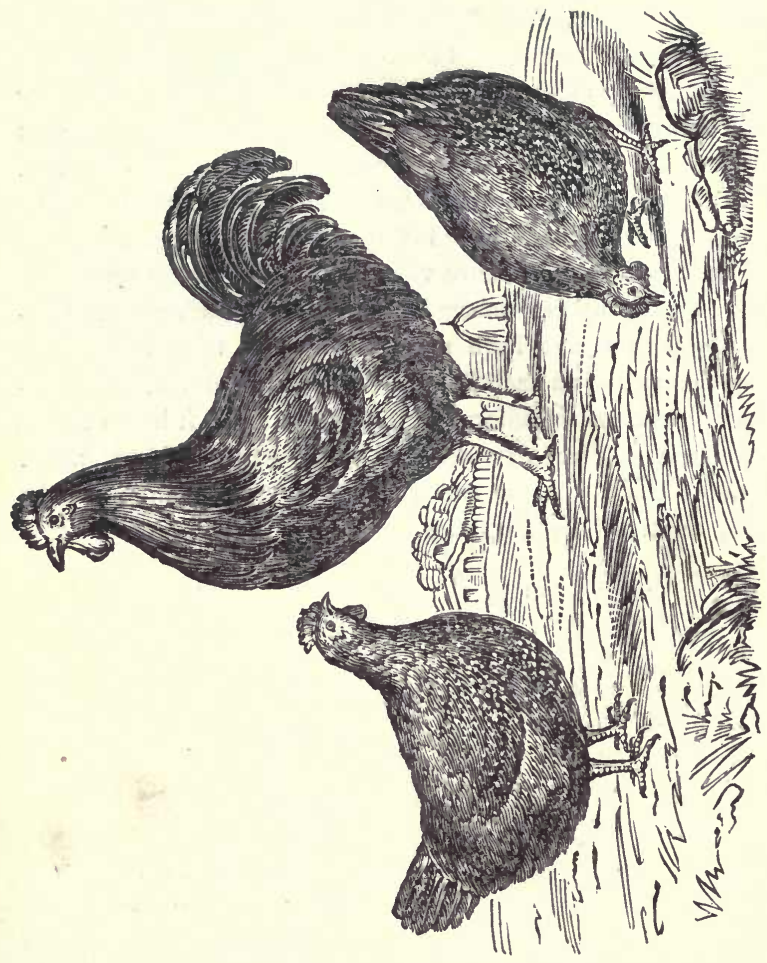




\section{THE PLYMOUTH ROCK FOWL.}

This plate contains portraits of fowls from a brood raised by G. P. Burnham, Esq., of Roxbury, hatched last April. I have given this name to a very extra breed of fowls, which I produced by crossing a cockerel of Baylies' importation of Cochin China with a hen, a cross between the Fawn-colored Dorking, the Great Malay, and the Wild Indian. Her weight is six pounds and seven ounces. The Plymouth Rock Fowl, then, is, in reality, one half Cochin China, one fourth Fawn-colored Dorking, one eighth Great Malay, and one eighth Wild Indian ; having five primitive bloods, Shanghae, Malay, Game, Turkish, and Indian, traceable by referring to the history of those breeds and their crosses respectively. There are several of this breed in Plymouth, from my original stock, belonging to Messrs. John H. Harlow, Samuel Shaw, and myself, that are now a little over one year old; the cockerels measure from thirty-two to thirty-five inches high, and weigh about ten pounds, and the pullets from six and a half to seven pounds each ; forming, in my opinion, the best cross that has ever been produced. The pullets commenced laying when five months old, proving themselves very superior layers. Their eggs are of a medium size, rich, and reddish-yellow in color. Their plumage is rich and variegated; the cocks, usually red or speckled, and the pullets darkish brown. They are very fine fleshed, and early fit for the table. Their legs are very large, and usually blue or green, but occasionally yellow or white, generally having five toes upon each foot. Some have their legs feathered, but this is not usual. They have large and single combs and wattles, large cheeks, rather short tails, and small wings in proportion to their bodies. They are domestic, and not so destructive to gardens as smaller fowls. There is the same uniformity in size and general appearance, at the 
same age of the chickens, as in those of the pure bloods of primary races. The demand for this breed has exceeded all others, during this season, and they have been sent into most of the New England States and Western New York.

Mr. Burnham, in a communication to the Massachusetts Ploughman, thus describes his fowls, and bears his valuable testimony to the excellence of the breed :

" The cock here represented weighs nine pounds and a quarter, and the two pullets thirteen pounds. The stock came from Dr. Bennett, and I am daily more and more pleased with this fine species. I have the 'Plymouth Rocks' at all ages, now - from a few days, up to about eight months old; and my specimens embrace five or six different broods. The color of all of them is peculiarly uniform, and I am satisfied that the variety (or breed) is now well established. The body plumage on the pullets is a rich deep brown, speckled with golden-tipt feathers; the under down is black, (or a deep blue-black,) and the tail is brown, black and gold.

The legs of the pullets are very dark colored, and one half of them, or more, are five toed; but some of them do not come so. The comb is single, and the wattles thin and small. The head and neck are well formed, the legs are shorter than the average of fowls, and the hens are not only deep and broadchested, but the bodies are proportionally very long - as you will observe in the drawing.

The roosters are noble birds - among the finest I have ever met with. I have two well-grown crowers, very similar in their appearance, carriage, color, size and general points; the above is a true and life-like drawing of the male birds, which, for their age, will compare favorably - so far as my experience goes - with any known breed of domestic fowl.

I am satisfied that the Plymouth Rock fowl, carefully bred, will become a most valuable one to the poulterer or the agri- 
culturist ; and I believe that a pair of the specimens shown in the accompanying engraving will weigh, at laying time next spring, full eighteen pounds - perhaps more. I deem this ample, for size; and with the other good qualities of these fowls, which I have already tested, - for laying, quietness, easy keeping, and general hardiness, - I think these must cause them to rank among the very best in our country, eventually.

The plumage of the roosters is dark red hackles, on neck and rump; the legs are bright yellow, slightly feathered; the body, dark red and green, relieved with stray feathers of a golden tint; and the under portion of the body and breast is a rich, deep, glossy blue-black - partaking of the plumage of the Wild Indian fowl, the original cross. The tail-plumes on the above crower are not grown out, as yet, of course, nor does he yet show any spur; but he is pictured exactly as he is at this time, after his first moult. When in full plumage, the tailfeathers are heavy, and give the male bird not only a much larger proportionate appearance, but very greatly improve his form."

In the Massachusctts Ploughman, also, there is a communication from Mr. John A. Harris, of South Boston, concerning the laying of this breed, which is here subjoined.

\section{"South Boston, Nov. 27th, 1849.}

Dear Sir :- In answer to your inquiry respecting the Plymouth Rock fowls, I will make the following statement : Sept. 7th, I received of Dr. Bennett two hens, one year old, and one cockerel, four months old. One of the hens laid, the next day; and in five weeks laid thirty eggs. She then stopped laying till Nov. 18th, when she commenced again. The other hen began to lay Sept. 22d, and in twenty-four days laid twenty eggs. She then (Oct. 15) stopped laying, but began 
to lay again on the $3 \mathrm{~d}$ Nov., and both hens continue to lay averaging about six eggs per week. About once a week, each hen lays an egg of very large size. I have twelve other hens, of common kinds, from which I have had fifty-three eggs; while, in the same time, the two Plymouth Rock hens laid seventy-seven. Oct. 12th, I weighed three lots of eggs, as follows, namely :-

Six Plymouth Rock hen's eggs, largest size, nineteen and a half ounces; six Plymouth Rock hen's eggs, smallest, thirteen and a half ounces; six common hen's eggs, eleven and a half ounces.

The Plymouth Rock fowls appear to be very quiet, and of remarkably amiable disposition, and thus far I am much pleased with them.

Yours, very respectfully,

John A. Harris."

Mr. John Giles, of Providence, in a letter dated "Sept. 19th, 1849," says - " The 'Rocks' are a splendid bird, and if their table qualities prove to be good, will make a valuable breed of fowls." Again, in the same letter he says, - "On more close examination of the 'Rock' chick, I am more confirmed that they must prove an invaluable breed. Could you not cross so as to have one distinct color of leg and plumage?"

In conformity with this suggestion, I shall endeavor hereafter to produce them with uniform plumage, preferring the dark color, dark legs, and four toes only ; as I consider the fifth toe objectionable, when it can be avoided. 


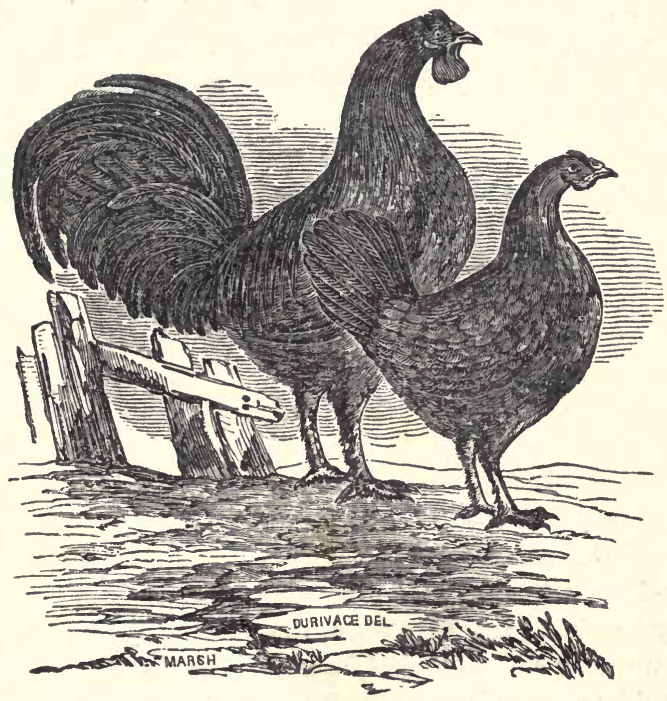

THE GUELDERLAND FOWL.

The fowls which are portrayed in this cut were obtained from Dr. E. G. Kelly, of Newburyport, and are now in possession of Mr. Joseph Rider, of Plymouth, for breeding. An inspection of the engraving will show the extraordinary symmetry of these birds; and they are very graceful in their motions. They have one very noticeable peculiarity, which consists in the absence of a comb in either sex. This is replaced by an indentation, on the top of the head; and from the extreme end of this, at the back, rises a small spike of feathers, as shown in the picture. This adds greatly to the beauty of the fowl. The presence of the male bird is especially dignified, not to say majestic, and the female is little inferior in carriage. The 
plumage is of a beautiful black, tinged with blue, of very rich appearance, and bearing a brilliant gloss. The legs are black, and usually heavily feathered. The specimens represented above are unusually so. The wattles are of good size in the cock, while those of the hen are slightly less. The flesh is fine, of white color, and excellent flavor. The eggs are large and delicate, - the shell is thicker than in those of other fowls, and are much prized for their good qualities.

This excellent breed has never been described, to my knowledge; and, as it appears below they have been some time in the country, this fact is somewhat extraordinary. They possess all the characteristics of a perfect breed, and in breeding them this is demonstrated by the uniform aspect which is observable in their descendants. No surer proof of the purity of a race can be demanded. The only objection which I have discovered in them is the tenderness of the chickens; but with a degree of care equal to their value, this difficulty can be surmounted, and they may be raised. In time to come, when this breed shall be better known, they will be eagerly sought after, and highly appreciated by all who have a taste for beauty, and who desire fine flesh and luscious eggs.

I am indebted to Mr. H. L. Devereux, of Boston, for the following account of the original importation of this breed, and a description of those in his possession.

"The Guelderland fowls were imported from the north of Holland, some years since, by Captain John Devereux, of Marblehead, in the ship Dromo ; and since that time have been bred purely by him, at his place in that town. They are supposed to have originated in the north of Holland. They are clad in a beautiful blue-black plumage, but the flesh is white, tender and juicy. They have no comb, but a small, indented, hard, bony substance instead, and large red wattles. They are of good size, great layers, seldom inclining to sit; bright, 
active birds, and are not surpassed, in point of beauty or utility, by any breed known in this country."

This description applies with great exactness to the fowls engraved in this volume. Their weight is from five pounds for the pullets, to seven pounds for the cocks. The laying qualities of the hens are very respectable, and in this respect they will prove profitable to their owners. It is safe to pronounce the Guelderlands to be a first rate breed for profit, and especially for beauty.

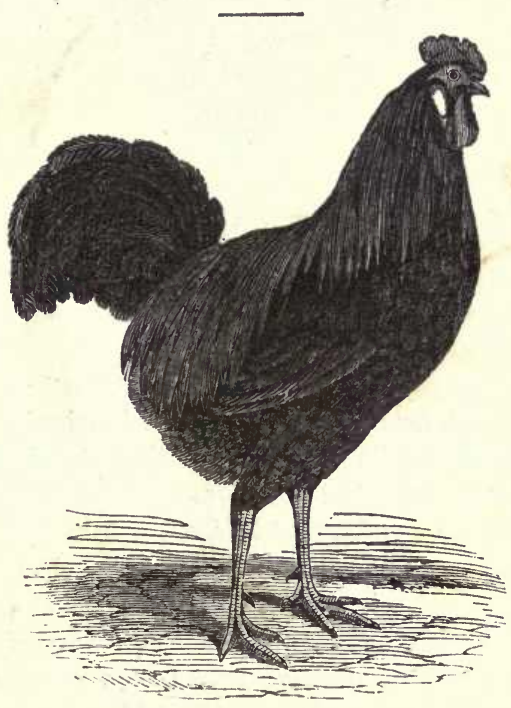

THE SPANISH FOWL.

" This fowl," says Richardson, " is clad in black plumage, but possesses quite the reverse of black flesh. I regard these 
birds as the result of the highest possible artificial culture, and adduce, in support of my opinion, their unusually large comb and wattles, characteristics not commonly to be met with among the primitive varieties.

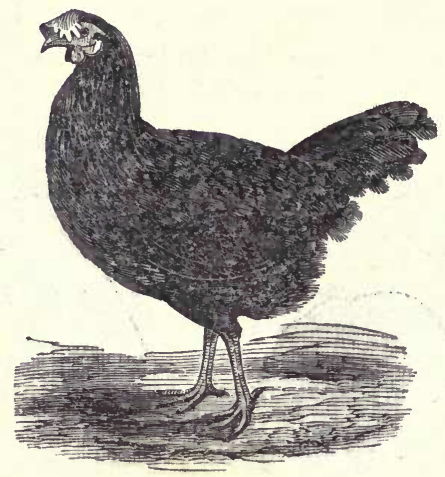

SPANISH HEN.

The Spanish fowl is, perhaps, a little inferior in size to the old 'Shakebag,' but in every other quality, wherein excellence and value are to be looked for, it is more than that bird's equal. The color of the Spanish fowl is black, and the feathers of the legs, thighs, and belly, are particularly decided in their hue, and of a velvety aspect. It is a stately bird, and of a grave and majestic deportment, and is, in either utility or beauty, to be surpassed by none of its congeners. One of the most striking characteristics of this fowl is a white cheek, and the comb and wattles are singularly large, simple, and of a very high color. The feet and legs are of a leaden color, except the soles of the feet, which are of a dirty fleshy hue. This is a fowl well de- 
serving the attention of the breeder. They have long been naturalized in England, and are consequently well 'climatized,' and present no peculiarities of constitution that would suggest difficulties in either hatching or rearing. As table birds they hold a place in the very first rank, their flesh being particularly white, tender, and juicy, and the skin possessing that beautifully clear white hue, so essential a requisite for birds designed for the consumption of the gourmand. The hens are likewise layers of the first order; and of all naturalized or indigenous varieties of fowl, with the exception of the Columbian, these lay the largest and the best-flavored eggs. They are, besides, prolific, extremely easily fed, and, in short, I know of no fowl I would rather recommend to the notice of the breeder; but let me here observe, that spurious specimens of this fowl are often in the market, which will occasion, perhaps, an equal outlay at their original purchase - will decidedly cost as much to feed - be, perhaps, harder to rear, but will most unquestionably not bring in an equal return in the way of profit. By applying, in the first instance, to a breeder of known respectability, you will avoid much disappointment; and though you may conceive the price demanded of you to be high, it may not, perhaps, at the same time, be higher than what you might have foolishly paid for a bad article; and even should you have to lay out a few shillings extra, do so willingly, and recollecting the old proverb, avoid being 'penny wise and pound foolish." "' 


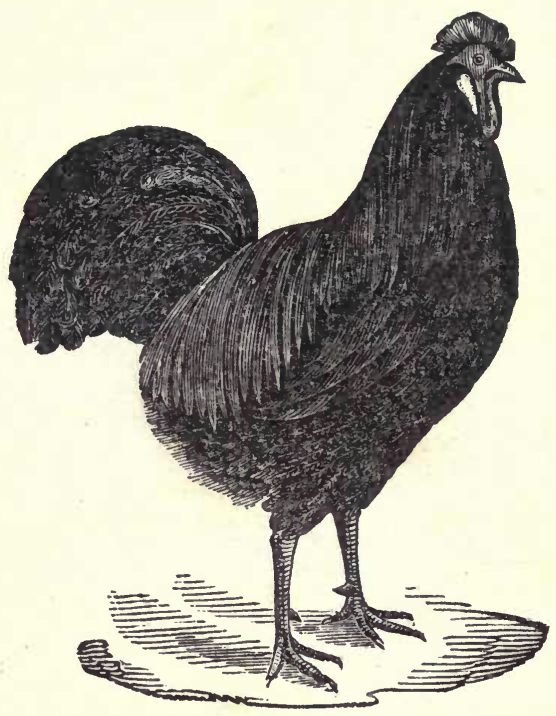

BLAKE'S SPANISH FOWL.

This plate represents a fowl belonging to Mr. Francis Blake, of Boston, who has obligingly furnished the annexed description. Mr. Blake's fowls were exhibited at the late fowl fair in Boston, and excited very general admiration. The portrait is very accurate, and is taken from the life.

"These fowls were imported by me from England early in the winter of 1847. Being exposed to the severity of the season, and being debilitated by the voyage, the comb of the cock suffered from the cold, as its present appearance indicates, being smooth upon the top, instead of being indented. He soon recov- 
ered his usual vigor, and I have not discovered the slightest variation in the characteristics of his progeny; - in fact, the chickens produced by a cross between this breed and my other fowls differ but slightly in appearance from the pure Spanish, showing, I suppose, the purity and strength of the breed. Having kept but few fowls, for the amusement and convenience of my family, I made no arrangements for keeping this breed distinct, till during the last season, when I became so well convinced of their decided superiority, as to be induced to prepare a separate establishment for them, with reference to keeping the breed pure.

The hen is a most inveterate layer. During the two years I have had them she has manifested no inclination to sit, and with the exception of brief intervals during her different litters, which have consisted of about eighty eggs, has layed constantly. The eggs are of large size, fine flavored, and, unlike most of the eggs from dark-colored poultry, the shells are as white as alabaster.

For grace and beauty, I think this breed is unsurpassed by any that I have noticed. I am, sir,

Respectfully, your obedient servant,

Francis Blake."

Mr. John Fussel, of the firm of Shorey \& Co., Boston, has also some of the true Spanish fowl, imported by him from Fayal. 


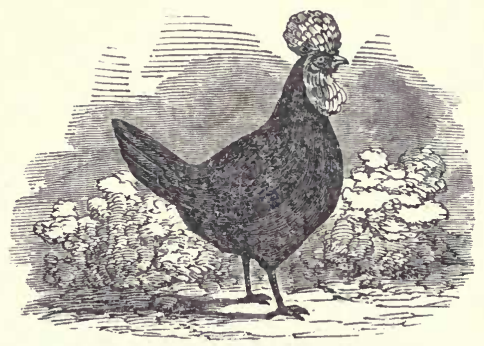

THE BAVARIAN FOWL.

This portrait is from life, and is an accurate likeness of a hen of this breed. The plumage of this fowl is jet black, and they have also black legs, frequently feathered heavily. Both cocks and hens are muffled, with a heavy "imperial," or " goat-beard," under the throat, and usually quite a crest, or top-knot, much resembling, in all these respects, the Golden Pheasant; with this difference, however, that the crest of the Bavarian is smaller, and the imperial larger, the muffler being about the same in both breeds. Tails and wings longer than most of the large breeds, excepting the Dorkings.

The eggs are usually large, white and well-flavored. They are among the very best layers, and are good sitters, and careful nurses. All things considered, perhaps these fowls have few, if any, superiors. The weight is generally from five to eight pounds. They come to maturity very early, are more hardy than either of the two preceding varieties, and the chickens are very easily raised. Although I esteem the Guelderland and the Spanish fowls as pure breeds, and excellent in all respects, yet I prefer these, especially on account of the size of their eggs.

Occasionally one of this breed, of perfectly pure blood, may be seen entirely destitute of a crest, with a large muffler, small imperial, and lightly feathered legs. Those with these marks zre usually the best, actually being larger and better layers. 


\section{THE POLISH FOWL.}

"It appears probable," says Dickson, " that the Polish fowl is a hybrid between the Crested and the Spanish fowls. It is, however, quite unknown in Poland, and takes its name from some resemblance having been fancied between its tufted crest and the square-spreading crown of the feathered caps worn by the Polish soldiers. These fowls are exceedingly handsome, and remarkably good for the table. The hens are excellent layers, and produce very large, finely flavored eggs; but they are bad sitters.

The breed of crested fowls is much esteemed by the curious, and is bred with great care. Those who are desirous of propagating any singular varieties separate and confine the individuals, and do not suffer them to mingle with such as have the colors different. The varieties are more esteemed in proportion as the colors are more rare, or as the tuft contrasts with the rest of the plumage; but though the differences of plumage are thus preserved pretty constant, they seem to owe their origin to the same breed, and cannot be reproduced pure without careful superintendence. These cocks are much esteemed in Egypt, in consequence of the excellence of their flesh, and are so common that they are sold at the rate of twopence or threepence a piece. They are equally abundant at the Cape of Good Hope, where their legs are feathered. Some travellers assert that the Mexican poultry are crested, and that what are called Poland fowls are natives of either Mexico or South America ; but these, as well as all the rest on the continent of America, have been introduced from the ancient continent."

" Of the Polish fowl," says Richardson, " there are three subvarieties, one of which, however, would appear to be nearly, if not altogether, extinct, even in its native country. This fowl is, perhaps, the most unchanged from the primitive stock of any we 
are now acquainted with, being, beyond doubt, the immediate and almost unmixed descendant of the ' Gallus giganteus,' or great wild cock of St. Jago. The three varieties of Polish fowl are -

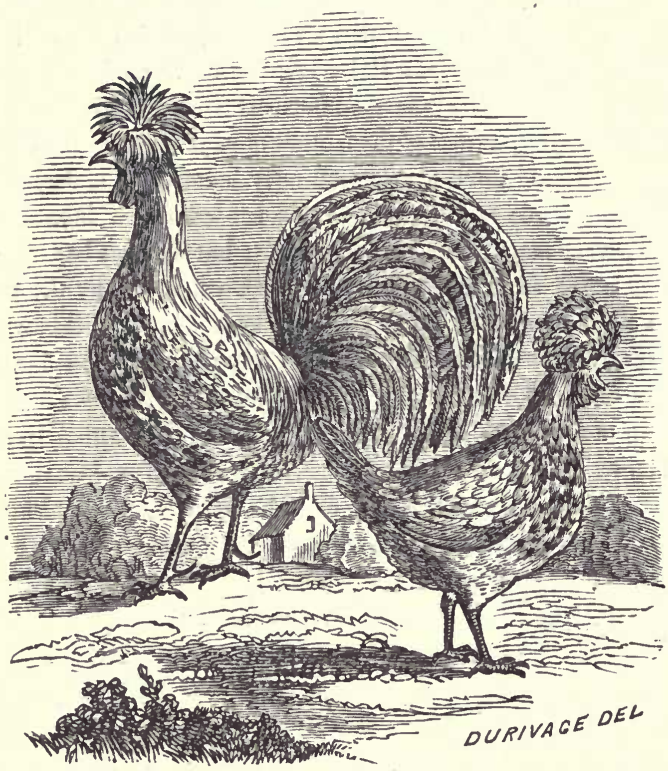

1. The Spangled Polish. - A bird of extraordinary beauty, extremely scarce, and very difficult to be procured. This fowl presents a symmetrical and regular combination of the following colors, namely, - a bright orange, a clear white, a brilliant green, and a jetty black, softened down with a rich and pure brown, every feather being tipped with white, so as to produce the effect whence has been derived the term of spangled. The color of the hen is a prevailing golden yellow, with white 
spangles, like the cock. In the cock the thighs are black, and are, likewise, though in a less degree, marked and spangled with black and golden yellow. The hinder end of the body is furnished with green and orange-brown hackles, and the tail is carried well up. The flesh of these birds is of a good quality, and they are very prolific. They also fatten quickly, and have, by some, been compared to the Dorking, for similarity of flesh, and other excellences of quality. I, however, must unequivocally award the preference to the latter bird, independent of the enhanced price occasioned by the far greater scarcity of the former."

The fowl known in this country as the Golden Pheasant is a hybrid, bred from the variety just described, and the Black Polish fowl, which will be described below, by Col. S. Jaques, of Ten Hills Farm, Medford. Col. Jaques is known throughout the country as a veteran and scientific breeder of stock. The above plate represents a cock of the kind described by Richardson, and a pullet of Jaques' cross breed, both taken from life. The only difference between the two consists in the fact that the feathers of the hybrid are not tipped with white, but are golden color tipped with black, which gives them a spotted appearance.

I have some very superior specimens of this variety, and $\mathrm{Mr}$. Drake, of Fiskdale, is equally fortunate. The portraits above given are exceedingly accurate representations of my fowls. A glance at this plate, and attention to the description, will show that the birds generally which purport to be Golden Pheasants are very inferior fowls, and unlike mine in important respects. The extreme beauty of this, variety is not its only recommendation, as they are profitable for the table, and also for their laying qualities. 


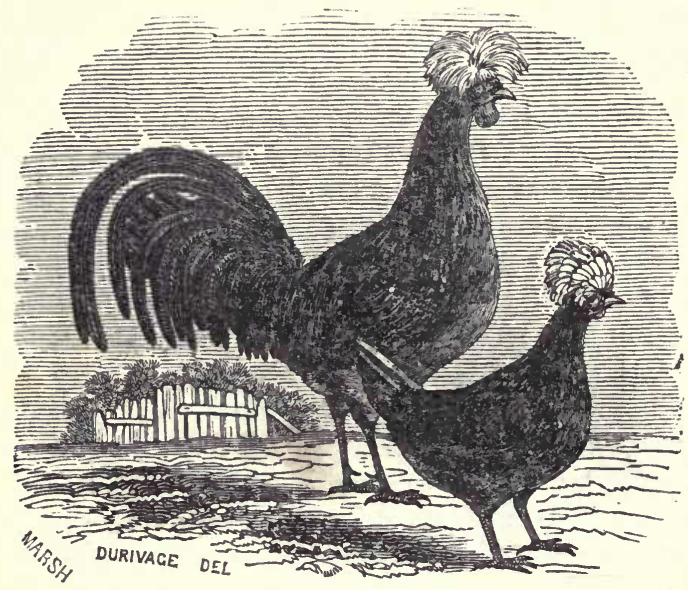

2. The second variety of the Polish fowl is the well-known Black fowl, with a white tuft on the crown. The portraits are taken from fowls imported by J. Jacob Bower, Esq., of Baltimore, direct from Hamburgh, and now owned by Joseph A. Sampson, of Duxbury, and Rev. Dorus Clarke, of Boston. Mowbray describes this fowl with accuracy, but errs in supposing its original country to have been Holland; these birds having been brought from St. Jago by the Spaniards, to whom they owe their first introduction into Europe. Their color is a shining black, and both cock and hen have the white top-knot. The head is flat, surmounted by a fleshy protuberance, out of which spring the crown-feathers constituting the tuft. These are remarkably good layers, and will, if kept warm, lay nearly throughout the year; and it is this cause, probably, that has induced Mowbray, and other writers, to confound them with the 
Dutch brecd, which, from a similar circumstance, have been styled 'Every-day layers.'

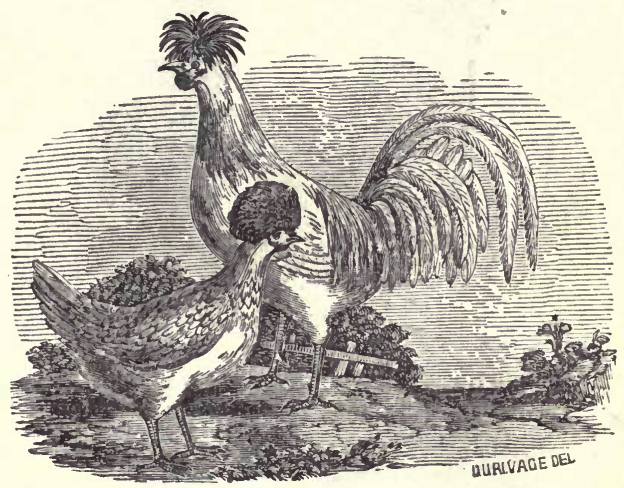

3. This variety of Polish fowl is the most pure and unmixed of the three; it is, indeed, the uncontaminated descendant of the great fowl of St. Jago. Its color is a brilliant white, with a jet-black top-knot. This variety was described by Aldrovand, and more recently by Dr. Bechstein. I have never myself seen a specimen of the breed, and have every reason to suppose it to be extinct, or very nearly so. Applications have been made to several persons in both Germany and Poland, connected with the poultry fancy, for the purpose of procuring specimens of these birds at any cost, but the answers returned were, without one exception, that they were no longer to be had."

Of this third variety there are some beautiful specimens in this country. Their qualities are the same as the Black Poland fowl, but they are decidedly handsomer. 


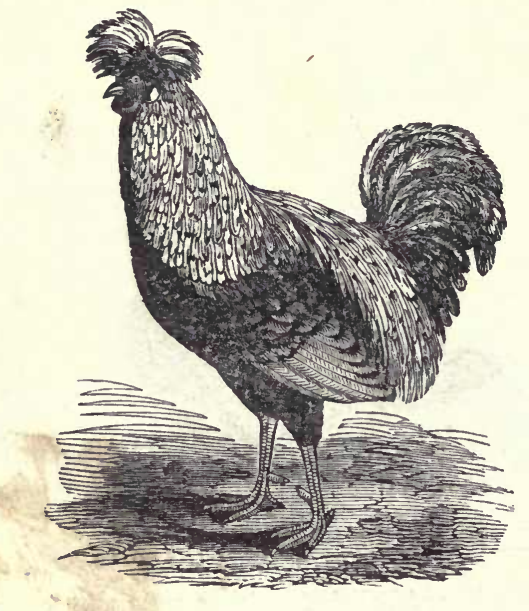

THE SPANGLED HAMBURGH FOWL.

These portraits are drawn from life, from the stock of $\mathrm{J}$. Jacob Bower, Esq., of Baltimore, a celebrated breeder, who imported them direct from Hamburgh. The description is from Richardson, and is perfectly accurate.

"The Spangled Hamburgh fowl are divided into two varieties, the distinctive characteristics being slight, and nearly altogether dependent upon color ; these varieties are termed the Golden and Silver spangled. The former will suffice for me to describe, as the points of form, \&c., excepting only color, are identical.

The Golden Spangled Hamburgh fowl is one of no ordinary beauty; it is well and very neatly made, has a good body, and no very great offal. On the crest, immediately above the beak, are two small, fleshy horns, resembling, to some extent, an abortive comb. Above this crest, and occupying the place of 
a comb, is a very large brown or yellow tuft, the feathers composing it darkening towards their extremities. Under the insertion of the lower mandible, or that portion of the neck corresponding to the chin in man, is a full, dark-colored tuft, somewhat

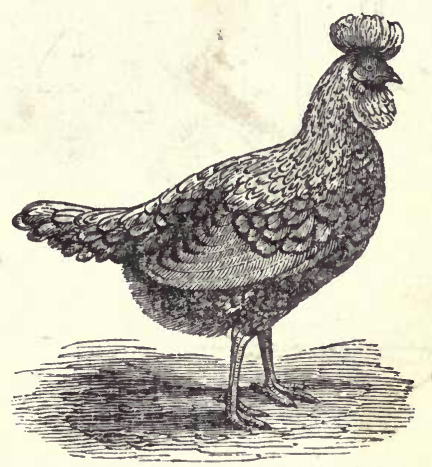

resembling a beard. The wattles are very small. In the Golden variety, the hackles on the neck are of a brilliant orange, or golden yellow; and the general ground-color of the body is of the same hue, but somewhat darker. The thighs are of a darkbrown or blackish shade, and the legs and feet are of a bluish gray.

In the Silver Spangled variety the only perceptible difference is, that the ground-color is a silvery white. The extremity, and a portion of the extreme margin of each feather, are black, presenting, when in a state of rest, the appearance of regular semicircular marks or spangles - and hence the name of "Spangled Hamburgh," the varieties being termed gold or silver, according to the prevailing color being bright yellow, or silvery white. In mere excellence of flesh and as layers, they are inferior to the Dorking or Spanish varieties." 


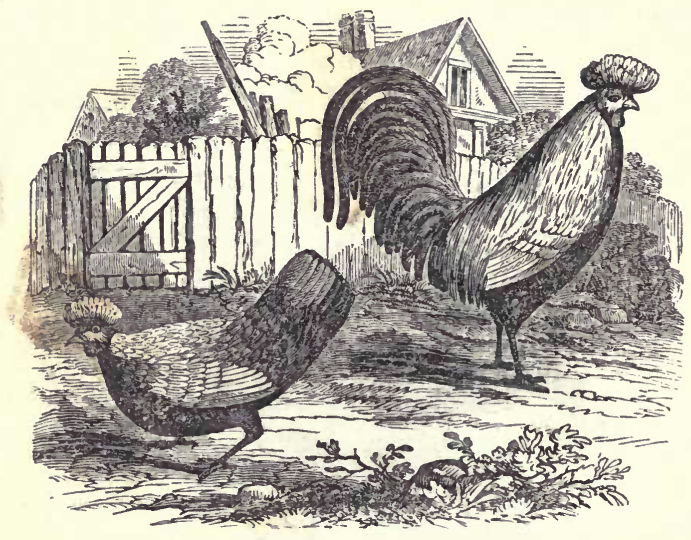

THE SILVER PHEASANT.

This variety of fowls is remarkable for great brilliancy of plumage and diversity of colors. On a white ground, which is usually termed silvery, there is an abundance of black spots. The feathers on the upper part of the head are much longer than the rest, and unite together in a tuft. They have a small double comb, and their wattles are also comparatively small. A remarkable peculiarity of the cock is, that there is a spot of a blue color on the cheeks, and a range of feathers under the throat, which has the appearance of a collar.

The hen is a smaller bird, with similar plumage to the cock, and at a little distance seems to be covered with scales. On the head is a top-knot of very large size, which droops over it on every side. These are beautiful and showy birds, and are chiefly valuable as ornamental appendages to the poultry-yard. 


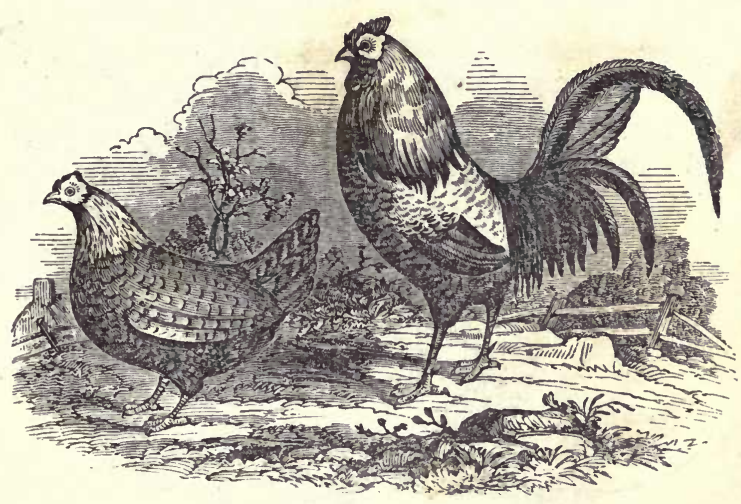

THE BOLTON GRAYS, OR CREOLE FOWL.

Mowbray gives an accurate description of this variety, as follows :

"Small-sized, short in the leg, and plump in the make. The color of the genuine kind, invariably pure white in the whole cappel of the neck; the body white, thickly spotted with bright black, sometimes running into a grizzle, with one or more black bars at the extremity of the tail; they are chiefly esteemed as very constant layers, though their color would mark them for good table food."

These fowls derive their name from having been originally bred at Bolton, in Lancashire, England, and are much esteemed. In Pennsylvania they have the name of Creole; but why, it is difficult to say. They are said to be a very hardy fowl, and maintain their reputation for laying, under this name, as well as by their more appropriate designation. 


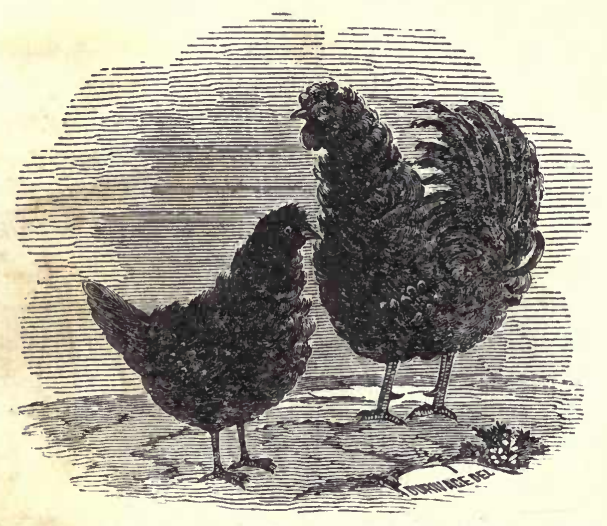

THE FRIZZLED FOWL.

This fowl is erroneously supposed to be a native of Japan, and, by an equally common error, is frequently called the "Friesland" fowl, under the notion of its being derived from Friesland. Its name, however, is given from its appearance. The feathers are ruffled or frizzled, giving the bird a singular aspect, which is well delineated in the plate. The plumage is variegated in its colors, and there are two varieties, which are called the Black and White frizzled. This fowl does not withstand the severity of a northern climate, and is rather curious than valuable. The beautiful specimens shown at the late fair attracted great attention.

Mr. S. W. Cole, a frequent writer on poultry, and the very able editor of the New England Farmer, makes the following remarks on this fowl : 
"The Frizzled fowl has its feathers pointing forward, so that it cannot run amongst the grain; and this is its peculiar advantage."

Dr. Eben Wight, of Boston, the distinguished importer of fowls, has imported many of this variety.

Our portraits represent the beautiful Black Frizzled fowl, from the stock of Mr. George C. Peirce, of Danvers, who, in connection with his partner, Mr. Stephen Osborn, Jr., has one of the most extensive assortments of fowls in New England, having twenty different breeds. The above portraits speak well of them as breeders, and, in fact, no fowls were more highly admired than their stock, at the late exhibition. 


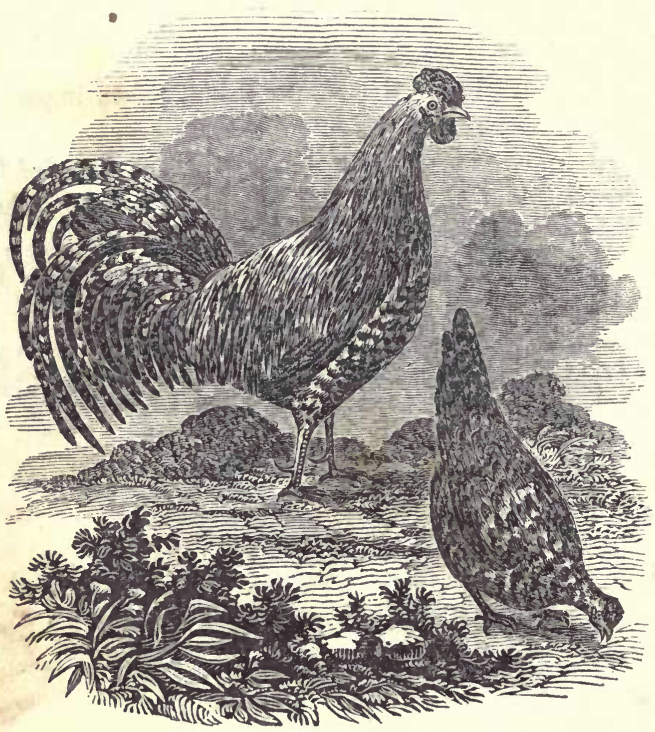

\section{THE DOMINIQUE FOWL.}

These portraits are from the extensive stock of Geo. C. Peirce and Stephen Osborn, Jr., of Danvers, and are fine specimens. The fowls are a very perfect breed. I have never witnessed the least variation in their appearance, for the last thirty years. Plumage, invariably gray, both cock and hen - all over gray ; heads, small and smooth; combs, double generally, though occasionally single, and small; wattles, small ; size, below ordinary. 'They are very hardy, healthy, and excellent layers. I know of no fowls which have stood the test of mixing without deteriorating, better than the pure Dominique. They are said to be from the Island of Dominica, but I very much doubt 
it; I should rather incline to the opinion that they took their name from having been "tenants at will" of some feudal sovereignty; at all events, they are very "lordly" fowls, and among the best races for profit or for looks, "for fashion or for fight." Why it is that so perfect bloods should have escaped description by poulterers, I am unable to divine. It is true they are rather small, and that is the worst thing that can be said of the Dominiques. They were introduced into this country by the French, and I think them a French, and not a Dutch fowl, as some suppose.

Mr. George C. Peirce, of Danvers, a breeder of merit, says, in a letter concerning these fowls, as follows :

"Taken all in all, I believe them to be one of the very best breeds of fowls we have, and I do not know of any breed that alters so little by in and in breeding; they are first rate layers, and although they do not come in to laying so young as the Spanish, I think them far better sitters and nursers. I thought the best information I could give you, with regard to their laying qualities, would be the statement of Mr. Philip S. Osborn, of Danvers, who has a very fine stock of this breed. His statement is a correct account of the cost of keeping thirty-eight fowls, and the number of eggs obtained from them, during the months of December, 1848, and January, February, and March, 1849 , and is as follows :

Dec. 1848, 234 eggs, sold for Jan. 1849, 298 " " " "

Feb. 1849,450 " " " "

Mar. 1849,684 " " "

11 bushels manure sold for

The whole expense of keeping 38 fowls four winter months, 
"It may be proper here to say, that the profits were more than could generally be obtained, as eggs were very high most of the time; but taken at the average price of eggs for the last two years, it will be hard to find any person who has realized as much from the same number of any other breed of fowls, in the four coldest months of the year."

THE BANTAM FOWL.

Richardson says that "the original of the Bantam is the Bankiva fowl, a native of Java, several specimens of which are kept by her Majesty, at Home Park. These are very beautiful, of a perfectly white color, and exceedingly small size, and they exhibit some peculiar traits of habit and disposition, that we cannot overlook. Amongst other strange propensities, the cocks are so fond of sucking the eggs laid by the hen, that they will often drive her from the nest in order to obtain them nay, they have even been known to attack her, tear open the ovarium, and devour its shell-less contents. In order, if possible, to subdue this unnatural propensity, her Majesty's keeper gave the cocks first a hard-boiled and then a marble egg to fight with, taking care, at the same time, to prevent their access either to the hens or to any real eggs. After a few weeks, the birds gave up their unprofitable labor, and, as the keeper had anticipated, wholly abandoned, for the future, attempting the destruction either of the hen or of the actually laid egg. Another strange propensity was exhibited in a passion for sucking each other's blood. This passion chiefly exhibited itself when the birds were moulting, when they had been known to peck each other naked, by pulling out the new feathers as they appeared, and squeezing with their beaks the blood from the bulbs at the base. The intelligence of the keeper 
found means to overcome this propensity likewise. That person observing that the birds were subject to great heat of the skin, and that its surface occasionally became hard and tightened, conceived that, in such cases, the hard roots of the feathers being drawn into a position more nearly at right angles with the body than at ordinary times, the skin and superficial muscles were thus subjected to an unusual degree of painful irritation; and it immediately occurred to him, that the disagreeable habit in question was simply a provision of nature for the relief of the suffering birds. Impressed with this idea, he tried the effect of artificial relief, by washing with warm water, and the subsequent use of pomatum to the skin. His experiment was successful, and the birds' plumage has been ever since untouched.

As might be inferred, when such a propensity to devour the eggs exists in the male bird, the female is a secret layer. In this respect, these fowl show their.identity with the original bird of Java, the Bankiva cock, whose wildness of disposition I have already mentioned. These birds are both good layers and good sitters. One in her Majesty's possession sat for nine weeks, on three successive sets of eggs.

The fowl commonly known as the Bantam is a small, elegantly-formed, and handsomely-tinted variety, evidently not remotely allied to the game breed. This bird is furnished with feathers to the toes." 


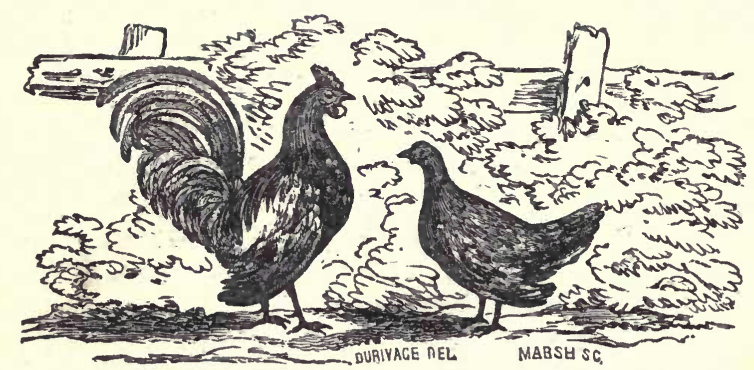

THE AFRICAN BANTAM.

This plate represents a pair of beautiful fowls of a variety which is denominated by Mr. Giles, of Providence. the African Bantam. These individuals are from Mr. Giles' stock. The cock is red upon the neck, back and hackles; tail, black and erect, studded with glossy green feathers upon the sides; breast, black ground, spotted with yellow, like the Golden Pheasant ; comb, single; cheeks, white or silvery; the pullet is entirely black, excepting the inside of the wing-tips, which is perfectly white. In size, they compare with the common pigeon, being very small ; and their wings are about two inches longer than their bodies, their legs dark and destitute of feathers. They are very quiet, and of decided benefit in gardens, in destroying bugs. It would be difficult to find a more symmetrically formed bird. They are highly prized, both by the fancier and utilitarian, and the pure bloods are very rare. They are the best of all the Bantam race, yet I have never seen them described in the books on ornithology.

These fowls weigh from eight to twelve ounces each for the hens, and the cocks from sixteen to twenty ounces. Mr. Giles 
has also some Pheasant Bantams which are about the same weight. They are of fawn-colored plumage, tipped with black. There are many varieties of this fowl, highly prized as ornamental birds, but it does not comport with the design of this book to describe more of them at present.

A long catalogue of breeds and varieties of the domestic fowl might be inserted here, - some more, and others less valuable. But it has only been my object to describe the best varieties, and, for the most part, such as could be identified by authentic portraits, taken from the life. In subsequent editions of this work, others will be described, - all others which have really meritorious claims, - as they can be identified, and original portraits procured. I would therefore request all breeders and fanciers who may be in possession of valuable or favorite fowls, not here described, to communicate with me, and to furnish such information as may be pertinent and valuable.

\section{CHAPTER IV.}

\section{THE TURKEY.}

ON this subject Mr. Richardson has written with singular ability, and in what follows a free use has been made of his labors.

"Various opinions," he says, " have been promulgated relative to the original country of the turkey, but it is now ascertained, beyond a doubt, to have been America; and it is in that country alone that the true original of the domestic turkey $s$ yet to be met with in all its primitive wildness, clothed in its natural plumage, genuinely wild in all its habits, the unreclaimed denizen of the wilderness. As to the medium through 
which this bird was first introduced into Europe, much doubt still exists, and we have, indeed, no authentic proof as to either the period of time, or by what agency, that event took place; it is, however, not unreasonable to suppose that the Spaniards, after their discovery of Mexico, where the turkey is known to be indigenous, brought specimens away with them, on their return to their own country; and Oviedo, the earliest describer of this bird, speaks of it as having been domesticated by the Christian inhabitants of New Spain and the Spanish Main.

In 1530, the turkey was introduced into England; but it seems more probable that that country owes its introduction to Cabot's having brought it direct from America, than that it was obtained from Spain; for if the latter were the case, I think it likely that some record of its transmission would remain.

In 1541, we find turkeys enumerated among the delicacies of the table, and classed with the crane and swan ; but the bird was too important an addition to our stock of domestic poultry to remain very long a rarity. Attention was drawn towards it, it was bred extensively; and in 1573 we find it mentioned in 'Five Hundred Points of Good Husbandry,' as forming the staple of the farmer's ordinary Christmas dinner.

The origin of the popular name, 'Turkey,' appears to be the confusion that at first so unaccountably subsisted relative to the identity of the bird with the Guinea fowl, which is really a native of that country, and which was introduced into England from the Levant, and at the time of the introduction of the turkey was still scarce. Some say it arose from the proud and Turkish strut of the cock." 


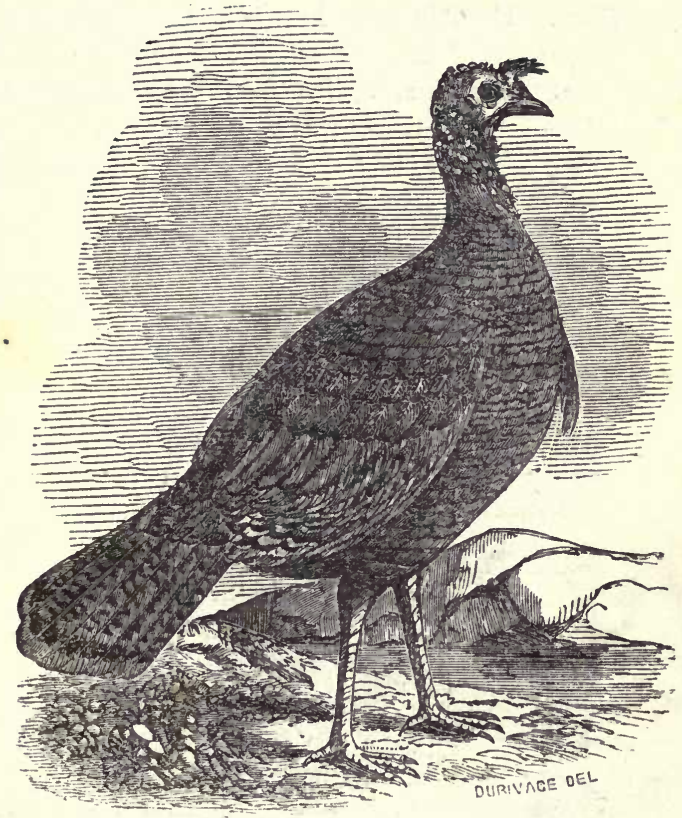

THE WILD TURKEY.

These portraits are taken from a pair purchased by me from Mr. John Giles, and are perfect specimens of the breed. The hen turkey was procured from the wilds of the West, by Mr. Giles. She is three years old next spring. The cock turkey here represented is one of her last spring brood.

"No one," says Richardson, "who has seen only the domesticated inhabitant of the poultry-yard, can form any idea 
of its wild original. The cock measures about three feet and a half, or nearly four feet, in length, and almost six in expanse of the wings. The skin of the head is of a bluish color, as is also the upper part of the neck, and is marked with numerous reddish, warty elevations, with a few black hairs scattered here and there. On the under part of the neck the skin hangs

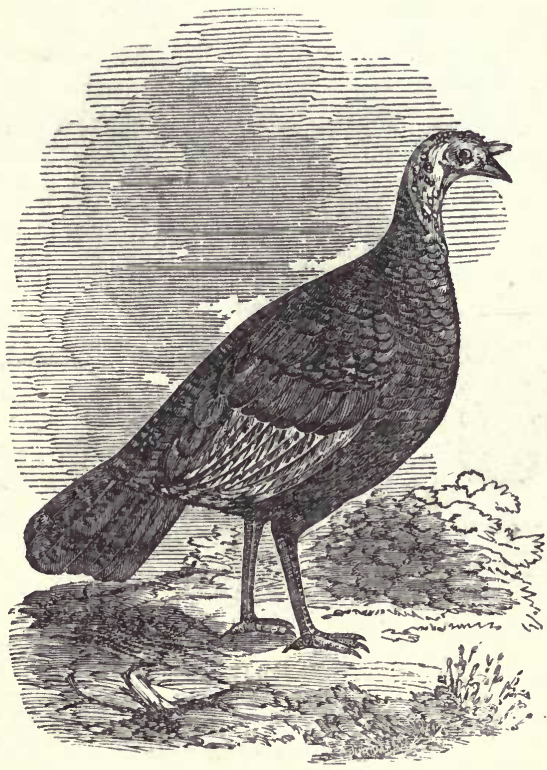

down loosely, and forms a sort of wattle; and from the point where the bill commences and the forehead terminates, arises a fleshy protuberance, with a small tuft of hair at the extremity, which becomes greatly elongated when the bird is excited; 
and at the lower part of the neck is a tuft of black hair, eight or nine inches in length.

The feathers are, at the base, of a light, dusky tinge, succeeded by a brilliant metallic band, which changes, according to the point whence the light falls upon it, to bronze, copper, violet, or purple; and the tip is formed by a narrow, black, velvety band. This last marking is absent from the neck and breast. The color of the tail is brown, mottled with black, and crossed with numerous lines of the latter color: near the tip is a broad, black band, then a short, mottled portion, and then a broad band, of dingy yellow. The wings are white, banded closely with black, and shaded with brownish-yellow, which deepens in tint towards the back. The head is very small in proportion to the size of the body; the legs and feet are strongly made, and furnished with blunt spurs, about an inch long, and of a dusky, reddish color; the bill is reddish, and horn-colored at the tip.

The hen is less in size than the cock; her legs are destitute of spurs; her neck and head are less naked, being furnished with short, dirty, gray feathers; the feathers on the back of the neck have brownish tips, producing on that part a brown, longitudinal band. She also frequently, but not invariably, wants the tuft of feathers on the breast. Her prevailing color is a dusky gray, each feather having a metallic band, less brilliant than that of the cock, then a blackish band, and a grayish fringe. Her whole color is, as usual among birds, duller than that of the cock; the wing-feathers display less white, and have no bands; the tail is similarly colored to that of the cock. When young, the sexes are so much alike, that it is not easy to discern the difference between them; and the cock acquires his beauty only by degrees, his plumage not arriving at perfection until the fourth or fifth year. 
The wild turkey was formerly found in Canada, and in several districts of the United States, but has been gradually driven backwards, as population increased. It is now chiefly to be found in the wilder regions of Kentucky, Ohio, Illinois, and Indiana. The wild turkey is, to a certain extent, migratory in its habits; and about the latter end of autumn, large flocks assemble, and gradually desert their barren wilds for the richer plains of Ohio and Mississippi. The cocks associate in parties by themselves, and seek for food apart from the hens. The latter remain with the poults, which they take care to keep away from the cocks, which are very apt to attack and destroy them.

Early in March the hens separate again from the herd, roost apart, and carefully shun the cock. They still, however, remain near the latter; and when a hen utters her call, every cock within hearing responds with his 'gobble,' 'gobble,' 'gobble.' This noisy wooing usually continues for about an hour, before sunrise, after which the birds silently alight from their perches, and the cocks strut about with expanded tails, seeking to obtain the favor of their desired mates. They sometimes, while thus employed, encounter each other, in which case desperate conflicts take place, terminated only by the death or flight of the vanquished.

After pairing, the birds remain together for the season, until laying begins, when the hen is again compelled to seclude herself, as the cock would otherwise destroy the eggs. About the middle of April, the hen forms her nest, of a few dry leaves, on the ground, in some sheltered spot, where it will be concealed from every hostile eye; here she deposits her eggs, to the number of from ten to twenty. They resemble, in size and color, those of the domestic bird. Whenever she leaves the nest, she covers it up with leaves, so as to secure it from observation. She is a very close sitter, and will, also, when 
she has chosen a spot, seldom leave it on account of its being discovered by a human intruder. Should she find one of her eggs, however, sucked by a snake, or other enemy, she abandons the nest forever. When the eggs are near hatching, the hen will not forsake her nest while life remains.

The young are very sensible to the effects of danip; hence, after a rainy season, wild turkeys are always scarce. The flesh of the wild turkey is very superior to that of the domestic bird; yet that of such of the latter as have been suffered to roam at large in the woods and plains is, in no respect, improved by this partially wild mode of life. The wild bird is frequently domesticated in America; but I understand that these individuals are not very steady, and will, on the first opportunity, return to their native haunts. C. Lucien Bonaparte relates that a gentleman in West Chester county, New York, once procured a young female wild turkey, in order to try the experiment of crossing the breed with the domestic bird ; but, owing to some accident, it did not succeed, and in the ensuing spring the hen disappeired. She returned, however, in the autumn, followed by a large brood, and remained in the farm till the following spring, when she again disappeared, but returned in autumn with a second brood; and this she continued to do for several years.

Some writers have greatly exaggerated the weight of the wild turkey; and some have even asserted that they have met with individuals of sixty pounds' weight. M. Bonaparte states the average weight of the hen to be from eight to nine pounds, and that of the cock from fifteen to twenty. A knowledge of the natural habits of the bird is of the greatest importance in guiding us as to its treatment in a state of domestication; and we, accordingly, should avoid condemning to the confinement of close, and often filthy hen-houses, a bird which, in a state of nature, always perches in the open air. Open sheds and 
high perches are what they require; and their dislike to the mode of housing I speak of, may be recognized in the eagerness with which they rush out the instant the door is opened in the morning. The domestic turkey has been known to go wild in England, (Sp. Mag., Aug. 24,) and remain so for two or more years; and there is no doubt that it would be possible to naturalize them amongst us, like the pheasant."

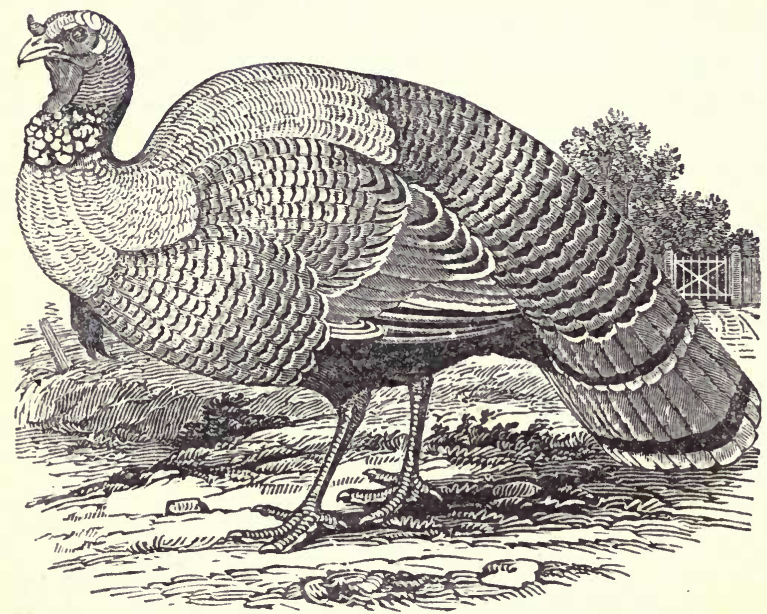

THE DOMESTIC TURKEY.

"There is a question," says Richardson, "whether the domestic turkey is actually a second and distinct species, or merely a variety of the wild bird, owing its diversity of aspect to circumstances dependent on locality, and consequent change 
of habit, combined with difference of climate and other important causes, which we know, in the case of other animals, produce such remarkable effects.

As to the relative value of the ordinary varieties, it would be almost difficult to offer an opinion; but those who suppose the white turkey to be 'the most robust, and most easily fattened,' are decidedly mistaken, both in theory, as far as analogy may guide us, and in practice, where the certain test of experience has shown to the contrary. The bronze and copper-colored varieties are generally undersized, and are amongst the most difficult of all to rear; but their flesh is certainly very delicate, and, perhaps, more so than that of other kinds - a circumstance, however, that may partly result from their far greater delicacy of constitution, and the consequent extra trouble devoted to their management.

The brown and ashy-gray are not particularly remarkable: but the black are decidedly superior, in every respect, not only as regards greater hardiness, and a consequent greater facility of rearing, but as acquiring flesh more readily, and that being of the very best and primest quality. Those of this color appear to be less far removed than the others from the original wild stock. Fortunately, too, the black seems to be the favorite color of nature, and black turkeys are produced far more abundantly than those of any other hue.

With respect to the hest mode of keeping turkeys, I hare merely to repeat what I have already remarked relative to a due attention to the habits of the original wild breed in its native state. Let them have a large, roomy, open shed, sufficiently protected, of course, from the weather, and, above all, from moisture. Let the perches be high - and here, again, you will do well not to omit the use of the hen ladder, for although these birds can usually fly well, still, when fat, they become too 
heavy for their wings, and are apt to injure themselves in their descent from a lofty perch, especially when in confinement; when at full liberty, they ean take better care of themselves. During warm weather they may be permitted to select their own roosting-places on the trees about a farm; but should be well watched, lest they stray away; and this indulgence should on no account be granted them if frost be anticipated, as their toes are tender, and apt to become frost-bitten. Indeed, summer is the only time of the year when this out-roosting may, with safety, be permitted.

The turkey is a most profitable bird, for it can almost wholly provide for itself about the roads and hedge-rows; snails, slugs and worms, are among the number of its dainties, and the nearest stream serves to slake its thirst. To the farmer, however, it is often a perfect nuisanee, from its love of grain, and should, therefore, be kept in the yard until all corn is too strong in the root to present any temptations.

Notwithstanding the separation which, with the exception of certain seasons, subsists in a wild state between the cock and hen turkey, they have been brought to feed and live amicably together in a state of domesticity. The former, however, retains sufficient of his hereditary propensities to give an occasional sly blow to a chick, or forward poult, but that very seldom of a seriously malicious character.

Mascall, in describing a turkey cock, (such as the breeder should select,) says that he should be ' a bird large, stout, proud, and majestical; for when he walketh dejected, he is never good.' - Cheap Husb., p. 151.

M. Parmentier says, that 'both cock and hen should have short legs, full shapes, and general vivacity and energy in all their movements; likewise, that they should be both wellshaped and in healthy condition.' 
Mascall says, that the cock should not be 'passing a yere or two yeres old; three yeres is the most, and too much,' \&c.

For my own part, I hold a turkey cock, at the age of three years, to be only in his prime, and to continue, in every respect, suitable for your purpose, until five. The hen is at her prime younger, and, probably, at the second year is as good as ever she will be afterwards.

It has been stated by some, and yet as positively denied by others, that one fecundation will render all the eggs of that laying fertile; still, however, were it my own case, I should prefer making 'assurance doubly sure,' by allowing one cock to every dozen or fourteen hens. Even this, however, will render it unnecessary for every poor man who may desire to breed turkeys to have a cock, as one cock will thus prove amply suffcient for the hens of a whole townland. This fact should encourage farmers to keep a good turkey cock of a valuable breed, and so afford an opportunity of improving upon the commoner varieties they may possess.

The approach of the laying season is easily known by the increased liveliness and proud strut of the hen; and she, likewise, further expresses her feelings by a peculiar self-satisfied cry, that soon becomes familiar to the observer. This usually takes place in the month of March (nearly a month earlier than the wild bird.) When the breeder perceives those symptoms, he should provide a nest, and put an egg, or a bit of chalk formed like one, into it, to induce the hen to commence laying there. Partaking of the retiring propensities of the wild hen, (although she has not equal reason to dread the destructive passions of the cock,) the turkey is a secret layer, and does her best to elude the vigilance of her keeper, and steal away to some secluded spot. The peculiar note of which I have spoken betrays, however, the fact; and whoever has the care of the 
fowl should trace her to her retirement, and bring her back to the nest prepared for her.

The time when the hen turkey lays is usually morning. Some lay daily; others only every second day. The number of eggs laid is commonly from fifteen to twenty ; but this varies with the age of the bird, a hen of mature age laying more and larger eggs than one of a year old. When the turkeys are to be let out in the morning, you may examine the hens, and keep in such as are about to lay. This precaution will, of course, prevent the loss of a single egg. While the hen is laying, the cock should be kept from her, as he would ill-treat her and break the eggs. The eggs should be taken away as soon as laid, lest they might be broken, through the awkwardness of the hen, or sucked by vermin. They will keep till the hens are done laying, if put in a basket and hung up in a dry place. It is unnecessary to keep the eggs belonging to each hen in a separate place. The turkey is not troubled with any very exclusive feelings, or, rather, her disposition overflows with an excess of maternal love; for she will rear a clutch belonging to another quite as carefully as if they were her own, and will, also, if required, hatch the eggs of ducks, geese, or common fowl. In the second laying the eggs are fewer in number, seldom exceeding from ten to thirteen; and, on this occasion, extra care is requisite.

The turkey hen is a most persevering sitter; and when her eggs are taken away, she would sit upon stones, if she could not procure the eggs of another bird, and would perish before quitting the nest. Eggs should, therefore, be left with her, not only to tranquillize her, but because sitting upon eggs fatigues her less than sitting upon an empty nest; but these eggs must be marked, in order to distinguish them from those the poor bird continues to lay; for any eggs that seem to her to be slow of hatching will be abandoned, as she will quit the 
nest as soon as she perceives the chick; conscquently, as soon as the eggs you have placed under her are hatched, she will leave the nest, and the eggs of her own laying will be sacrificed. Remove, therefore, the former; and it is for this reason that I recommend them to be marked. Keep the nest clean while the turkey hen is sitting, as dirt will injure the eggs. No one should go near a hen when sitting, except her keeper; and no one should turn the eggs, or meddle with them further than I have already indicated. The bird will turn her eggs with more judgment than you can.

M. Parmentier relates that he successfully employed the turkey cock as a sitter, and found that he acquitted himself to admiration up to the period of hatching - 'When the young chicks appear, their cries and motions scare him, and he either kills or abandons them.'

On the thirty-first day of sitting, the chicks leave the eggs; but as some quit their prison before others, they must be placed in a basket filled with feathers, and if the weather be cold, placed in some warm spot. When all are out, they may be given to the hen. Sometimes the chick will require assistance in leaving the egg; and, if so, the same caution must be observed that $I$ have insisted upon in the case of the common fowl. Be very sparing of your aid, or you may do far more harm than good.

Many writers recommend a vast deal of quackery in the treatment of the young chicks. Some go the length of ordering them wine, pepper, bathing in cold water! \&c. It is far better to let them alone. For a few hours after hatching, the chicks require no food at all; and then, instead of cramming them - a process in which you are extremely likely to break the tender beak of the little chick - chop up a few hard eggs with boiled nettles, parsley, and a little bread or curd; make this into a paste, and present it to the birds in the palm of your 
hand, or place it before them on a stone, taking care that the hen does not rob them. In supplying them with water, be careful to put it in such very shallow vessels that they cannot wet themselves; for the least moisture appears fatal to them. As the turkey chick does not seek its food immediately on leaving the egg, as the hen seems incapable of instructing her little offsprings how to do so, it is a practice with some to put a few common hen's eggs among the turkey's, (which must be done about nine or ten days after sitting,) that these, coming out with the little turkeys, may, by force of example, teach them to provide for themselves.

Unless in very warm weather, the hen and chicks should be housed for a month. If they appear drooping, put powdered caraway seed, and a little Cayenne pepper, into the fond. If you mix the food with milk, let it be previously boiled. Unboiled milk will purge the chicks; but, for my own part, I prefer pure water.

At the age of about two months occurs the most critical period in the life of the turkey, called 'shooting the red;' or the time when the head and neck acquire the reddish color of the adult. This crisis once passed, the bird may be regarded as past danger, and exchange the name of chicks for that of turkey poulls. The only treatment necessary, when the bird is shooting the red, is nutritive food, and the addition of a small pinch of Cayenne pepper. Bruised hemp-seed is also found serviceable.

I know of no birds more calculated to be profitable to the breeder than turkeys.

The well-known William Cobbett, who, with all his failings, was a.shrewd and accurate observer, thus writes: 'To raise turkeys in this chilly climate, is a matter of much greater difficulty than in the climates that give great warmth; and so true is this, that in America, where there is always a "wet 
spell" in April, the farmers' wives take care never to have a brood come out until that spell is passed. In England, where the wet spells come hap-hazard, the first thing is to take care that young turkeys never go out, on any account, (except in dry weather,) until the dew be quite off the ground; and this should be adhered to till they get to be the size of an old partridge, and have their backs well covered with feathers; and in wet weather they should be kept under cover all day long. As to the feeding of them when young, many nice things are recommended - hard eggs chopped fine, with crumbs of bread, and a great many other things; but that which I have seen used, and always with success, and for all sorts of young poultry, is milk turned into curds. This is the food for young poultry of all sorts. Some should be made fresh every day ; and if this be done, and the turkeys be kept warm, not one out of a score will die. When they get to be strong, they may have meal and grain; but still, they always love the curds. When they get their head-feathers, they are hardy enough; and what they then want is room to prowl about. It is best tc breed them under a common hen, because she does not ramble like a hen turkey; and it is a very curious thing that the turkeys bred up by a hen of the common fowl do not themselves ramble much when they get old; and for this reason, when they buy turkeys for stock in America, (where there are such large woods, and where the distant rambling of turkeys is inconvenient,) they always buy such as have been bred under the hens of the common fowl - than which, a more complete proof of the great powers of habit is, perhaps, not to be found. And ought not this be a lesson to fathers and mothers of families? Ought not they to consider that the habits which they give their children are tó stick by those children during their whole lives?

' The hen should be fed exceedingly well, too, while she 
is sitting, and after she has hatched; for though she does not give milk, she gives heat, and let it be observed, that as no man ever yet saw healthy pigs with a poor sow, so no man ever saw healthy chickens with a poor hen. This is a matter much too little thought of in the rearing of poultry ; but it is a matter of the greatest consequence. Never let a poor hen sit ; feed the hen while she is sitting, and feed her most abundantly when she has young ones; for then her labor is very great. She is making exertions of some sort or other during the whole twenty-four hours ; she has no rest ; is constantly doing something, in order to provide food or safety for her young ones. As to fatting turkeys, the best way is never to let them be poor. Cramming is a nasty thing, and quite unnecessary. Barleymeal mixed with skim-milk, given to them fresh and fresh, will make them fat in a short time, either in a coop, in a house, or running about. Boiled carrots and Swedish turnips will help, and it is a change of sweet food. In France they sometimes pick turkeys alive, to make them tender; of which I shall only say, that the man that can do this, or order it to be done, ought to be skinned alive himself.'

"As I observed already, once the turkey chicks shoot the red, (which takes place at or about eight weeks old,) they may be considered out of danger; hence, many persons conceive it more profitable to buy lean, young poults, after they have got the red, and then fatten them for market, to breeding them. If the mortality among the chicks were greater, and were not so easily to be avoided by a very little care, this might be the preferable mode of going about the matter; but as it is, there can be no doubt of the greater advantage to be derived from rearing our own chicks.

In feeding the poults, after the second month, it will suffice to give them such boiled common plants and herbs as are of a nutritive character - nettles, wild succory, milfoil, turnip-tops, 
cabbage-sprouts, or the outside leaves of greens well boiled down. With these, potato-skins and an odd potato or two itself, nay be given. The meal of buckwheat, barley, beans, oats, - according to whichever is most plenty with you, - will, when incorporated as I have described with potatoes, fatten the poults with great rapidity. You may also use the meal of Indian corn with advantage, but recollect that it requires treble the boiling of oat-meal, and is more salutary when mixed with an equal bulk of the latter. If you desire to meet the market hastily, and with profit, you will be compelled to resort to more expensive feeding than otherwise, but you will be repaid by the result. When the poults are about five months old, or earlier, if it be late in the season and cold weather seems at hand, give them boiled potatoes mashed with meal, and then chopped small, as I have described. Let this be given fresh and fresh, and the vessel in which they are fed well washed daily, as otherwise it will speedily contract a sour smell, and become repulsive to the birds; for turkeys are both cleanly and nice in their appetite. After having persevered in this feeding, morning and evening, for about a month, during which time the exercise of the poults should be greatly curtailed, and they should likewise be kept much of their time (especially after meals) in the dark, they will be found fit for use, and, if of a good kind, at least upwards of eighteen pounds' weight.

As damp or cold is fatal to turkey poults, so is intense sunshine; and hence they should not be led to pasture under a scorching sun, unless, indeed, care be taken that the walk is shaded. Should rain come, let them be at once housed. Poults should also not be suffered to stray too far, for, independently of the risk they incur, in case of a sudden shower, it must be remembered that they are as yet incapable of encountering any 
great fatigue, and that their condition will be anything but benefited thereby.

It will always be recollected, in reckoning the advantages with the expense attendant on the rearing of these birds, that until you want to fatten them for sale, or your own consumption, you need be at no pains relative to their food, as they are quite able to provide for themselves, being in this respect superior to any other of our domestic fowl. In thus readily providing for themselves, they are also greatly assisted by the easy character of their appetite - grass, herbs, corn, berries, fruit, insects, and reptiles ; in short, hardly anything coming amiss to them.

Audubon says, that, in their native forests, 'they cannot be said to confine themselves to any particular kind of food, although they seem to prefer the peccan nut and winter grape to any other; and where these foods abound, are found in the greatest numbers. 'They eat grass and herbs of various kinds, - corn, berries, and frutits of all descriptions. I have even found beetles, tadpoles, and small lizards, in their crops.' Ornith. Bing., l. ii. A favorite repast of this bird in its native forests is said also to be in the seed of a kind of nettle, and at another season a small red acorn, on which latter fond they soon become so fat that they cannot fly, and are easily run down by dogs.

It may not be generally known, that there are many sorts of food which, though nutritious and highly salutary as concerns other fowl, are little short of downright poison to turkeys. Amongst others, I may enumerate vetches or tares, marrowfat peas, and most sorts of pulse, which are little less deleterious to them than such well-known poisons as hemlock, foxglore, or henbane.

I think I have now afforded my readers not only all the information relative to the management of turkeys that I have 
been able to collect, but also all that my own experience enables me to add, on my part.

The weight of turkeys has been much exaggerated by careless, ignorant, or, perhaps, credulous writers ; and sixty pounds is by some mentioned as a common weight. On the contrary, twenty pounds is a fair weight for any fat yearling bird, and a very great weight for a bird of six months old ; thirty pounds is a fine turkey of any age; and few, save the Norfolk, ever exceed forty pounds. The greatest weight that these have been known to attain, recorded by such authority as we can rely upon, is fifty-six pounds. I have never seen a turkey of sixty pounds' weight; nor do I know any one that has. The hen takes fat more readily than the cock, and is, in proportion to her size, a tenderer and a better dish." - Richardson.

Mr. Charles H. Pendleton, of Pendleton Hill, Connecticut, a breeder of reputation, says; in relation to his turkeys :-

"I have the largest turkeys that you can find in New England. My turkey cock weighed twenty-seven pounds the winter before he was a year old; and I have no doubt he will weigh, well fatted, next winter, thirty pounds dressed. One of iny turkey hens weighed fifteen pounds and twelve ounces, last spring." 


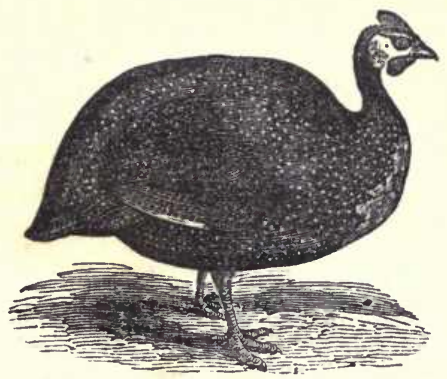

THE GUINEA FOWL, OR PINTADO.

"The Guinea fow] (Numidia meleagris) is a native of Africa, long domesticated in Europe. It may be considered as somewhat intermediate between the pheasant and turkey.

Like most domesticated fowls, there are several varieties of the pintado, besides the mitred, the crested, and the Egyptian, which are considered by naturalists as distinct species. One of these varieties is wholly white; another has only the breast white; and a third has the caruncles, or wattles, at the mouth, double.

The Guinea fowl is about twenty-two inches long, and, from standing high on its legs, appears to be larger than it really is. It is a noisy bird, having a very peculiar call-note, and is turbulent and restless, continually moving from place to place, and domineering over the whole poultry-yard, boldly attacking even the fiercest turkey-coek, and keeping all in alarm by its petulant pugnacity

This species differs from all other poultry in its being diffcult to distinguish the cock from the hen; the chief difference being in the color of the wattles, which are more of a red hue in the cock, and more tinged with blue in the hen. The cock f as also a more stately strut. 
It is more from curiosity than profit that Guinea fowls are kept, though they are excellent for the table; and their eggs, though small, are much esteemed; but they are not easy to rear in our cold climate. The hens, says Mascall, sit thirty days, and the young must be managed like young turkeys, as they are equally, if not more tender. In fact, the whole management of both the young and the old may be precisely the same as that of turkeys, in feeding, hatching and fattening." - Dickson.

"As a source of profit," says Richardson, "I cannot recommend these fowl; the eggs are very small, three of them being scarcely equal to an ordinary hen's egg, and the flesh not being likely to please every palate, though, indeed, it is in tolerable request in the London markets, when the game season closes, its flavor resembling pheasant ; still, however, as the Guinea fowl require but little trouble or attention, and their eggs, though of small size, are well-flavored and numerous, they are generally kept wherever there is accommodation for them. The chief objection to them is their cry, or scream; and even this, again, has its advantages, invariably predicting a change of weather; they can hardly, however, be kept with other poultry, on account of their pugnacity. They have been let out on the heaths and mountains in England, with a view to their naturalization; during summer they did very well, but were unable to stand the winter.

The Guinea fowl dislikes confinement, and will not thrive unless it has free liberty; where such, therefore, cannot be afforded, it is useless to attempt keeping it.

These fowl are prolific; the hen commences to lay in May, and lays throughout the entire summer; for the table they are in season from February to June. The period of incubation is twenty-eight days; but it is more advisable to keep the Guinea hen entirely for laying, and if you desire to hatch any of the eggs, to do so under the hen of the common gallinaceous fowl. 
You must keep the male bird away, or he will, like the pheasant, destroy the eggs.

When designed for the table, let these fowl be killed at an early age; the flesh is then superior to any other fowl at the same age; but when at all old, it is peculiarly tough and repulsive."

\section{CHAPTER V.}

\section{THE GOOSE.}

A wrIter in the Monthly Journal of Agriculture writes as follows :

"The goose differs in many respects from the fowls already noticed, being aquatic in its habits. It is marked by a flat bill and webbed feet, characters also possessed by the duck and swan, which, in conjunction with the goose, may be held as forming a distinct family (Anatide) of the feathered aquatic tribes.

Our common table goose is the wild species domesticated, known to naturalists by the name of the fen or stubble goose. Where people have a right of common, or live in the vicinity of marshy heaths, the breeding and rearing of geese will prove very profitable, for in such situations they are kept at a trifling expense; they are very hardy, and live to a great age. If properly kept, and fed regularly, although sparingly, they will lay upwards of a hundred eggs yearly. If these are set under large hens, each having half a dozen, with the assistance of the goose herself, they may be nearly all hatched. For the first three or four days, they must be kept warm and dry, and fed on barley-meal or oat-meal, mixed with milk, if it is easily procured ; if not, let these ingredients be mixed with water. 
They will begin to grow in about a week. For a week or two the goslings should not be turned out till late in the morning, and should always be taken in early in the evening. In Ireland, the tenantry depend much on the breeding of these birds and turkeys to pay their rent; and with those who are industrious and favorably situated for rearing geese, they even do more, in many instances. In the early part of the year they are allowed to feed on grass, on heaths, meadows, and commons ; and as most of the peasantry have small bits of corn land of their own, the geese are turned out on the stubble to pluck what grass is left; and they also fatten upon it, and improve the flavor of their flesh.

Although water be the natural element of geese, yet it is a curious fact that they feed much faster in situations remote from rivers and streams. To fatten geese it is necessary to give them a little corn daily, with the addition of some raw Swedish turnips, carrots, mangel-wurtzel leaves, lucerne, tares, cabbage-leaves, and lettuces. They should not be allowed to run at large when they are fattening, as they do not acquire flesh nearly so fast when allowed to take much exercise. Therefore, those who can only afford to bring up a goose or two should confine them in a crib, or some such place, about the beginning of July, and feed them upon the ingredients above recommended, with a daily supply of clean water for drink. If, on the contrary, from a dozen to twenty are kept, a large pen of from fifteen to twenty feet square must be made, and well covered with straw in the bottom, and a covered house in a corner for protection against the sun and rain when required, because exposure to either of these is not good. It will be observed that, about noon, if geese are at liberty, they will seek some shady spot, to avoid the influence of the sun; and when confined in small places, they have not sufficient room to flap their wings and dry themselves after 
being wetted; nor have they room to move about so as to keep themselves warm. There should be three troughs in the pen, one for dry oats, another for vegetables - which ought always to be cut down - and a third for clean water, of which they must always have a plentiful supply. It must be remembered that the riper the cabbages and lettuces which they are supplied with, the better. In the neighborhood of large towns, the most profitable way of disposing of geese is in a dead state; as nearly the same sum can be obtained for them as if they were alive, and then you have the feathers, which are valuable, and may be sold to much advantage by themselves, when you have collected a sufficient weight.

Geese are kept in vast quantities in the fens of Lincolnshire, several persons there having as many as a thousand breeders. They are bred for the sake of their quills and feathers, as well as for their carcass ; it is therefore customary to strip them partially of the fine downy feathers, and leave them to grow afresh, and also to take quills from their wings, - both practices barbarous in the extreme, however they may be attempted to be justified. Geese breed in general only once a year; but if well kept, they sometimes hatch twice a season. The best method for promoting this is to feed them with corn, barley, malt, fresh grains, and, as a stimulant, they should get a mixture of pollard and ale. During their sitting, each bird has a space allotted to it, in rows of wicker pens placed one above another, and the goose-herd who has the care of them drives the whole flock to water thrice a day, and, bringing them back to their habitation, places every bird (without missing one) in its own nest. One gander is generally put to five geese. The time of incubation varies from twenty-seven to thirty days. The goose begins to lay in March, but the time of the month depends upon the state of the atmosphere. When goslings are first allowed to go at 
large with their dam, every plant of hemlock which grows within the extent of their range should be pulled up, as they are very apt to eat it, and it generally proves fatal to them. Nightshade is also equally pernicious to them, and they have to be poisoned by eating sprigs of yew tree."

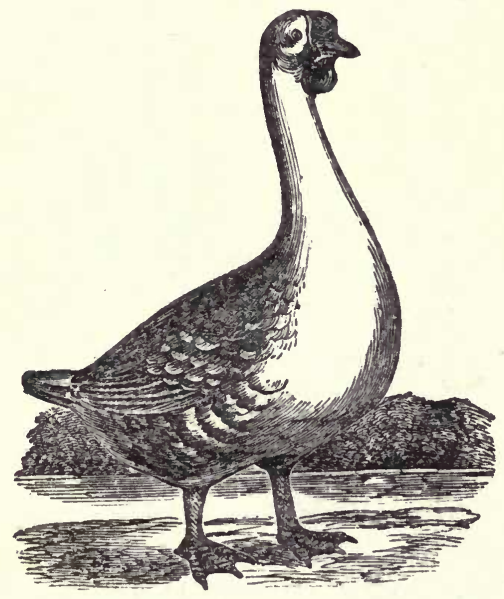

THE AFRICAN GOOSE.

This beautiful plate, by Durivage, is a very successful representation of a fine specimen of this gigantic bird. By comnıon consent, this goose is installed the head of his tribe, for size and imposing appearance.

The breed is thus described in Buffon's Natural History :

"The appellation of Swan Goose, given by Willoughby to this large and beautiful bird, is very apt; but the Canada goose, which is at least as beautiful, has an equal right to the 
name; and besides, all compounded epithets ought to be banished from natural history. The Guinea goose exceeds all other geese in stature; its plumage is a brown-gray on the back, and light-gray on the fore side of the body, the whole equally clouded with rusty-gray, and with a brown cast on the head and above the neck: it resembles, therefore, the wild goose in its colors ; but its magnitude and the prominent tubercle at the root of its bill mark a small affinity to the swan; yet it differs from both by its inflated throat, which hangs down like a pouch, or little dewlap; a very evident character, which has procured to these birds the denomination Jabotieres (from Jabot, the Crane.) Africa, and perhaps the other southern countries of the old continent, seem to be their native abode; and though Linnæus has termed them Siberian geese, they are not indigenous in Siberia, but have been carried thither and multiplied in a state of domestication, as in Sweden and Germany. Frisch relates that, having repeatedly shown to Russians geese of this kind, which were reared in his courtyard, they all, without hesitation, called them Guinea geese, and not Russian or Siberian geese. Yet has the inaccurate denomination of Linnæus misled Brisson, who describes this goose under its true name of Guinea goose, and again, a second time, under that of Muscovy goose, without perceiving that his two descriptions refer precisely to the same bird."

"It is somewhat larger," says Brisson, "than the tame goose; the head and the top of the neck are brown, deeper on the upper side that on the under; $* * * *$ on the origin of the bill there rises a round and fleshy tubercle; **** under the throat also there hangs a sort of fleshy membrane."

Mr. Giles, an original importer of this breed, in a letter to the author, thus describes it :

"The Guinea goose shall stand forth first;-brown-gray on the back, light-gray on the fore-front, brown on the head 
and upper neck, prominent black tubercle on the root of the bill, with pouch or dewlap under the throat. Weight will vary from twenty to twenty-five pounds each. Is a very rare and ornamental bird."

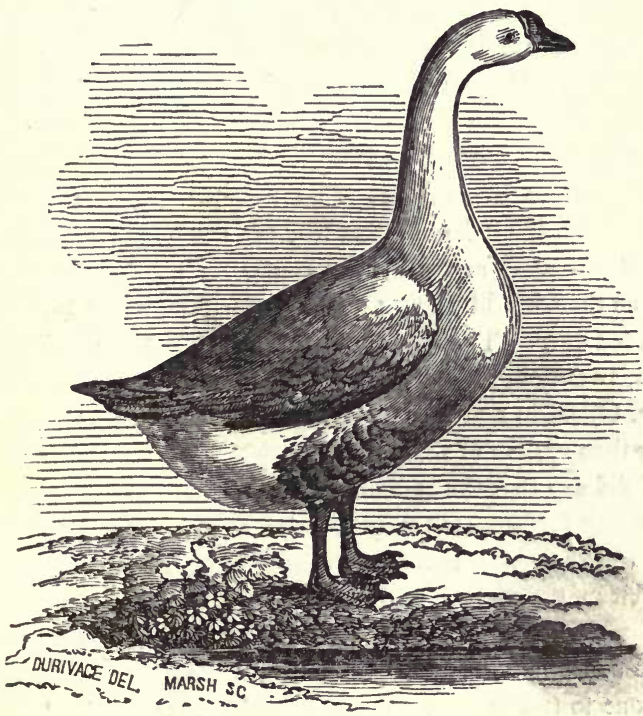

THE INDIAN MOUNTAIN GOOSE

This portrait is from life, and represents a goose (a native of India) from the stock of Dr. J. N. Bates, of Barre, now in my possession. The preceding description of the African goose will answer for this variety in most respects, except in regard to size, color, and a peculiarity there noticed. The Indian goose 
is dunnish on the breast and belly, and is entirely destitute of what Buffon calls a "pouch or dewlap." It is smaller in size than the African, but much larger than the Chinese. As will appear from the portrait, they are the most symmetrical of the goose tribe, and, if such a thing may be said of a goose, this variety is decidedly graceful in its appearance.

From a letter of Dr. Bates, I extract the following remarks : "The gander is twelve years old, and the goose seven months old. For the furtherance of your work, I have consented to send you the gander from my own stock, as being the only perfect old specimen in this region; and I should have sent his mate, were it not she is about laying her second litter of eggs, which she has not failed to do in the month of Dec., for several years. I regret the specimens are not in better condition, as they would present finer shape, if fat; they have been grass-fed only. The gander has weighed, when in high condition, twenty-eight pounds."

Mr. Giles, in a communication to the author, dated Jan. 17, 1850 , thus speaks of this goose :

"I did say that the Indian geese of Dr. Bates are pure, and I now say further, that they are the most pure and best specimens I have seen in this country, or any other; but the Guinea or African goose is a different bird altogether, being full as large again, and differs in color; they have a coarse voice, unlike any other goose. The pouch, or dewlap, hangs down from one to two inches. A stately and beautiful bird." 


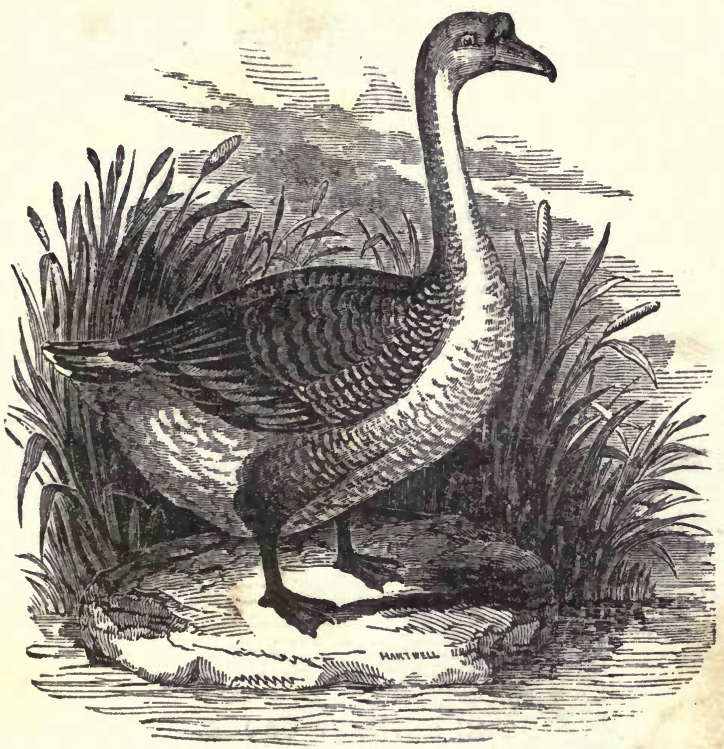

THE POLAND GOOSE.

This goose is a hybrid of the two varieties of the African goose and the Chinese goose. It is smaller than the African or Guinea goose, and larger than the Chinese. Its appearance is good, and the flesh is approved for the table. It is as easily raised as any other variety, and quite as profitable. 


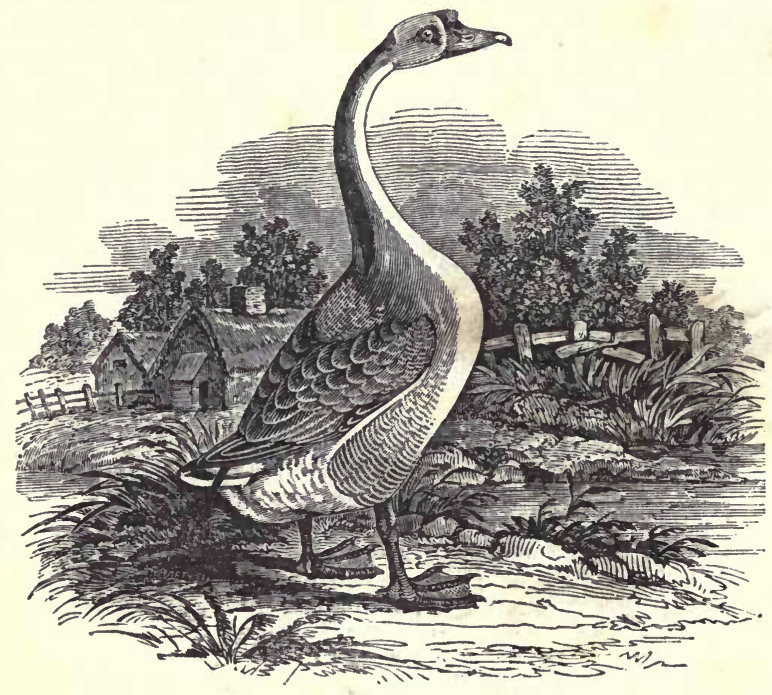

THE CHINESE GOOSE.

Some beautiful specimens of this variety were brought out from China by Fletcher Webster, Esq., and are now on the farm of the Hon. Daniel Webster, at Marshfield.

Richardson describes three sub-varieties of this species, all which, however, agree in the general characteristics.

\section{6'I. THE HONG KONG.}

This bird has a large horny nob on the bill and forehead; $i^{\text {'s }}$ prevailing color is gray, with a longitudinal stripe of a deep brown running above the back of the neck. The legs are of a red color, whence it is sometimes distinguished as the ' Redlegged China goose.' This is the same long known amongst us under the erroneous name of the 'Poland goose.' 


\section{BLACK-LEGGED CHINESE GOOSE.}

Also knobbed, and usually with a white edging round the $k n o b$, somewhat similar to that of the wild breed called the 'White-fronted goose.'

\section{THE WHITE CHINESE GOOSE.}

A very handsome bird, knobbed as the rest, of a snowwhite color, and with legs of a bright orange-red.

These geese are inferior in size to the Toulouse, but, nevertheless, very fine birds, and worthy the attention of the breeder. The white variety especially, with red legs, is very beautiful, and would form an appropriate ornament on a piece of water; it has sometimes been called the 'Swan goose.' The flesh of the Chinese goose is also good; they feed well, fatten easily, and are very prolific."

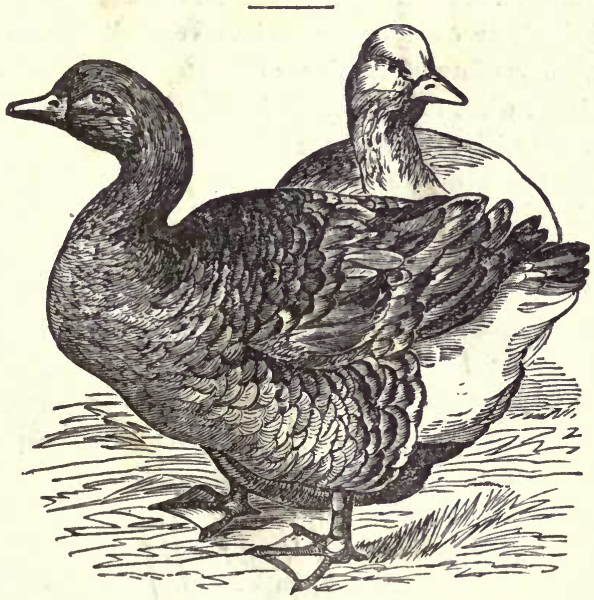

THE TOULOUSE GOOSE.

Mr. Ricnardson also describes this variety, and the plate is eopied from his work 
"This bird was originally imported from the Mediterranean by the Earl of Derby, and is known indiscriminately by the names of Mediterranean, Pyrenean, or that of Toulouse, which I have here given it. This bird is chiefly remarkable for its vast size-a property in which it casts every other known breed far into the shade; it is, indeed, the Mammoth of geese, and is to be regarded as a most valuable addition to our stock. The prevailing color of the Toulouse goose is a slaty blue, marked with brown bars, and occasionally relieved with black; the head, neck, as far as the beginning of the breast, and the back of the neck, as far as the shoulders, of a dark-brown; the breast is slaty blue; the belly is white, as also the under surface of the tail; the bill is orange-red, and the feet are fleshcolor. There ean be little doubt of this valuable bird being the unmixed and immediate descendant of the Gray-lag, and it was, indeed, at once pronounced to be such by the Royal Zoological Society of London, at their poultry exhibition of June, 1845, when the pair figured above, the property of Mr. Nolan, of Dublin, obtained the first prize.

These fine birds also obtained the prize at the exhibition in the Royal Dublin Society's yard, April, 1846, and subsequently at that of the Zoological Society of London, in the same year, when they were purchased by his Highness Ibrahim Pacha, and taken by that prince with him to Egypt.

In habit the Toulouse goose resembles his congeners, but appears to possess a milder and more easy disposition, which, I need scarcely add, greatly conduces to the chance of his early fattening, and that, also, at a little cost. Of his other peculiarities I need only observe, that the curl of plumage on the neck comes closer to the head than in common geese, and that the abdominal pouch, which, in other varieties, is attendant only upon age, exists in these birds from the shell; the flesh of the Toulouse goose is said to be tender and well flavored : 
they are, however, as yet, rather too scarce to permit of ordinary persons trying the experiment, a pair of young, halfgrown birds, costing from three to five pounds. As a cross with our common domestic goose, I am certain they will be found most valuable, and we may thus expect eventually to arrive at a degree of perfection not hitherto anticipated "

\section{THE BREMEN GOOSE.}

This variety of the goose species, now become exceedingly common, was first imported by Mr. James Sisson of Warren, R. I., who received a premium for his stock from the Rhode Island Society for the Encouragement of Domestic Industry. Mr. Sisson thus describes them, in the New England Farmer:

"In the fall of 1826, I imported from Bremen (north of Germany) three full-blooded perfectly white geese. I have sold their progeny for three successive seasons; the first year at $\$ 15$ per pair, the two successive years at $\$ 12$. Their properties are peculiar; they lay in Feb.; sit and hatch with more certainty than common barn-yard geese; will weigh nearly, and in some instances quite, twice the weight; have double the quantity of feathers; never fly, and are all of a beautiful snowy whiteness. I have sold them over the interior of New York, two or three pairs in Virginia, as many in Baltimore, North Carolina and Connecticut, and in several towns in the vicinity of Boston. I have one flock, half-blooded, that weigh, on an average, when fatted, thirteen to fifteen pounds ; the full-blood weigh twenty pounds."

Col. Jaques, of Ten Hills Farm, has also imported this variety, and bred them with great success. The advantages of this breed consist in their great size and excellent flesh, and 
they can be raised with great facility. They are also very heavily feathered, and in this respect are profitable.

The description of the following varieties is furnished by Mr. John Giles, of Providence, who has fine specimens of each in his possession.

"The Barnacle goose. - The forehead and cheeks white, the rest of the head and neck black; body grayish, barred with black and white; belly white.

The Egyptian goose.-Dark red round the eyes; red ring round the neck; white bill ; neck and breast light fawngray; a maroon star on the breast; belly red and gray; half of the wing-feathers rich black, the other part of them pure white; black bar running across the centre; back light-red, growing dark-red towards the tail; the tail a deep black.

It is a most stately and rich bird, reminding one of the solemn antiquity of the Nile, with its gorgeous mantle of golden hues and its long history. My Egyptian geese are very prolific, bringing off three broods a year, from eight to twelve each time; their weight is about eight pounds each.

The Java goose. - The gander white, with head and half the neck light fawn; red tubercle at the root of the bill; larger than the common goose, and longer in the body; walks erect, standing as high as the Guinea goose, the female appearing to carry two pouches, or egg-bags, under the belly ; very prolific - meat fine flavor. Imported by Mr. Colt.

White Wild goose. - All white, except about four of the end quill-feathers - these are black. Native of this country ; hardy and good breeders ; weight about five pounds." -

There are other varieties of geese, but the description of them must be reserved for another edition. 
THE DOMESTIC DUCK.

\section{CHAPTER VI.}

\section{THE DOMESTIC DUCK.}

"THE duck," says Mr. Richardson, "should always find a place in the poultry-yard, provided only that it can have access to water; without water, it is useless to endeavor to keep these fowl, but even a very small supply will suffice. I myself have kept them with success, and fattened the ordinary duck to the weight of eight pounds, with no further supply of water than what was afforded by a large tub sunk in the ground, as I have already described, when treating of poultry-yards. It must be remembered, that the flesh of these birds will be found to partake, to a great extent, of the flavor of the food on which they have been fattened; and as they are naturally very foul feeders, care should be taken, for at least a week or so before killing, to confine them to select food. Boiled potatoes are very good feeding, and are still better, if a little grain be mixed through them; Indian meal will be found both economical and nutritive, but should be used sparingly at first.

Some recommend butcher's offal ; but I may only warn my readers, that although ducks may be fattened on such food to an unusual weight, and thus will be profitable for the market, such feeding will render their flesh rank and gross, and not at all fit for table. In a garden, ducks will do good service, voraciously consuming slugs, frogs, and insects ; nothing coming amiss to them: not being scratchers, they do not, like other poultry, commit such a degree of mischief, in return, as to counterbalance their usefulness.

The duck is very prolific. I recollect reading an account, in an English newspaper, of a duck belonging to a Mr. Morrell, of Belper Dally, which laid an egg daily for eighty-five succes- 
sive days. This was in 1823-4. The egg of the duck is by some people very much relished, having a rich piquancy of flavor, which gives it a decided superiority over the egg of the common fowl; and these qualities render it much in request with the pastry-cook and confectioner - three duck eggs being equal in culinary value to six hen eggs. The duck does not lay during the day, but generally in the night; exceptions, regulated by circumstances, will, of course, occasionally occur. While laying, the duck requires more attention than the hen, until they are accustomed to resort to a regular nest for depositing their eggs; once, however, that this is effected, she will no longer require your attendance.

The duck is a bad hatcher; she is too fond of the water, and is, consequently, too apt to suffer her eggs to get cold: she will, also, no matter what sort of weather it be, bring the ducklings to the water the moment they break the shell, a practice always injurious and frequently fatal; hence the very common practice of setting ducks under hens. The eggs of the duck are thirty-one days in hatching; during incubation, they require no turning, or other attention; and when hatched only require to be kept from water for a day or two: their first food may be boiled eggs, nettles, and a little barley; in a few days they demand no care, being perfectly able to shift for themselves; but ducks at any age are the most helpless of the inhabitants of the poultry-yard, having no weapons with which to defend themselves from vermin, or birds of prey, and their awkward, waddling gait precluding their seeking safety in flight; a good, stout, courageous cock, and a sharp little terrier dog, are the best protectors of your poultry-yard. The old duck is not so brave in the defence of her brood as the hen; but she will, nevertheless, although Mr. Waterton thinks otherwise, occasionally display much spirit. I have witnessed this repeatedly, and I recollect a striking painting, illustrative 
of my remark, by that eminent artist, Charles Grey, representing a duck rushing furiously on a magpie, which had transfixed a duckling with its talons. Grey, like Landseer, never paints from imagination; he never depicts scenes that could not happen, and he is a close observer of nature."

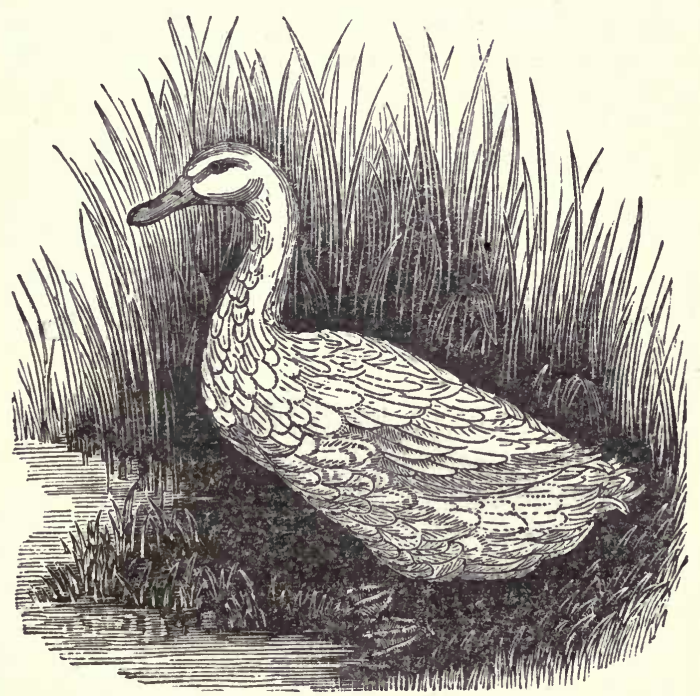

THE AYLESBURY DUCK.

The bird here portrayed is a faithful likeness of a duck in my possession, from the stock of Mr. Giles, of Providence. Mr. Giles says of these fowls:- "The breed I brought out with me from England are white, with white bills; their flesh is of a beautiful white, weighing from eight to ten pounds 
per pair when full grown. They are considered a rarity in London, commanding one third more price than any other ducks brought to market."

The pair of these ducks which I obtained of Mr. Giles are certainly extraordinary birds. They are now only about ten months old. The duck commenced laying in February, and has at this date, (March 4th, 1850,) laid twenty-seven eggs, and they are very large, for a young duck. All things considered, I deem these ducks to be worthy of a place at the head of their race. Col. Thomas H. Perkins, of Boston, is in possession of a brace from Mr. Giles' stock, which weigh nearly twelve pounds.

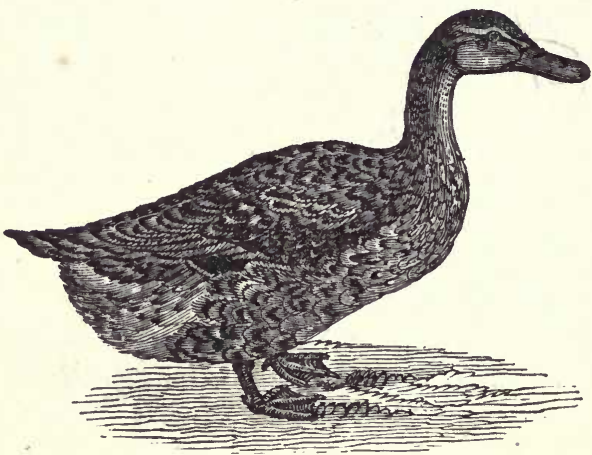

THE ROUEN DUCK.

This bird derives its name from the city of Rouen, on the Seine, and is esteemed highly by epicures. It is a prolific bird, and lays large eggs. Its size is the criterion of its value. 


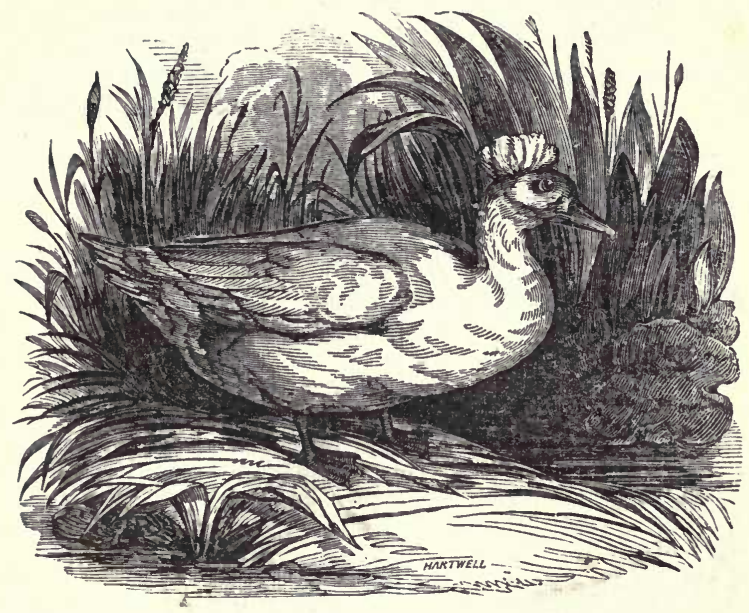

THE POLAND DUCK.

This plate is taken from life, from the white Poland ducks, now in possession of Samuel Shaw, of Plymouth, from the original stock of Rev. N. S. Smith, of Buffalo. Mr. Sinith has a high reputation as a scientific fowl-breeder. There are specimens of the black Poland duck, from the same stock, in possession of Mr. Sidney Packard, of East Bridgewater. The white are deemed the most desirable fowl, though the black are the largest; there is also a pied variety, which is a hybrid between the two. They breed early, and they are excellent layers. The head is ornamented with a crest, and the above is a fair representation of this breed. 


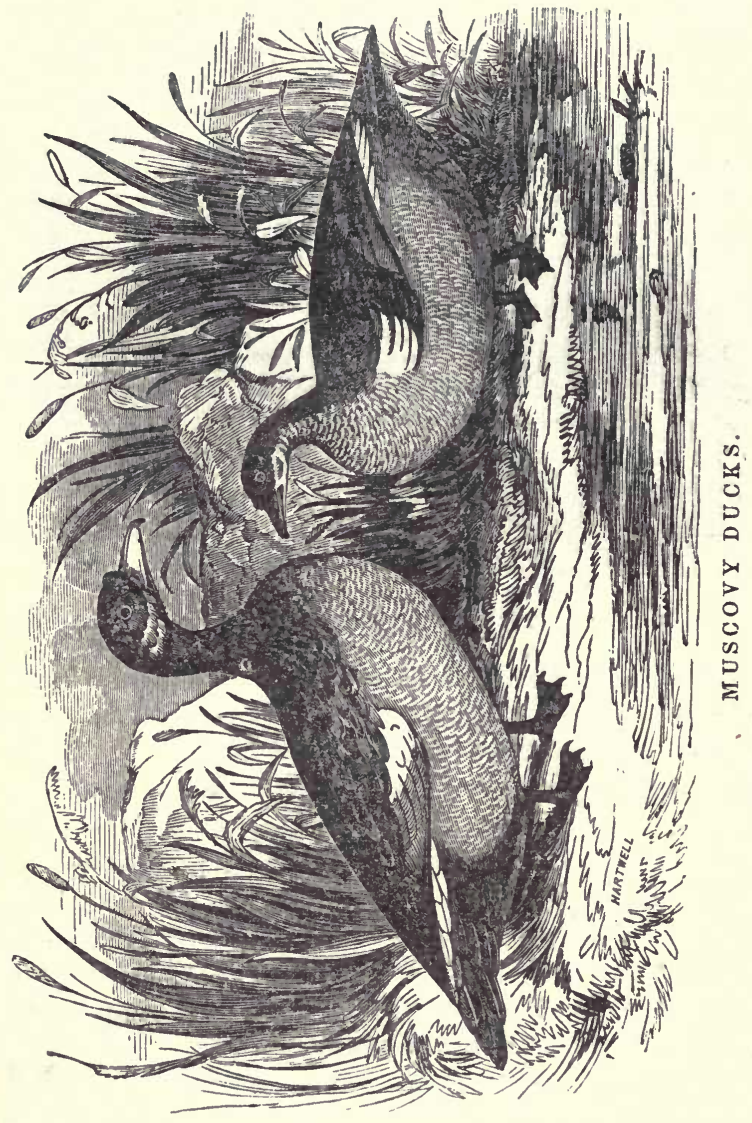


THE MUSCOVY DUCK.

The portraits represent ducks of this breed, in possession of Mr. Stephen Perkins, of Plymouth, and from the Rev. Mr. Smith's stock, at Buffalo. These are very noble specimens of the race.

"This duck does not, as some suppose, derive its name from having been brought from that country, but from the flavor of its flesh, and should more properly be termed the Musk duck, of which its other name is only a corruption; it is easily distinguished by a red membrane surrounding the eyes, and covering the cheeks. These ducks, not being in esteem, on account of their peculiar odor, and the unpleasant flavor of their flesh, are not worth breeding unless to cross with the common variety, in which case, let it be remarked, that the Musk drake must be put to the common duck; this will produce a very large cross, but vice versa will produce a very inferior one.

The Musk duck is a distinct species from the common duck; and the hybrid race will, therefore, not breed again between themselves, although they are capable of doing so with either of the species from the commixture of which they sprung." - Richardson

\section{CHAPTER VII.}

\section{PIGEONS.}

"Pigeons," says a writer in the Monthly Journal of Agriculture, " are amongst the most ornamental and useful appendages to a rural dwelling. If permitted to fly abroad to seek their food, little expense will be incurred for their keep, while the value of their young will be of some importance. The 
pigeon has a great power of flight, and will go to a distance of many miles in quest of the means of subsistence; but wherever it may fly, it never fails to return home. The leading features of the district around its habitation appear to be impressed upon its memory, and flying at a great height, and with a wonderful power of vision, it sees the well-remembered landmarks, and directs its path homeward. This habit of seeking for the place where it was reared makes it difficult to keep pigeons in any new home. The best plan of inducing them to settle in a new abode is to clip one wing, which prevents their flying, and keep them in a cot near the ground, till they get accustomed to the place.

Many persons keep their pigeons in the space between the garret and roof of their dwelling-house, with holes at which they go out and in; and this arrangement answers very well, for the animal's lodging must be dry and comfortable. A more regular plan is to furnish them with a properly constructed dove-cot, aloof from any building. The cot should consist of a substantial wooden box, with a sloping roof, and divided interiorly by partitions into as many cells as pairs are to be kept, for each pair requires a distinct cell. Each cell should be twelve inches deep from front to back, and sixteen inches broad; the entrance hole should not be opposite the centre of the cell, but at a side, so that the pigeons may build their nest a little out of sight. In front of each cell there should be a slip of wood to rest and coo upon; but as different pairs incessantly quarrel about the right of walking on these slips, and are apt to fight for the possession of cells, it is best to separate the slips with upright partitions ; and it would be an improvement to have two or three small cots, instead of one large one. The cot, of whatever size or form, should be elevated on a wall facing the south-east, or otherwise placed at such a height as will be out of the reach of cats and other 
vermin. The cot should be painted white, as the pigeon is attracted by that color. Gravel should be strewed on the ground in front of the dove-cot, the birds being fond of picking it; and a little straw or hay is necessary for the nests. Cleanliness is indispensable to the health of the birds, and a scouring out of the cot should therefore take place regularly. The quantity of dung produced in the nests is very great, and its removal to the compost heap will amply repay the trouble of cleaning.

In commencing to keep pigeons, a pair or two should be procured which have not flown, and they should be shut up for a time, and well fed. Their chief food is grain, and the kind which they prefer to all others is dried tares. Small horsebeans are another favorite article of diet, and very nutritious to them. Wheat, barley, oats, and peas, with rape, hemp, and canary seeds, are also prized by them, but should not be made constant articles of food under any circumstances.

The house-dove or common pigeon, as is well known, begins to breed about the age of nine months, and breeds every month. During breeding time, they associate in pairs, and pay court to each other with their bills; the female lays two eggs, and the young ones that are produced are for the most part a male and female. When the eggs are laid, the female, in the space of fifteen days, not including the three days during which she is employed in laying, continues to hatch, relieved at intervals by the male. From three or four o'clock in the evening, till nine the next day, the female continues to sit; she is then relieved by the male, who takes his place from ten till three, while his mate is feeding abroad. In this manner they sit alternately till the young come out. Kept with ordinary eare, a pair will give to the breeder nine pairs or so in a year, and will continue to do this for four years.

With regard to the best breeds of the common domesti- 
cated pigeon, it is difficult to give any useful instructions. They have been cultivated to a great extent, and many distinct varieties have been formed; but the differences rest chiefly in colors, and the special value of each lies in the taste of the fancier. The leading varieties of fancy pigeons are known by the names of the English Pouter, the Dutch Cropper, the Horseman, the Unloper, the Dragoon, the Tumbler, the Leghorn and Spanish Runt, the Trumpeter, the Nun, the Fan-tail, and the Capuchin. The peculiarities of some of these breeds are very odd. The Tumbler, for instance, derives its name from a practice of tumbling in the air while on the wing. Instead of pursuing a steady, straightforward flight, it turns over, or casts somersets backward, whirling round, heels over head, as expertly as a first-rate rope-dancer does when he makes the back spring. The Fan-tail derives its name from the circumstance of its having a remarkably broad tail, which it has the power of spreading out, like the tail of a turkey cock. The prime quality of the bird consists in its ability to make its tail touch its head, and surround it with a wide glory of feathers. If it cannot do this, it is valueless to the fancier, no matter how excellent are its other properties. Amusing as this absurdity is, it is not so laughable as the qualities which recommend the English Pouter to public favor. This bird, which is a cross between a Horseman and Cropper, possesses the remarkable property of blowing out its breast or crop to such an extent that it rises to a level with its beak, and the bird appears to look over the top of an inflated bladder."

\section{CARRIER PIGEONS.}

" Pigeons have been put to the remarkable purpose of acting as carriers for letters, or other light objects. A particular species, larger than common, is trained for the purpose, and in 
some countries the rearing of them forms a lucrative employment. The instinct which has rendered the carrier pigeon so serviceable is the strong desire manifested by all pigeons to return to the place of its ordinary residence; and man has adopted various precautionary measures, in order to make its return on particular occasions more certain. A male and female are usually kept together and treated well; and one of these, when taken elsewhere, is supposed to have the greater inducement to come back. It is even considered necessary by some that the bird should have left eggs in the process of incubation, or unfledged young ones at home, in order to make the return certain; but probably these are superfluous precautions. It is obvious that the carrier pigeon can only be put to use in conformity with some contemplated plan, for which the proper preparations have been made. It must have been taken from a place to which it is wished that it should return, and it must, at the moment when its services are wanted, be temporarily at the place from which the intelligence is to be conveyed. It is usually taken to that place hood-winked, or in a covered basket; the instinct by which it finds its way back upon its own wings must of course be independent of all knowledge of the intermediate localities. When the moment for employing it has arrived, the individual requiring its services writes a small billet upon thin paper, which is placed lengthwise under the wing, and fastened by a pin to one of the feathers, with some precautions to prevent the pin from pricking, and the paper from filling with air. On being released, the carrier ascends to a great height, takes one or two turns in the air, and then commences its forward career, at the rate of forty miles in the hour, or about a thousand a day."

Mr. Abel Moore, of Boston, has an extensive assortment of pigeons, the best that I have ever seen, and fanciers can obtain almost any desirable variety at his establishment. 


\section{CHAPTER VIII.}

\section{FOOD OF POULTRY.}

IN order to determine the best sorts of aliment for fowls. experience in their management and close observation of their habits are indispensably necessary. But to these advantages must be joined some knowledge of their digestive apparatus, both as to structure and functions. In the chapter on the diseases to which fowls are liable will be found some anatomical outlines of their more important organs. It will only be necessary here, therefore, to make such observations in regard to those functions which are connected with digestion, as will prepare the way for a better comprehension of the whole subject of feeding these animals.

It has been demonstrated, by the cruel experiments of Spallanzani, that what may be called the gastric juice in fowls has not sufficient power to dissolve their food, without the aid of the grinding action of the gizzard. Bcfore the food is prepared for digestion, therefore, the grains must be subjected to a triturating process, and such as are not sufficiently bruised in this manner, before passing into the gizzard, are there reduced to the proper state, by its natural action. The action of the gizzard is in this respect mechanical, and it serves as a mill to grind the food to pieces, and then, by means of its powerful muscles, presses it gradually into the intestines, in the form of pulp. It is said that the power of this organ is so great that hollow globules of glass have been pulverized by it, in a very short time, and solid masses of the same substance, in a few weeks. The rapidity of this process seems generally to be proportionate to the size of the bird. A chicken, for instance, breaks up such substances as are received into its stomach less 
speedily than a capon, while a goose performs the same operation sooner than either. Other experiments have proved that needles, and even lancets, given to a turkey, were broken in pieces and voided, without the stomach appearing to sustain any injury from them. The reason undoubtedly is, that the larger species of birds have thicker and more powerful organs of digestion.

The opinion has been almost universally received, that from some deficiency in the digestive apparatus, fowls have been obliged to resort to the use of stones and gravel, in order to enable them to dispose of the food which they consume. Some writers have supposed that the use of these stones was to sheathe the gizzard, in order to fit it to break into smaller fragments the hard, angular substances which might be swallowed. Spallanzani, however, has ascertained that this supposition is unfounded, by a series of experiments made with this object in view. He took wood-pigeons as soon as escaped from the egg, and nursed them under his own eye, until they were able to peck. They were forthwith confined, and in a month hard substances, such as tin and fragments of glass, were introduced with their food. In two days, they were killed. No pebbles had been allowed to enter either one of the stomachs, and yet these hard substances were bruised and flattened, and the glass especially blunted and broken. Nor did any wound or laceration appear on the coats of the stomach. Similar experiments were tried, likewise, on the chickens of the hen and turkey, with great care, and with effects precisely similar.

By some, the stones and gravel eaten by fowls have been considered to have a medicinal effect; and others have imagined that they acted as absorbents for undue quantities of acids in the stomach, while another office, namely, that of stimulants to digestion, has been assigned to them. Extravagance has 
even gone so far as to assert that these substances contributed directly to nutrition. Reor, an Italian physician, made experiments by which this notion is entirely exploded. He shut up two capons, with nothing but water and small pebbles for food, and found that they drank much water, but died, - one in twenty, the other in twenty-four days, - neither of them having swallowed a single stone.

In the light of these experiments, the question of the use and effects of the swallowing of pebbles by poultry seems to be decided. It is certain that they are not at all necessary to the trituration of the hardest kinds of substances which can be introduced into the stomach; and, of course, the usual food of fowls can be sufficiently bruised without their aid. It is not to be denied, however, that they serve a useful auxiliary purpose. When put in motion by the muscles, they are capable of producing some effects on the contents of the stomach, and thus assisting to grind down the grain, and separating its parts, the digestive fluid, or gastric juice, comes more readily in contact with it.

It seems that fowls have some power of retaining the stones taken into the gizzard, and of evacuating them when they become smooth; but they are never known to disgorge them, as birds of prey throw off what they cannot digest. Sometimes, also, they swallow too great quantities; and instances are cited by some writers, in which the whole cavity of the gizzard has been filled with gravel. Disease and death, in such cases, are likely to supervene.

\section{VARIETIES OF FOOD.}

Fowls about a poultry-yard can usually pick up a portion of their subsistence, and, under favorable circumstances, the largest portion; and in such situations, poultry-keeping decid- 
edly pays best. A caution is necessary, however, against depending for the support even of poultry not designed for fattening, on such precarious resources. Fowls should be fed with punctuality, faithfulness and discretion.

Poultry are fond of all sorts of grain, such as Indian corn, wheat, oats, rye, buckwheat, barley, millet, \&c., but their particular preferences are not so likely to guide, in the selection of their food, as the consideration of what is most econokaical, and easiest to be procured on the part of their proprietors. They will readily eat most kinds of vegetables in their green state, both cooked and raw. They likewise manifest an inclination for animal food, such as blood, fish and flesh, whether raw or otherwise, and seem by no means averse to feeding on their own species. Insects, worms and snails, they will take with avidity.

It is usual to give to domestic fowls a quantity of grain once or more daily, but commonly in less quantity than they would consume if unrestricted. They feed with great voracity, but their apparent greediness is not the criterion by which we are to judge of the possibility of satisfying them. Moderate quantities of food will suffice, and the amount consumed will usually be proportioned to the size of the individuals.

Mr. Bement says he was eurious to ascertain the quantity of each sort of grain which a given number of fowls, when abundantly supplied, would consume; and for that purpose he confined one cock and seven hens of the Poland variety. The first feed he gave them was one peck of Indian corn, which they consumed in eleven days. He then fed them one peck of oats, which they ate in six days. The next feed was the same quantity of barley, which lasted them seven days. The like quantity of wheat they consumed in ten days. The same quantity of millet lasted eight days, and the like quantity of wheat screenings they devoured in seven days. During this 
tria], they had no other food, except a few boiled potatoes. Fowls of common size will consume of corn, wheat, rye or barley, about a gill a day, in the months of January and February.

The most full and accurate information, in regard to the whole subject of the food proper for fowls, and as to the quantities consumed by different individuals under different circumstances, is derived from the researches and experiments of $\mathrm{M}$. Reaumur, a French writer of considerable distinction. A brief account of his proceedings and opinions will bring into view, in the most complete manner, what is desirable to know on this subject. To Mr. Dickson is due the credit of making this valuable matter generally accessible.

It appears that Reaumur was desirous of ascertaining the quantity of each sort of grain which a fowl would consume, when supplied in ample quantities during the whole day. $\mathrm{He}$ found, on experiment, that individual fowls varied much in the quantity consumed, and that this diversity was usually in proportion to their size. The quantity, for instance, consumed in one day by a large fowl, was found to be to the quantity of the same grain eaten by one of ordinary size, in the proportion of four to three; and of a dwarf or bantam, as two to one. Amongst fowls of the same size and kind, there are individuals which require more food than others, and this depends upon various circumstances. Reaumur says that four common fowls ate as much as eight others; and of these last, three were of the largest size, and three more, out of the remaining five, were but a little smaller. In order to determine with accuracy the quantities of food taken, Reaumur confined fowls, separately, under basket coops, and others in hutches, enclosed with wooden gratings, where they had every convenience, and might even lay, if disposed. In each hutch containing hens he put a cock, in order that the experiment might be complete. 
In some hutches he placed seven hens, and in others different numbers, even as low as two. For several consecutive days, he gave to the fowls in coops, and to those associated in hutches, the same quantity of grain, measured so as to be more than would fill their crops; and the precaution was taken that the box into which the grain was put for them should never be empty. This box was of greater length than breadth, with a bottom, and a piece of board on each side, projecting some five or six inches, in order to prevent the chance of upsetting it by the fowls hopping upon it, while the sides were sufficiently high not to allow them to scrape the grain out of the box. By this careful contrivance the experiment might be made with perfect accuracy, and every grain of corn could be accounted for. Gravel was also spread on the bottom of the hutches and coops, and also in a separate vessel, in order that it might be used as when the fowls were at liberty.

The result of this experiment was, that nearly the same measure of grain was found sufficient for a fowl every day, of whatever sort it happened to be. Whatever, therefore, is cheapest, at any given time, may be given, without regard to other considerations. Different circumstances and different seasons may produce variations in the appetite of fowls, but, as already observed, a gill is about the usual daily portion. Some very voracious fowls, of the largest size, will need the allowance of a third of a pint per diem.

It is allowed that wheat, with perhaps the exception of rice, is the most nutritive of cereal grains, as an article of human food. It is natural to suppose, therefore, that it is the best for fowls; and the avidity with which they receive it would induce the conclusion that they would eat more of this than any other kind of grain. Yet it appears that when fowls have as much wheat as they can consume, they will eat about a fourth part less than of oats, barley, or buckwheat: the largest quantity 
of wheat eaten by a fowl in one day being about three sixteenths of a pint. However, the difference in bulk is compensated by the difference in weight, these three sixteenths of wheat weighing more than four sixteenths of a pint of oats. It is not true that, in every instance, the difference in weight is the reason that a fowl is satisfied with a larger or smaller measure of one sort than another. Rye weighs less than wheat, but still a fowl will be satisfied with half the quantity of this grain. The seven hens and the large cock just mentioned consumed daily a pint and a half measure of wheat, while of rye they only devoured three quarters of a pint; and hence the consumption of the rye by each bore the proportion of one to two, to their consumption of wheat.

Indian corn was found to rank intermediate between rye and wheat. When this was exclusively given, the greatest eaters on the first day only ate about one eighth of a pint measure; but when accustomed to it, they appeared to relish it more, and the cock and seven hens, which were rather above the average rate of eaters, consuimed each day a pint and a quarter. It follows, therefore, that five fourths of Indian corn to them was equal to six fourths of wheat, and to three fourths of rye.

In estimating the quantity of grain daily consumed by the common fowl, it is wise to use data a little above than below the average. We may safely, therefore, say that a fowl of the common size, having free access to as much as can be eaten during the day, will consume, day by day, -

Pint. Meas.

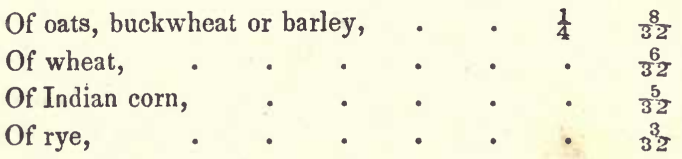

Although it appears, from the experiments already given, as 
regards wheat and rye, that the average consumption is not always in proportion to the specified weight of the grain, yet it is of some importance to know the relative weights of each kind of grain, in all such experiments. M. Reaumur carefully weighed a pint measure of each, in order to ascertain the difference of weight between them, with the following result :-

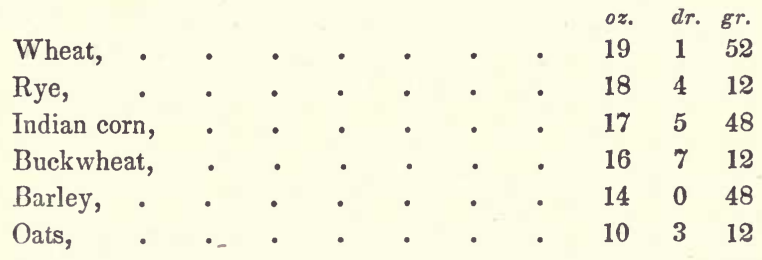

After weighing, each of the sorts was put by itself in a paper bag, and placed in a low and damp room, for nearly two months, when they were again weighed. The measure, which had first been carefully struck, was now found to have the grain considerably above the brim, owing to the increase of bulk from moisture. The weight of the different kinds was now as follows :-

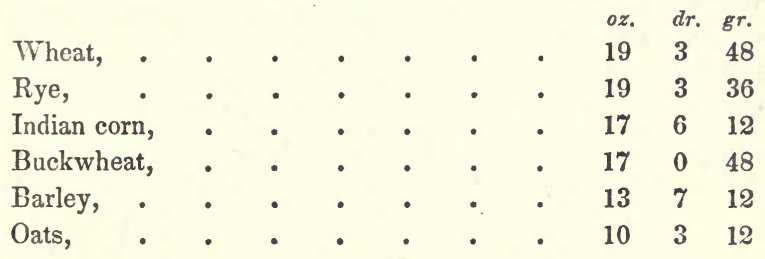

The same grains, after the second weighing, were kept in a hot room of a uniform temperature, sufficient to hatch eggs, for three months successively; when they were again measured and weighed. They did not now fill the measure by a third 
of an inch, though they had stood above the brim when taken from the damp room: the weights were the following :-

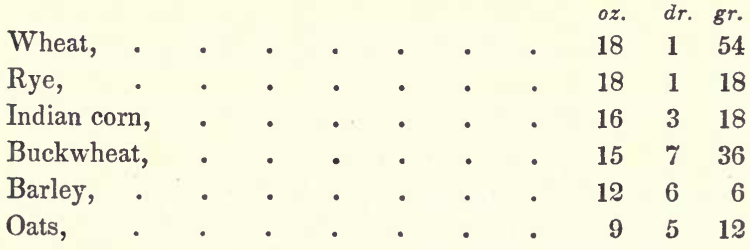

By these tables it is shown that buckwheat is considerably heavier than barley or oats; yet a fowl will require as much, by measure, of buckwheat daily, to satisfy it, as of any of the other two sorts of grain. It is possible that this anomaly may be accounted for on the ground of peculiarity in taste. It is certain that one sort of grain is often more palatable than another, and that fowls eat voraciously more than might suffice them in such a case. In order to determine this matter, M. Reaumur caused a partition to be made in the feeding-box, by which it was divided into two equal compartments, into one of which he put a measure of wheat, and into the other a measure of rye. Three hens and one cock were put to feed upon these, and did not show any preference to either of the sorts of grain, as there remained, after their first morning's repast, about an equal quantity of wheat and rye; while, in the course of the day, they finished what they had left, emptying the two compartments almost at the same time.

Experiments of this kind, which ought to be repeated with all the sorts of food given to poultry, are important, as furnishing criteria by which to determine what sort of food is most agreeable to fowls. This is of consequence to be ascertained, because, as a general rule, what is most relished in eating agrees with the animal best, and is most easily digested. With 
this end in view, M. Reaumur extended his experiments to other sorts of grain, by not only offering the fowls each sort in different compartments of their feeding-boxes, but also by putting a mixture of grains in each box. He put, for example, a measure of wheat and another measure of oats into the same box, and mixed them. A cock and a hen, to which this mixture was given, exhibited a greater liking to the wheat than to the oats, for there remained at night in the box a portion of the oats, as much as a fourth or a sixth part of the whole quantity, but there was not left a single grain of wheat. From a subsequent experiment, however, it appeared that it would have been too hasty to draw a general conclusion from the taste of these particular birds. On the same day there was given to a hen, kept alone under a basket coop, a measure of wheat in one compartment and a measure of oats in another, of the same feeding-box. In the course of the day, this hen devoured the whole of the oats, but left almost half of the wheat. A measure of rye was given to her next day, and she preferred eating that rather than the portion of wheat which she had left the day before. To the same hen was given a measure of wheat and oats, mixed in equal quantities. At first she was seen to eat both sorts of grain, but as she continued to feed, the oats began to disappear, and the wheat to predominate, till at length every grain of oats was consumed, and about one sixth of the wheat was left untouched.

On another occasion, M. Reaumur gave to a cock and a hen, kept in the same hutch, three different sorts of grain, namely, Indian corn, oats, and buckwheat, each put separately in three different compartments of the feeding-box. The cock came first to the corn, and after eying it for a time, he finally refused to touch it, but turned to the buckwheat, of which he picked up a few grains, and then went to the oats. He continued for some minutes to taste, alternately, a little of the one and the 
other. On the other hand, the hen no sooner saw the Indian corn than she pounced upon it voraciously, and never offered to quit it for either of the others. As their motions were confined by the hutch, he tried the effect of turning the box, so as to bring the corn opposite the cock, and the others more within the reach of the hen; but the cock did not offer to touch the corn, but went round to the other two sorts, while the hen also changed sides, and recommenced eating the corn with avidity. Next day, the same birds were served with the three sorts of grain, as before; but the hen fixed on the buckwheat, avoiding the corn, and the cock evidently preferred this to the oats, of which, however, he from time to time ate some grains, leaving it directly for the buckwheat, which between them was soon consumed.

These experiments were varied and extended by giving to the seven hens already mentioned an equal quantity of each of the six sorts of grain usually given to poultry, each put separately into the divisions of a common feeding-box, the whole quantity given being calculated to serve two days. The first day, the whole of the buckwheat was despatched; on the second morning, there was no barley left; the wheat and the corn were entirely consumed nearly at the same time, on the second afternoon; while a little rye and oats were left for the third day.

It would be superfiuous to detail with similar minuteness the numerous experiments of the same kind, which were varied and combined in every possible way that M. Reaumur could devise, as he found it was by no means so easy as might have been previously supposed to determine the sorts of grain which fowls prefer. At first, it appeared that there were some hens which ate more readily any particular sort they had been most accustomed to than sorts entirely new to them. On the contrary, it also appeared that the appetite of others was excited 
by any new sort. In a word, similar eccentricities of taste appear amongst fowls, with respect to particular sorts of food, as amongst ourselves. It is very certain, at least, that it is not because one sort of grain is larger, heavier, or more plump, than another, that they eat more or less of it, or prefer it to others. It is probable that the grain of which they consume the least furnishes the greater proportion of chyle - the fluid which is prepared by digestion, to mix with the blood, for promoting the growth and repairing the waste of the body - in a word, that which supplies the most nourishment.

Experiments which will be given elsewhere proved that the sorts of food most easily digested by fowls are those of which they eat the greatest quantity. Of the several kinds of grain already mentioned, they evidently became soonest tired of, and least partial to, rye.

\section{DIFFERENT SORTS OF FOOD.}

It is a general opinion, that grain when boiled so as to burst is better for fattening poultry than when used in its dry or natural state. The French method is to boil the grain given to fowls intended to be fatted until it is soft enough to be bruised between the fingers. By boiling, the grain is caused to swell till the farina burst the envelope by which it is confined. But the opinion alluded to has not probably been grounded on a sufficient number of accurate experiments to give it an established authority. It is important, at any rate, on economical considerations, to discover whether there is any difference of expense in feeding poultry on dry or boiled grain, or, in other words, whether fowls will eat more or less of the one or the other. M. Reaumur's patient endeavors are again valuable on this point. To ascertain this, he caused four pint 
measures of each of the six common sorts of grain to be boiled till they burst, and the increase in bulk of each sort was as follows : Four pint measures of oats, thus prepared, filled seven pint measures; of barley, ten ; of buckwheat, fourteen ; of Indian corn, above fifteen; of wheat, a little more than ten; and of rye, nearly fifteen.

Rice is stated to swell more by boiling than any of these six sorts, but it is rarely given to poultry, except for fattening. There is a popular notion that it tends to whiten the flesh.

In order to determine whether the boiling changed the preference of fowls for any of the particular sorts, M. Reaumur made experiments similar to those already described, varied in every possible way. The fowls were furnished with two, three, four, five and six, different sorts ; at one time all the compartments of the feeding-box being filled with burst grain, each different from the other, and at others, each sort of grain filled two of the compartments, one of them having nothing but boiled, and another nothing but dry grain. All that could be collected from these repeated experiments was, that the greater number of fowls prefer boiled grain to raw, though there are many of them which show a preference to the dry grain on certain days, and no permanency could be discovered in the preference shown for any sort of burst grain. The same fowls which one day preferred boiled wheat would on other days make choice of buckwheat, Indian corn or barley, and sometimes, though seldom, of rye; but rye, either cooked or raw, is manifestly the least favorite sort of grain.

The conclusion, then, derived from these experiments, is abundantly fortified, that we may choose for fowls that sort of grain which happens to be cheapest or most convenient, avoiding rye, when necessity does not compel its use.

Reaumur deemed it necessary to make other experiments, in order to settle the question as to the economy of feeding poultry 
on boiled grain ; and this he effected by ascertaining, in the first instance, how much dry grain sufficed one or more fowls, and then by boiling the same quantity, and by feeding it to them, to find out how much was required by them. The results of these experiments with the different grains will now be stated.

Rye was found to be considerably increased in bulk by boiling ; but as fowls eat more of it in this state than when dry, it is demonstrated that the process of boiling does not render it more sufficing. The fowls already mentioned as the subjects of these experiments, which consumed only three fourths of a pint measure of dry rye per diem, ate, in the same time, three pint measures of the boiled grain. It would therefore cost one twentieth more to feed fowls with boiled than with dry rye.

Oats are increased by boiling nearly one half, but it was found that the increase of bulk makes them no more satisfying to the fowls who feed on them. The fowls in question, which in two days would have eaten four pint measures of dry oats, consumed in the same time seven pint measures, when boiled. Oats have been recommended for promoting laying; but in the opinion of Mowbray, there are objections to this grain as a constant food, from its effects on the intestines, and young fowls will not long continue to relish it as a constant diet.

Buckwheat is yet more increased in bulk by boiling - four pint measures will swell to fourteen; but it was found that this last quantity was consumed by the fowls in about the same time that four pints of the dry grain was despatched. It appears, therefore, that it is not good economy to boil these varieties of grain for food.

Indian corn, on the contrary, is much more profitable when boiled than when given in the raw state. The fowls used in Reaumur's experiment consumed only three pint measures of the boiled corn, which are scarcely equal to one of the dry, while they found no difficulty in devouring a pint and a quarter 
of the same, when fed to them in a dry state. This continued, to be sure, but two days, and after that, they, for some cause, only ate about two pint measures. But even if this were the general rule, and should fowls consume three pints a day of the grain when boiled, there would be a saving of about one half.

Barley is also more economical when given boiled than dry. The fowls which would have eaten two pint measures of dry barley a day consumed but three pint measures of the boiled grain. With the increase of bulk in the boiled barley considered, the saving amounts to two fifths, in favor of the boiled.

Wheat is augmented in bulk in about the same proportion as barley. The facts brought to view by these experiments, however, show that the saving by boiling this grain is not so great as might be supposed. The fowls which consumed three pint measures of boiled barley in one day ate three pint measures of boiled wheat. But as a pint of boiled wheat is equal to no more than two fifths of a pint of the dry grain, the three pints consumed in a day are equivalent only to six fifths of dry wheat. It follows, therefore, that there is a saving of but one fifth, by feeding with boiled wheat, while the saving in barley is two fifths.

The results of these experiments conclusively prove that there is the best economy in feeding poultry with boiled grain, in every case, rather than with dry, when either of the three kinds last mentioned can be procured. The expense of fuel, and the additional trouble necessary in the process of cooking, is inconsiderable in comparison with the advantages to be derived therefrom. In the case of the first-mentioned-oats, buckwheat and rye-boiling is useless, when profit is concerned.

Bran is sometimes given to fowls, in order to save expense. But it is an erroneous notion, that money may be saved in this way. In bran there is so little of the farina of the grain 
remaining, that the nourishment derived from its use is hardly worth mentioning. When boiled, as it always must be, the bulk is but slightly increased. Reaumur estimates that two measures of dry bran, mixed with water, are equivalent to three fifths of a measure of dry barley only.

Millet is said to be excellent food for young chickens. Fowls always prefer it raw, though, as by boiling its bulk is increased one half, it is doubtless more economical to feed it cooked.

Rice. - Of this food fowls are especially fond, though when they are allowed it at discretion they soon lose their relish for it. It should always be boiled, but for daily diet is decidedly too expensive, and cannot be recommended. When used continuously, it should always be mixed with some substance containing less nutritive matter, in order that the appetite of the fowls may not be cloyed by it.

Potatoes. - There can be no doubt that potatoes are a wholesome food for fowls, and under most circumstances they form a cheap diet. The quantity which fowls will consume has, however, never been ascertained with the same precision as in the case of the different sorts of grain which have been already specified.

Potatoes are very nutritious, and are usually acceptable to fowls, when properly prepared. When raw, or given in a cold state, they appear to dislike them. They should therefore be boiled, and thrown to poultry while moderately hot. It is said that when very hot, the fowls will eat them, and injure themselves by burning their mouths. They should also be broken into pieces of convenient size, for otherwise they will be avoided. Occasionally raw pieces of potato will be devoured, but fowls cannot be said to be fond of the root in this state. The same remark applies to most other roots, especially carrots and parsnips; these should always be prepared, in order to be wholesome and palatable. Fowls should never be confined to 
a root diet, in any case; but such food should be mingled or alternated with a sufficient quantity of grain.

Green food. - Almost all kinds of green food are acceptable to poultry, and indulgence in this kind of diet is absolutely indispensable to their health, and is also advantageous in an economical point of view. The more delicate kinds of green vegetables are eaten with the most avidity. All succulent weeds, grass, and the leaves of trees and shrubs, will also be consumed by them. Reaumur says, that if hens have green plots to graze in during the day, which they are inclined to do, and which they must do, if sparingly fed with grain, the expense of their keeping will be diminished one half.

The same author advises that all the refuse of the kitchen, of a vegetable nature, should be freely thrown into the poultryyard, and says that this will form for fowls an agreeable and wholesome salad.

Green food, however, will not answer for an exclusive diet. Experiment has shown that fowls fed with this food alone for a few days together exhibited severe symptoms of relaxation of the bowels; and after the lapse of eight or nine days, their combs become pale and livid, which is the same indication of disease in these birds, as paleness of the lips in the human species. M. Parmentier recommends the adoption of his own practice, of giving bread to fowls. He took the trouble to bake bread expressly for his own poultry-yard, composed of the flour of different sorts of grains. From this he made a soup, of which the fowls were very fond, when given to them hot, and he pronounces this method to be economical. Such pieces of bread, pie-crust, and fragments of pudding, \&c., as are liable to be wasted in a family, will be readily consumed if bestowed upon the fowls. Broken biscuit of the variety called ship-biscuit, or pilot-bread, even if mouldy or infested with 
insects, when soaked in hot water, is also a desirable and profitable food.

Earth-worms. - These animals are regarded as delicacies by the inhabitants of the poultry-yard, and the individual who is fortunate enough to capture one, may often be observed to contend with the surrounding fowls most vigorously for the possession of the prize. To many it will doubtless appear ridiculous to recommend this sort of food, on account of the supposed difficulty of obtaining a supply. But the difficulty only exists in imagination. On the contrary, in the years of greatest plenty, it may be affirmed, without fear of contradiction, that the hardest labor will not produce from the surface of the earth grain equal in weight to that of the worms which lie beneath the same extent of ground. But these animals are more plentiful in moist land, such as pastures, \&c., than in that which is cultivated. In gardens, also, worms exist in vast numbers, and appear to be designed by a beneficent Providence as food for the various tribes of birds.

With caution and dexterity, multitudes of worms may be easily captured. It is only necessary, when it is desirable to take them in quantities, to thrust a stake or three-pronged fork into the ground to the depth of about a foot, and to move it suddenly backwards and forwards, in order to shake the soil all around. The worms are instinctively terrified by any motion in the ground, and when disturbed hasten to the surface.

It is advisable to store worms, on account of the trouble and difficulty of making frequent collections. They may be placed in casks filled one third full with earth, in quantities equal at least in bulk to the earth. It will be requisite to sprinkle the earth occasionally, to prevent it from becoming too dry. Care should be taken, however, to prevent the earth from becoming too moist, for in such an event the worms will perish. In rainy weather the casks should be protected by a covering. 
It is customary in Europe, where there are large poub id yards, to have within them a hollow place, for a reservoir of worms. These are about a foot deep, and built up on the sides with stones. The bottom is covered with a layer of earth two or three inches deep, and is watered occasionally. The worms, when collected from the fields, are thrown upon the earth. Fowls are fond of scratching among earth thus prepared, and it is found to be a healthy exercise for them to hunt their prey in this manner.

Olivier de Serres, the father of rural economy in France, constructed what he called a Verminier on a large scale. He caused a hollow place to be dug, about twelve feet square and four feet deep, sloped at the bottom, so as to allow superfluous water to run off. The buttom was strewed with straw to the depth of six inches, and upon this was laid a quantity of fresh horse-dung to the same depth, and this was covered with sifted earth. Over the earth was poured a quantity of blood, and any garbage which was handy mixed with chaff. This process was repeated until the pit was wholly filled in layers. It was then covered with bushes, to protect it from the wind, and to prevent the fowls from scratching among it. The rains soon rendered the whole sufficiently moist to produce a putrefactive fermentation of the mass, and myriads of worms were engendered.

It is the French practice to give the fowls, early in the morning, a quantity of grain, considerably less than they would eat - for breakfast. When this is consumed, the verminier is opened, and a few spadefuls of the mass, with the worms in it, is thrown into the yard. Upon this the fowls eagerly pounce, and scatter it about with great delight, till they have devoured every worm it contains.

By proceeding regularly this way, dealing out only a few spadefuls at a time, the heap of compost will last a considerable 
time. If the number of fowls be considerable, other verminiers may be constructed, so that when one is exhausted, another may be ready for use. These repositories are more valuable in winter than in summer, and should therefore be constructed where they may best be defended from the inclemency of the season.

Care should, however, be taken, in using this sort of food, that too many worms should not be given at one time. Reaumur fed a hen entirely on worms for a fortnight, and she seemed well pleased with her fare. She grew very fat, and as she had as many as she could devour, her appetite, so far from decreasing, became every day more keen. At first she ate about a pint, soon increased to a quart, and at last she devoured nearly three pint measures per day. Of course, her health suffered from such gluttony. On the whole, it may be said that worms are both a useful and economical food for poultry.

Fish, Flesh and Fowl. - As fowls appear to be omnivorous, they eat readily both fish and flesh meat, and they have no reluctance to feed on their own kind. They will pick bones, even more faithfully than quadrupeds. Blood of any kind is esteemed a delicacy by them, and fish, even when salted, is devoured with a relish.

It seems to be a matter of comparative indifference to them whether animal food is given in a boiled or raw state, so far as the gratification of appetite is concerned, though, if any preference can be observed, it is for raw meat. They are sometimes so greedy that they will attack their fellows in order to taste the blood which flows from the wounds they inflict, and it is quite common for them, in the moulting season, to gratify themselves by picking at the sprouting feathers belonging to their companions and to their own bodies. They appear to be partial to suets and fat, but they should not be allowed to devour these 
substances in large quantities, on account of their tendency to render them inconveniently fat.

It is highly advantageous to fowls to allow them a reasonable quantity of animal food for their diet. It should be fed to them in small pieces, both for safety and convenience. Bones and meat may be boiled, and the liquor, when mixed with bran or meal, is healthy, and inexpensive.

Insects. - Fowls will readily eat most sorts of insects. They have a decided liking to flies, beetles, grasshoppers, and crickets, and grubs, caterpillars, and maggots, are held by them in equal esteem. It is difficult, however, to supply the poultryyard with sufficient quantities of this species of food, but enough may be provided, probably, to answer as luxuries.

Where silk-worms are raised in great numbers, there is always abundance of the pupæ after winding off the silk, not required for breeding purposes, and these are good for poultry. Caterpillars, in their season, are also numerous, and easily secured. M. Parmentier says that too much insect food is not wholesome.

Dickson recommends that pailfuls of blood should be thrown on dunghills when fowls are allowed to run, for the purpose of enticing flies to deposit their eggs, which, when hatched, produce swarms of maggots for the fowls. With the same view, any sort of garbage or offal may be thrown out, if the dunghill is so situated that its exhalations will not prove an annoyance.

M. Reaumur mentions the circumstance of a quantity of wheat, stored in a corn loft, being much infected with the caterpillars of the small corn moth, which spins a web, and unites several grains together. A young lady devised the plan of taking some chickens to the loft, which devoured the caterpillars without touching a single grair. of the wheat. 


\section{METHODS OF FEEDING FOWLS.}

It is the advice of Richardson, whose counsel is always valuable, and to whom we acknowledge great indebtedness, not to feed hens too highly before they begin to lay, or while laying, or immediately after ceasing to lay, unless the design is to fatten them for the table; for as soon as a fowl begins to fatten, she stops laying. " "You must, therefore," says he, " separate the two classes of fowl, layers and fatteners, at all events at feeding time. Make some separate provision for your cocks; if they are only fed in company with the hens, they are apt to think too much of their mistresses, and to neglect their own appetites ; and recollect that to have strong chickens, you must have a strong cock, which an ill-fed bird cannot be expected to prove. You should also make separate provision for such fowl as are bullied or oppressed by the rest. Fowl are much given to jealousy; the cock's favor is sometimes the cause of this, but by no means invariably so; and, indeed, the cause is not at all times to be ascertained : however obscure the cause, it is incumbent on the poultry fancier to prevent the effect, by adopting the separative system at the times indicated.

In such an occurrence, which is easily recognizable by the cock's continually running at that particular bird, to the neglect, or comparative neglect, of the others, it is better to remove the favorite at once; if not, quarrels will ensue; this hen will nearly always be made a victim, and in many cases the quarrels on her account will give rise to other and more general affrays. On such occasions, the cock usually interferes and endeavors to establish peace; he almost invariably does so when the contest is carried on per duello; when, however, a number of his mistresses fall upon one, his interference is of little avail ; and, as if he were conscious of this, in such cases he usually leaves the poor favorite to her fate. I would not be so minute, but that I 
feel that these remarks, the result of long observation, will interest the naturalist as well as the mere poultry fancier. I have also known a cock to take a dislike to a particular hen; and, in one instance, he did not desist from his persecution till the poor thing died. This is a much more rare case than the preceding, and I have no doubt of its cause ; it is this, - when a vigorous, healthy cock is mated with very few hens, he is very persevering in his attentions to them; when hens are in moult, they will not accept of any such. In most instances of this kind, I have found the hen thus victimized by her lord to have been moulting, and to have incurred his hatred by a refusal of conjugal rights. The cock will sometimes fall upon a hen newly introduced into your yard, especially if of a different color from his other mates. This recently occurred amongst my own fowl, they being chiefly black Spaniards, and the new hen, a yellow Hamburgh. I tried the experiment of coloring the latter black; the cock no longer beat her, and he did not seem to notice the subsequent gradual renewal of the yellow, as the black wore off."

The substances which may be used in poultry feeding have already been described and particularized. But it is not advisable to feed fowls wholly upon one species of food; nor is it proper to confine them to one class of food. They require a mixture of green food with hard food, as much as cattle and horses do. As a general thing, dry grains are best for usual aliment, because much of the nutritious matter which they contain is lost by boiling. It is an advantage, also, to have the grain swell in the crop of the fowl, rather than to have it swollen previously. When, however, green food is necessary, if the birds are not so circumstanced that they ean find it for themselves, it must be provided for them. Richardson recommends that cabbages, lettuce, \&c., should not be chopped small, on the ground of waste, but that they should be fastened 
in some suitable place by their roots, so that the fowls may pick them themselves. This practice, by furnishing amusement, is deemed conducive to health; and there can be no doubt that innocent amusement is as beneficial to fowls as recreation is to man. When green food cannot be easily obtained, turnips or potatoes will answer as a substitute. These must be prepared by slicing them in moderate sized pieces, and never given whole.

One circumstance connected with the feeding of poultry, and that an important one, is not sufficiently well known, and that is the necessity they are under of obtaining azotized, or, in other words, animal, food. Of course, when the birds possess the advantage of an extensive run, they can themselves pick up worms, snails, or slugs; and, as in the case of ducks, \&c., frogs, and other small reptiles; but in cases where they do not possess this advantage, it is necessary that you cater for them. I have always experienced the best effects, especially as manifested in greatly increased laying, of giving scraps of animal food about twice or thrice a week to the fowl; the best mode of doing so is throwing down a bullock's liver, leaving it with them, and permitting them to pick ad libitum; of course, care must be taken that cats or dogs do not steal it; the liver is better given raw than boiled. Lights or guts, or any other animal refuse, will be found to answer the same purpose, but these substances require, or at all events are the better for, boiling.

Several substances have been at different times recommended as calculated to increase the fecundity of the various classes of the feathered inhabitants of the farm-yard ; amongst these, perhaps, hempseed and buckwheat are preëminent. There can exist no doubt of the peculiar efficacy of these seeds in this respect, when properly used.

When a hen pines, or seems disposed to be thin, there need be no hesitation in giving buckwheat with even a liberal hand; 
but it must be so managed as not to permit to share in this department of your bounty such hens as are disposed to become too fat. According as hens take on fat, they usually fall off in laying; and this should be particularly kept in mind in feeding. When hens are disposed to flesh, hempseed is the best promoter of laying; at the same time, it will be necessary that they should be restricted as respects other descriptions of food, fattening and laying being nearly always, if not absolutely so, incompatible with each other.

A varied dietary may be best illustrated by a description of the method of feeding for a single day. In the morning, about seven o'clock in spring or autumn, or at six in summer, the fowl may be let out, and permitted to roam about till nine, when grain may be given to the amount of about a handful to every three birds; they may then be left to amuse themselves, and in this time they will pick up a great deal. About three o'clock, they should be fed again on grain in about the same quantity as before, and such vegetable refuse may be added as is convenient. Some portion of animal food should generally be accessible to them all the time. In winter, all feeding, and especially of grain, should be increased in quantity, and particular attention should be paid to the substitutes for green food.

Cayenne pepper, in fact, all descriptions of pepper, but especially cayenne pepper in pods, will be found a favorite with fowls, and will be greedily devoured by them. It acts as a powerful stimulant, and is said to promote laying. When mixed with boiled meal, it is productive of the best effects, when given in moderation. Pepper will be found particularly useful in feeding young turkeys, as indeed all stimulating vegetables, such as horse-radish, \&c. Geese and ducks will eat greedily, as well as other fowls, of cabbage or other greens 
mixed with boiled bran; and this mess, with the addition of pepper, forms a valuable dietetic.

It is of great importance to remark, that, in order to promote natural and healthy digestion, quantity in the food is as necessary as quality, bulk is as requisite as nutriment. Improper combinations and concentrations are decidedly pernicious, and must be carefully avoided. This rule is as imperative in regard to other animals as to poultry; and a single fact will supply an apt and ample illustration. In some of the early importations of blood eattle from Great Britain, many of them died from want of hay, though they had sufficient corn, or concentrated nutritious matter, for their daily food. The reason was at once supposed to be that their diet, though excellent in itself, and amply sufficient to sustain life so far as its nutritive properties was concerned, was, nevertheless, deficient in the property of distending the stomachs of the animals, and thus to assist in the process of digestion. As it was impossible, on ship-board, to obtain a supply of the desired article, the person having charge of them hit upon a happy and successful expedient. He caused the extra pine spars on board to be shaved fine, and given to the cattle as a substitute for hay. On this food, mixed with their usual diet, the remaining animals entirely recovered before reaching the end of the voyage. Bulk is absolutely necessary to be considered in feeding the minor animals, and its use is to facilitate the peristaltic motion, and to promote the natural and healthy secretions. It is certain, moreover, that such food as does not swell in the stomach, and thus expand that organ, will, if constantly given, induce a well-defined dyspepsia, and all its consequent train of maladies, and the victim of ignorance and of earelessness must eventually die. 


\section{CHAPTER IX. \\ FATTENING OF FOWLS.}

Ir is a prime requisite in fowls brought to the table that they should be suitably fat, and the lean bird is neglected in the market and refused by the epicure. But unless some attention is paid by breeders to making their fowls fat, it will be found to be extensively true, that when left to themselves they will be rarely fitted for the purposes for which they are designed. The great desideratum seems to be to produce fowls which shall at once be healthy and likewise fat. Over-feeding is a sure cause of disease, and similar effects follow when the unfortunate fowls are too long and too closely confined. It may be well, therefore, to give some brief description of the nature of the substance called fat, and of what the process of fattening consists.

Fat is not a necessary part of any animal body. It is the form which superabundant nourishment assumes, which would, if needed, be converted into muscles and other solids. It is contained in certain membraneous receptacles provided for it, distributed over the body, and it is turned to use whenever the supply of nourishment is defective which should be provided by the stomach, and other great organs. It is in such emergencies, in the animal economy, taken up by the absorbents. If the absorbents, from any cause, act feebly, the health suffers. When, however, nourishment is taken into the system in greater quantities than is necessary for ordinary purposes, the absorbent vessels take it up. The fat thus made is generally healthy, provided there is a good digestion.

Nothing would seem to be plainer than the best manner of fattening poultry. To feed fowls with regularity, and plentifully on the best food, is the obvious mode. But experience 
and observation have shown that the desired object is attained with the greatest certainty and precision, by availing ourselves of certain auxiliaries to these, and by the adoption of fixed methods. Some of the old methods will now be described, and they are not only curious but useful.

\section{MASCALL'S MODE OF FATTENING.}

Chickens. - For the "fattening of bigge chickens," says Mascall, "in the coope or penne, they doe commonlye give them steeped breade in ale, sometimes of dry breade, and their drink, milke and water, or of soaked bran in milke; and sometimes ye must give them barly, and feel them one after another, if there be anything in their crops, for, if that which they have eaten is not gone or consumed, nor their craw yet emptie, that signifieth undigested and like not the meate, then give them no more till they have digested that. And for younger chickens, that goe yet with the damme, ye must not lette them go farre abroad, till they be strong, but lette them remayne with the henne in the house or penne, and give them oat-meale or barlymeale till they be stronger. Ye must see to have them in temperate places, not too hote nor too colde, for they may not (being yong) endure muche heate or muche colde, wherefore it were goode to keepe them temperate in the penne with the damme, fortye dayes, till they be more able to goe abroad. Ye must also clip the downe between their thighs, and under their rumpe, and see ofte unto them that their ventes may be issue."

Pullets. - "For the feeding and cramming of young pullets," continues he, "a verye good way is this to make them fat and tender to eate: ye shall keepe them in a dark place, or blindfold them; then take barlye ground small, and sifte out all the branne thereof, then they doe use to moysten this barlyemeale with warme milke; and some take ale, and some beare, so they cramme and feed them morning and evening, by giving 
them so much at once as they may well digest; and to helpe their digestion, some doe mixe with their meate of mustardseede, or anise-seedes. Thus ye may fat them in shorte space."

Hens. - "Because," he adds, "it is the common office of the countryman or woman to fat hens and poultrie, so likewise it is for the craftsman to buy, keepe, and sell them; and because it shall not be unmete for both sortes to feede them, ye shall understand ye must doe this: ye must prepare a warme place and darke, and put each henne by herselfe in a penne, made so narrowe that she cannot almost turne her therein, and those pennes must have on both sides two holes, the one to put forth her head, and the other her tayle and rumpe, and so to give her meate when she hath disgested that in her craw, and to cleanse her penne ofte, that her dongue doe not hinder her fatting. Ye must also put cleane strawe under her, or softe haye of the later season, for if they stand harde in the penne, they will scantily faste. Ye must place (cut) all the feathers on her heade and under her winges, and on her thighes; those of her heade and winges, because there shall come no lice to trouble her; the other feathers on her thighes, because the dongue shall not annoy and cumber her tuell. Her meate shall be barlye-meale made in paste with water and fashioned into pellets, longwaies, and so to make her swallow them. The first day it shall be better to give her but little meate, until she be accustomed to digest it, for above all, yee must see that she digest her meate well, and give her no more, so long as she hath any meate in her croppe; and when she is filde, let her go a little without the penne, so that she go not farre. And thus ye may see the general rule how to fat hennes; and if ye will have them fatte and tender withall, yee muste kneade your barlyemeale with water and honey, and that will fatte them and make them tender meat. Some doe put into three parts of water one part of wyne or strong ale, and steep wheaten brear there a, 
and that will also fat as well - ye shall have her fatte about the twentieth daye. Also, in the meane time, if she doe refuse her meate, ye must then diminish or give her lesse so many days as ye have fed her; the full tyme that ye should fatte her is but twenty-five dayes." (Husbandlie Ordering of Poultrie, c. 27 , black letter, 1581.)

\section{MARKHAM'S MODE OF FATTENING.}

Chickens. - "If you will have fat crammed chickens," says Markham, "you shall coope them up when the dame forsaketh them; and the best crammes for them are wheate-meale and milke, made into dough, and then the crammes steeped in milke, and so thrust down their throats; but in any case let the crams be small and well wet, for choaking. Fourteen days will feede a chicken sufficiently." (Good and cheape Husbandrie, p. 142.)

\section{BRADLEY'S MODE OF FATTENING.}

Chickens. - "To fatten chickens," says Bradley, "the best way and quickly, is to put them into coops as usual, and feed them with barley-meal : but in particular to put a small quantity of brick-dust in their water, which they should never be without. This last will give them an appetite for their meat, and fatten them very soon." He thinks the brick-dust acts, as gravel is so universally supposed to do, in bruising the food in the gizzard; an opinion experimentally investigated in a preceding part of this work. "This receipt," he adds, "I had from Mrs. Whaley, of Loftes, in Essex, a lady of great curiosity and ingenuity." (Country Gentleman's Director, p. 7.)

MODERN ENGLISH METHODS OF FATTENING.

Mr. Wakefield's. - In his extensive establishment near Livarpool, Mr. Wakefield fattened with steamed or roasted pota- 
toes given warm - which is indispensable - three or $\mathrm{fi}^{\boldsymbol{r}}$ times a day. The fowls were taken in good condition from the yard, confined in dry, well-ventilated coops, and covered in, so as to prevent the entrance of too much light. This method was attended with the greatest success.

Sir Isaac Coffin's. - The method recommended by Sir Isaac Coffin is said to produce quick results. He puts the fowls to be fattened in small cages or pens separately, so that they may be in a manner cased up, and so closely wedged in as to be able to move with great difficulty. These cages or pens must be placed in a warm situation, and the fowls crammed two or three times a day, by means of a cramming funnel, with the meal of barley, wheat, small millet, maize, or the like, soaked in milk. At first, this ought to be given in small quantity, in a rather liquid state, increasing this gradually till the crop be entirely filled. The whole of the cram must be digested before another be given, so that the process of digestion may not be disturbed.

Sir C. Cockerwell's. - The East Indian mode of fattening was introduced with great success, it is said, by Sir C. Cockerwell. The chief peculiarity is, that the cages or coops, made to contain only one fowl, are furnished, like the cages of singing-birds, with two sliding bottoms of wicker-work, which are changed and washed clean every day. The fowls are fed and crammed in the usual way, and the coops are put in a dark place, or covered with mats, to exclude the light. They become fat in a very short time. (Baxter's Library of Agriculture, 3d edition, p. 535.)

Similar methods are used in this country, and with complete success ; but Mowbray's ideas on this important subject seem to be most generally received, and the practice recommended by him is more extensively followed than any other. From his work, therefore, we extract the following hints and directions. 
"The well-known common methods are, to give fowls the run of the farm-yard, where they thrive upon the offals of the stable, and other refuse, with perhaps some small regular daily feeds; but at threshing-time they become fat, and are thence styled Barn-door fowls, probably the most delicate and highflavored of all others, both from their full allowance of the finest corn, and the constant health in which they are kept, by living in the natural state, and having the full enjoyment of air and exercise; or they are confined, during a certain number of weeks, in coops, those fowls which are soonest ready being drawn as wanted.

Feeding-houses, at once warm and airy, with earth floors, such as will be hereafter described, well raised, and capacious enough to accommodate twenty or thirty fowls, have always succeeded best, according to my experience. The floor may be slightly littered down, the litter often changed, and the greatest cleanliness should be observed. Sandy gravel should be placed in several different layers, and often changed. ' A sufficient number of troughs, for both water and food, should be placed around, that the stock may feed with as little interruption as possible from each other, and perches in the same proportion should be furnished for those birds which are inclined to perch, which few of them will desire, after they have begun to fatten, but which helps to keep them easy and contented until that period. In this mode, fowls may be fattened to the highest pitch, and yet preserved in a healthy state, their flesh being equal in quality to that of the barn-door fowl. I am aware that to suffer fattening fowls to pereh is contrary to the general practice, since it is supposed to bend and deform the breast-bone; but as soon as they become heavy and indolent from feeding, they will rather incline to rest in the straw; and the liberty of perching on the commencement of their cooping, 
has a tendency to accelerate the period when they are more inclined to rest on the floor.

It has always been a favorite maxim among feeders, that the privation of light, by inclining fowls to a constant state of repose, excepting when moved by the appetite for food, promotes and accelerates obesity. It may probably be so, though not promotive of health; but as it is no question that a state of obesity, obtained in this way, cannot be a state of health, a real question arises - whether the flesh of animals so fed can equal in flavor, nutriment, and solubility, that of the same species fed in a natural way? Pecuniary and market interest may perhaps be best answered by the plan of darkness and close confinement, but a feeder for his own table, of delicate tastes, and ambitious of furnishing his board with the choicest and most salubrious viands, will declare for the natural mode of feeding; and, in that view, a feeding yard, gravelled and sown with the grasses already described, the room being open all day, for the fowls to retire, at pleasure, will have a decided preference, as the nearest approach to the barn-door system.

Insects and animal food also form a part of the natural diet of poultry, are medicinal to them in a weakly state, and the want of such food may sometimes impede their thriving.

The London chicken butchers, as they are termed, are said to be, of all others, the most dexterous and expeditious feeders, putting up a coop of fowls and making them thoroughly fat within the space of a fortnight, using much grease, and that perhaps not of the most delicate kind, in the food. In this way, says. Mowbray, I have no boast to make, having always found it necessary to allow a considerable number of weeks for the purpose of making fowls fat in coops. In the common way, this business is often badly managed, fowls bcing huddled together in a small coop, tearing each other to pieces, instead of enjoying that repose which alone ean insure the wished-for 
object; irregularly fed and cleaned, until they are so stenched and poisoned in their own excrement, that their flesh actually smells and tastes of it when smoking upon the table.

All practical and practicable plans have their peculiar advantages; among others, that of leaving poultry to forage and shift for themselves; but where a steady and regular profit is required from ihem, the best method, whether for domestic use or sale, is constant high keep from the beginning, whence they will not only be always ready for the table with very little extra attention, but their flesh will be superior in juiciness and rich flavor to those which are fattened from a low and emaciated state. Fed in this mode, the spring pullets are particularly fine, at the same time most nourishing and restorative food."

Paine Windgate, in the Maine Farmer, says his experience tells him that the following process is the best mode of fattening hens. Shut them up where they can get no gravel. Keep corn by them all the time, and also give them dough enough once a day. For drink, give them skimmed milk. With this feed, they will fatten in ten days. If they are kept over ten days, they should have some gravel, or they will fall away.

A writer in one of our agricultural papers recommends the following:-Oats ground into meal and mixed with a little molasses and water, barley-meal with sweet milk, and boiled oats mixed with meat, are all excellent for fattening poultry, reference being had to time, expense, and quality of flesh.

The following practical suggestions should be attentively considered, and will, if followed, be productive of desirable results.

The least nutritious articles, so far as it can be done conveniently should be fed out first; afterwards, those that are more nutritive. Fattening fowls should be kept quiet, and suffered to take no more exercise than is necessary for their health. All exercise, more than this, calls for an expenditure of food, 
which does not avail anything in the process of fattening. They should be fed regularly, with suitable food, and that properly prepared, and as much should be given them as they are able to convert into flesh and fat, without waste. It should be remembered, as was stated in the early part of this chapter, that in the animal economy the accumulation of fat and extra flesh is only a deposit of superfluous nutriment, which, not being required by the system at one tirne, is laid by for future emergencies ; and it must be obvious that the larger the quantity of food which a fattening animal can be made to consume daily, with a good appetite, or to digest thoroughly, the greater will be the amount of flesh and fat gained in proportion to the whole quantity of food consumed.

Fowls will not thrive with any amount of food where they are uneasy and discontented, even if they were so closely confined that they cannot wear off their flesh by exercise; it is, therefore, important that they should be fed regularly, and tha: there should be nothing to disturb them, or excite fear or discontent.

The following hints on this subject, from that valuable agricultural journal, the Albany Cultivator, will be found of interest :

"'Substances in which the nutriment is much concentrated should be fed with care. There is danger, especially when the animal is first put to feed, that more may be eaten at once than the digestive organs can manage. Meal of Indian corn is highly nutritive, and when properly fed causes fowls to fatten faster than almost any other food. They will not, however, bear to be exclusively kept on this article for a great length of time. Meal made from the heaviest varieties of corn, especially that made from the hard flinty kinds grown in the northern and eastern States, is quite too strong food for fowls to be full-fed upon." 
Attention should also be paid to what is said in the chapter on food, in reference to the bulk of the food given to fowls. When fattening, let it not be forgotten, that sufficient bulk is necessary to effect a proper distension of the stomach, as a necessary condition of healthy digestion.

\section{CHAPTER X. \\ SELECTION OF STOCK AND PAIRING.}

$W_{E}$ are not sufficiently acquainted with the habits of the common fowl, in a wild state, to know whether the cocks always associate with the hens, or only occasionally. Though hens will lay some eggs without pairing, as this is not natural, the number will, for the most part, be less, and the laying uncertain; and hence it is indispensable to attend to the laws of nature in this respect.

Columella is perhaps among the earliest authorities who can be cited on the subject of the breeding and management of poultry. The following is his opinion as to the number of hens which should be allotted to an individual cock :-

"Twelve hennes shall be sufficient for one good cocke, which will cause them to be rather of one coloure, and yet," sayeth he, "our auncestors did use to give but five hennes to one cocke, which caused them rather to be of divers coloures, some white, some gray, some reddish, and some tawnye, some blacke, and some of a speckled coloure, which are not thoughte to be so good as the red and gray speckled: and to have the hennes all of one coloure (some the white) are best, and they are counted the best laiers." (Mascall, c. 15.) Stephanis repeats the directions of Columella. 
Bradly, in his Farmer's Director, advises one cock to be left with seven or eight hens, and hints that if a greater number be allowed him, the eggs will not prove fertile. The author of the Complete Farmer, and the writer of the article on poultry in Rees' Encyclopadia, recommend the same number.

M. Parmentier, a very eminent French writer, says, that one cock is much more than sufficient for fifteen, or even twenty hens, provided he be a young, vigorous, and healthy bird.

Those who breed game fowl for combat, and whose object is, of course, the production of strong chickens, limit the number to four, or at most five. Mr. Mowbray says, that in winter, or cold and damp weather, a cock should only have four hens. M. Bose (Encyclopedia Methodique) says, that in spring alone should any cock have fewer than twenty hens. Mr. Dickson says, that the number of hens allowed to one cock should vary with the object you have in view.

If you look for profit to the production of eggs alone, one cock - if a stout, young, and lively bird - may have as many as twenty-four hens. If, however, you want to obtain strong and thriving chickens, you must restrict him to at most five. If your object be the improvement of a worn-out or degenerate breed, the fewer hens you allow to one cock the better, and you should not, at any rate, allow him more than three.

\section{SELECTION OF A GOOD COCK.}

On this subject, Mr. Dickson may be safely followed, as presenting sound counsel, doubtless the result of faithful study, and long experience. He says :-

The old writers were very particular in giving the good properties of cocks, as much so as our cattle-breeders at present, in similar circumstances. According to Columella, who is so frequently copied without acknowledgment, "It is not good to keep a cocke, if he be not stout, hot, and knavishe, and of the 
same color as the hennes are, with as many clawes. But, in his body, to be hier raised, his combe to be hye, and red as blood, and straight withall, his eyes blacke, or azure coloure, his beke short and crooked, with a gray crest, shining like red or white, and all his feathers, from the head to the breast, to be of a changeable coloure, varying like gold or yellow; his breast large and bigge; his muscles on his wings bigge, like one's armes, with long wings; his tail fayre and long, with two ranks of crooked and rising feathers; and to be oft crowing, is a sign of lusty courage. The red color is thought to be the best cocke, his legges short and stronge, his thyes greate and thicke, and well covered with feathers, and armed with long spurs, rough and poynted, - strayhte of body, light, fyerce, eager in battayle, vigilante, readye, and often crowing, and not easily fearde." . (Mascall, c. 3.)

Markham does not differ much from the preceding. $\mathrm{He}$ says - "The cock should be of a large and well-sized body, long from the head to the rumpe, and thicke in the girthe; his necke should be long, loose, and curiously bending, and his body together being straight and high uprected, as the falcon, and other birds of prey are; his combe, wattles, and throat, should be large, of great compasse, jagged, and very scarlet red; his eyes round and great, the colour answering the colour of his plume or male, as gray with gray, red with red, or yellow with yellow; his bill should be crooked, sharpe, and strongly set on to his head, the colour being suitable to the colour of the feathers on his head; his mayne, or neckefeathers, should be very long, bright, and shining, covering from his head to his shoulders, his legs straight, and of a strong beame, with large long spurres, sharp, and a little bending, and the colour blacke, yellow, or blewish; his claws short, strong, and wrinkled; and his tail long, and covering his body very closely." (Cheap and Good Husbandrie, p. 138.) 
The choice of a cock, says M. Parmentier, is a very important thing. $\mathrm{He}$ is considered to have every requisite quality, when he is of a good middling size, when he carries his head high, has a quick, animated look, a strong and shrill voice, short bill, a fine red comb, shining as if varnished, wattles of a large size, and of the same color as the comb, the breast broad, the wings strong, the plumage black, or of an obscure red, the thighs very muscular, the legs thick, and furnished with strong spurs, the claws rather bent and sharply pointed. He ought also to be free in his motions, to crow frequently, and to scratch the ground often in search of worms, not so much for himself, as to treat his hens. He ought, withal, to be brisk, spirited, ardent, and ready in caressing the hens, quick in defending them, attentive in soliciting them to eat, in keeping them together, and in assembling them at night.

In breeding game cocks, says Mr. Dickson, the qualities sportsmen require in a brood cock are every mark of perfect health, such as a ruddy complexion, the feathers close, short, and not feeling cold or dry; the flesh firm and compact, while he ought to be full-breasted, (betokening good lungs,) yet taper and thin behind; full in the girth, well coupled, lofty and aspiring, with a good thigh, the beam of his leg very strong, the eye large and vivid, the beak strong, crooked, and thick at the base.

All authorities agree, that a cock is in his prime at two years old, though we have ourselves had cocks of four months so precocious as to show every mark of full vigor, while others of the same brood did not appear in this state for many months afterwards.

It is by no means unfrequent, however, to see unskilful persons keep cocks with their hens for six or eight years, when they are quite useless, though they may live on even till the 
age of twenty years. At three years old, a cock begins to lose the sprightly gait and bright color which distinguished him at two. The length of his feathers increases, and his hackles become of too loose a texture, and dangle over his throat. $\mathrm{He}$ then becomes lazy, languid, and inactive, and is fonder of sunning himself, and of pulverizing in the dust, than of attending to the hens.

As soon as the marks of declining vigor are perceived, the cock must be displaced, to make way for a successor, which should be chosen among the finest and bravest of the supernumerary young cocks, that ought to be reared for this special purpose. In making a choice between two cocks, which appear equally fine and vigorous, try them by making them fight together, and select the conqueror; for, as M. Parmentier well remarks, hens, like other females, always prefer the male who shows most courage and spirit.

The change of cocks is of much importance, and is frequently very troublesome to manage; for peace does not last long between them when they hold a divided dominion in the poultry-yard, since they are all actuated by a restless, jealous, hasty, fiery, ardent disposition, and hence their quarrels become no less frequent than sanguinary. A battle soon succeeds to provocation or affront. The two opponents face each other, their feathers bristling up, their necks stretched out, their heads low, and their beaks ready for the onslaught. They observe each other in silence, with fixed and sparkling eyes. On the least motion of either, they stand stiffiy up, and rush furiously forward, dashing at each other with beak and spur in repeated sallies, till the more powerful or the more adroit has grievously torn the comb and wattles of his adversary, has thrown him down by the heavy stroke of his wings, or has stabbed him with his spurs.

This pugnacious character arises wholly from the jealous 
disposition, originating in the cock's salacity. " Now," says Mascall, after Columella, speaking of a jealous cock, " to slake that heate of jealousie, ye shall slitte two pieces of thicke leather, and put them on his legges, and those will hang over his feete, which will correct the vehement heat of jealousie within him." - (Husbandlie Order. and Govern., c. 3.) "Such a bit of leather," says M. Parmentier, "will cause the most turbulent cock to become as quiet as a man who is fettered at the feet, hands, and neck."

The cock is fond of cleanliness, and very careful of the appearance of his plumes; and hence he may be frequently observed pruning and dressing his feathers with his bill : and, although he may not have the ambition, like the nightingale and the thrush, of excelling in his notes, it may be inferred that he is particularly jealous of proving his voice to be loud, shrill, and powerful. Hence, when he has crowed in his strongest manner, he always listens to know whether he may be answered by any rival, or neighbor ; and, if so, he replies by a strain, if possible, louder and bolder than the first. - Dickson.

M. Parmentier recommends the cock to be chosen of a middling size, carrying the head high, having a quick, animated look, strong, shrill voice, short bill, very red comb, large wattles, broad breast, strong wings, black or dull-red plumage, thighs muscular, spurs strong, claws bent and sharp, free in his action, a frequent crower, and frequently scratching the ground in search of worms; not, however, for himself, but to treat the hens.

"Not to weary my readers," says Richardson, "with an unnecessary citation of too many authorities, I may just observe, for their direction, that the cock should be in perfect health; feathers close and rather short; chest compact and firm ; full in the girth ; lofty and elastic gait; large and firm thigh; beak short, and thick at its insertion. 
Next to health and strength, age is to be duly considered. Neither select a cock that is too old, nor one that is too young; let the age be from a year and a half to three years and a half. Some cocks retain their vigor till they are even past six years old ; and some make a display of unquestionable virility at the premature age of five or six months. It is far better, however, for the fancier 'to be sure than sorry.' Secure a young and vigorous bird, at the summit of his prime; steer equally clear of premature and often deceptive developments, and of incipient age and decrepitude; avoid all extremes."

\section{CHOICE OF A HEN.}

In the opinion of Markham, the selection of a good hen is a matter of even more consequence than that of the cock for her companion, and he insists on " gray, grissell, speckt, or yellowish - black or brown is not amiss." This antiquated counsel, however, is entirely out of date ; and the many varieties of fowls introduced into the poultry-yard, since Markham's day, render his opinions, as to color, of little value.

Mascall, following Columella and Stephanus, says: "The signs of a good hen are these - a tawny color, or a russet, are accounted the chiefest colors; and, next, those hens which have the pens of their wings blackish - not all black, but partly so. As for the gray and the white hens, they are nothing so profitable."

This, also, was once valuable advice; but on this subject, in the present age, as each of the valuable varieties has its own peculiar hue, some other criterion must be adopted for selection. The general aspect, size, and habits of a particular bird, are chiefly to be regarded.

In breeding game cocks, sportsmen are very particular in selecting their hens; "for," says Gervase Markham, "they are like birds of prey, in which the female is ever to be pre- 
ferred and esteemed before the male; and so, in the breed of these birds, you must be sure your henne be right, that is to say, she must be of a right plume, as gray, grissell, speckt, or yellowish - blacke or browne is not amisse. She must be kindlie to her young, of large body, well pockt behind for large egges, and well tufted on the crowne, which shewes courage." (Pleasures of Princes, p. 41.)

Sketchley gives somewhat different properties for a game hen, which should not, he thinks, be large, making up for deficiency in size by the size of the cock; but, like the cock, they should have lofty necks, short and close feathered, with clear, sinewy legs, not giving way in the bone, well-set thighs, and long, clean, taper toes.

"When hens," says Lawrence, " have a large comb, or crow like a cock, they are generally deemed inferior; but he has, notwithstanding, had hens with large rose combs, and also crowers, equal to any in his stock."

M. Parmentier tells us, that in selecting hens, they should be chosen of a middling size, of a black or brown color, of a robust constitution, and with a large head, bright eyes, the comb pendent, and the feet bluish. He advises to reject crowers, and such as are savage, quarrelsome, or peevish, because such are seldom favorites with the cocks, scarcely ever lay, and do not hatch well. He also properly rejects old hens, meaning such as are above four or five years; as well as those which are too fat, and those whose comb and claws are rough, this being a sign of their having ceased to lay.

After the common hen, which, on account of her fecundity, is deservedly esteemed, the tufted hen may be, according to M. Parmentier, justly ranked, particularly from being more delicate eating, because she fattens more readily, on account of laying less. The large breed, though less prolific, is preferable in rearing chickens for the market, or for making capons. 
The general opinion of breeders, with regard to these three sorts, is, that the first is more prolific in the number of eggs, while the others produce larger chickens, which bring good prices.

"In the choice of a hen for sitting," says Richardson; "look for a large bird, with large, wide-spreading wings. Though large, however, she must not be heavy, nor leggy. No one of any judgment would sit a Malay, as, in such case, not only would many eggs remain uncovered, but many, also, would be trampled upon and broken. Elderly hens will be found more willing to sit than young and giddy pullets; indeed, the latter should never be allowed to sit, until, at least, the second year of their laying.

The Spanish fowl are not generally good sitters; but they are excellent layers. The Dorking reverse the order, being better sitters than layers; and these qualities will also be found to extend pretty generally to hens partaking of the prevailing colors of these two varieties, the black being usually the best layers, and but careless or indifferent sitters, while gray or checkered hens (especially such as have light-colored legs) are the best you can procure."

\section{CHAPTER XI. \\ ON BREEDING FOWLS.}

Is all works treating of poultry which have fallen under our observation, there is a lamentable deficiency in information respecting the important subject of breeding. When the topic is touched upon, amid meagre details and questionable principles, there is a loose and indefinite use of terms, which serves only to distract and confuse the inquirer. No doubt, much of 
the evil here complained of is to be attributed to the fact that most of the works hitherto produced on poultry are not the productions of practical men, but only comprise the lucubrations of the closet. Fowl-breeders, too, have never been forward to communicate such information as is derived from their experience; the amateur seldom feels any inducement to do so ; and the breeder, whose only object is profit, is well content to preserve his secrets, and secure the gain.

A few general principles, well understood and faithfully applied, will prove of great value; and the contents of this chapter, therefore, though they may wear an air of novelty to many, we are persuaded will be acceptable to all interested in poultry-breeding.

The various kinds of breeding are denominated " in and in," "close," " mixed," or " promiscuous." " High breeding" is also a term used with significance. Great confusion is often experienced in distinguishing between " in and in" and "close" breeding, but a single definition will immediately remove all ground for misapprehension. When we speak of " in and in" breeding, the meaning is simply that the breeding is by commerce between individuals of the same brood; or, if the term be allowed, between brother and sister. "Close" breeding is by commerce between the parent and his offspring, in whatever degree. "Mixed" breeding is sufficiently intelligible, being the connection between different breeds or varieties.

Crossing the Breed.- To insure successful and beneficial crossing of distinct breeds, in order to produce a new and valuable variety, the breeder must have an accurate knowledge of the laws of procreation, and the varied influences of parents upon their offspring. All the breeds in this country are crosses, produced originally by accident or design. Crossing does not necessarily produce a breed; but it always produces a variety, and that variety becomes a breed only when there is sufficient 
stamina to make a distinctive race, and continue a progeny with the uniform or leading characteristics of its progenitors.

High Breading. - When uniformity of plumage can be effected in mixed breeds or varieties without a resort to " in and in" or "close" breeding, and without sacrificing the health and vigor of the race, it is desirable, and, in many instances, it can be accomplished satisfactorily. In most cases, however, what is called "high" breeding is a mere humbug, being utterly absurd, and at variance with the fixed laws of nature, and with common sense. Too often, what are called "highlybred fowls" are the deteriorated offspring of progenitors far below the original stock. Most that goes under the name of " high breeding," at the present day, is neither more nor less than "close" breeding, for a succession of generations, back towards the primal stock, generally resulting in manifest degeneracy.

Real high breeding consists in the selection of parent stock of the same race, perfect in all the general characteristics, and of remote consanguinity. This should be resorted to periodically, in order to secure the best results.

The following physiological principles have an important bearing on this subject, and the analogy of nature will hold good in respect to domestic fowls :-

1. When animals, differing in order, genus, and species cohabit, no offspring results.

2. Where animals of the same order, differing in genus and species, resort to sexual congress, the progeny is sterile in the first generation, as with the mule, the mongrel-goose, etc. Occasional exceptions occur, but not enough to invalidate the principle.

3. Where animals of the same order and genus, differing in species or variety only, have sexual intercourse, the progeny becomes barren in the second generation, as with the mulattoes. 
Among mulattoes, where both male and female are of the second generation, there is no product resulting from copulation; though either will produce when united to one of the first or third generation, or with a white or black.

4. Where animals of the same order, genus, and species cohabit, all the ova which are fully matured and perfected, are impregnated either with or without the venereal orgasm on the part of the female. In the human species, whatever number of ova are matured and susceptible of impression at the time of any specific coitus, are impregnated, be they more or less. IIence, we frequently hear of twins, triplets, and even quadruplets, and superfoetation sometimes takes place, even of another race. Instances of this may he found recorded in Bard's Compendium of Midwifery, N. Y., 1819, pp. 53 and 54, and in the Boston Medical and Surgical Journal, vol. xLI., p. 188.

In an article on the generation of mammalia and birds, in the London Lancet, vol. 1., No. 2, (for 1850, new series,) p. 167 , it is said -

"Dr. Delfraysse, of Cahors, in France, lately made several experiments on various species of mammalia and birds, regarding the influence of the male upon the offspring. He found, by bringing individuals of different species together, that the first coition merely imparts life to the ovum, and that the subsequent ones bestow the cclors of the male upon the young; for, the more coition was repeated, the more likeness did the offspring bear to the parents." These views were submitted to the Academy of Sciences, of Paris.

If a race is pure - that is, if the species or variety is absolutely distinct and unsophisticated - the progeny resembles the progenitors in almost every respect. The color of the hair, the complexion, habits, general aspect, etc., will be similar. This is exemplified in the North American Indian, the Jews, \&c. If, however, a race is made up of mixed blood, as, for 
instance, the Anglo-Saxons, the children do not, necessarily, resemble their parents; and children of the same parentage differ widely from one another. Frequently, too, they have no resemblance to their parents. It may be observed, also, that when the race is pure, there is less danger from intermarriage than when the race is mixed.

The mixture of races, where the consanguinity is remote, is of decided benefit, producing greater intellectuality, energy, enterprise, and vigor, and improves the general appearance. This is peculiarly observable when a race of extraordinary mental power is mixed with a race of surpassing animal vigor.

These remarks apply to fowls. When the blood is unmixed, as with the Guelderlands and some others, the offspring, in all respects, resemble their parents, in plumage, general outline, form, habits, etc. They look almost identically the same in this case. But when the blood is mixed, as with the Cochin Chinas and many others, the plumage will vary widely, or slightly, according to circumstances, though many or most of the general characteristics may remain the same. The close breeding, to which many resort to produce uniformity, generally results in an absolute deterioration of the race in important respects.

There are instances in which the laws of nature seem to require " in and in" breeding, as with the race of domestic pigeons. As a general thing, the female lays two eggs at a litter, and from these two eggs a male and female is almost universally produced. They again, when of mature age, breed " in and in," and so they continue to do for successive generations, for hundreds of years, without the least deterioration; from the fact that the laws of procreation, as applicable to them, require it as the rule, the converse being the exception; and from the fact that they are perfect of their kind, or of pure 
breed, never varying, except by crossing, and never degenerating, except by confinement.

In other cases "close" breeding - and occasionally " in and in" - seems to be in accordance with the laws of nature, as with the wild turkey. Wild turkeys, in their natural state, most generally resort to "close" and "in and in" breeding; still the race does not change in appearance, or degenerate.

The rationale is - the breed is pure. In comparing tens, hundreds, or thousands of these noble birds of the forest, you cannot discover the least dissimilarity - all look alike - they always have, they always will. They are changed, or deteriorated, only by crossing or confinement.

Most breeds of the hen kind degenerate rapidly upon breeding " close," or " in and in," from the single fact, mainly, that they are not perfect of their kind ; that is, the breed is not pure, but of mixed blood; and in such objectionable breeding, the race degenerates just in proportion as the breed is imperfect, or impure. The perfect Guelderland will admit of "close," or " in and in," breeding, for a great length of time, without deterioration; but the impure, or mixed, will rapidly degenerate under such breeding. This is true also of all breeds wherein the characteristic marks are uniform and confirmed, showing perfection in the race. As a general thing, the breeders should carefully avoid "close" and "in and in" breeding where the race is not absolutely perfect, if they wish to improve the breed; and as all the breeds of this kind of fowls - (the hen kind) - are of mixed blood, the danger of such breeding is less or greater, in exact proportion, as the distinctive characteristics are fixed or variant; and the danger still increases if the breed is composed of bloods greatly dissimilar, or of races widely differing in their conformation, or general habits.

These remarks are equally applicable to quadrupeds. If the 
breed is pure, as with the rabbit ; you can breed "close," or " in and in," with perfect impunity, and nature seems to favor the process; for in a state of nature they almost uniformly resort to that manner of breeding, and the race remains precisely the same throughout all generations, unless they are crossed or confined. But if the animals are of mixed blood, as is the case with cattle, horses, etc., etc., such breeding must be carefully avoided, or the race soon runs out - first degenerating in size, then producing cripples, and deformed, rearless offspring ; and then terminating in impotency and sterility.

Preserving the Distinctive Breeds. - The question is frequently asked - "How soon should the different breeds of hens be separated in the spring, in order to preserve the breed pure?" Upon this subject there has been much speculation by our most able writers, but theory, in this instance at least, is at variance with facts. The most ample experience has indicated to us that the eggs may be preserved and set after a separation of two days, and the breed will be perfect, the offspring having all the characteristics, or distinctive marks. I have frequently taken a laying hen of one breed, and put her with a male of another breed, and set the egg laid on the second day thereafter, and the chicken had all the characteristic marks of both breeds of the parentage. This was the case when I first hit upon the famous Plymouth Rock breed, which now promises, all things considered, to be one of the best breeds in the country. The first of this breed was thus accidentally produced, and the experiment was followed up to a desirable result.

When a valuable breed is thus produced, either by accident or design, it should be preserved, and the subsequent breeding should continue from that stock; otherwise, there is no certainty of the purity of the blood of the new breed, for it does not follow that a different parentage, though of the same name or original breed precisely, will produce the same new breed, or 
anything resembling it. For instance, the Dorking fowl was originally produced by crossing the Great Malay with the English Game fowl, as an accident ; but it by no means follows, that Dorkings are the uniform, or even the common result of such a cross, for hundreds of such experiments have proved unsuccessful. In order, then, to produce pure Dorkings, the breeding must continue from the original stock, carefully avoiding "close" and "in and in" breeding. The same may be said of the Plymouth Rock fowl, for I have repeatedly tried, and as often failed, to produce this excellent breed from a similar parentage. The breeding, therefore, to be pure-blooded, must continue from the stock originally obtained by accident; and as such breeding produces the leading characteristics of the race, with great uniformity, the genuineness of the breed cannot be doubted. In order to produce a good cross, the parentage should be healthy, and from healthy races, not materially dissimilar in their general characteristics. The material points are: Are the fowls large, fine-fleshed, gentle and domestic in their habits, good layers of rich and well-flavored eggs? - (for the eggs of some breeds are twice as valuable as those of others, on this account - for instance, one egg of the pure Cochin China fowl, of the Baylies' importation, contains nearly as much nutritious matter as two eggs of the Black Poland or Golden Pheasant fowl, and is, consequently, much richer, better flavored and more valuable,) - close sitters, careful nurses, tractable, etc., etc.? and symmetrical conformation and gaudy plumage are general accompaniments to the foregoing essential prerequisites. The size of the leg should always be looked to, to judge accurately as to purity of blood. If the leg is large for the breed - that is, if larger than the generality of the same breed you can rely upon the purity of the blood, the fineness of the flesh, and most of the other valuable qualities; but if the legs are smaller than most others of the same breed, rely upon it, 
the fowl is spurious, and of deteriorated blood. The fifth toe and feathered legs of some breeds were originally the result of accident, but by long and careful breeding, they have become incorporated into the nature of certain races as general, though not universal or essential, requisites. When a fowl exhibits any special marks indicative of all the races or breeds from which the cross originated, it is a sure evidence of extraordinary purity of blood, and of the superior excellence of the race. The best fowls of the race should always be selected for crossing or for general breeding; otherwise, the breeds will degenerate.

The quality - that is, the fineness, juiciness and richness of flavor - of the flesh of domestic fowls, is of much more importance than their size; and I consequently reject all coarsemeated fowls, however large they may be. There is no difficulty in discriminating between coarse and fine fowls, at any time. When chickens, if the down is straight and stands out, and the body and limbs are loosely joined, the meat is coarse ; but if the down is glossy, and lies close to the body, and the body and limbs are compactly formed, the meat is fine: and when grown, if the fowl is light in weight, in proportion to its size, the flesh is coarse; but if heavy, the flesh is fine. There is also a fitness in the quality of the flesh; for if the meat is fine, the bones are fine, and the feathers are fine, and vice versa. If the flesh is fine, it is juicy and richly flavored; if coarse, dry, fibrous and insipid. The color of the legs, too, is quite material, in judging of the quality of fowls. All other things being equal, dark-legged fowls have the finest flesh, and are the most hardy. Turkeys, which have the finest flesh of any fowl of their size, have black legs; pheasants, partridges and quails, all of which are very fine-fleshed fowls, have dark legs; the game cock likewise, which is universally acknowledged to be the finest fleshed of any of the domestic fowls, except the Wild 
Indian fowl of Calcutta, has dark legs. I do not wish to be understood, however, to say that all dark-legged fowls are fine, or that all yellow or white legged ones are coarse, for much depends upon the breed; but I do say, that the darkest leg which pertains to the breed indicates the finest fowl. For instance, the Shanghae Cochin China fowls - of the pure blood - always have their legs of a bright red and yellow mixture, beautifully shaded together. Now, if you wish to select a fine fowl of this breed, choose one of the darkest shade of these colors. The Great Java fowl, of pure blood, uniformly has black or very dark legs; and if you wish a fine-fleshed one of this breed, select one with the blackest legs. The Black Poland fowl, of pure blood, has white or blue legs; select the blue for the finest, - that is, select the darkest of the natural color, whatever that color may be. Fowl-fanciers always select yellow legs; but fowl-eaters - that is, those who regard the quality of the bird - select dark legs. The color of the feathers, too, has more or less to do with the quality of the fowl. Some breeds have much more brilliant plumage than others; but when we speak of the brilliancy of the plumage, we mean in comparison with others of the same breed. If, therefore, you select a fowl of rich and glossy plumage, when compared with others of the same breed, depend upon it, the legs will be dark of the kind, and the quality of the bird will excel.

The best breeding is to cross or mix the races. This process improves the breeds, in all respects. The best mixture is the Yankee Game with the Cochin China fowls. This produces a race of equal proportions of Wild Indian Game, Spanish Game, Chittagong, and Shanghae. Such a mixture gives great size, fine flesh and brilliant plumage; and at the same time the breed will be very prolific. The increased length of tail, the brilliancy and uniformity of plumage, and the quality 
of the flesh, in this quadruple mixture, is a very decided improvement on the Cochin China fowl. The variety here described is called the "PrIDE of INDIA," and is undoubtedly the best cross known.

The following may be taken as brief practical directions to be followed in the business of breeding :

When the object in view is to perpetuate distinct varieties of uncontaminated blood, the first requisite is to procure fowls known to be of pure blood, and possessing all the necessary characteristics of their kind. Labor is lost unless the fowl selected is a perfect specimen of his variety, for whatever imperfection exists is likely to be perpetuated in the progeny. Regard should be had to plumage, to size and form, in making a selection either of a cock or a pullet, and those are preferable which are hatched earliest in the year. The age of the fowls is a matter of considerable importance, and though it is true that a pullet will lay the greatest number of eggs in her first year, yet it is believed that the chickens which are hatched from the second year's eggs are more vigorous and hardy. Old h'ns are preferred to pullets generally as sitters, on account of their more sedate and matronly character. A young cock, though more active in his earliest days, and likely to bestow his attentions on the hens with less reserve, is not, however, best for use in keeping up a breed. The eggs impregnated by him after his first season are likely to produce the strongest chickens. It is an error to suppose that his procreative power is decayed or vitiated, as is often represented, after three or four years. On the contrary, a healthy, vigorous cock, if not allowed to walk with too many hens, may be valuable and useful in the poultry-yard for a longer time.

An error is often committed by giving too many hens to one cock, and the result is a weakly and otherwise deteriorated progeny. Not more than five hens should ever be allowed to 
associate with a single cock, when the quality of a breed is a matter of interest. Three would be the better number for restriction, but five is the furthest limit which can be safely assigned.

Most persons, in obtaining a single vigorous cock and hen of a desirable variety, find their anticipations more than realized in the production of a fine progeny. The plumage is brilliant, and the chickens are of increased size, and remarkably strong and healthy. This happy state of things continues so long as the cock is restricted to a small number of hens. So soon, however, as his harem is enlarged, different effects are manifested, and a deterioration in the stock is clearly observable. This is not to be attributed to close breeding, but to the increased disproportion of females to the male, and the consequent overtasking of his virile powers.

In breeding-time great cleanliness should be observed in the lodgings of the fowls, and the quantity and quality of the food is a matter of great consequence. They should not be suffered to feed to repletion, and such kinds of food as are most nutritious should be carefully provided. Variety of food is essential, and a proper proportion of animal and green food should be given with their usual fare.

Suitable arrangements should, of course, be made to prevent any intermixture of different breeds. A ceaseless vigilance in this respect is the price of success, and when all proper precautions are taken, the breeder may rest in a perfect security that his anticipations will be realized.

In the report of the Committee of Supervision, at the late Convention of Fowl Fanciers and Breeders, are many remarks which deserve attention. The following, especially, are of permanent value, and are inserted with pleasure as a suitable conclusion to this chapter :

"Generally, the system of breeding poultry is conducted in 
the most loose and unscientific manner, and no real dependence can be placed on other than the purest stock. By selecting it, the articles early maturity, large size, and liberal produce, are surely to be depended upon; whereas, by indiscriminately adopting impure stock, there is no security that these will result.

Under the loose system of breeding referred to, it is equally impossible to keep up, as it is to establish, a distinctive breed of poultry. To conserve the purity of any variety, so that 'like will produce like,' in appearance and properties, is of the highest importance - is, in fact, (next to the securing of these in a distinctive shape,) the grand aim of the scientific breeder. There are no errors, or indications of the work of chance, in the law and order of the Great Ruler of the universe, as these apply to either the animal or vegetable kingdoms. The farmer may as well collect a miscellaneous list of seeds, and strew them athwart his soil, in the expectation that an excellent crop of corn should be produced from them, as the poultry-breeder depend on the heterogeneous admixture of mongrel breeds of fowls, to produce improved specimens. A chance appearance may be made among them, to be sure, that might look promising, in the same way that one ear of corn might appear among the farmer's produce; but, unlike the ear of corn, the ' bird of promise' can never be depended on to produce its like: the absence of mathematical exactitude in the animal composition forms an organic error in it, which nothing can obviate, so far as itself is concerned. It may produce all or any of the kinds, or crosses, concentrated in itself, but none of them in their pure distinctiveness ; the leaven of deterioration will always be found a ruling element in their composition.

We have alluded above to a difficulty involving the greatest care in preserving the different varieties of fowls distinct; and this difficulty attaches to the improved crosses as well. To 
blend the characteristics of the two separate breeds, so that there will be no undue preponderance of the blood of either in the produce, is a work of great labor and the most jealous care. The process must be carried on with the same degree of exactness, and be accompanied with as much careful calculation, as an astronomer would use to satisfy himself regarding the future appearance of a comet. Many generations of fowls must be operated upon, before anything like perfection can be attained. This being the case, it is perfectly evident that it becomes imperatively the duty of fowl-breeders to apply their care and observation to the preservation of pure stock, as upon that, and that alone, the profit of their labor depends."

\section{CHAPTER XII.}

\section{LAYING.}

IT would seem a providential arrangement, in behalf of man, that the domestic hen should be endowed with so great fecundity. The ordinary productiveness of a single individual of the species is astonishing. While few hens are capable of hatching more than fifteen eggs, and are incapable usually of sitting more than twice in the year, frequent instances have occurred of hens laying three hundred eggs annually, while two hundred is the average number. Some hens are accustomed to lay at longer intervals than others. The habit of one variety is to lay once in three days only; others will lay every other day, and some produce an egg daily. A hen, exhibited at the American Institute, in 1843, was reported to lay two eggs per diem, and Aristotle mentions a breed which laid as often as three times a day. 
Undoubtedly much depends on circumstances, as to the productiveness of hens. Climate has a great influence in this respect; and the lodging, food, and care which is bestowed upon these animals, have more or less effect in promoting or obstructing their fecundity,

There seem to be naturally two periods of the year in which fowls lay, - early in the spring, and in the summer; and this fact would seem to indicate that, if they were left to themselves, like wild birds, they would bring forth two broods in a year. The laying of hens continues, with few interruptions, till the end of summer, when the natural process of moulting causes them to cease. This process, which is annual, commences about August, and continues through the three following months. It is the constitutional effect which attends the beginning, continuance, and consequences of this period, which prevents them from laying. This period is a very critical one, in the case of all feathered animals. Until its very close, when the entire coat of new feathers replaces the old ones, the wasting of the nutritive juices, which are yielded by the blood for the express purpose of promoting this growth, is a great drain upon the system. It is easily understood, therefore, why the constitutional forces, which would otherwise assist in forming the egg, are rendered inoperative. The approach of cold weather, also, at the close of the moulting period, contributes to produce the same effects. As the season of moulting is every year later, it follows that the older a hen is, the later in the spring she will begin to lay. As pullets, on the contrary, do not moult the first year, they commence laying sooner than the elder hens; and it is possible, by judicious and careful management, so to arrange, in a collection of poultry tolerably numerous, as to have eggs throughout the year.

Mr. Dickson makes the following observations in regard to 
signs of desire, on the part of hens, to lay, and concerning the process :

"When a hen is near to the time of laying, her comb and wattles change from their previous dull hue to a bright red, while the eye becomes more bright, the gait more spirited, and she occasionally cackles for three or four days. These signs rarely prove false; and when the time comes that a hen wants to lay, she appears very restless, going backwards and forwards, visiting every nook and corner, cackling the while, as if displeased because she cannot suit herself with a convenient nest. Not having looked out for one previously, she rarely succeeds in pleasing herself till the moment comes she can no longer tarry, when she is compelled to choose one of the boxes or baskets provided for this purpose in the fowl-house. There she settles herself in silence, and lays.

In some instances, a hen will make choice of a particular nest to lay in, and when, on desiring to lay, she finds this nest preöccupied by another hen, she will wait till it is vacated; but, in other cases, hens will go into any nest they find, preferring, for the most part, those which have the greatest number of eggs. The process of laying is most probably rather painful, though the hen does not indicate this by her cries; but the instant she has done, she leaves the nest, and utters her joy by peculiarly loud notes, which are reëchoed by the cock, as well as by some of the other hens. Some hens, however, leave the nest, after laying, in silence."

It seems ever to have been an object of great importance, in an economical point of view, to secure the laying of hens during those parts of the year when, if left to themselves, they are indisposed to deposit their eggs.

" Man," says M. Parmentier, "who thinks of nothing but his own interest, has attempted several means of rousing hens from their torpidity, when they cease, at the natural period of 
the year, to lay, inasmuch as it seems very hard to pass through the winter without the luxury of eating new-laid eggs."

The methods adopted by the ancients were, rich and stimulant feeding. "Ye must," says Mascall out of Columella, " mixe their meat with chalk, and put water fresche into their troughs with some wine and water mixte, and so let them have it daylye for a space. Or give them of barlye halfe soddan, and mixte with tares, or the graine called millet wheate."

Lawrence says, "Old hens are seldom to be depended upon for eggs in winter, such being scarcely full of feather until Christmas; and then, probably, may not begin to lay till April, producing, at last, not more than twenty or thirty eggs."

M. Reaumur made several experiments with a view to the object in question. "A certain class of food and of seeds," he says, "are much extolled, in many places, as tending to promote the laying of eggs, but nothing has yet been determined in this respect upon rational principle and experiment. I fed some hens, for a whole month together, with hemp-seed, which people pretend to be better adapted than any other food to make them lay. But, in those trials, I did not succeed in procuring a single egg.'

"It will be less troublesome, and no less rational," says Dickson, " as pullets commence laying before older hens, and do not moult the first year, to have an early summer brood hatched in April or May, which will begin to lay about Christmas. In fact, by attending to the period of hatching, hens may be got to lay all the year. A friend informs us, that a neighbor of his, in this way, has a brood of chickens soon after Christmas, which, by being carefully sheltered from the cold and wet, and fed once a day on boiled potatoes, hot, begin to lay early the ensuing winter."

"When," says M. Bosc, " it is wished to have eggs during 
the cold season, even in the dead of winter, it is necesssary to make the fowls roost over an oven, in a stable, in a shed where many cattle are kept, or to erect a stove in the fowl-house on purpose. By such methods, the farmers of Auge have chickens fit for the table in the month of April, a period when they are only beginning to be hatched in the farms around Paris, although further to the south. It would be desirable that stoves in fowl-houses were more commonly known near great towns, where luxury grudges no expense for the convenience of having fresh eggs."

A writer in the Southern Agriculturist says:- "To make hens lay in winter, they should be shut up in a warm place. Boiled potatoes, turnips, carrots, and parsnips, are cheap and good food," \&c.

" The reason why hens do not lay in winter," observes a writer in the New England Farmer, " is because the earth is covered with snow, so that they can find no ground, or other calcareous matter, to form the shells. If the bones of meat or poultry be pounded and given to them, either mixed with their food or by itself, they will eat greedily, and lay eggs as well as in warm weather. When hens are fed on oats, they lay better than when fed on any other grain."

As to the number of eggs, the varieties which possess the greatest fecundity are the Shanghaes, Guelderlands, Dorking, Poland, and Spanish fowls. The Poland and Spanish fowls lay the largest; the Dorking fowls lay eggs of good size; while Game fowls and the smaller kinds produce only small eggs. Those eggs which have the brightest yolks are the finest flavored, and this is usually the case with the smaller kinds. The large eggs of the larger varieties have often yolks of a pale color, and are inferior in flavor. 
PRESERVATION OF EGGS.

The ancients had very imperfect notions of preserving eggs fresh, if they knew no other method than what the elder Pliny says - "The best way to keepe egges is in bean-meale or floure, and during winter in chaffe, but for summer time, in branne." - (Holland's Plinie, i., 301.) This would no doubt preserve them longer than if they were left entirely uncovered; but it could not be depended upon, as we shall presently see, no more than the similar advice of Columella, who says "The manner to keep egges a long tyme is, in the winter in straw, and in summer in branne or meale."

Old Gervase Markham says - " Because egges of themselves are a singular profit, you shall understand that the best way to preserve or keepe them long is, as some thinke, to lay them in straw and cover them close ; but that is too cold, and besides will make them mustie. Others lay them in branne, but that is too hot. The best way to keepe them most sweet, most sound, and most full, is only to keepe them in a heape of old malt, close, and well covered all over." (Cheape and Good Husbandrie, p. 142. 4to. London, 1616.)

Nothing was known scientifically on the subject of preserving eggs till M. Reaumur was led to take it up. Eggs after being laid, it was shown, lose daily by transpiration a portion of the matter which they contain, notwithstanding the compact texture of their shell, and of the close tissue of the flexible membranes lining the shell, and enveloping the white. When an egg is fresh, it is proverbially full, without any vacancy; and this is matter of common observation, whether it be broken raw, or when it is either soft or hard boiled. But in all stale eggs, on the contrary, there is uniformly more or less vacancy, in proportion to the loss they have sustained by transpiration; and hence, in order to judge of the freshness of an egg, it is usual to hold it up to the light, when the translucency 
of the shell makes it appear whether or not therc be any vacancy in the upper portion, as well as whether the yolk and white are mingled and muddy, by the rotting and bursting of their enveloping membranes.

The transpiration of eggs, besides, is proportional to the temperature in which they may be placed, cold retarding and heat promoting the process ; and hence, by keeping fresh-laid eggs in a cool cellar, or, better still, in an ice-house, they will transpire less, and be preserved for a longer period sound, than if they are kept in a warm place, or exposed to the sun's light, which has also a great effect in promoting the exhalation of moisture. As, therefore, fermentation and putridity can only take place by communication with the air at a moderate temperature, some means must be devised to exclude such connection, by closing the pores of the shell.

The first material which M. Reaumur tried was spirit of wine varnish, made with lac, and he says that "it was impossible to distinguish the varnished eggs, which had been kept for a year, from those newly laid." (L'Art de faire éclorre, sub fin.)

It is an indispensable condition of the material used for stopping the pores of the shell of the egg, that it should not be capable of being dissolved by the moisture transpired from the interior, and the varnish fulfilled this condition; but, unfortunately, though varnish is not very expensive, it is not a common article in country places, where eggs are most abundantly produced, while many people, besides, are not easily brought to make use of anything to which they have not been accustomed.

In order to get over this difficulty, M. Reaumur was led to try other substances, and soon found that another material, very cheap and everywhere to be had, would very well supply the place of varnish. This material was fat or grease, such as 
suet, lard, or dripping ; but the best of these was proved to be a mixture of mutton and beef suet, melted together over a slow fire, and strained through a linen cloth into an earthen pan. When thoroughly melted, an egg was dipped into it, and immediately taken out again, when it was in a fit state to be kept for twelve months or more. Five pounds of this melted fat might prepare all the eggs produced in a neighborhood in one season.

The ehief advantage in the use of this fat, rather than varnish, is, that the eggs rubbed over will boil as quickly as if nothing had been done to them, the fat melting off as soon as they touch the hot water; whereas the varnish, not being soluble even in hot water, only becomes moistened by it, and, still hanging about the egg, prevents the transpiration of the juices necessary to bring the egg into tliat state in which it is to be eaten. When the egg, on the other hand, which has been preserved by the fat, is taken out of the water, there remains very little fatness upon it, and what there does, is easily wiped off upon a napkin.

The method of preserving eggs by means of fat is greatly preferable to that of varnish, when they are intended for putting under a hen to be hatched; for the fat easily melts away by the heat, while the varnish remains and impedes the hatching. By this means, the eggs of foreign fowls might be carried to a distance, hatched, and naturalized, in this and other countries.

The transpiration of matter from the egg was proved to be as effectually stopped by the thinnest layer of fat as by a thick coating, so that no sensible vestige be left on the surface of the shell. All sorts of fat, grease, or oil, were found well adapted to preserve eggs. M. Reaumur used butter, hog's lard, olive oil, and similar substances, and thereby preserved 3ggs for nine months, as fresh as the day on which they were raid. 
There is another method of preserving eggs a long while fresh, depending on very different principles from the preceding, but well worth notice. We are indebted for the discovery, if indeed it may be termed one, to the same ingenious French experimenter, M. Reaumur. Having remarked that there was a very great difference among eggs as to the rapidity with which they became unfit for use and putrid, he investigated the causes of this difference, and found that it was the eggs which had not been rendered reproductive by the cock, that continue long uncorrupted.

In order, therefore, to have eggs to keep fresh from spring to the middle or even the end of winter, it is only necessary to deprive the hens of all communication with cocks, for at least a month before the eggs are put away. Without knowing this, people often find, among the eggs they buy, some which soon spoil, and others that will keep for a long time.

Mr. Dickson also says that eggs keep well when preserved in salt, by arranging them in a barre] - first, a layer of salt, and then a layer of eggs, alternately. This can only, however, act mechanically, like bran or saw-dust, so long as the salt continues dry, for in that case the chlorine, which is the antiseptic principle of the salt, is not evolved. When the salt, however, becomes damp, its preservative principle will be brought into action, and may penetrate through the pores of the shell.

The dealers are reported to have recently discovered that immersing eggs in vitriol or sulphuric acid is a very effectual means of preservation, and it is very probable it is so ; for the sulphuric acid will act chemically on the carbonate of lime in the shell, by setting free the carbonic acid gas, while it unites with the lime, and forms sulphate of lime, or plaster of Paris. The pores of the shell will in this way be closed up with plaster of Paris, and in a more minute and effectual way, too, than could be done by its direct application. 
M. Gagne says, that a very excellent method of preserving eggs is, to mix a bushel of quick-lime, two pounds of salt, and eight ounces of cream of tartar together, adding a sufficient quantity of water, so that an egg may be plunged in to the point. When a paste has been made of this consistence, the eggs are put into it, and may be kept fresh, it is said, for two years.

It ought not to be overlooked, with respect to the preservation of eggs, that they not only spoil by the transpiration of their moisture and the putrid fermentation of their contents, in consequence of air penetrating through the pores of the shell, but also by being moved about, and jostled when carried to a distance by sea or land. Any sort of rough motion, indeed, ruptures the membranes which keep the white, the yolk, and the germ of the chick, in their appropriate places, and, upon these becoming mixed, putrefaction is promoted.-Dickson.

Eggs may be preserved, for hatching, for weeks, and even months, if kept in a cool, dry place.

\section{WEIGHT AND VALUE OF EGGS.}

It is most extraordinary that the varieties in weight and value in eggs, as an article of merchandise, should have been so universally overlooked, both by buyers and sellers. So far as known, it has always been the custom everywhere to sell eggs by number, without respect to size, weight, or peculiar quality. Yet no absurdity can be greater, as the following facts will show.

It has been ascertained, by careful experiment recently made by the author, that the fair average weight for a dozen of eggs is twenty-two and a half ounces. Recently, on application to a provision dealer, he made answer to the inquiry addressed to him, that he made no difference in the price of his eggs. : On 
examination of his stock, it appeared that the largest eggs weighed twenty-four ounces per dozen, and the smallest only weighed fourteen and a half ounces per dozen! In the one case, therefore, a fraction over eleven eggs would equal the average weight of a dozen, and in the other, it would require over eighteen eggs to reach the proper weight. It appeared, to mutual astonishment, that the difference in weight between the two kinds was about one half, while the price of both was the same.

It will be seen, by reference to the description of the Plymouth Rock fowls in this work, that Mr. Harris' largest eggs, of that breed, weighed nineteen and a half ounces per half dozen, or thirty-nine ounces per dozen; and his smallest, thirteen and a half ounces per half dozen, equal to twenty-seven ounces per dozen - averaging thirty-thres ounces per dozen, which is ten and a half ounces over the usual weight. Eight of such eggs, therefore, would be equivalent to a dozen, by weight, of the common sort.

A gentleman of Plymouth, some years since, called on a provision dealer, and inquired the price of eggs. In this instance, he was told that the price varied in proportion to the size. The eggs which were contained in one basket, which was pointed out, were to be sold for ten cents a dozen, and those in -another, twelve and a half cents. The purchaser was vexed at this, as something unusual ; and asserting that " an egg was an egg, the world over," declared that he would buy only where he could obtain them indiscriminately at ten cents, the then common market price. He made his purchase elsewhere, and returned, boasting that he had bought eggs for ten cents as good as his friend could furnish for twelve and a half. The dealer offered to test the matter by weight. This was agreed to, as the best means of settling the dispute. The result was, that six of the dealer's eggs weighed down eleven of the pur- 
chaser's! Thus it appears that, if the purchaser had paid what he deemed an extra price, in the first instance, he would have been the gainer.

From these facts an important conclusion may be drawn; and, without doubt, the time will soon arrive when either a certain standard by weight will determine what constitutes a dozen of eggs, as merchandise, or, perhaps, as an easier and better way, eggs will be sold by the pound. While, however, the present practice prevails, of reckoning by the dozen, it should be remembered that a dozen of eggs ought to weigh twenty-two and a half ounces. A dozen, then, may sometimes consist of eight, twelve, or even eighteen eggs. In other words, the price should be the same for a certain weight, how many soever eggs are required to produce it in the scales. Careful housekeepers should hereafter insist on receiving a suitable quantity for their money; and, as a general rule, eight very large eggs, twelve medium-sized, or eighteen small eggs, are equivalent to the rightful average weight of a dozen.

It is important, also, to notice the varieties in eggs, which are also of some account in domestic economy. Yellow, mahogany, or salmon-colored eggs, are generally richer than white ones. They contain a larger quantity of yolk, and are mostly produced from hens of southern origin. They are generally preferred for culinary purposes, for cakes, \&c., though some esteem them the best for eating.

White eggs commonly contain an excess of albumen, and are preferred for boiling, \&c., for the table. These are usually produced by hens of northern origin.

Epicures and the wealthy purchase two kinds of eggs, and are willing to pay a price accordingly. They separate entirely the sorts fit for eating and for cooking, and eventually, no doubt, the course thus pursued by a small class will become general. 


\section{CHAPTER XIII.}

\section{INCUBATION.}

BEFORE describing the interesting process of incubation, it is desirable to give some account of the structure of the egg. In a laying hen may be found, by opening the body, what is called the ovarium, which is a cluster of rudimental eggs, of different sizes, from very minute points up to shapes of easily distinguished forms. These rudimental eggs have as yet no shell or white, which are exhibited in a different stage of development, but consist wholly of yolk, on the surface of which the germ of the future chicken lies. The yolk and the germ are enveloped by a very thin membrane.

"When the rudimental egg, still attached to the ovarium, becomes larger and larger, and arrives at a certain size, either its own weight, or some other efficient cause, detaches it from the cluster, and makes it fall into a sort of funnel, leading to a pipe, which anatomists term the oviduct.

Here the yolk of the rudimental egg, hitherto imperfectly formed, puts on its mature appearance of a thick yellow fluid, while the rudimental chick or embryo, lying on the surface at the point opposite to that by which it had been attached to the ovarium, is white, and somewhat paste-like.

The white, or albumen, of the egg now becomes diffused around the yolk, being secreted from the blood-vessels of the egg-pipe, or oviduct, in the form of a thin, glairy fluid; and it is prevented from mixing with the yolk and the embryo chick by the thin membrane which surrounded them before they were detached from the egg-cluster, while it is strengthened by a second and stronger membrane, formed around the first, immediately after falling into the oviduct. It is proper 
to mention, also, that this second membrane, enveloping the yolk and the germ of the chick, is thickest at the two ends, having what may be called bulgings, termed chalazes by anatomists; these bulgings of the second membrane pass quite through the white at the ends, and being thus, as it were, imbedded in the white, they keep the enclosed yolk and germ somewhat in a fixed position, preventing them from rolling about within the egg when it is moved. .

The white of the egg being thus formed, a third membrane, or rather a double membrane, much stronger than either of the two first, is formed around it, becoming attached to the bulgings, or chalazes, of the second membrane, and tending still more to keep all the parts in their relative positions.

During the progress of these several formations, the egg gradually advances about half-way along the oviduct. It is still, however, destitute of the shell, which begins to be formed by a process similar to the formation of the shell of a snail, as soon as the outer layer of the third membrane has been completed. When the shell is fully formed, the egg continues to advance along the oviduct, till the hen goes to her nest and lays it.

From ill-health, or accidents, eggs are sometimes excluded from the oviduct before the shell has begun to be formed, and in this state they are provincially termed oon or wind eggs.

Reckoning, then, from the shell inwards, there are six different envelopes, one of which only could be detected before the descent of the egg into the oviduct.

1. The shell.

2. The external layer of the membrane lining the shell.

3. The internal layer of the same lining.

4. The white, composed of a thinner liquid on the outside, and a thicker and more yellowish liquid on the inside.

5. The bulgings or chalaziferous membrane.

6. The proper membrane. 
One important part of the egg, which we have not hitherto noticed, is the air-bag, or folliculus aeris of the anatomists, placed at the larger end, between the shell and its lining membranes. It is, according to Dr. Paris, about the size of the eye of a small bird in new-laid eggs, but is increased as much as ten times in the process of hatching.

This air-bag is of such great importance to the development of the chick, probably by supplying it with a limited atmosphere of oxygen, that, if the blunt end of an egg be pierced with the point of the smallest needle, (a stratagem which malice not unfrequently suggests,) the egg cannot be hatched, but perishes.

Instead of one rudimental egg falling from the ovarium, two may be detached, and will of course be enclosed in the same shell, when the egg will be double-yolked. If these doubleyolked eggs be hatched, they will produce rarely two separate chickens, but, more commonly, chickens with two heads and the like.

The shell of an egg, chemically speaking, consists chiefly of carbonate of lime, similar to chalk, with a small quantity of phosphate of lime and animal mucus. When burnt, the animal matter and the carbonic acid gas of the carbonate of lime are separated, the first being reduced to ashes or animal charcoal, while the second is dissipated, leaving the decarbonized lime mixed with a little phosphate of lime.

The white of the egg (albumen) is without taste or smell, of a viscid, glairy consistence, readily dissolving in water, coagulable by acids, by spirits of wine, and by a temperature of $165^{\circ}$ Fahrenheit. If it has once been coagulated, it is no longer soluble in either cold or hot water, and acquires a slight insipid taste. Experiments show that it is composed of eighty parts of water, fifteen and a half parts of albumen, and four and a half parts of mucus, besides giving traces of soda, ben- 
zoic acid, and sulphureted hydrogen gas. (Bostock's Physiology.)

The latter, we observe, on eating an egg with a silver spoon, to stain it of a blackish purple, by combining with the silver, and forming sulphuret of silver.

The yolk has an insipid, bland, oily taste; and, when agitated with water, forms a milky emulsion. If it be long boiled, it becomes a granular, friable solid, yielding, upon expression, a yellow, insipid, fixed oil. It consists, chemically, of water, oil, albumen, and gelatine. In proportion to the quantity of albumen, the egg boils hard.

The white of the egg is found to be a very feeble conduciur of heat, retarding its escape, and preventing its entrance to the yolk; a contrivance of Providential Wisdom, not only to prevent speedy fermentation and corruption, but, as Dr. Paris remarks, to avert the fatal chills which might occur in hatching, when the mother hen leaves her eggs, from time to time, in search of food. Eels, tench, and other fish, which can live long out of water, secrete a similar viscid substance on the surface of their bodies, furnished to them, no doubt, for a similar purpose. (Linnaan Transactions, x., 306.)"-Dickson.

The process of incubation, now to be described, is exceedingly curious, and has attracted great attention from naturalists. By the use of artificial methods of hatching, all the changes which the egg undergoes have been discovered, and the results of observation have been recorded with great precision. The usual time of incubation is twenty-one days, though sometimes the chick is excluded on the eighteenth day.

The changes which the egg passes through in hatching may be briefly described from the statements of Dickson. In twelve hours, traces of the head and body of the chicken may be observed as in the cut. 

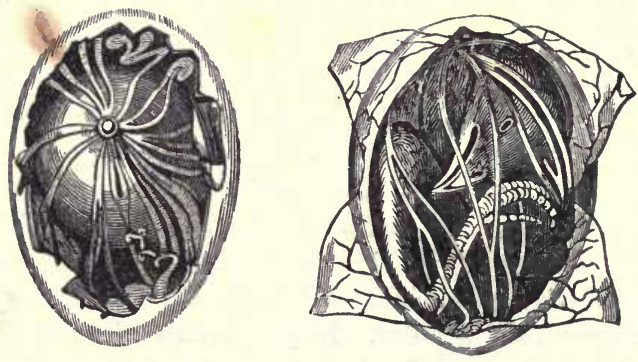

First and Last Stages of Incubation.

At the end of the second day, it assumes the form of a horse-shoe, but no red blood as yet is seen.

At the fiftieth hour, two vesicles of blood, the rudiments of the heart, may be distinguished, one resembling a noose folded down on itself, and pulsating distinctly.

At the end of seventy hours, the wings may be seen; and, in the head, the brain and the bill in form of bubbles.

Towards the end of the fourth day, the heart is more completely formed; and, on the fifth day, the liver is observable.

At the end of a hundred and thirty hours, the first voluntary motion may be observed; in seven hours more, the lungs and stomach appear; and, in four hours after this, the intestines, the loins, and the upper jaw.

At the end of the one hundred and forty-fourth hour, two drops of blood are observable in the heart, which is also further developed.

On the seventh day, the brain exhibits some consistence.

At the hundred and ninetieth hour, the bill opens, and the muscular flesh appears on the breast; in four hours more, the breast-bone is seen; and, in six hours after this, the ribs may be observed forming from the back 
At the end of two hundred and thirty-six hours, the bill assumes a green color, and, if the chick be taken out of the egg, it will visibly move.

At two hundred and sixty-four hours, the eyes appear; at two hundred and eighty-eight hours, the ribs are perfect : and at three hundred and thirty-one hours, the spleen approaches near to the stomach, and the lungs to the chest.

At the end of three hundred and fifty-five hours, the bill frequently opens and shuts.

At the end of the eighteenth day, the first cry of the chicken is heard; and it gradually acquires more strength, till it is enabled, as we shall presently see, to release itself from confinement.

Some people, upon the eleventh or twelfth day, examine the eggs which have been sitten upon, to pick out the bad ones. With this view they place the eggs on a drum, or between the hands, in the sunshine, and observe the shadow. If this wavers, by the motion of the chick, the eggs are good; if the shadow shows no motion, they throw them away.

\section{EXCLUSION OF THE CHICK.}

About the twenty-first day, the chick is excluded from the egg, whose shell is not broken by the hen, as is sometimes ignorantly asserted, but by the chick itself, in a highly interesting process, first investigated by M. Reaumur, though it was known to Albertus Magnus in the thirteenth century.

For the purpose of breaking the shell, the chick is furnished with a horny-pointed scale, greatly harder than the bill itself, at the upper tip of the bill - a scale which falls off after the chick is two or three days old. The chick is rolled up in the egg in the form of a ball, with its fore part towards the biggest end, and its beak uppermost, with the hard scale nearly touching the shell 

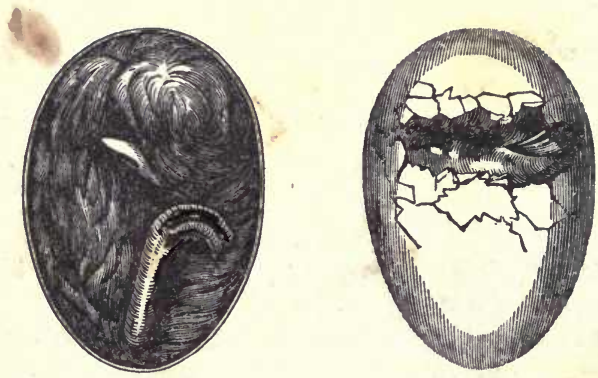

Position of the chick immediately before hatching, and of the situation of the bill in the act of chipping the egg.

The first few strokes of the chick's beak produce a small crack, rather nearer the larger than the smaller end of the egg, when the egg is said to be chipped. From the first crack, the chick turns gradually round, from left to right, chipping the shell as it turns, in a circular manner, never obliquely.

All chicks do not succeed in producing this result in the same time, some being able to perform the task within an hour, others taking two or three hours, while half a day is most usually employed, and some require twenty-four hours or more, rarely two days.

Some chicks begin to break the shell too soon, that is, before they have taken in the necessary provision of food, by the yolk passing into their bodies through the navel-string. The chick, indeed, which comes out of the shell before the yolk is thus taken up, is as certain to droop and die as a calf would doy without milk.

Some chicks, it may be remarked, have greater obstacles to overcome than others, from all shells not being alike in thickness and hardness; and hence the directions given for assisting in the process. 
Other chicks, again, though sufficiently strong, and enclosed in a shell of the usual thickness, are unable to make their way out, even when a breach in the shell is made for them, in consequence of some unknown cause depriving them of the power of turning on their own bodies; and by remaining in the same position, they become glued to the shell.

The signs that a chicken is in this condition, in which he needs must die, if not assisted, are, when a large fracture that has been made in a shell, together with a rending of the membrane, remains the same for five or six hours, and is not enlarged. It may be concluded from this that the chicken adheres to the inside of the egg. We must not hesitate, in that case, to do for the chicken what he would infallibly do, were he not deprived of all liberty of acting. We may often, without any danger to the chicken, tear the membrane round the whole circumference of the egg, with the nails or with the fingers, by making the gentlest efforts to take off the fore-part of the shell, which is already separated from the other by the fracture; the membrane that sticks to it is torn by the efforts thus made against it. But generally we ought not to attempt to break off all at once the whole fore-part of the shell ; and the resistance experienced in that case is a sufficient warning that we cannot do it without causing an excessive pain to the chicken." - Dickson.

Mr. Richardson says, "Sometimes a few scales of albumen, or of the lining membrane of the egg, may remain on the bird's plumage for some days. Do not be uneasy about them. Leave them alone, and as they dry they will fall off of themselves. In affording your assistance to the embarrassed chick, be extremely tender with your fingers. You may otherwise often kill, when your intention is only to cure. For my own part, my confidence in the unassisted powers of nature is such, that I would be disposed to permit at least eight hours to elapse before I resorted to mechanical means of interference. A chick, 
so weak as to perish before that time, is not worth striving to extricate; and, on the score of humanity, its death within the shell will be less painful than after quitting it."

As an universal rule, twenty-one days after vivification, under the ordinary heat, is the time for the hatching of the brood. If the nest be so prepared as to secure warmth, and the number of eggs is small, the heat will be extraordinary. The brood, under these circumstances, will frequently be hatched in twenty days, and instances have been known of the extrusion of the chicks in nineteen days. On the other hand, if the heat be less than the average, which will occur when the nest is faulty and the number of the eggs is too large, the period of hatching may be extended to twenty-three or twenty-four days. A single instance has occurred when twenty-five days was required before the hatching took place.

My recent experience, in the care of a brood from my Wild Indian hen, will illustrate the principles here laid down. Nine of her eggs were set under a hen, in a well-prepared nest, and on the twentieth day a fine, healthy brood came out. Within thirty minutes from the first picking of the shell, all the chicks were at liberty, and exhibited forthwith every symptom of liveliness and great vigor. I placed seventeen eggs, from the same hen, under another, and they were not hatched for twenty-two and a half days, plainly showing that the eggs had been cooled in consequence of their number. The chicks were not all extruded until two and a half days after their pick was heard. Some appeared on the twenty-first day, but the most remained two days longer. Not more than half the number hatched. The chicks were feeble, and were saved only with great care.

As a general rule, from nine to twelve eggs will hatch out more chickens than eighteen, placed with a hen under the same circumstances. The chickens will also be more vigorous; 
they will attain a larger size, and command a greater price in the market. It is a common, but fatal error, to set too many eggs under the hen. I have also observed that the vigorous, healthy chickens of the small broods are not likely to be injured by the hen, in her movements about the nest, and when at large, while the feebler and less active ones produced in the larger broods are frequently trodden to death, and otherwise damaged, by the mother. These latter are also much more liable to disease, and I think a careful observation will convince all breeders that they are much more difficult to rear, and far less profitable, in the long run.

\section{FOOD OF THE CHICK.}

For about twenty-four hours after birth, the chick not only can do well enough without any extraneous nourishment, but will positively be far more likely subsequently to thrive, if let alone, than if crammed or incited to eat prematurely. It is, however, no harm to turn them in among older chicks, that already feed themselves. They will then ordinarily follow the example of the rest, and pick away at whatever is going.

After a day or two, chickens will eat anything; but if they are of a delicate and valuable sort, chopped bits of fresh meat, unbaked pie-crust, and rice, are an excellent nourishment.

"We are certain," says Mr. Bement, "more chickens are destroyed by over-feeding than are lost by the want of it. We have remarked also that hens which stole their nests generally hatched all the eggs; and if suffered to seek the food for her chickens, if the season was somewhat advanced, she would, unless some casualty occurred, raise the whole brood, while with too much kindness or officiousness, not half would be raised. All watery food, such as soaken bread, or potatoes, should be avoided. If Indian meal is well boiled, and fed not too moist, it will answer a very good purpose, particularly 
after they are eight or ten days old. Pure water must be placed near them, either in shallow dishes or bottle fountains, that the chickens may drink without getting into the water, which, by wetting their feathers, benumbs and injures them. After having confined them for five or six days in the box, they may be allowed the range of the yard, if the weather is fair. They should not be let out of their coops too early in the morning, or whilst the dew is on the ground; far less be suffered to range over the wet grass, which is a common and fatal cause of disease and death. Another cause of the utmost consequence to guard them against is sudden unfavorable changes of the weather, more particularly if attended with rain. Nearly all the diseases of gallinaceous fowls arise from cold moisture.

At the end of four weeks, the hen may be allowed to lead her little ones into the poultry-yard, where she will soon leave them and commence laying again."

The first feathering of chickens. - This is the most trying time with chickens of all breeds. If chickens feather rapidly when very young, (as is the case with the Golden Pheasant, Black Poland, Guelderland, etc., etc.,) they are always weakly, however healthy in other respects, from the fact that their food goes to sustain their feathers instead of their bodies; and they frequently languish and die, from this circumstance alone; but if, on the other hand, they feather slowly, (as is the case with the Shanghaes Pride of Indias, Plymouth Rocks, Cochin Chinas, etc., etc.,) the food in early life goes to nourish and sustain their bodies until they become more vigorous, and old enough to sustain the shock of feathering without detriment. This is the reason why the pure Fawn-colored Dorkings are easier raised than others of the race-simply because they feather more slowly. This, too, accounts for the extraordinary healthiness of the Yankee Game fowl-they feather very 
slowly, and their long legs, like stilts, carry them above the wet grass. Chickens which feather rapidly must be kept perfectly dry and warm, however strange it may appear, or they will die; while naked chickens, as they are called, or those which feather at a more advanced age, and very slowly, seldom suffer from the cold, from the fact that their down is very warm, and their blood is hotter, and circulates more rapidly, as their food principally goes to blood, and flesh, and bones, and not to feathers.

In the hatching of poultry, nature is the best guide, and all arrangements made for the accommodation of the hen should conform as far as possible to the example which nature sets before us. "Hens in a state of nature make their nests on the ground. This method, however, cannot at all times be acted upon, unless the nest be properly secured from vermin, particularly from rats, as these animals will frequently convey away the whole of the eggs from under a hen.

The mode of making the nests of sitting hens of moss or heather, as practised in her Majesty's poultry-houses at Windsor, offers a medium between the natural habits of the hen and the dryness of a wooden box filled with straw. The heather also affords the hen an opportunity of freeing herself from those insects which are frequently so troublesome to hens when sitting. As, however, it may not always be convenient to have boxes filled with heather, the nests for the sitting hens may be made in baskets or wooden sieves, and lined with such warm and clean materials as are most conveniently obtained.

The desire to sit is made known by a particular sort of clucking, which is continued till the chickens are full grown; and a feverish state ensues, in which the natural heat of the hen's body is very much increased. The inclination, or, as physiologists term it, the storge, ( $\sigma \tau \circ \gamma \eta$,$) soon becomes a strong and$ ungovernable passion. The hen flutters about, hangs her 
wings, bristles up her feathers, searches everywhere for eggs to sit upon; and, if she finds any, whether laid by herself or others, she immediately seats herself upon them.

These signs of an inclination to sit ought generally to be indulged in all hens; but those are best adapted for sitting which have rather short legs, a broad body, large wings, well furnished with feathers, and their nails and spurs not too long nor sharp.

The sitting hen will sometimes exhibit impatience at her close confinement, and want to get frequently off the nest. When this is observed, M. Parmentier directs one half of the food that usually forms her meal to be withheld; and, when she has only had half of her due allowance, to replace her on the nest, and hold out to her in the hand some hemp or millet seed. This second meal has the effect of reconciling her to sit constantly, without deserting her eggs.

With the same view, others put food and water so near the nest that the sitting hen may feed without leaving her eggs for any great length of time. But Sketchley well remarks, that this is not so conducive to health as the more natural method of letting her come off to enjoy good water and food at some little distance; and M. Parmentier says, it is important that sitting hens should have a little exercise, as well as that the eggs should be exposed to the circulation of air, to carry off any stagnant vapor, which was proved by M. Reaumur's experiments to be so deleterious and destructive to the chicks still in the egg. We have ourselves remarked, that sitting hens are as fond of rubbing themselves in the dust as they are of food and water; and we have always indulged them, evidently with benefit, in this habit. - Dickson.

Other hens will sit so closely and long, that they are in danger of starving themselves for want of food. Mr. Lawrence says, he has had hens of this kind faint outright, as if dead; 
and which, when the chickens were hatched, were so exhausted as scarcely to be able to attend to them. He recommends such hens to be fed on the nests.

Mr. Richardson gives the following excellent advice as to the choice of eggs for sitting, and his remarks comprise all that is necessaiy to be known on the subject.

"In selecting eggs for sitting, choose such eggs as you have reason to know or believe to have been rendered productive. Those of medium size-i. e., the average size that the hen lays - are most apt to prove productive. Sketchley tells us that he has always found the round egg to contain the female chick, and that of oblong shape, the male. This, however, though it may have been newly discovered by Sketchley, was known to Columella and Stephanus. If you examine the egg between your eye and a candle, you will be able to discern the position of the vacancy caused by the little air-bag at the blunt end of the shell. If this be in the centre, the egg will produce a cock; if at one side, a hen. You may form a very fair judgment of your eggs from their specific gravity. Put them into a bowl of tepid water, and reject such as do not sink to the bottom. Choose, also, such as present a marked disparity of size between the two ends. Such as are equal in size at both ends usually contain two yolks; and these, be it - observed, instead of producing twin chickens, as might naturally be expected, commonly produce monstrosities : reject them. The number of eggs to be placed under a hen is from nine to eleven. The number is, however, of course, dependent on the size of both eggs and hen; an odd number is to be preferred, as being better adapted to the covering in the nest. Be sure that they are all fresh; and carefully note down the day on which you place them beneath the hen. Never turn the eggs ; the hen can do that better than you. About the twelfth day of incubation, you may be enabled to reject such eggs as are 
unfruitful. For this purpose, hold the egg between your hands in the sunshine; if the shadow which it forms waver, keep the egg, as the wavering of the shadow is occasioned by the motion of the chick within; if it remain stationary, throw it away. If your eggs have been very fresh laid, the chick will be developed earlier than otherwise; if they have been fresh, you will, about the sixteenth day, if you apply your ear to the egg, hear a gentle piping noise within; if the eggs have been stale, this will not be perceptible until about the eighteenth day; and, at this time, the yolk, which had previously lain outside and around the chicken, will now be gradually entering into the body of the bird. This serves as nourishment to the little prisoner until his subsequent efforts shall have set him free. From this period let your attention be assiduous, but, at the same time, cautious: for the hen has heard the cry before you have, and all her maternal anxieties and tenderness are, from that moment, greatly augmented, and any unnecessary interference will only tend to irritate her."

In Mr. Dickson's opinion, the characters by which one hen may be chosen in preference to the other, for giving her the management of her chickens, are a full-sized breast, and a great compass of wings, in order that the chickens may be gathered together by the hen under her, and thus kept from unhealthy chills.

From the same eminent author we cannot forbear the quotation of the following beautiful remarks on the maternal character of the hen, as an appropriate conclusion to this chapter :

"The tenderness and solicitude of the hen for her little ones, and the alteration which maternal love has produced in her temper and her habits, are really worthy of admiration. Previously, she was ravenous, insatiable, vagrant, and timid ; but as soon as she becomes a mother, she becomes frugal, generous, courageous, and intrepid ; she assumes, indeed, all the qualities that distinguish the cock, and even carries them to a 
higher degree of perfection. When we see her come into the poultry-yard, surrounded by her little ones, for the first time, she seems as if she was proud of her new dignity, and took a pleasure in performing her duty. Her eyes are lively, animated, and constantly on the alert; her looks are so quick and rapid, that she could take in every object at one glance; and she appears to discover at once the smallest seed on the ground, which she points out to her young ones; and, in the clouds, the bird of prey she dreads for their sake; and giving them notice by a doleful cry, she induces them immediately to hide themselves under her protecting wings.

Incessantly taken up with the welfare of her chickens, she excites them to follow her, and to eat. She picks their food; she scratches the ground in search of worms, which she gives up to them; she stops now and then, she squats down, and forming a cradle as it were with her wings, she invites her tender offspring to come and gather round, and warm themselves beneath her. She continues to bestow these cares on them till they are of no further use to them, which takes place when the chickens are quite feathered, and when they are come to half the size they are to grow to."

\section{CHAPTER XIV.}

\section{CAPONIZING.}

Capons have ever been esteemed among the greatest delicacies of the table ; and though, from Shakspeare's time, certain characters have been known by their " fair round belly with good capon lined," they are, comparatively, a recent luxury in this country. The capon is made by the extirpation of the reproductive organs in male fowls. If a cock, when 
young, is emasculated, a remarkable change takes place in him. His natural fierceness is quelled; he becomes placid and peaceful ; his pugnacity has deserted him; he no longer seeks the company of the hens; he grows to a far larger size than he otherwise would have done; he acquires flesh with far greater rapidity, and that flesh is peculiarly white, firm, and succulent, and even the fat is perfectly destitute of rankness. To these advantages another may, perhaps, be added - viz., the capon may, by a little management, be converted into an admirable nurse.

" The art of making capons has been practised," says Dickson, "from the earliest antiquity, in Greece, India, and China, for the purpose of improving the flesh of birds for the table, in tenderness, juiciness, and flavor. In England, it is chiefly practised in the great poultry-breeding districts of Sussex, Essex, and Berks, and is not so well understood in other parts of the country. There are individuals, indeed, who make a trade of it, and it is best to employ one of those, when they can be had.

Various methods are used in performing the operation. The Chinese mode, as detailed by Dickson, is as follows :

"The Chinese, who are very expert in the art of making capons, use the following method. The wings of the fowl being folded back till they meet, the left foot of the operator is placed on them, the fowl being laid on its left side; the great toe of the right foot is placed on its legs. The feathers are then plucked off by the side; an incision, about an inch in length, commencing about an inch from the back-bone, and extending obliquely downwards, is then scooped out. The other stone is removed in the same manner. No blood issues from the spermatic cords, nor does the animal seem to feel any pain. The hooks are then removed, the wound is closed, the feathers which had been plucked off are stuck upon the wound 
with the blood, and the wing being put down on it, the animal walks off as if nothing had happened.

The French mode is more simple. In France, young cocks, three months old, are made choice of for the operation, which must, if possible, be performed before July, as it has been remarked that capons made later than this seldom prove fine. The incision is made as already explained, the finger inserted, the stone removed with a dexterous twist of the finger, only acquired by experience, the wound sewed up and rubbed with oil, and, finally, the comb is cut off.

It is usual, among the French, after the operation, to feed them for three or four days with bread soaked in wine, cooping them up in a place where the temperature is not too high ; for, when the weather proves to be very hot, the wound is apt to mortify and cause death."

Mr. Richardson, who seems to have devoted considerable attention to the subject, gives the following directions, in his recent popular work :

"This process has been made a subject of much unnecessary mystery ; and, I regret to add, of much unnecessary cruelty. In point of fact, the process of caponizing is an extremely simple affair, and one which the country henwives in France perform with facility and certainty, (assuredly there are some 'things' which 'they manage better in France.') The practice of the French country-women is to select the close of the spring, or the beginning of autumn, as well as fine weather, for the performance of their work. The parts necessary to be removed being fixed in the abdomen, and attached to the spine at the region of the loins, it is absolutely necessary to open the abdominal cavity for the purpose of their extraction. The bird should be healthy, fasting, and about three months old. He is then to be secured by an assistant, upon his back, his belly upwards, and his head down, that the 
intestines, \&c., may fall up towards the breast; the tail is to be towards the operator. The right leg is then carried along the body, and the left brought backwards, and held in this position, so as to leave the left flank perfectly bare, for it is there that the incision is to be made. The said incision is to be directed from before backwards, transversely to the length of the body, at the middle of the flank, and slightly to the side, between the ends of the breast-bone and the vent. Having plucked away the feathers from the space where it is intended to make the incision, you take a bistoury, or a razor, and cut through the skin, abdominal muscles, and peritoneum; it is better to do this at two or more cuts, in order to avoid the possibility of wounding the intestines - a casualty that would, in most cases, be attended with fatal results. The intestines present themselves at the orifice, but you must not suffer them to come out; on the contrary, you press them gently aside, so as to have room for action. I may observe, that the incision should have been sufficiently large to admit of the forefinger, previously well oiled, being passed into the abdomen, and carried carefully towards the lumbar region of the spine; you will there find what you are in search of. You first reach the left substance, which you detach with your nail, or with your finger bent hook-fashion; you then arrive at the right; which you treat similarly - bring both substances forth; you finally return the intestines, sew up the wound with a silk thread - a very few stitches will suffice - and smear the place with a little fresh butter. Some persons recommend the amputation of the comb, close to the skull, of the newly-made capon; but this is surely an unnecessary piece of torture - an useless addition to the sufferings of the poor bird. The proposed object of this amputation is to insure the recognition of the capon amongst his co-mates of the poultry-yard. Were such a distinctive mark necessary, it strikes us that the operation must have been, 
so to speak, thrown away; inasmuch as the superior size and bulk of the capon should, of themselves, be sufficiently indicative of his identity. But, independent of these, I may observe that the comb of the capon does not grow to any size, and always retains a pallid color. Should it be proposed to caponize cocks belonging to varieties not naturally possessing combs, it will surely be found, at the very most, sufficient to cut the tail-feathers down to a stump. In some parts of the continent, the caponizers resort to still more unnecessary brutality. They cut off the spurs of the poor, caponized bird; and, making an incision in its comb, as it were, plant them in it. They are so held for about twenty minutes - in short, just until the blood coagulates; they then become not merely permanently adherent, but actually grow. The less, however, said about these very and needlessly inhuman practices, the better.

To return to our more immediate subject. The process having been performed as above described, the bird is placed in a warm house, where there are no perches, as, if such appliances were present, the newly-made capon might very probably injure himself in his attempts to perch, and, perhaps, even tear open the sutures, and possibly occasion the operation, usually simple and free from danger, to terminate fatally. For about a week, the food of the bird should be soft meal porridge, and that in small quantities, alternated with bread steeped in milk; he may be given as much pure water as he will drink, but I recommend that it be tepid, or at least that the chill be taken off it. At the end of a week, or, at the furthest, ten days, the bird, if he has been previously of a sound, vigorous constitution, will be all right, and may be turned out into the walk common to all your fowl.

It is, perhaps, proper to remind the operator, that when he conceives it necessary, in either case, to employ sutures for the purpose of closing the wound, great care must be taken to 
avoid involving the intestines in the stitches. It is also right that I should warn the operator that, if he be tedious in the performance of his work, the chances are greatly against his success. On this account, I would strongly advise that whoever proposes to caponize should acquire dexterity of manipulation, by practising on the dead bird, before he endeavors to use his knife upon the living. When such precautions are used, the operation will be divested of much of its apparent cruelty ; and if it be to be resorted to at all, surely every precaution should be taken that is calculated to cause as little outrage to humanity as possible."

It seems desirable that whenever this operation is about to he performed, the fowl should be shut up for perhaps two days and nights, and debarred all access to food or drink. The advantages to accrue from this regimen are, that the intestines will be likely to be empty, and there will be less danger of subsequent inflammation. The summer season is said to be the most appropriate time for the operation; and, in all cases, the fowls should be less than a year old.

Hens are sometimes operated on in a similar manner, and are then called Poulardes. In this case, they are subjected to the knife either before they have begun to lay or after they have ceased to do so, for the purpose of preventing them from laying in future. This renders them, as the other does the cock, more susceptible of taking flesh, and that of a finer quality than ordinary. It is proper to remind the reader that, of course, when it is deemed advisable thus to deprive a hen of the power of reproduction, such an one should always be selected as presents deformities, or other defects that ought to render her unfit for breeding purposes.

The caponizing of pullets is performed in much the same manner as in the case of cocks. The oviduct is found towards the loins, and is extracted in the same manner as already 
described in the former case. Some French writers, however, and Schreger amongst the first, state that in the case of pullets or hens the operation is unnecessary, it being only required to make a small incision just above the vent, on a little eminence that will be perceived in that place ; then, by repeated pressure, you cause the protrusion of the uterus - a little whitish body ; this is cut away, the wound heals of itself, and nothing further is required.

Capons are fattened precisely in the same manner as chickens, by keeping them cooped up in a quiet, dark place, and cramming them, or otherwise feeding them abundantly. They often attain a great size, some having been known to weigh ten or twelve pounds. They come to their full growth in about two years, but require but a week or two of close keeping before being brought to market.

\section{CHAPTER XV.}

\section{POULTRY-HOUSES.}

IN order to the profitable keeping of fowls, it is indispensable that they should be properly lodged, and that such conveniences should be provided for them as will secure their comfort and health. Every collection of poultry requires some place to be provided for them, to secure these advantages. Often they are left to take care of themselves, and roaming at large over the farm, or about a smaller premises, they become at last burdensome to themselves, unprofitable to the proprietor, and a nuisance to the neighborhood. A certain degree of confinement is therefore necessary for fowls. Close confinement, however, will, in a degree, prevent them from laying, and destroy their 
health. A yard or walk, connected with a place for shelter and roosting, is what is required.

Care should be taken in fixing upon a situation for these accommodations. A south or south-easterly exposure is the most proper place to be chosen, and a building of brick or stone is preferable to one built of wood. The extent of the place should be proportioned to the number of fowls kept; and if any error is to be tolerated, it might better be on the side of small buildings. It is said, on good authority, that infectious diseases are not to be feared, even in the case of confined accommodations; and laying, in the winter season, is rather promoted than otherwise, when fowls are thus situated. A medium course should be adopted, as at once the wisest and most economical. If fowls are not sufficiently ciefended from the cold of winter, they become torpid ; if exposed to intense heat in summer, they are enfeebled. To avoid the numerous diseases which are induced by dampness, care should be taken that the poultry-house should be in a dry situation, and properly defended from the effects of rain. A due regard to ventilation is indispensable to guard against an infected atmosphere, and suitable facilities should be afforded for the necessary exercise which all kinds of poultry daily demand. Arrangements for securing an ample supply of water must never be overlooked, and it is advisable to have receptacles of ashes or dry sand within the enclosure, in which the fowls may enjoy the luxury of rolling themselves, in order to free themselves from vermin, and for amusement.

When poultry are kept on a large scale, a yard is set apart for their use, enclosed either by a wall or by a fence of paling, of sufficient height to prevent any escapade. This yard should be well drained, but if a stream of water can be made to flow through it, it is an important advantage. A part of the yard should be floored or flagged, to feed the fowls upon; a part 
should be covered with sand or gravel, for them to wallow in ; a part should be laid down in grass, or planted with such plants as furnish them proper food; and somewhere, there should be a deposit of dry mortar or broken oyster-shells, so prepared that the fowls may pick and scratch amongst it.

The house, as already stated, is preferable, if built of brick or stone; but whatever the material, it is of the first consequence that it should be so constructed that the access and harboring of all vermin may be prevented. The floor should be raised from the ground sufficiently to allow of its being kept scrupulously clean. The entrance should be large enough for convenience, and strong enough for security, and a hole at some distance from the ground may be made, to allow the poultry to go in to roost. To reach this, a ladder may be constructed, by making a slanting board with strips of wood nailed across, by which the fowls may ascend on the outside, and a similar one to allow them to descend within.

All fowls like to roost high ; and they should, therefore, have some rails fixed for them near the roof, so arranged that the fowls on the lower rails may not be exposed to the droppings from those above. The rails are frequently only branches, or the trunks of young trees; but if made of timber, they should be nearly square, with only the corners rounded off, as the feet of fowls are not formed for clasping smooth round poles; and there may be boxes or baskets against the walls, for the fowls to lay in.

It is reckoned best to have various roosting-houses constructed for the different kinds of poultry, and a separate nest provided for each; as, without this precaution, the same nest will frequently have three or four visitors. The best kind of nests are said to be those made of wood, wicker-baskets being calculated to let in the cold air. The floors of the roost-houses 
should be kept sanded, and in fine weather the doors should be thrown open to give access to fresh air.

In the erection of poultry-houses, of course, considerations of fancy or economy will furnish the rule, in fixing upon a plan. A sufficiently good, and in every respect suitable poultry-house, may be built very readily, and at an insignificant cost; but others are in existence which exceed in expense many dwellings considered comfortable, and even elegant, inhabited by mankind. We proceed, therefore, to describe several sorts of poultry-houses, from those on the most magnificent scale, down to that which will merely answer the purpose for which it is erected.

Her Majesty, the Queen of England, stands first on the list of poultry-fanciers, and her establishment may here be briefly described.

THE ROYAL POULTRY-HOUSE.

The royal poultry-house is situated on the farm attached to Windsor Castle, called the "Home Farm," in her Majesty's private desmesne of Home Park. The farm is situated in a secluded part of the Home Park, and is well sheltered. This establishment originated with George III., in 1793; but the buildings, which were then thought sufficient for all purposes, were, in 1843 , found by her present Majesty to be wholly inadequate to the proper carrying out of more modern discoveries and improvements.

The present establishment was erected under the immediate superintendence of her Majesty and the Prince, aided by Colonel Wemyss, Lord Lincoln, and Mr. Engall. It is universally admitted, that the royal farm and dairy of Home Farm are among the chief embellishments of the domain of Windsor, and the royal poultry-house is, perhaps, the fairest ornament of Home Farm. 
The royal poultry-house is a simple, but at the same time beautiful building, of a semi-Gothic character. It consists of a central pavilion, flanked by roosting-places, and breeding and laying nests. The pavilion is used as a spot whence the fowl can be conveniently inspected, and is surmounted by an elegant pigeon-house, remarkable for its lining of looking-glasses, in which pigeons delight to gaze, and before which they are constantly pruning and dressing themselves.

The ground slopes in front towards the park, and is divided by slight wire fences into yards, as walks or places for the daily exercise of the fowl ; these wards are laid out in gravel-walks or grass-plots, the former leading to the entrance of the houses. The apartments are large and airy; the fittings and general economy of the house have been carefully regulated with reference to the natural habits of the birds; an equal temperature is constantly maintained; and in form and structure the nests are made, as much as possible, to resemble the close and bramblecovered recesses which would form the dwelling of poultry in a state of nature.

\section{LORD PENRHYN'S POULTRY-HOUSE.}

Perhaps one of the most splendid poultry-houses that has ever been erected is that of Lord Penrhyn, at Winnington, in Cheshire. It consists of a regular and handsome front, about one hundred and forty feet in length, having at each end a neat pavilion, with a large arched window. These pavilions are united to the centre of the design by a colonnade of small castiron pillars, painted white, which support a cornice and a slate roof, covering a paved walk, and a variety of conveniences for the poultry, for keeping corn, eggs, \&c. The doors into these are all of lattice-work, painted white, in green framing. In the middle of the front are four handsome stone columns, and four pilasters, supporting, also, a cornice and a slate roof, under which, 
and between the columns, is a very beautiful Mosaic iron gate ; on one side of this gate is an elegant little parlor, most tastefully papered and furnished; and at the other end of the colonnade, a very neat kitchen ; behind is a large, neatly-paved court, with a pond and pump in the centre. The whole fronts towards a little paddock, where the birds are turned in between meals. The strictest attention is paid to cleanliness, and, notwithstanding that about six hundred poultry of different kinds were kept in the establishment, neither dung nor litter was ever to be seen lying about for a moment. This building is of brick, except the pillars and cornices, and the lintels and jambs of the doors and windows; but the bricks are concealed by a covering of fine slate, brought from his lordship's quarries in Wales.

\section{MR. ENGLAND'S POULTRY'HOUSE.}

In a paper published in the Transactions of the Highland and Agricultural Society of Scotland, for 1833, Mr. England gives a plan of a poultry-house which presents some features, at that time regarded as novelties, but which have since come into general use. This house was divided into separate wards, each ward calculated to accommodate twenty-four hens and one cock, with a yard attached to it of about twelve feet square. The houses were supplied with nests, which had small platforms in front, and were reached by commodious ladders. $\mathrm{He}$ had also provided a storm-house, for shelter in bad weather, and a dry bath-house, or a place supplied with fine sand, in which fowl delight to roll or bathe, and which they likewise swallow, to facilitate the process of digestion.

\section{MR. WAKEFIELD'S POULTRY-HOUSE.}

Mr. Wakefield, who kept a very large stock of geese, ducks, turkeys, and poultry, near Liverpool, adopted a very simple, but, as the result showed, most successful plan of operation. 
He had an acre of ground enclosed with a fence, about six or seven feet high, formed of boards or slabs set on end, and fastened by two rails, one at the top and the other at the bottom; these stakes were pointed sharp, which prevented the fowl from attempting to fly over. Within this enclosure were lodging-places, slightly built, but at the same time well secured from wet, with small, separate enclosures for each sort of poultry, and a stream running through each.

\section{COL. PERKINS' POULTRY-HOUSE.}

Among the most beautiful and appropriate of American poultry-houses, is that which Col. Thomas H. Perkins has erected at his beautiful seat at Brookline, Massachusetts The name of Col. Perkins is so intimately associated with every useful project, that his reputation is universal, not only as a man of elegant taste, and large benevolence, but as one in whose judgment and efficiency in all branches of rural economy, the most perfect confidence may be reposed. By his courtesy, permission has been given to engrave the beautiful representation of his poultry-house which adorns this work, and from his correspondence the data has been derived from which the following description has been drawn.

The building stands in an enclosed park of about two acres, which space is entirely appropriated to the accommodation of the poultry. It fronts the south, or rather the south-east, and presents an elevation of seventy-five feet in length, by eleven feet in height. The foundation is sunk two feet below the surface, and the brick-work rises some two feet above the ground. Great care has been taken in the substruction, and by the use of hydraulic cement precautions have been adopted against dampness, and the intrusion of vermin. The brickwork is rough, plastered on the outside, and lined with boards within. The roof rises at a quarter pitch, and the room thus 


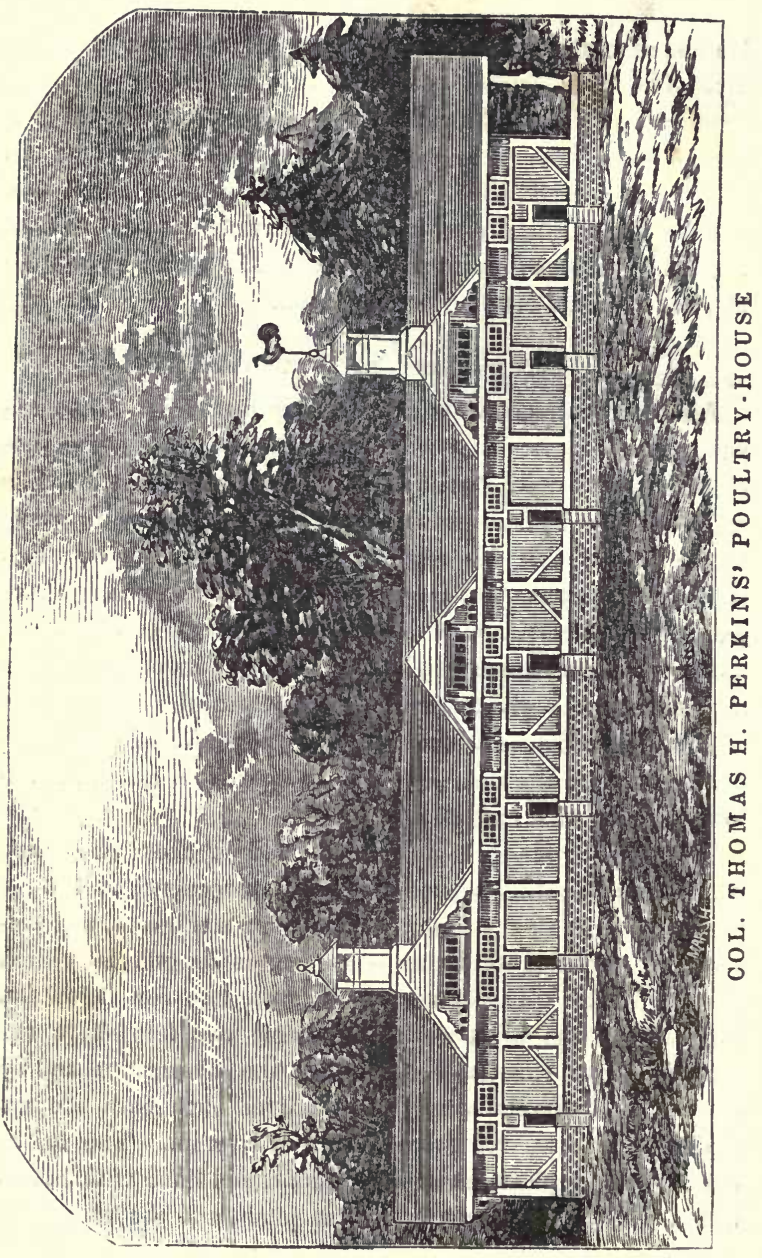


formed is occupied as a dove-cote. This is divided into three apartments, each furnished with an entrance, as seen in the drawing. The east end of the building contains a room ten feet by twelve, for the use of visitors. On one side is a window looking into the garden, another looks towards the house, and a third opens upon a court, intended for the use of the fowls. In the centre of the building is a small drawing-room, to which the fowls may retreat in inclement weather, and between this and the east room is an apartment to be occupied for purposes of roosting and laying, provided with the requisite fixtures. On the west of the retiring or storm-room, are accommodations for ducks and geese, and separated from these, others for turkeys and Guinea fowls. The place appropriated for the turkeys is glazed throughout the whole south-westerly end of the building.

On the south front there are eight windows, which extend from the brick foundation nearly to the eaves ; these are divided into three compartments, the lower moving upon rollers, and the part over the main window opening upon hinges, and secured, when open, to the floor of the dove-cote above. The edifice is surmounted by two cupolas for purposes of ventilation and ornament, and in one of them is hung a chime of bells, by the ringing of which the fowls are summoned to their food.

The portion of land devoted to the use of Col. Perkins' poultry, is divided by a rustic fence, eight feet high, into a court and a park. The former is covered with soil and gravel, and the latter is laid down to grass, thus furnishing every desirable facility for the healthful exercise and amusement of the fowls. Col. Perkins has also caused to be built a pond of suitable dimensions, of a diamond form, three feet in depth, laid in cement, and capped with freestone. A supply of water is provided for this by means of a well, and from the spouts which lead to it from the roof of the building. 
This is probably one of the most complete and elegant poultry-houses in the country. All the arrangements are made with reference to the best principles, and every desirable accommodation is afforded to its fortunate inmates. There can be no doubt that, in future, the example which has been set by this distinguished man will be followed by others, possessing taste and ample means, and the result will be eminently beneficial, in demonstrating what can be accomplished by judicious care, in rearing the finest kinds of stock.

COMMON POULTRY-HOUSE.

A simple poultry-house of small size may be formed by building a shed against the gable of the house, opposite to the part warmed by the kitchen fire, and placing cross-bars in it for roosting, with boxes for laying in, or quantities of fresh straw. There should always be an opening, to allow of the cleaning out, once a week at least, of the poultry-house - a process too often neglected, but very essential to the health of the poultry. They never will thrive long amid uncleanness; and even with the utmost care, a place where poultry have been long kept becomes what the housewives call tainted, and there they will thrive no longer. The surface of the ground becomes saturated with their exuviæ, and is therefore no longer healthy. To avoid this effect, some poulterers in the country frequently change the sites of their poultry-houses, to obtain fresh ground; and to guard against the same misfortune, farmers, who cannot change their hen-houses and yards, purify the houses by fumigations of blazing pitch, by washing with hot lime-water, and by strewing large quantities of pure sand both within and without the poultry-houses. Washing the floor of the house every week is necessary ; for which purpose, it is of advantage that it be paved either with stones, bricks, or tiles. But as these three modes are expensive, a good flooring, which is 
cheaper, may be formed by using a composition composed of lime and smithy ashes, together with the riddlings of common kitchen ashes; these, having been all firely broken, must be mixed together with water, and put on the floor with a mason's trowel, and nicely smoothed on the surface. If this is put on a floor which is in a tolerably dry situation, and allowed to harden before being used, it will become nearly as solid and compact as stone, and is almost as durable. The inside of the laying boxes requires frequent washing with hot lime-water, to free them from vermin, which greatly torment the sitting hens. For the same purpose, poultry should always have a heap of dry sand, or fine ashes, laid under some covered place, or thick tree, near their yard, for them to dust themselves in; this being their resource for getting rid of the vermin with which they are annoyed. In every establishment for poultryrearing, there ought to be soms separate crib or cribs into which to remove fowl when laboring under disease; for not only are many of the diseases to which poultry are liable highly contagious, but the sick birds are also regarded with dislike by such as are in health; and the latter will generally attack and maltreat them, thus, at the very least, aggravating the sufferings of the afflicted fowls, even if they do not actually deprive them of life. The moment, therefore, that a bird is perceived to droop or appear pining, it should be removed to one of these infirmaries.

Separate pens are also necessary, to avoid quarrelling among some of the highly-blooded breeds, more particularly the game fowl. They are also necessary when different varieties are kept, in order to aroid improper or undesired commixture from accidental crossing. These lodgings may be most readily constructed in rows, parallel to each other ; the partitions miay be formed of lattice-work - they will be rather ornamental than otherwise, and the cost of their erection will be but trifling. 
Each of these lodgings should be divided into two compartments, one somewhat larger than the other. One compartment is to be close and warm, for the sleeping-room; the other, and the larger one, should be airy and open, that the birds may enjoy themselves in the day-time ; both must be kept particularly dry and clean, and be well protected from the weather.

"Among the most necessary appendages to every poultryhouse," says Richardson, " is " the HEN-LADDER. This is a sort of ascending scale of perches, one a little higher than the other; yet not exactly above its predecessor, but somewhat in advance. By neglecting the use of this very simple contrivance, many valuable fowl may be lost or severely injured, by attempting to fly down from their roost - an attempt from succeeding in which the birds are incapacitated, in consequence of the bulk of their body preponderating over the power of their wings. This would not, of course, take place among wild birds ; but we are not to forget that our improvements in the breed of all animals tend to remove the varieties on which we expend our care gradually further and further from their primitive condition, and conduce to deprive them of much of their native activity, and, as our improvements proceed, to render them ultimately almost helpless; hence the necessity for such artificial aids as the hen-ladder."

The office of keeping and managing domestic fowls should be performed by some individual whom the hens know, as the voice and presence of a stranger scare the fowls, and disturb the operations of the hen-house. To distribute food and drink at regular hours, to visit the nests, to remove eggs as soon as laid, and carry them to a cool place, to examine, by candle-light, what eggs are fecundated, and to place these under the hen, and mark the time, are among the daily duties performed by the keeper. When the hens lay in a secret place, the keeper 
may readily discover it by placing a few grains of salt in the oviduct, which hurries on the process of laying, and causes the hen to retire to the spot anew.

\section{CHAPTER XVI.}

\section{DISEASES OF POULTRY.}

Pountry, like other animals, are liable to numerous diseases, some of them malignant, and many of them fatal. In our climate, however, the number of important disorders is small, and they usually yield to judicious treatment. That little attention has been bestowed on this subject, may arise from the fact that, in an economical point of view, the value of an individual fowl is comparatively insignificant; and, while the ailments of other domesticated animals generally claim a prompt and efficient care, the unhappy inhabitants of the poultry-yard are too often relieved of their sufferings in the most summary way. But there are reasons which will justify a more careful regard to this matter, besides the humanity of adding to the comfurt of these useful creatures; and the attenpt to cure, in cases of disease, will often be rewarded by rendering their flesh more palatable, and the eggs more wholesome.

Most of the diseases to which poultry are subject are the result of errors in diet or management, and should have been prevented, or may be removed by a change, and adoption of a suitable regimen. When an individual is attacked, it ought to be forthwith removed, to prevent the contamination of the rest of the flock. Nature, who proves a guardian to fowls in health, will nurse them in their weakness, and act as a most efficient physician to the sick. We can do no more than 
coöperate with her; and the aim of all medical treatme $c$ should be to follow the indications which nature holds out, and assist in the effort which she constantly makes for the restoration of health.

Before treating in detail the maladies of greatest consequence, it is desirable to present a brief view of so much of the anatomical structure of fowls as will be necessary to the comprehension of disease and its management.

The digestive function in poultry is partly mechanical and partly chemical. In its several stages, it differs widely from that of some quadrupeds who feed on similar food. In these, grains are frequently swallowed without being crushed by the teeth, and as their stomachs have not the power of digesting solid grain, it is voided whole. In fowls, on the other hand, the grain is all swallowed whole, and it is digested in the stomach. From this fact, the opinion has been derived of the necessity of giving stones and gravel to fowls, in order to enable them to grind the food which they take. But this is a vulgar error; for, though there are advantages derived from furnishing facilities to a flock to pick among gravel, it is by no means necessary to a perfect and regular digestion.

The digestive organs of fowls consist of the gullet and crop, the gizzard, stomach, liver, and intestines. The gullet, or æsophagus, runs down the neck towards the right side, swelling out, in front of the chest, into a membraneous bag, which is called the crop or craw.

The crop is somewhat analogous to the paunch in the ox or sheep. It receives the gullet into its upper part, and proceeds downwards, about the middle of the bag, in such a manner that the crop is in some measure aside from the regular communication between the upper and lower opening of the gullet. Its office is to receive the food when first swallowed, and to macerate it, and dissolve it by means of a liquor, which is 
separated by the glands, which may be observed covering its surface.

The food, after passing the crop, goes through the remaining part of the gullet into a cavity, shaped like a funnel, of smaller dimensions. This is similar to the second stomach in some quadrupeds, and is furnished with a large number of glands. These glands may be called gastric glands; they are placed near each other, and are hollow. Their office is to secrete a solvent or digestive fluid, and to discharge it through a small opening into the cavity. When this fluid has diluted and digested the food sufficiently, it is prepared to pass into the gizzard.

The gizzard is the last stomach, and is composed of a body of very firm and dense muscles, and lined with a thick, gristly membrane. Towards the cavity of the stomach, this lining forms folds and depressions, which on the opposite surfaces are adapted to each other. The gizzard is comparatively small and narrow, and has its outlet near its entrance. It is calculated, in every respect, for producing very powerful trituration, and is adapted to answer the purposes which are subserved by grinding teeth in other animals. In consequence of the hard, gristly structure of the gizzard, it possesses little sensibility, and it is not uncommon for fowls to eat even when dying, while in the case of other animals, in such a state, all food becomes loathsome.

The outlet of the gizzard discharges the digested food in the form of paste, having a grayish color, into the chyle-gut, which is the first of the intestines. This is situated on the right side, depending into the belly, and joined at each end to the liver. The liver prepares bile from the blood conducted to it by the veins, and by means of a duct carries the bile from the gall-bladder into the chyle-gut, in a downward direction, to be mixed with the digested food. This peculiarity is different 
from other animals. Another fluid, 'brought from the pancreas to the chyle-gut, completes the apparatus for digestion.

The food now proceeds on to the small intestines. The surface of these is lined with the mouths of numerous absorbents, which perpetually open to take up the aliment prepared in the stomach and chyle-gut. The refuse is passed to the rectum, to be discharged from the body.

- Fowls are also furnished with kidneys, for removing superfluous fluid from the blood. The kidneys lie in a hollow beside the back-bone, and the urine is carried from there in a bluish-colored canal into the vent-gut, or rectum. It here mixes, and is discharged with the dung. Fowls have no bladder, and it is, therefore, a criterion of health when the excrement is moist.

The diseases affecting the organs now described will be considered in their order.

\section{DISEASES OF THE DIGESTIVE ORGANS.}

I. THE PIP, OR GAPES.

This is the most common disorder of poultry and all domestic birds. It is especially the disease of young fowls, and is most prevalent in the hottest months. It is not only troublesome, but frequently fatal. There is a great diversity of opinion respecting its cause and its nature. Dr. Bechstein considers it a catarrhal inflammation, which produces a thickening of the membrane which lines the nostrils and the mouth, and particularly the tongue. M. Buchoz, however, is of opinion that it is caused by want of water, or by bad water. Others describe the disease as commencing in the form of a vesicle on the tip of the tongue, which oceasions a thickened state of the skin, by the absorption of its contents.

"A writer in the Farmer's Cabinet says positively, that the gapes in chickens is occasioned by worms in the windpipe; 
and this opinion is corroborated by the editor of the American Farmer. A writer of authority also remarks : - "On the dissection of chickens dying with this disorder, it will be found that the windpipe contains numerous small red worms, about the size of a small cambric needle; on the first glance, they would be likely to be mistaken for blood-vessels." It is supposed by some that these worms continue to grow, until, by their enlargement, the windpipe is so filled up that the chicken is suffocated.

Symptoms. - The common symptoms of this malady are the thickened state of the membrane of the tongue, particularly towards the tip. The breathing is impeded, and the beak is frequently held open, as if gasping for breath. The beak becomes yellow at its base, and the feathers on the head appear ruffled and disordered. The tongue is very dry. The appetite is not always impaired; but yet the fowl cannot eat, probably on account of the difficulty which the act involves, - and sits in a corner, to pine in solitude.

Remedy. - Most writers recommend the immediate removal of the thickened membrane. This is said to be best done by scraping it off, with the nail or with a needle; but it seems to be attended with a degree of cruelty. Richardson says the same effects may be produced by anointing the part with butter or fresh cream. If necessary, the scab may be pricked with a needle. He also recommends a pill, composed of equal parts of scraped garlic and horse-radish, with as much cayenne pepper as will outweigh a grain of wheat, to be mixed with fresh butter, and given every morning - the fowl to be kept warm.

If the disease is in an advanced state, which is shown by the chicken holding up his head and gaping, for want of breath, it should be thrown on its back. and while the neck is held straight, the bill should be opened, and a quill should be inserted into the windpipe, with a little turpentine. This 
being turned round, will loosen and destroy a number of small red worms, some of which will be drawn up by the feather, and others will be coughed up by the chicken. The operation should be repeated the following day, if the gaping continues. If it ceases, the cure is effected.

There can be little doubt that this troublesome disease is caused by inattention to cleanliness in the habits and lodgings of fowls. An intelligent and lucid writer in the Southern Planter says, "The worms in the lungs of chickens are produced by the inhalation of the eggs of the hen-lice. The minute eggs are deposited in the feathers and down of the hen, and the chickens being hovered over by the hen, the eggs are drawn into the cells of the lungs, at each inspiration, which hatch and produce the worms which smother the chickens." Mr. C. F. Morton, of New Windsor, also says :- "There is one fact connected with this disease - that it is only old henroosts that are subject to it ; and I am of opinion that when it prevails, if the chicken-houses and coops were kept clean, and frequently whitewashed with thin whitewash, with plenty of salt or brine mixed with it, and those chickens that take the disease operated on and cured, - or, if they should die, have them burned up, or so destroyed that the eggs of the worms would not hatch out, - that the disease would be eradicated.

With my first brood of chickens. there was not one escaped the gapes. But all that have been hatched since I had the chicken-house and coops well whitewashed, inside and out, with thin whitewash, with plenty of brine in it, and kept clean, have been exempt from the disease, with occasionally an exception of one or two chickens out of a brood."

Mr. Benjamin Anderson, in the Southern Planter, states that some of his neighbors have entirely prevented this disease, by mixing a small quantity of spirits of turpentine with the food of their fowls. "From five to ten drops, to a pint of meal, to 
be made into dough, are the proportions used." And Major Chandler, in the Tennessee Agriculturalist, gives the following recipe, as an infallible preventive:- "Keep iron standing in vinegar, and put a little of the liquid in the food every few days. Chickens so fed are secure from gapes."

It is the opinion of Garret Bergen that this malady is prevented simply by "scanting them in their food ;" and he pertinently asks, "Who ever heard of chickens, which were not confined with the hen, but both suffered to run at large and collect all their own food, to be troubled with this disease?"

\section{INDIGESTION.}

Cases of indigestion among fowls are common, and deserve attention according to the causes from which they proceed. A change of food will often produce crop-sickness, as it is called, when the fowl takes but little food, and suddenly loses flesh. Such disease is of little consequence, and shortly disappears. When it requires attention at all, all the symptoms will be removed by giving their diet in a warm state. Sometimes, however, a fit of indigestion threatens severe consequences, especially if long continued. Every effort should be made to ascertain the cause, and the remedy must be governed by the circumstances of the case. Mowbray mentions a hen manifesting all the symptoms of indigestion, in whose crop beans were found, which had obstructed it long enough to present marks of vegetation. An incision was made, the wound healed, and health was restored. Generally, affections of this kind, as in the human species, proceed from over-feeding or want of exercise. The symptoms are, heaviness, moping, keeping away from the nest, and want of appetite.

Remedy. - Lessen the quantity of food, and oblige the fowl to exercise in an open walk. Give some powdered cayenne and gentian, mixed with the usual food. Iron-rust, mixed with 
soft food, or diffused in water, is an excellent tonic, and is indicated when there is atrophy or diminution of flesh. It may be combined with oats or grain. In England, it is said that milkwarm ale has a good effect when joined to the diet of diseased fowls.

III. COSTIVENESS.

The existence of this disorder will become apparent by observing the unsuccessful attempts of the fowl to relieve itself. It frequently proceeds from continued feeding of dry diet, without access to green vegetables. Indeed, without the use of these, or some such substitute, as mashed potatoes, costiveness is certain to ensue. The want of a sufficient supply of good water will also produce the disease, on account of that peculiar structure which has already been explained, by which fowls are unable to void their urine except in connection with the fœces of solid food, and through the same channel.

Remedy. - Soaked bread, with warm skimmed milk, is a mild remedial agent, and will usually suffice. Boiled carrots, or cabbage, are more efficient. A meal of earth-worms is sometimes advisable, and hot potatoes, mixed with bacon-fat, are said to be excellent. Castor-oil and burned butter will relieve the most obstinate cases, though a clyster of oil may be sometimes required, in addition, to effect a cure.

\section{DIARRHCEA.}

There are times when fowls dung more loosely than at others, especially when they have been fed on green or soft food; but this may occur without the presence of disease. But should this state deteriorate into a confirmed and continued laxity, immediate attention is required, to guard against fatal effects. The causes of diarrhœa are, dampness, undue acidity in the bowels, or the presence of irritating matter there.

The symptoms are, lassitude and emaciation, and, in very 
severe cases, the voiding of calcareous matter, white, streaked with yellow. This resembles the yolk of a stale egg, and sticks to the feathers near the vent. It becomes acrid, from the presence of ammonia, and causes inflammation, which extends speedily throughout the intestines.

Remedy. - This, of course, depends upon the cause. When the disease is brought on by a diet of green or soft food, the food must be changed, and water given sparingly. When it arises from undue acidity, chalk mixed with meal is advantageous, but rice flour boluses are most to be depended on. Dr. Handel, of Mayence, in cases of chronic looseness, recommends water impregnated with iron-rust, with great confidence. Alum-water, of moderate strength, is also beneficial.

In cases of bloody flux, boiled rice and milk, given warm, with a little magnesia or chalk, may be given with success.

\section{DISEASES OF THE RESPIRATORY ORGANS.}

Fowls are so constructed, in their respiratory system, that their method of breathing is somewhat peculiar. The principal organ used by them in breathing is the nostril, rather than the mouth. It will easily be observed, that their nostrils are comparatively large. They have an immediate communication with the windpipe. The windpipe is constructed with a series of firm cartilages, bound together by strong membranes. These are exceedingly elastic, and are able to resist considerable pressure; so that it is difficult to disturb the cylindrical form of this organ, or to impede the free ingress or egress of the air necessary to breathing.

The windpipe reaches down to the chest, and is there divided into branches, which become constantly smaller, till they seem to be mere holes. These ramifications of the windpipe, together with numerous blood-vessels, constitute the substance of the 
lungs. The spaces between them are occupied with a delicate nnembrane, which unites them, and gives a regular appearance to the mass. The holes in which the branches of the windpipe terminate are apertures into large air-sacs, which communicate with the various parts of the body, and constitute, as it were, an auxiliary lung. The whole mass of the lungs proper is encased with a membrane called the pleura, of great delicacy, which secretes a watery fluid, of great use in preventing any adhesion of the several parts.

\section{OBSTRUCTION OF THE NOSTRIL.}

When the nostrils, which we have seen are so important a portion of the breathing apparatus, are obstructed, disease supervenes. This is sometimes produced in consequence of wounds received in fighting. The comb, when lacerated, will plug up the nostril with a hard crust, of great tenacity. Canker and ulceration of the nostril is not infrequent, and a catarrhal affection commonly produces this annoying disorder. The symptoms are similar to those attending the pip, - the bird gapes and pants for breath.

Remedy. - In cases of laceration, the parts should be washed with warm water or suds till the crust is loosened and removed. Canker or ulceration, if recent, may be rubbed with honey, to defend from the effects of the air; but if of long standing, Dickson recommends to touch with a red-hot wire, which will produce a scab, and thus facilitate a cure. When obstructions arise from catarrh, bathe the nostrils with warm milk and water, or anoint with sweet oil or fresh butter.

\section{ASTHMA.}

This disease, common among fowls, seems to differ in characteristics sufficiently to authorize a distinction into two species. In one, it appears to be caused by an obstruction of the air-cells, 
by an accumulation of phlegm, which interferes with the exercise of their functions. The fowl labors for breath, in consequence of not being able to take in the usual quantity of air at an inspiration. The capacity of the lungs is thereby diminished, the lining membrane of the windpipe becomes thickened, and its minute branches are more or less affected. These effects may reasonably be attributed, as Richardson thinks, to the fact, that, as our poultry are originally natives of tropical climates, however well they may appear acclimated, they, nevertheless, require a more equable temperature than is afforded except by artificial means.

Another variety of asthma is induced by fright, or over excitement. It is sometimes produced by chasing fowls to eatch them, by seizing them suddenly, or by their fighting with each other. In these cases, a blood-vessel is often ruptured, and sometimes one or more of the air-cells.

The symptoms are short breathing, opening of the beak often. and for a space together, heaving and panting of the chest; and in case of a rupture of a blood-vessel, a drop of blood appearing on the beak.

Remedy. - Confirmed asthma is difficult to cure. For the disease in its incipient state, it is recommended that the fowl be kept warm, and be treated with repeated doses of hippo-powder and sulphur mixed with butter, with the addition of a small quantity of cayenne pepper.

\section{ROUP.}

This term is used very loosely, both in common speaking and among writers on poultry, to characterize disease. It is indifferently applied to describe maladies as dissimilar as obstruction of the rump gland, the pip, and catarrh. It should be confined, however, to a dangerous disorder, with symptoms sufficiently marked to identify it, which is caused mostly by 
cold and moisture, but often ascribed to improper feeding, want of cleanliness and exercise.

The roup affects fowls of all ages, and is either acute or chronic ; sometimes commencing suddenly, on exposure; at others, gradually, as the consequence of neglected colds, or damp weather or lodging. Chronic roup has been known to extend through two years.

Symptoms. - The most prominent symptoms of roup are difficult and noisy breathing, gaping, terminating in a rattling in the throat. The head swells and is feverish. The eyes are swollen, and the eye-lids appear livid; the sight decays, and sometimes total blindness ensues. There are discharges from the nostrils and the mouth, at first thin and limpid, afterwards thick, purulent and fetid. In this stage, which resembles the glanders in horses, the disease becomes infectious. As secondary symptoms, it may be noticed that the appetite fails, except for drink, the crop feels hard, and the feathers are staring, ruffled, and without the gloss which appears in health. The fowl mopes by itself, and seems to suffer much pain.

Remedy. - When fowls are infected with roup, they ought to be kept warm, and have plenty of water and scalded hran, or other light food. When chronic, change of food and air is advisable. The common remedies, such as salt dissolved in water, are inefficacious. Richardson gives the following formula : powdered gentian and ginger, each one part; epsom salts, one and a half part, and flour of sulphur, one half part, to be made up with butter, and given every morning.

But for roup and all putrid affections, I confidently prescribe the following, and consider it the only true treatment. Take finely pulverized, fresh-burnt charcoal, and new yeast, of each three parts; pulverized sulphur, two parts ; flour, one part; water, quantity sufficient; mix well, and make into boluses of 
the size of a hazelnut, and give one three times a day liness is no less necessary than warmth, and it will sometimes be desirable to bathe the eyes and nostrils with warm milk and water, or suds, as convenient.

With regard to this disease, Mr. Giles says :-

" $\mathrm{My}$ method with the roup, or swelled head, which, by the way, is caused by a cold, is as follows: As soon as discovered, if in warm weather, remove the infected ones to some well ventilated apartment, or yard; if in winter, to some warm place; then give a dessert spoonful of castor-oil ; wash their heads with warm castile soap-suds, and let them remain until next morning fasting. Scald for them Indian meal, adding two and a half ounces of epsom salts for ten hens, or in proportion for a lesser or larger number; give it warm, and repeat the dose in a day or two, if they do not recover."

Mr. Giles is excellent authority, having had " more than thirty years' practice among the feathered tribes," and being now the owner of one of the most extensive collections of pureblooded fowls in this or any other country.

\section{CONSUMPTION.}

We should be apt to imagine from the warm clothing of feathers with which fowls are provided, that they would be exempt from colds and consumption. But all the symptoms of cold, such as hoarseness, sneezing, \&c., are readily observed. That they should be susceptible to such influences appears reasonable, when the peculiar structure already adverted to is remembered. The air taken into the lungs of fowls is not stopped there, but by means of air-cells reaches every part of the body - pervading the interior of the bones. Their great susceptibility, also, is connected with the fact that they are originally tropical animals. They are also affected, more or less, by the circumstances in which they are placed, spend- 
Ing a large part of their existence in coops and under shelter, so that they are more liable to be affected by exposure.

The researches of M. Flourens, a distinguished French physiologist, who has investigated the subject of disorders produced in fowls by cold with great care and success, produce the following important results.

1. "That in these creatures cold exercises a constant and determined action on the lungs."

2. "That this action is more sudden and more serious, in proportion as the creature is of tender age."

3. "That when cold does not produce a pulmonary inflammation, acute and speedily fatal, it produces chronic inflammation, which is in fact pulmonary phthisis."

4. "That warmth uniformly prevents the access of pulmonary phthisis, and as uniformly suspends its progress, when this has commenced; and sometimes even stops it entirely, and effects a complete cure."

5. "That this disease, at whatever stage it may have arrived, is never contagious. The chickens affected were with healthy chickens, and roosted at night in the same baskets, without inconvenience."

The symptoms of this disease are unmistakable, and are like all other symptoms of cold, hoarseness, sneezing, \&c. \&c.

Remedy. - Shelter and housing, and sometimes the indulgence of the fireside. Temperature alone is the dominant principle, to which attention ought to be paid.

\section{DISEASES OF THE CIRCULATION.}

The heart in fowls, as in man and quadrupeds, consists of two ventricles for throwing the blood into the arteries - one to be distributed to the lungs, and the other through the rest of the body, - and two auricles, for receiving the returned blood. The 
blood itself is composed of a yellowish substance, called serum, and a red-colored mass, or crassamentum.

The blood of fowls is liable to several diseases, the chief of which may be described as fever and inflammation.

\section{FEVER.}

The most decided sort of fever to which fowls are subjected occurs at the period of hatching. At this time the animal heat is so increased that it is perceptible to the touch. A state of fever may also be observed when fowls are about to lay. This is generally of small consequence when the birds are otherwise healthy, but is of moment if any other disorder is present, as in such case the original disorder will be aggravated. Fighting frequently occasions fever also, and sometimes proves fatal.

Symptoms. - An increased circulation of the blood, excessive lieat, and restlessness.

Remedy. - Light food and change of air, and, if necessary, aperient medicine, such as castor-oil, with a little burnt butter. "In a case of highly inflammatory fever in a chicken, supposed to have been caused by sudden hot weather in May, so that it burned the hand like hot water, a dose of nitre, in milk and water, at night, produced so great a change that the chicken was cool and brisk in the morning. The dose was repeated, and brought on a cold fever fit, like ague, which, however, changed to an intermittent, and the chicken completely recovered."-Dickson. Such symptoms are probably rare, at least in this climate!

In the country, it is common to stop the hatching fever by turning the hen rapidly round, in order to produce giddiness, which effects a reduction in the velocity of the blood. The fever produced by the excitement of fighting may be abated by plunging the fowl in cold water. In this case, the patient must be immediately dried and housed. 


\section{INFLAMMATION.}

Inflammation may be described, for all practical purposes, as consisting in increased arterial action of the parts immediately surrounding points of stagnation, and it may occur indifferently in the external or internal parts. Inflammation of the lungs has been already considered, and various parts of the fowl are liable to similar affections. But most of these are of small consequence. The most serious is an inflammation of the eyes. When this occurs, small abscesses are formed on the cornea, which are filled with a white-colored pus. In an aggravated form, the whole of the eye becomes inflamed, the eye-lids swell to a great extent, and a coagulable albuminous matter, like the white of an egg, accumulates beneath the swelling. This affection sometimes results in blindness, and is sometimes fatal.

This disorder is originated by the vapors arising from close confinement, when over care is exercised to shield the fowls from the effects of eold; - and it is produced likewise by exposure, and particularly to moist cold.

Treatment and Remedy. - Like other cases of inflammatory attacks, relief is to be sought in a suitable temperature being maintained where fowls are kept. A little aperient medicine will be beneficial, and applications of warm suds, made from castile soap, in case of abscess, or great swelling of the inflamed part

\section{RHEUMATISM.}

M. Flourens states cases of acute rheumatism and sciatica as occurring among fowls under his own observation. Dickson says that he has seen rheumatic affections among his fowls " even at midsummer, after much wet, and more than once as a consequence of plunging them in water for the hatching fever." After much exposure, especially in long-continued 
damp and rainy weather, this disease is very likely to exhibit itself.

The symptoms are, a stiffness of the limbs, and manifest pain in the attempt to move about, which also renders the gait unsteady.

Remedy. - Warmth and shelter, with a cooling and opening diet.

\section{GOUT.}

This disorder is almost confined to old fowls, and therefore the opportunity afforded for observing it but seldom occurs. It will not always repay the necessary trouble to attempt a cure.

The symptoms are somewhat like those of rheumatism, but a swelling of the joints is the most marked characteristic.

Remedy. - Sulphur, mixed with scalded bran or soaked bread. Pellets of colchicum are also recommended.

\section{DISEASES OF THE BRAIN.}

The structure of the brain in fowls is very peculiar. There are two distinct parts, - one unmarked by convolutions; and the other, which may be ealled the cerebellum, is distinguished by cross parallel streaks. In several other respects, there is an important difference between the brain of fowls and that of quadrupeds or man.

\section{APOPLEXY.}

The principal disorder to which the brain is subjected, among fowls, is what most resembles apoplexy. Some writers have spoken of this disease under other names, as Dr. Bechstein, who calls it epilepsy, and Mr. Clater, who chooses to designate it as the megrims. The causes are alleged to be, improper food, and general neglect or improper treatment. M. Flourens, who has devoted considerable attention to the subject, says 
that there are two degrees of this disease, which he denominates " deep-seated" and "superficial."

Symptoms. - Deep-seated apoplexy is characterized by complete disorder of movement; while superficial apoplexy is manifested only by deficient muscular energy, and instability in walking. The deep-seated apoplexy is accompanied with the other; but, as this is the precursor of the former, it ought to be carefully attended to, in order to prevent the more serious attack. In sudden attacks, the fowl falls instantly, rolls on the back, struggles for a short time convulsively, and appears stupid and giddy. The fit often recurs at short intervals, and each one is more violent than the other.

M. Flourens had brought to him a young fowl, whose gait indicated that of a tipsy animal so much that the peasants called it the tipsy hen. Whether standing, walking, or running, it reeled and staggered, and apparently without control of its motions. It would go backward when it attempted to go forward, and vice versa. It often fell, from the bending of the legs beneath the body; and, on attempting to fly to the perch, it fell and rolled on the ground, without the power to recover its legs, or to find its balance. M. Flourens examined the brain, and found the bone of the skull to be covered with black, carious points. On penetrating the dura mater, clear water exuded. The cerebellum was yellow, with streaks like rust, and in the centre was a mass of purulent, coagulated matter, contained in a cavity by itself, the sides of which were thin and smooth.

Remedy. - The old method of treating this disease is the result of ignorance of its cause and nature; and the hitherto popular recipe of castor-oil and syrup of ginger is to be avoided as useless, or worse. The application of leeches to the nape of the neck alone promises a successful cure. The diet should be light, and the quantity of food small. The diseased fowl should be confined in a dark coop. 


\section{MELANCHOLY AND MOPING.}

Under these terms, such symptoms as want of appetite, drooping, and other effects of indigestion, are mentioned as indicating a separate disease. It is reasonable, however, to refer these characteristics to a disordered state of the nervous system. Such remedies as have already been mentioned, for costiveness, \&c., should be attended to ; and if any symptoms of greater gravity appear, such treatment as belongs to nervous affections will be indicated.

\section{DISEASES OF THE SKIN.}

I. MOULTING.

Moulting is a natural process of annual occurrence; and, though it can scarcely be called a disease, yet it is necessary to treat it as if it were such, from the effects produced by it. It not unfrequently happens that young fowls do not pass the season of moulting safely, but sicken and die. Chickens of the latest broods are most liable to bad effects, because the season of moulting comes to them so late, when the weather is most unfavorable. The summer moult is usually gradual, but few feathers falling at a time, and these being at once replaced. On the contrary, when the moult happens in autumn, the feathers fall faster, and are not so speedily replaced. The consequence is, that the fowl is in a degree naked, and suffers from the necessary exposure.

It is the remark of Dr. Bechstein, that, in a state of nature, moulting occurs to wild birds precisely when their food is most plenty; hence, nature points out that the fowl should, during that period, be furnished with an extra supply of food.

After the third year, it has been observed that fowls begin to moult later every succeeding year, so that it is frequently as late as January before the older fowls come into full feather ; 
and, the weather being then cold, they are not in a laying state till the end of March, or later. The time of moulting continues, according to the age and health of the fowls, and also with reference to mild or cold weather, from six weeks to three months. " I think I have observed," says Dickson, " in some instances of late hatching, that the process is favorable to moulting."

Symptoms. - A falling off in appetite, moping, and inactivity; the feathers staring and falling off, till the naked skin appears.

Remedy. - In diseased moulting, M. Chomel advises to add sugar to the water which the fowls drink, and to give corn and hempseed. They should be kept warm, and occasionally be treated to doses of cayenne pepper.

\section{LOSS OF FEATHERS.}

This disease, which is common to confined fowls, is by no means to be confounded with the natural process of moulting. In the annual healthy moult, the fall of the feathers is occasioned by the protrusion of new feathers from the skin. In the diseased state, which we now consider, where the feathers fall, no new ones come to replace them, but the fowl is left bald and naked. A sort of roughness appears also on the skin.

The symptoms are like those just described in the previous article, and are easily distinguishable.

Remedy. - This affection is probably constitutional, rather than local. External remedies, therefore, may not always be sufficient. Stimulants, applied externally, will serve to assist the operation of what medicine may be given. SuIphur may be thus applied, mixed with lard. Sulphur and cayenne, in the proportion of one quarter each, mixed with fresh butter, is good to be given internally, and will act as a powerful altera- 
tive. The diet should be changed, and cleanliness and fresh air are indispensable.

III. VERMIN.

The whole feathered tribe seem to be peculiarly liable to be infested with lice; and there have been instances when fowls have been so covered in this loathsome manner, that the natural color of the feathers has been undistinguishable.

Old Mascall says, " They get them in scraping abroad among foule strawe, or on dunghills, or when they sit in nests not made cleane; or in the hen-house, by their dung lying long there, which corruptes their bodyes and breedes lice and fleas."

The presence of vermin is not only annoying to poultry, but materially interferes with their growth, and prevents their fattening. In trifling cases, no particular attention is requisite; but where the cases are bad, the fowl should be secluded from the rest. It is Dickson's opinion that the infected fowl should be killed; but this does not seem to be necessary, except where the nuisance becomes intolerable. He thinks, likewise, that vermin are the result of a constitutional state, and that they cannot be extirpated. But there can be no doubt that, in this respect, he has fallen into serious error.

Remedy. - A writer in the Cultivator recommends to mix with Indian meal and water, and feed in the proportion of one pound of sulphur to two dozen fowls, in two parcels, a few days apart. It is said that this will exterminate the lice, and produce a healthy and glossy appearance in the fowls. Another writer says " lice may be destroyed by placing lard beneath the wing and on the back of the chicken." But Mr. Bement says, " that the best remedy we have ever found is cleanliness, and to place plenty of slacked lime, dry ashes and sand, where they can roll and dust themselves, by which means they will soon free themselves." In this opinion we are happy to concur. 


\section{EXTERNAL DISORDERS.}

\section{DISEASE OF THE RUMP GLAND.}

Mowbray speaks of an obstruction of the gland of the rump in fowls, under the name of Imposthume, and strangely enough denominates the disease as Roup. Concerning the functions of this gland, erroneous ideas have very generally prevailed; and the common notion has been, that its use was to secrete an oily matter, which was applied by the fowl to the purpose of making their feathery coating water-tight. M. Reaumur has effectually exploded this fancy, by showing conclusively the perfect impracticability of producing a secretion of sufficient quantity to enswer this end. And, in confirmation of this opinion, it is only necessary to mention, that while, in the case of the Rumkin fowl, there is no perceptible difference in the feathers so far as shedding water is concerned, they are deprived of any such gland.

But this gland frequently becomes diseased, and in consequence of obstruction, it is inflamed and swollen, and occasions great pain and uneasiness. In severe cases, the whole rump is affected, and the consequences may be serious.

This affection should be treated as a boil; when it becomes hard and ripe, let the pus or matter out by a slight incision. Reaumur advises that the outlet or duct of the gland should be cleared from obstruction by means of a tent introduced into the orifice.

\section{FRACTURES AND DISLOCATIONS.}

In most cases, when severe fractures occur to the limbs of fowls, unless they are very valuable, undoubtedly the best course to pursue, in mercy to the birds, is to kill them at once. But when it is deemed worth while to preserve them, splints may be used, when practicable. Great cleanliness must be observed, the diet should be reduced, and every precaution taken against 
the inflammation which is sure to supervene. When it is established, cooling lotions, such as warm milk and water, may be applied.

\section{II. WOUNDS AND SORES.}

Fowls are exposed to wounds from many sources. In their frequent encounters with each other, severe wounds often occur. The poultry-house is besieged by enemies at night, and despite of all precaution, rats, and weasels, and other animals, will assault the occupants of the roost, or nest, to their damage. These wounds, if not attended to, often degenerate into painful and dangerous ulcers.

When such injuries occur, cleanliness is the first step to cure. The wound should be cleared from all foreign matter, washed with tepid milk and water, and excluded as far as possible from the air. The fowl should be removed from its companions, who in such eases seldom or never show sympathy, but, on the contrary, are always ready to assault the invalid, and aggravate the injury. Should the wound not readily heal, and ulcerate, it may be bathed with alum-water. The ointment of creosote is said to be effectual, even when the ulcer exhibits a fungous character, or proud flesh is present. Richardson says, that ulcers may be kept clean if dressed with a little lard, or washed with a weak solution of sugar of lead. If they are indolent, they may be $\mathrm{t}$ suched with bluestone.

\section{VERMIN IN POULTRY-HOUSES.}

As a remedy for vermin in poultry-houses, Mr. E. C. Dyer, of Boston, recommends the following, in a letter to the author:

"For the extermination of vermin or lice, the most effectual way of doing it is by putting some flour of sulphur into a vessel and setting fire to it - closing up the hen-house. It then penetrates every crevice." 
On the same subject, Mr. Giles, of Providence, remarks :" The best method that I have found to prevent the lice is to keep their house clean, whitewashing spring and fall, having the house well aired and lighted; and once in six months close the windows, procure an old iron pot, put into it six pounds of roll brimstone, make a fourteen pound iron ball red hot, put the ball into the brimstone, then fly, and close the door and every other opening. Do this in the morning early, return at three o'clock in the evening, throw open the doors and windows, and let them remain through the night, and the work of destruction is complete; not a living vermin will you find in that house for six months to come. When a hen comes off with her brood, clean out the old nest, put in a new one; take tobacco-leaves, dry, and rub them to powder between your hands, then mix it with the hay of your nest, and you will have added much to the health of your poultry."

Relative to which, Mr. Pedder, of the Boston Cultivator, says, "If he will mix a little salt-petre with the roll brimstone, the next time he fumigates his poultry-house, he will find that he need not heat his fourteen pound iron ball ; for, by merely touching the mixture with a heated poker, his business will be as effectually done, leaving ' no trace behind.'," 


\section{A P P E N D I X.}

\section{THE EXHIBITION OF POULTRY IN THE PUBLIC GARDEN, NOVEMBER 15 AND 16, 1849.}

I REGARD it as a matter of some interest and importance, that the account which has been published of the fowl show held in the Public Garden, at Boston, on the 15th and 16th of Nov., 1849 , should be preserved in a permanent form. It is natural that I should feel a peculiar interest in the matter, as the show was originally suggested by me. From the documents printed below, it will appear that the first idea was much less comprehensive than the result. On the 8 th of October, 1849, I addressed the following communication to the editor of the Boston Cultivator, which will explain itself, on perusal.

CONVENTION OF DOMESTIC FOWL-BREEDERS.

Mr. Editor:- Permit me, through the Cultivator, to say that, as many persons have been impused upon and deceived into the purchase of spurious fowls, supposing them to be pure bloods, I will exhibit, in Quincy Market, Boston, on Thursday, the 15th of November, from ten o'clock, A. M., to three o'clock, P. M., perfect samples of the full-blooded domestic fowls of the following breeds : -

Golden Pheasants,

Shanghaes,

Cochin Chinas,

Great Malays,

Great Javas,

Wild Indian,
Plymouth Rocks,

Yankee Games,

Fawn-colored Dorkings,

Pearl-white Dorkings,

English Ravens,

Bavarians. 
These comprise some of the handsomest and best fowls in the world. Fowl-breeders, and the best judges of poultry generally, are respectfully invited to attend, and any person who supposes he has the best specimens of any of those breeds is invited to present them at that time, and compare side by side. And I would here request Col. Josiah Stevens, of Concord, N. H., Mr. S. A. Drake, of Fiskdale, Massachusetts, Mr. John Giles, of Providence, R. I., Mr. Robert Estes, of East Abington, Mass., and Mr. Timothy House, of Boston, Mass., either by themselves, or in conjunction with such others as gentlemen interested may on that occasion appoint, to act as a committee to make an impartial report for the benefit of the public. It would be agreeable to me to have the editors of the agricultural papers in Boston, and others interested in the improvement of domestic fowls, appoint on said committee twice the number that I have done, so that their report may be perfectly satisfactory to all.

After the exhibition above alluded to, I shall, with your permission, communicate for the Cultivator some additional matter in relation to domestic fowls, which may not prove uninteresting to your patrons.

J. C. Bennett.

Plymouth, Mass., Oct. 8, 1849.

P. S. If you approve the plan as an important and beneficial one, please make the 15th a great day of gathering of fowlfanciers, and fowl-breeders, by your influence in the Cultivator. I shall bring $m y$ best, and if others can bring better, it will only be for the public good, and I shall be happy to acknowledge it, and as ready to do so as any other man. I shall abide the judgment of the committee, and I want you, and others interested, either to act on the committee, or appoint some others to do so, or both, at your option.

It is with much pleasure that we add the above postscript, 
since received; we can assure Dr. Bennett of a most cordial welcome for his novel and interesting suggestion.-ED. of Cultivator.

Mr. James Pedder, the editor of the Cultivator, entered into the project with great zeal, and with his characteristic enlarge ment of views, proposed that the plan of the exhibition should be extended, and become a general Fowl Show. In an editorial article, in his paper of Oct. 27, he says, -

"According to a promise made to many applicants, we would propose to Dr. Bennett 'to use his influence in the formation of a convention of domestic fowl breeders and fanciers, on a magnificent scale, giving to New England the honor of being the first in a movement that will be felt in every state in the Union.' In this country we have cattle-shows, conventions of fruit-growers, \&c., and in England they have not only these, but ' gooseberry shows!' while nowhere have they a 'convention of domestic fowl-breeders and fowl-fanciers,' nor have we. In view of this step, we presume it will be necessary to select a more suitable place for the annual exhibition - a feature which we are fully prepared to see the proposal assume - than the Quincy Market; and where comfort and shelter might be secured for the numerous visitors which will be sure to be present, as also for the animals to be exhibited: and we would venture to propose, that the meeting be held in the Public Gardens, where pavilions might be prepared, with a sale of entrance tickets at the doors, if four-pence only in price, to pay expenses and render it more select, each ticket holding good for the whole time of exhibition. This, we conceive, would be to give a respectability to the occasion, and if proper persons are selected to form a committee of arrangements, and give it their countenance, we think the end in view might be accomplished, as our friends express it, ' on a magnificent scale.' We would be pleased to be made the depository 
of proposals for securing a full attendance on the coming occasion, and a permanent existence of the ' New England Convention of Domestic Fowl Breeders and Fanciers."

In a succeeding number of the Cultivator, the annexed correspondence appeared.

$$
\text { Plymouth, Mass., Oct. 25th, } 1849 .
$$

To Col. Samuel Jaques, Dr. Eben Wight, John Giles, Esq., Mr. Timothy House, and Mr. H. L. Devereux.

Gentlemen : - You are aware that I have taken incipient measures to get up and organize a convention of breeders and fanciers of domestic fowls, to be called the "New England Ornithological Association," which, at the suggestion of Mr. Pedder, will, in all probability, establish an annual exhibition for laudable competition in that department; and that I have solicited the coöperation of all interested in the improvement and perfection of such stock. In order to give it respectability and popular favorable consideration, it will be necessary to have order and fitness in the organization and assemblage. Therefore, suffer me to respectfully request you to act as a "Committee of Supervision," with plenary powers, until discharged or confirmed by the convention. - All of which is respectfully submitted by

Yours, respectfully,

J. C. Bennett.

In accordance with the above suggestion of Dr. Bennett, the committee would give notice, that the first annual exhibition of the "New England Ornithological Association" will take place on the 15th of November instant, at the store of Messrs. Parker \& White, No. 10 Gerrish Block, Blackstone-street, Boston,- commencing at nine o'clock, A. M., to continue through the day.

All those who take an interest in improving the breeds of 
domestic fowls, or who have specimens of choice stock - imported or otherwise - are respectfully invited to be present on the above occasion, and to forward their stock in season for exhibition on that day. The committee suggest, that contributors of fowls shall send them in compact coops, each labelled with the name of the breeder, class of stock, and age, upon a card attached to each box.

Boston, Oct. 29, 1849.

$$
\left.\begin{array}{l}
\text { Samuel Jaques, } \\
\text { Eben Wight, } \\
\text { John Giles, } \\
\text { Timothy House, } \\
\text { H. L. Devereux, }
\end{array}\right\} \text { Committee, } \& c \text {. }
$$

It is well known that, in accordance with the above, the contemplated meeting took place at the Public Gardens, and with the most unexpected results. Upwards of ten thousand persons were estimated to have been in attendance, and there was a general coöperation of fowl breeders and fanciers throughout the country. All who contributed to the show did credit to themselves by the fine samples of fowls produced, and I consider it due to them to publish the entire report of the committee, in order that their names may be perpetuated. Great praise is due to Mr. James Pedder, of the Boston Cultivator, and Mr. George E. White, of the firm of Parker \& White, of Boston, for their indefatigable exertions on this occasion.

The official report is taken from the Boston Cultivator.

THE COMMITTEE OF SUPERVISION,

For the exhibition of poultry, held at Boston, on the 15th and 16th days of Novernber, 1849,

REPORT : - This exhibition may be said to have been, in its character, unprecedented in this country ; it being, so far as we are informed, the first meeting ever convened here for the 
special purpose of bringing together this description of Live Stock; and considering that it was simply a spontaneous gathering, produced without organization or previous concert, the result has been peculiarly gratifying, both as regards the number and variety, and quality of the different breeds of poultry, and the interest manifested in the display by the public.

The number of specimens of the different feathered races, presented on this occasion, numbered one thousand four hundred and twenty-three, and the number of exhibitors was two hundred and nineteen, recorded. The number of people admitted to the show was not less than ten thousand.

The sum of three hundred and sixty-four dollars was received at the gate, notwithstanding the admission of ladies and children gratis. Of this amount, the committee have expended $\$ 198.25$ in defraying various expenses incident to the exhibition, leaving in their hands a balance of $\$ 165.75$. The organization of an association, whose object should be the improvement of the different kinds of poultry, has been suggested, and the committee have devoted some attention to the subject; but are not prepared to offer a definite plan.

They would, however, remark, that, in their opinion, such an association, if established on a proper basis, and judiciously managed, would be of much utility; and they would express the hope, that at no distant day some efficient action may be taken by the friends of this measure. To the furtherance of such an object, the committee will give an early notice through the public journals, for the convening of those who may feel an interest in the subject.

In the mean time, the funds remaining in their hands will be deposited, in the name of the treasurer, George E. White, (Parker \& White,) at Exchange Bank.

The committee have thought it proper to present a general enumeration of the different kinds of poultry exhibited on the 
present occasion, together with the names of the exhibitors; but have not felt themselves authorized to make any critical observations.

A sufficient justification of this course will, we think, be found in the fact, that the committee was, in some degree, informally organized, and that their duties were understood to be merely supervisory; and as there were no premiums to bestow, they would avoid even the semblance of invidious comparisons.

'The committee, for the purpose of systematizing their account of the exhibition, have adopted the following arrangeinent.

Of the Gallinaceous family, the display was very extensive; the different specimens of which may be comprised under the following heads :

1. The Large Asiatic, or Great Malay tribe; of which several varieties were offered, under the name of Chinese, Cochin China, Red Shanghae, White Shanghae, Bucks County, Jersey Blues, and Java; the exhibitors of which were J. Giles, Providence, R. I. ; J. W. French, East Randolph ; David Blanchard, East Randolph; Geo. P. Burnham, Roxbury ; Franeis Alden, Dedham ; B. Lancaster, Jamaica Plain ; Asa Tribou, North Bridgewater; G. W. Mears, Boston ; E. B. Little, Haverhill ; G. W. George, Haverhill ; Sidney Packard, East Bridgewater ; S. H. Peck, Lynn ; A. White, East Randolph ; E. Jackson, East Bridgewater ; S. \& G. Hyde, Newton ; Linus Manley, Easton; C. J. Floyd, Dorchester ; T. Tyrrel, Easton; M. H. Tyrrel, Easton; B. W. Balch, Dedham ; A. W. Merrill, Brookline; Theodore Drew, Plymouth; John Chamberlin, Jr., Danvers ; C. M. Gillett, Kingston ; John W. Hunt, North Bridgewater; S. L. Read, Watertown; A. A. Andrews, Roxbury; W. W. Hague, Jamaica Plain; J. H. Noble, Somerville; Thos. Thorpe, West Cambridge; T. 
A. Stanley, Attleboro'; T. K. Hutchinson, West Cambridge; C. F. Manson, Cambridgeport ; C. B. Marsh, West Roxbury ; E. Howard, Easton; John F. Davis, Gloucester ; Nathan G. Hodgson, Stoughton; Shurtleff \& Coolidge, North Chelsea ; J. P. Bateman, Georgetown; H. L. Devereux, Buston; Geo. S. Pierce and Stephen Osborn, of Danvers; Clinton Clark, Brookline; W. J. Buckminster, Framingham; S. J. Howe, South Boston; G. E. White, Melrose ; J. C. Bennett, Plymouth; Samuel Jaques, Ten Hills Farm, Medford; S. B. Morse, Jr., East Boston; C. H. Pendleton, North Stonington, Conn.; Abel Moore, Boston ; S. G. Howe, South Boston; Joseph A. Stranger, Kingston ; Pliny Chapman, Springfield; John Allen, Jr., Salem; Whiting Metcalf, Franklin; John W. Porter, North Bridgewater; William L. Alley, Lynn; Geo. R. Carlton, Danvers; Samuel C. Hatch, Franklin, Conn.; E. E. Cole, Somerville; Samuel S. Gerrish, Somerville ; E. S. Roe, East Windsor, Conn. ; John Eaton, Reading; Josiah H. Stickney, Watertown; Henry Little, Marshfield; J. S. Houghton, North Chelsea.

2. The Dorking, Spanish, Italian, Guelderland, of which specimens were offered by W. E. Richardson, Brookline; John Giles, Providence, R. I. ; T. G. Morrill, Georgetown ; A. White, East Randolph; Calvin B. Austin, Danvers; O. M. Stacey, Lynn; Theodore Drew, Plymouth; John Chamberlain, Jr., Danvers; John W. Hunt, North Bridgewater; J. W. Spooner, Plymouth; Joseph A. Sampson, Duxbury; A. A. Andrews, Roxbury ; Daniel Buxton, Jr., Danvers; Shurtleff \& Coolidge, North Chelsea; A. P. Bateman, Georgetown; H. L. Devereux, Boston; Geo. C. Peirce and Stephen Osborn, of Danvers; L. H. Stoddart, Brookline; Clinton Clark, Brookline; Eben Wight, Dedham; E. G. Kelley, Newburyport; S. B. Morse, Jr., East Boston; W. 
J. Buckminster, Framingham; Francis Blake, Needham; Nathaniel Coolidge, Chelsea.

3. The Game Fowl, Bolton Gray, or Creole Fowl, the Frizzled Fowl, the Spangled Hamburgh, the Pencilled Dutch FowlJohn Giles, Providence; George Dorr, Dorchester; O. M. Stacey, Lynn ; John Chamberlain, Jr., Danvers ; D. M. Robertson, Manchester; John W. Hunt, North Bridgewater; W. W. Hague, Jamaica Plain ; Nathan G. Hodgson, Stoughton ; Joseph A. Stranger, Kingston； A. P. Bateman, Georgetown; Geo. C. Peirce and Stephen Osborn, of Danvers; James Houghton, Dorchester ; S. B. Morse, Jr., East Boston ; J. C. Bennett, Plymouth ; E. E. Cole, Somerville ; H. C. Parker, Manchester, N. H. ; Nathan Moore, Lynn.

4. The Crested or Top-knot varieties, of which there were specimens of the Black Poland, the White Poland, the Golden Spangled, and the Silver Spangled, offered by J. N. French, East Randolph; T. G. Morrill, Georgetown; A. White, East Randolph ; D. Holmes, Malden ; Theodore Drew, Plymouth; Isaac Pratt and John W. Hunt, N. Bridgewater; W. Beers, Woburn; J. W. Spooner, Plymouth ; Joseph A. Sampson, Duxbury ; A. A. Andrews, Roxbury ; J. M. Rowell, Manchester, N. H. ; H. L. Devereux, Boston ; T. G. Tilton, Newburyport; Geo. C. Peirce and S. Osborn, Danvers; Nathan Moore, Lynn; Clinton Clark, Brookline; W. H. Beckett, Lawrence; J. C. Bennett, Plymouth; S. Jaques, Ten Hills Farm; C. B. Marsh, West Roxbury; Geo. Spofford, Georgetown ; F. W. Davenport, Milton ; John W. Porter, North Bridgewater; Calvin B. Austin, Danvers ; P. Vose, Framingham; Elisha Jacobs, Brookline; Charles R. Belcher, East Randolpl.

5. Bantam Fowl, of different varieties, offered by John Giles, Providence, R. I. ; E. B. Little, Haverhill ; Henry Little, Marshfield; A. H. Hale, Rockport; B. W. Balch, 
Dedham; Cilvin B. Austin, Danvers ; E. B. Richardson, Brookline; A. A. Andrews, Roxbury; H. L. Devereux, Boston; Geo. C. Peirce and Stephen Osborn, Danvers; Z. Cooley, Boston ; S. B. Morse, Jr., East Boston; Francis Blake, Needham; J. C. Bennett, Plymouth; John Eaton, Reading; G. F. Brown, Boston ; J. H. Peck, Lynn.

6. Fowls produced by crosses of various breeds and varieties, offered by S. M. Stanley and P. M. George, Attleboro'; Parker Barnes, Dorchester; J. N. French, East Randolph ; Geo. P. Burnham, Roxbury ; Henry Little, Marshfield ; T. G. Morrill, Georgetown: A. White, East Randolph; Linus Mauloy, Easton; Philip S. Osborn, Danvers ; C. J. Floyd, Dorchester ; N. H. Tyrrel, Easton; A. H. Hale, Rockport ; Theo. Drew, Plymouth; Isaac Pratt, North Bridgewater; John Chamberlain, Jr., Danvers; John W. Hunt, North Bridgewater; W. Beers, Woburn; I. W. Spooner, Plymouth; A. A. Andrews, Roxbury; I. A. Butters. Boston; A. P. Davis, Gloucester; T. A. Stanley, Attleboro'; T. K. Hutchinson, West Cambridge ; E. Howard. Easton ; I. M. Rowell, Manchester, N. H. ; Joseph A. Stranger, Kingston; P. B. Burke, West Newton; I. W. Hallum, Lynn; A. P. Bateman, Georgetown; H. L. Devereux, Boston ; N. C. Day, Leominster; G. C. Peirce and Stephen Osborn, Danvers; Otis Putnam, Danvers; E. G. Kelley, Newburyport; S. B. Morse, Jr., East Boston; W. J. Buckminster, Framingham ; J. C. Bennett, Plymouth; Geo. R. Carleton, Danvers.

Under this head, the committee would mention, as worthy of notice, the Plymouth Rock Fowls, so called, bred by Dr. J. C. Bennett, of Plymouth, and presented by Geo. P. Burnham, of Roxbury; and also the fowls called English Grays, specimens of which were offered by several individuals.

Of Pheasants, the only specimen offered was one pair of the English Pheasant, by Samuel Jaques, Ten Hills Farm. A 
pair of Turkey Partridges was offered by B. F. Dow, East Boston.

7. The Peacock and Peahen, offered by I. Kinsley, Foxboro'.

8. The Guinea Fowl, or Pintado, offered by John Giles, Providence, R. I., (the only specimen entirely white;) I. R. Bartlett, Newburyport.

9. Of the Turkey, the only specimen offered was a pair of Wild Turkeys, by John Giles, Providence, R. I.

10. The Pigeon, of different varieties, offered by John Giles, Providence, R. I. ; Geo. W. Boynton, Georgetown.

11. The Swan; the only specimen offered was a pair of imported White Swans, by John Giles, Providence, R. I.

12. The Goose; of this variety, several specimens were offered, - by Daniel Webster, Marshfield, the Wild Goose and Goslings; Samuel Jaques, Ten Hills Farm, Bremen Geese; John Giles, Providence, R. I., Poland and Barnacle.

13. The Duck, of different varieties, offered by Edward S. Rand, Dedham, Wood; John Giles, Providence, R. I., Aylesb̆ıry; W. F. Churchill, Roxbury, Muscovy; B. W. Balch, Dedham; Jona. C. Ellis, Walpole.

Until quite recently, the breeding and rearing of poultry, in this section of the country, has been considered too insignificant an article of stock to require any, or very little notice.

The rearing of poultry, as will be slown, is certainly not the least important article of stock to the farmer. And the subject is now beginning to assume an importance which the committee hope may produce an honorable competition at our fairs, for the best stock, - that stock, whichever it may be, that shall give the best fowl - those giving the greatest amount of meat with the least offal, - and which shall, at the same time, give the largest number of eggs, or return in profit, for the amount invested. 
That the rearing of poultry for market can be made profitable, the committee could produce facts from well authenticated sourees, which should convince the most incredulous; but they will omit doing so in this report, and confine themselves to a few statistical remarks.

The article of poultry is readily converted into money, and is probably quite as readily prepared for market as any other at ticle of stock produced on the farm. The expense of feeding the best stock is no more than would be the expense of feeding and rearing the poorest dunghill fowl, while the return shows a heavy balance in favor of the large-bodied and finemeated fowl, with little offal.

Our convenience to the London market, by the aid of steamers, weekly, enables the farmer, through the egg-merchant, to make sale of his surplus eggs in that quarter.

The amount of sales of poultry at the Quincy Market, Boston, for the year 1848, was six hundred and seventy-four thousand four hundred and twenty-three dollars. The average sales of one dealer alone amounted to twelve hundred dollars per week, for the whole year. The amount of sales for the whole city of Boston, for the same year, (so far as obtained,) was over one million of dollars.

The amount of sales of eggs, in and around the Quincy Market, for 1848, was one million one hundred and twentynine thousand seven hundred and thirty-five dozen, which, at eighteen cents per dozen, (the lowest price paid eleven and a half cents, and the highest thirty cents per dozen, as proved by the average purchases of one of the largest dealer's books,) makes the amount paid for eggs to be two hundred and three thousand three hundred and fifty-two dollars and thirty cents. And from information already obtained from other egg-merchants, in the same city, the whole amount of sales will not fall much, if any, short of a million of dollars, for 1848 . 
The average consumption of eggs, at three of the hotels, was more than two hundred dozen, each day, for the year 1848.

The value of eggs brought from the Penobscot and Kennebec rivers, during the running season of the steamboats plying between Boston and those two rivers, was more than three hundred and fifty thousand dollars, for that season.

In one day, from Cincinnati, Ohio, it is stated in one of the public journals, there were shipped five hundred barrels, containing forty-seven thousand dozen of eggs. One dealer, in the egg trade, at Philadelphia, sends to the New York market, daily, nearly one hundred barrels of eggs. It is estimated, from satisfactory returns, that the city of New York, alone, expends nearly a million and a half of dollars, in the purchase of eggs.

By reference to the Agricultural statistics of the United States, published in 1840, it will bo seen that the value of poultry in the state of New York was two million three hundred and seventy-three thousand and twenty-nine dollars; which was more than the value of its sheep, the entire value of its neat cattle, and nearly five times the value of its horses and mules.

The same authority exhibits the total valuation of poultry, in various states and territories of the Union

States.

Value in Dollars.

Maine, .............. 123,171

New Hampshire, . . . . . . . . 97,862

Vermont, ............... 176,437

Massachusetts, ............ . 540,295

Rhode Island, . . . . . . . . . . 61,492

Connecticut, ............. . 176,659

New York, ........... 2. 2,373,029

New Jersey, . . . . . . . . . . . 412,487

Pennsylvania,.............. 1,033,172 
Delaware, . . . . . . . . 4 47,465

Maryland, ............... 219,159

Virginia, ............ 752,467

North Carolina, ........... . 544,125

South Carolina, .......... 590,594

Georgia,..................... 473,158

Ohio,................... 734,931

Kentucky, ............ . . . 536,439

Tennessee, ........................ 581,531

Louisiana, . . . . . . . . . 273,314

Mississippi, .............. 369,481

Alabama, ............... . 829,220

Missouri, ............ 230,283

Indiana, . . . . . . . . . . 393,228

Illinois, . . . . . . . . . . 330,968

Michigan, .............. 82,730

Arkansas, . . . . . . . . . 9 93,549

Florida, ............ 61,007

Wisconsin, ................. 16,167

Iowa, .................... 17,101

District Columbia, . . . . . . . 3,092

Total, ........... \$12,176,170

It is probable that, since 1840 , the value of poultry lias doubled.

In Bixio's Journal of Practical Agriculture and Gardening, for April, 1848, it is estimated, that the whole valuation of eggs consumed and exported in France will amount to fiftyseven millions of dollars. The value of eggs shipped from Dublin to Liverpool and London was more than five millions of dollars, for the year 1848. France, in 1835, had seventythree millions of dollars invested in poultry. England, in 1840 , had fifty millions of dollars invested in poultry. Since that time, the numbers have, of course, increased.

The committee presume it is a very important part of their duty to warn amateurs and others of the impropriety of 
selecting their stocks from any other than the most approved breeds of fowls. Generally, the system of breeding poultry is conducted in the most loose and unscientific manner, and no real dependence can be placed on other than the pure stock. By selecting it, the articles early maturity, large size, and liberal produce, are surely to be depended upon; whereas, by indiscriminately adopting impure stock, there is no security that these will result.

Under the loose system of breeding referred to, it is equally impossible to keep up, as it is to establish, a distinctive breed of poultry. To conserve the purity of any variety, so that " like will produce like," in appearance and properties, is of -the highest importance - is, in fact, (next to the securing of these in a distinctive shape,) the grand aim of the scientific breeder. There are no errors, or indications of the work of chance, in the law and order of the Great Ruler of the universe, as these apply to either the animal or vegetable kingdoms. The farmer may as well collect a miscellaneous list of seeds, and strew them athwart his soil, in the expectation that an excellent crop of corn should be produced from them, as the poultrybreeder depend on the heterogeneous admixture of mongrel breeds of fowls, to produce improved specimens. A chance appearance may be made among them, to be sure, that might look promising, in the same way that one ear of corn might appear among the farmer's produce; but, unlike the ear of corn, the " bird of promise" can never be depended on to produce its like: the absence of mathematical exactitude in the animal composition forms an organic error in it, which nothing can obviate, so far as itself is concerned. It may produce all or any of the kinds, or crosses, concentrated in itself, but none of them in their pure distinctiveness : the leaven of deterioration will always be found a ruling element in their composition. 
The committee have alluded above to a difficulty, involving the greatest care, in preserving the different varieties of fowls distinct; and this difficulty attaches to the improved crosses as well. To blend the characteristics of two separate breeds, so that there will be no undue preponderance of the blood of either in the produce, is a work of great labor, and the most jealous care. The process must be carried on with the same degree of exactness, and be accompanied with as much careful calculation, as an astronomer would use to satisfy himself regarding the future appearance of a comet. Many genera tions of fowls must be operated upon, before anything like perfection can be attained. This being the case, it is perfectly evident that it becomes imperatively the duty of fowl-breeders to apply their care and observation to the preservation of pure stock, as upon that, and that alone, the profit of their labor depends.

It is, perhaps, no part of the duty of the committee, in making up their report, to enter on more specific details concerning the procuring and preserving the various breeds of fowls, - and they might, under this dubious feeling, have contented themselves with what they have already hinted, on these subjects; but a gentleman of Boston, known as an ornithologist, and a natural historian, having been solicited to furnisł them with his views on the classification of domestic poultry and the kinds which might, with advantage, be introduced into our New England poultry-yard, his kind compliance with the wish of the committee has determined them to carry the subject further. 


\section{REMARKS}

Upon the wild stocks from which the varieties of our domestic poultry are derived, and also upon those which might with advantage be introduced to enrich our poultry-yards.

The order from which the most valuable poultry is derived is that known to naturalists as Gallinæ, or Gallinaceous birds. The genus of these first in order is that known as Penelope, or Guan, of which there is not much to be said, as regards their fitness for the poultry-yard, as I know of but one instance in which one has been brought to this country. I brought a female specimen of crested Guan with me, on my return from Yucatan, which did not live a year after its arrival. This bird is of the size of a small turkey, weighing, when full grown, seven or eight pounds; the meat is very good. They live principally on the leaves of trees, and such like food, greedily eating grass, clover, \&c., - in short, almost any green herbage, and also fruits of various kinds. They are not diffcult to domesticate in their native countries, but, I think, could hardly be made to survive our cold winters.

The next genus would be that of Crax, or Curassow, known here as the Mexican pheasant. There are a number of species of this genus, of which several are frequently domesticated in their native country. I brought with me three different species to this country, viz., one Crax rubra, one Crax alector, and one Crax globicera. The Crax alector was killed by a dog, a few days after we arrived; the other two lived until winter, when, in order to save myself the trouble of keeping, I lent them to a travelling menagerie, and they soon died, - owing, probably, to neglect. These birds are larger and more hardy than those of the previously mentioned genus. Their meat is very good, and they feed on much the same food as the Guans. They might, perhaps, with care, be kept in this country; but of this I do not feel very sanguine. 
The next genus which affords anything likely to be of value in the poultry-yard is that of Pavo, or Peacock. There are three known species belonging to this genus, of which the $P$. Cristatus is the one generally known. This bird used to be highly valued for the table, and I see no reason why it should not be again.

The next genus likely to afford valuable poultry is one closely allied to the preceding, viz., that of Polyplectron. All the species of this genus, though much smaller than the peacock, quite rival them in brilliancy of plumage. Some species, particularly $\mathrm{P}$. bicalcaratum and $\mathrm{P}$. thibetanum, are frequently domesticated in their native country, (India ;) and I think that they might be easily introduced here, as they are found mostly in mountainous countries, where the climate is quite cold at some seasons of the year. They have two and sometimes three spurs on each leg, whence their name.

Next comes the genus Phasianus, or Pheasants. These birds are more valuable in a wild state, in parks and preserves, on account of their beauty, and the sport afforded in shooting them, than as mere poultry. Our winters, however, are too cold for them.

Next to this comes the most valuable genus to the poulterer of any yet mentioned, that of Gallus, or Cock. Our present domestic varieties are derived principally from the G. Bankiva, but some of the larger varieties probably come from G. giganteus, and G. æneus, and perhaps from some of the other large species. The native country of this genus is India and its islands. In the same country is also found another genus, some species of which are frequently domesticated by the natives. It is that of Gallophasis, Cock-pheasants, which could undoubtedly be introduced here. The most common species are G. ignitus, or fire-backed pheasant, and G. erythropthalmus, or red-eyed pheasant. 
Besides this, in the same country is found the genus Ceriornis, or Tragopans, which also would bear our climate perfectly well.

The next genus in value, as well as order, is that of Meleagris, or Turkeys. There are but two species, however, belonging to this genus, one of which is found in the north, and the other in Central America. M. gallopavo is the common North American species, which has been spread all over the world. The other species, M. ocillata, was almost unknown, until within a few years. It is much more beautiful than the common turkey, and also much more delicate and difficult to rear ; so that I doubt whether they can be successfully domesticated in this country, though they are not uncommon in a domestic state in Yucatan. I started from the port of Sisal with three living specimens, which were unfortunately lost overboard in the Gulf of Mexico.

I understand that the Earl of Derby had some at Knowsly Park, but I doubt whether they are still living.

Next in order is the genus Numida, or Guinea fowl, of which there are five known species, all natives of Africa; only one species is domesticated, viz., N. meleagris, or common Guinea fowl.

Besides the birds already mentioned, we might add the splendid Lopophorus, or Monaul, from the Himmaleh Mountains; the Tetraogallus caucasicus, and the Pacrasia macrolopha, all from the same region; also, our Tetrao cupido Grouse, or Prairie hen; the Tetrao urogallus, or Cock of the Woods, and the Tetrao tetrix, or Black cock of Europe.

From the order Columbæ are derived some species of considerable importance to the poulterer. All the principal varieties of pigeons come from the genus Columba, species livia, or rock-pigeon of Europe, which, in the wild state, breed in the sides of rocky islands, as the Faroe Islands, and 
the rock of Gibraltar. This habit of building in caves fits them particularly for our dove-cotes. Many other wild species of this order might doubtless be domesticated.

The next order from which is derived an important part of our poultry is that of Anseres. The first genus is that of Cygnus, or Swan. It comprises nine species, of which four are European, two are North American, two are South American, and one New Holland. All of these might be domesticated with us. The species now domesticated is C. olor.

The second genus is that of Anser, or Goose. There are eight known species belonging to this genus, of which two, the snow and the white-fronted goose, are common to Europe and America, and five are common to Europe and Asia. The Anser ferus, or common wild goose of Europe, is the stock from which descend nearly all our domestic varieties. All the species of this genus might be introduced into our poultryyard.

The third genus of this order is that of Bernicla, or Barnacle goose. The most important species of this genus is Bernicla canadensis, or our common wild or Canada goose. Nearly all the species of this genus might be domesticated. Our common Brant, B. brenta, is frequently found in a domestic state, along the sea-coast of Massachusetts.

The fourth genus likely to afford poultry is that of Aix. There are but two species belonging to this genus, viz., A. sponsa, our summer or wood duck, and A. galericulata, the Mandarin duck of China, both of which are occasionally domesticated, and are chiefly valuable as ornaments to pleasuregrounds, on account of their brilliant plumage.

The fifth genus, that of Mareca or Wigeons, has been almost totally neglected by our poulterers and bird-fanciers, although having very beautiful plumage and excellent flesh; almost all the species would bear domestication perfectly well. 
The sixth genus, that of Dafila, or pintailed ducks, affords two or three large and very beautiful ducks. Dafila acuta, our common gray duck, is occasionally domesticated.

The seventh, and most important genus of this order, is that of Anas, or ducks proper. The common tame duck is derived from A. boschas, or Mallard, a species common to Europe and North America, which is occasionally crossed with $\mathbf{A}$. obscura, our common black or dusky duck, and with $\mathbf{A}$. Moschata, the Muscovy duck. This last belongs more properly to a different genus, - that of Cairina, - and is of considerable value in the poultry-yard.

The eighth genus, that of Querquedula, and the ninth, that of Pterocyanea, to which belong our green and blue-winged teal, might be of some value to the amateur poulterer. To these might perhaps be added the Cereopsis, or Bustard goose, of New Holland; the Gadwall and Shoveller ducks, and some species belonging to the Fuligulinæ, or sea ducks; in fact, I have heard that the Eider duck makes very excellent poultry, when domesticated.

The committee cannot resign their labors without a few words to those who came forward so handsomely, on the occasion of the exhibition, to lend it their countenance and support. To those gentlemen we would have had much pleasure in paying personal compliments, had such been within the limit of our functions. It is doubtful whether a more satisfactory reparation could be made to them for their time and trouble, than the assurance that their example has induced thousands to determine on imitating their efforts, whose circumscribed knowledge, previous to the exhibition, would never have suggested an attempt. This promise of improvement is the result of the public spirit of the gentlemen exhibitors alluded to, and 
the committee are satisfied that they will, each and all, be proud of the reward.

In conclusion, the committee would suggest that, as there is a small balance of cash on hand, some arrangement might be made to invest it in the procurement of suitable cages for the next exhibition, as, in many instances connected with the former one, the lack of the proper means for the full display of the beauties of the stock shown detracted from the character of the exhibition. The suggestion is merely thrown out, so as to receive the consideration of those interested, preparatory to discussion and decision, at their organization, which is proposed to take place in January; and, as before mentioned, sufficient intimation as to time and place will be given in the papers.

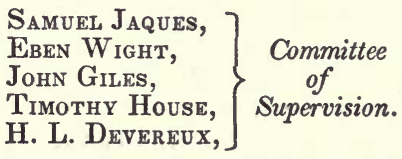

CONSTITUTION OF THE NEW ENGLAND SOCIETY FOR THE IMPROVEMENT OF DOMESTIC POULTRY.

ORGANIZED FEBRUARY 28, 1850.

NEW ENGLAND SOCIETY FOR THE IMPROVEMENT OF DOMESTIC POULTRY.

A meeting was held, on the evening of February 28th, in the Legislative Hall of the State House, for the purpose of hearing the report of the Committee of Supervision of the Convention of Fowl Breeders and Fanciers, whose show of domestic fowls was held in the Public Garden, of Boston, on the 15th and 16th of 
November, 1849 ; and also to organize an association for the improvement of the breeds of domestic poultry.

The Hon. W. B. Calhoun, president of the Legislative Agricultural Society, called the meeting to order at seven o'clock, at which time it is estimated that there were five hundred gentlemen present.

The president, after stating the objects of the meeting, called on the Committee of Supervision to present their report, which was read by Mr. S. B. Morse, Jr.*

On motion of Dr. J. C. Bennett, of Plymouth, the report was accepted.

Colonel Thayer, of Braintree, moved that a committee of three be appointed to furnish a draft of a Constitution and ByLaws, as recommended in the report which had been read to the meeting.

The president appointed Samuel Jaques, of Ten Hills Farm, W. S. King, of Rhode Island, and John C. Moore, of Boston, a committee for that purpose.

\section{PREAMBLE.}

Fully satisfied regarding the extended advantage arising from united effort in carrying out all objects of improvement, and being thoroughly impressed with the fact that a more systematic principle applied to breeding and management of domestic fowls would be productive of general and individual profit, those who may become members of this society agree to the following Constitution and By-Laws, for the government of the association, whose object is to improve the breeds and produce of domestic poultry.

* For the Report, see p. 279. 
CONSTITUTION.

ARTICLE 1. NAME OF THE SOCIETY.

The society shall be denominated "The New England Society for the Improvement of Domestic Fowls."

\section{ARTICLE II. OFFICERS OF THE SOCIETY.}

The society shall be governed by a President, twelve VicePresidents, (two from each of the New England States,) a Recording Secretary, Corresponding Secretary, and Treasurer, who shall be Trustees ex-officio, and nine other Trustees chosen at large, all of whom shall be continued in office until others shall be elected in their stead.

\section{ARTICLE III. EXHIBITIONS OF THE SOCIETY.}

There shall be two stated exhibitions of the society annually, namely, on the second Tuesday of February and the second Tuesday of November, the former to commence at seven o'clock in the evening, and the latter at eight, morning. These meetings are to be held at such places as the Trustees shall appoint, of which they will give notice in two or more of the Boston newspapers, and one newspaper, at least, published in the capital of the States of Maine, New Hampshire, Vermont, Connecticut, and Rhode Island, said announcements to be made not less than three weeks previous to the time the exhibition is to take place

\section{ARTICLE IV ELECTION OF OFFICERS.}

There shall be an annual election of officers, which shall take place at the stated meeting to be held in February. Forty members shall be necessary to form an elective quorum. The choice shall be made by ballot, and the election determined by a majority of votes. 
ARTICLE V. FEES AND PRIVILEGES OF MEMBERS

Any gentleman may become a member by paying two dollars to the Treasurer, who shall furnish a certificate of membership for the same for life; every member will be entitled to a free admission, for himself and the ladies of his family, to the society's exhibitions.

ARTICLE VI. DUTIES OF THE PRESIDENT, ETC.

'The President, or, in the event of his absence, any of the Vice-Presidents, with the advice of the Trustees, may call special meetings of the society; or, when written applications, with the reasons assigned therefor, shall be presented by any twelve members of the society - addressed to the President and Trustees - they shall call such meeting. In the event of the absence of the President or Vice-Presidents from any meeting of the Trustees, or of the society, the members present may appoint one from among their number to preside.

ARTICLE VII. MEETINGS AND DUTIES OF TRUSTEES.

The meetings of the Trustees shall be held at such times and places as they shall, from time to time, agree upon. Seven of their number, with their president, shall constitute a quorum.

The Trustees shall manage all the concerns of the society during the intervals between its meetings - recommending such means of improvement to the attention of the public as may be advisable; publish such communications, and offer such premiums, in such form and value, as they shall think proper, (provided the premiums offered do not exceed the available funds of the society ;) and they shall lay before the society, at each of its meetings, a statement of their proceedings, and a list of the communications made to them in the intervals. 
ARTICLE VIII. DUTIES OF THE RECORDING SECRETARY.

The Recording Secretary shall take minutes of all the proceedings and votes of the society and trustee meetings, and enter them in separate books; shall record all such communications as the Trustees may direct, and otherwise act by their instructions.

ARTICLE IX. DUTIES OF THE CORRESPONDING SECRETARY.

The Corresponding Secretary shall write all letters relating to the business of the society, as the Trustees shall direct. He shall also copy such communications as he shall send to parties. in a book which he shall keep for that purpose.

ARTICLE X. DUTIES OF THE TREASURER.

The Treasurer shall receive all moneys due or payable to the society, and all donations made to it, for which he shall give duplicate receipts - one of which shall be lodged with the Recording Secretary, and also make a fair record thereof. He shall, also, from time to time, pay out such moneys as the Trustees shall instruct him so to do; and shall, annually, and whenever required so to do, render a fair account of all his receipts and payments, to the society, or a committee thereof. The Treasurer shall give security for the full discharge of his duty, in such sum as the Trustees may direct.

ARTICLE XI. CHOICE OF AUDITORS - THEIR DUTIES.

A committee of three members shall be chosen annually, by the society, at its meeting in November, to audit the Treasurer's accounts. It shall be their duty to report at the February meeting next ensuing. The report, being accepted, shall be entered on the society's books, by the Recording Secretary. 
ARTICLE XII. PROCEEDINGS RELATIVE TO VACANT OFFICES.

In the event of the death, resignation, incapacity, or removal out of the limits of the society, of either of the Secretaries, or the Treasurer, the Trustees shall take charge of the official books, papers, and effects, belonging to the office that may be vacated, and give receipts for the same; such books, papers, or effects, they may deliver to some person whom they may appoint to fill the office vacated, until the next meeting of the society, at which there shall be a choice made.

ARTICLE XIII. NOMINATIONS, ETC., OF CANDIDATES FOR OFFICE.

The candidates for office shall first be nominated by members of the society ; and, on being balloted for, if the number of votes include a majority of those of the whole number present, such persons so proposed and voted for shall be considered as duly elected.

\section{ARTICLE XIV.}

The names of persons to be balloted for, at the annual election, shall be contained on one ballot; and the offices for which they are respectively nominated shall be distinctly designated.

ARTICLE Xv.

The society may elect honorary members at its general meetings. Officers of the navy, and ship-captains from New England who trade at foreign ports, shall be eligible as honorary or corresponding members.

\section{ARTICLE XVI.}

This Constitution may be altered or amended, at any of the stated meetings of the society, by a vote of two thirds of the members present - provided notice has been given of such alteration or amendment the stated meeting immediately preceding. 
On motion of Mr. Giles, of Providence, Messrs. S. W. Cole, P. Lothrop, James Pedder, William Stickney, Samuel Carpenter, Edward Carnes, and W. J. Buckminster, were appointed by the President a committee to nominate officers to fill the various offices prescribed by the Constitution.

The Nominating Committee reported the following list of officers, which was accepted by the meeting :-

PRESIDENT. - Samuel Jaques, Ten Hills Farm.

Vice Presidents. - Massachusetts - Paoli Lothrop, South Hadley; J. C. Bennett, Plymouth. Rhode Island-John Giles, Providence ; W. S. King, Woodland Farm. Maine Russell Eaton, Augusta; Rufus McIntire, Parsonsfield. New Hampshire - Josiah Stephens, Concord ; H. C. Parker, Manchester. Vermont-Frederick Holbrook, Brattleboro'; N. T. Sheaf, Westminster. Connecticut-C. H. Pendleton, Pendleton Hill; Ethan Allen, Pomfret.

Treasurer. - Josiah Stickney,* Boston.

Recording Secretary. - John C. Moore, Boston.

Corresponding Secretary. - Henry L. Devereux, Boston. Trustees. - Timothy House, W. J. Buckminster, Eben Wight, Boston ; E. S. Kelley, Newburyport ; B. W. Balch, Dedham; Alfred A. Andrews, Roxbury; John Brooks, Princeton; John Merrill, William Stickney, Cambridge.

A large number of gentlemen then came forward and united with the society, by the payment of the initiation fee of two dollars, His Excellency, George N. Briggs, Governor of Massachusetts, heading the list.

The meeting was then adjourned.

* In place of George E. White, resigned. 
Boston, March 1st, 1850.

Dr. J. C. Bennett, Plymouth, Mass.

SIR:- Having now concluded our official duties as a Committee of Supervision in connection with the exhibition of Poultry, held in the Public Garden, on the 15th and 16th days of Nov., 1849 , we deem it a special duty to do you the justice of recognizing the active share you had in originating that exhibition.

We congratulate you on the success which has followed your original suggestion. It is but rarely that such promising results reward disinterested action such as yours. Previous to the time you first proposed an exhibition, there were but few who manifested any interest in the improvement of domestic poultry, although its importance tacitly operated on the practice of many, who acted on no regulated principle of management. That interest, within the past six months, has extended far beyond our most sanguine expectations; and it gratifies us to find that the correct principles of breeding and managing poultry are so generally inquired after.

It especially gratifies us, as it must also satisfy you, to find that an interest has been taken in our exhibition which includes men belonging to every section of our large community, as in this fact we foresee a liberal distribution of benefit. Our excellent Governor was the first to enrol his name on the list of members of the society just established.

The future is so full of promise, that we entertain the hope our labors have not been altogether in vain.

Receive the assurance of our highest esteem and respect.

We'are, sir, your very obedient servants,

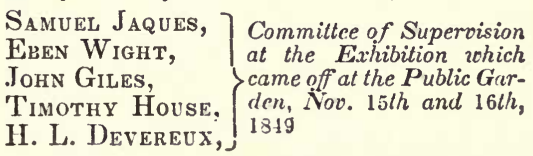




\section{COCHIN CHINAS AND SHANGHAES}

There are in reality many pure Cochin China fowls which are supposed to be Shanghaes, from the fact that they were imported direct from China. The three which were imported by Captain Bennett Forbes, in 1846, and taken to Newton, which stock may be seen at Mr. Brackett's, and at Mr. Hyde's, - are of this description. Though brought from China, they are not Chinese, but uncommonly superior samples of Cochin China fowls. They differ materially from the Shanghaes, being much larger birds. The cocks weigh from eleven to thirteen pounds, and the hens from eight to nine pounds each ; and, in some instances, they even exceed these weights. They, in my opinion, constitute one of the best importations ever made. By reference to the article on Cochins, it will be seen that these noble birds of Messrs. Hyde, Alden, and Marsh, are especially alluded to. These remarks apply to several other importations. All Shanghaes are very heavily feathered on the legs and toes, which mark does not uniformly characterize the Cochin Chinas. These are generally quite lightly feathered on those parts, while the Royal Cochins are commonly destitute of feathers below the knee, on account of their participation in the blood of the Wild Indian Game. The confounding of breeds and varieties which closely resemble each other is an error to be deprecated by every careful and intelligent breeder. The unmistakable characteristics of each breed and variety, noticed in this book, are clearly depicted in the body of the work. 


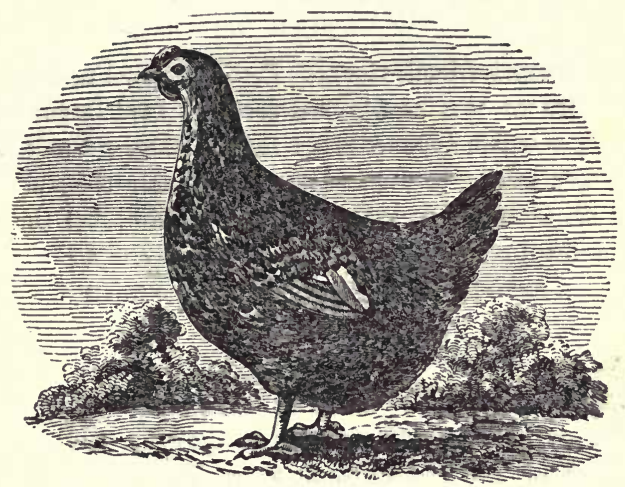

THE CHITTAGONG FOWL.

This portrait (drawn by that eminent artist, F. A. Durivage, Esq., from life, and engraved by Henry Marsh, noted for his great accuracy and ability) represents a hen purchased by me for Mr. Joseph A. Sampson, of Duxbury, of Asa Rugg, Esq., of Kensington, Philadelphia. This individual is unquestionably the largest hen in America, weighing THIRTEEN POUNDS AND FOUR oUNCES! The description of this imperial bird will be found under the head of its variety, in the body of this work; but the portrait is presented here, on account of the peculiar merits of this particular specimen. She is of the Brown Chittagong variety, her plumage being of a yellowishbrown, with the feathers tipped with black, producing a spotted appearance. She has five toes on each foot, as is sometimes the case with all the varieties of the Chittagong and Shanghae races.

With regard to the Imperial Chittagong race, (the Gallus giganteus,) as compared with the Royal Cochin China, Mr. 
Rugg remarks, in a letter to the author, of January 28, 1850, as follows :-

"Our mutual friend, George P. Burnham, Esq., of Roxbury, writes me that he has just received his 'Royal Cochin Chinas ;' to which I immediately replied, that, without seeing them, I was willing to wager him the best pair of fowls I have, against his Gray Chittagongs which I sent him, that the latter would outweigh his Cochin Chinas, by three and a half pounds per pair! I know, as to weight, they have no fowls in all England equal to ours ; nay, every sailor and cabin-boy knows as much."

Mr. Burnham, in an editorial in the Boston American Union of February 2, 1850, after giving a glowing and beautiful description of his late importation of Royal Cochin China fowls - the same to which Mr. Rugg alludes - says : - "As compared with the Chittagong, however, we rather prefer that fowl, as yet."

$I$, nevertheless, prefer the Royal Cochins, from the fact that they participate in the fine blood of the Wild Indian Game fowl, than which the world produces no better.

I have myself lately received some very superior specimens of the Imperial Chittagong from Mr. Rugg, of which he writes as follows : - "They are quite equal to Mr. Burnham's."

That is enough. To have said more would have been a work of supererogation. It is my intention to breed from these on a large scale, and I shall have the pleasure of enabling persons interested in the improvement of poultry to procure the best blood possible to be obtained; as will, also, Asa Rugg, Esq., of Kensington, (Philadelphia,) George P. Burnham, Esq., of Roxbury, Mr. Joseph A. Sampson, of Duxbury, and Messrs. Theodore Drew, William Gooding, Samuel Shaw, and Abijah Drew, of Plymouth.

Some superb specimens of the Imperial Chittagong Fowl 
may likewise be seen at the beautiful country seat of Timothy G. Coffin, Esq., of New Bedford.

No superior race exists in this country, except the Wild Indian Game, with its crosses, (the Yankee Game and the Pride of India being DECIDEDLY the best of all the breeds, possessing all the good laying qualities, combining fineness and flavor of flesh with great size, excelling in beauty, and breeding to the feather,) which, as will be seen by the descriptions in the work, have the most savory flesh, and the most brilliant plumage, of any known variety.

In a communication published in the Boston Cultivator of February 9, 1850, Mr. Rugg observes :

"I am surprised that I, as well as some others, should have thought it expedient or necessary to send across the Atlantic for large fowls, when we have at home those which in every respect are quite as good, and, in many respects, even much better. I have no hesitation in saying, that, in the large breeds and varieties, we are much in advance of the English breeders. I will, therefore, record some of the results of my experience and correspondence.

In the first place, the fowl denominated Cochin China, said to have been presented to the queen, a few years since, has been described and drawn so variously and conflictingly, that it is difficult to say what it really is ; especially as no one, save, perhaps, the queen herself, or the person who presented the fowl, seems to know whence or how it came into England. The latest, and perhaps the most reliable description, represents the male bird as having a large, single, deeply-serrated upright comb, of a bright scarlet color. The wattles are said to be also large, wide, and pendent, and the legs of a flesh color, sometimes slightly feathered. 'The feathers on the breast and sides are of a bright chestnut-brown, well-defined, giving a scaly or imbricated appearance to those parts. It is 
said that in some birds only there is a horse-shoe marking, black on the breast, which is increased with age. The double comb, peculiarly jointed wings, and reversed feathers on the back of the cock's neck, are all without foundation. The hen is of a bay color, light-brown or yellow on the neck, somewhat squatty, like the Dorking, differing little from the latter, except that the tail is shorter, and carried lower.'

Now, I doubt whether the fowl, as thus described, is anything more or less than the Wild Shanghae, found in the mountains of Northern China, of which I have a few beautiful specimens, imported in 1847. As we have no history of the queen's fowls, of course, we are left to infer the place of their nativity from their reputed characteristics. They agree so much in description, and also, as I shall show, in weight, with my pure Wild Shanghaes, which weigh, when full grown, from fifteen to sixteen pounds per pair, that I have little or no hesitation in saying they were born and bred in Northern China, and not in Cochin China. My Chittagongs and Cochin China, which come, the one from the vicinity of Calcutta, and the other from Southern China, are, as I shall show, considerably larger. From gentlemen with whom I have corresponded, I recently learned the weights of several specimens of fowls in England, which I shall now put in juxtaposition with some of my own.

POULTRY RECENTLY WEIGHED IN ENGLAND.

lbs. $0 z$

Dorking cock, two years old, .......... . . 4

Dorking cock, age not named, ........ 612

Malay cock, young, ............. 8

Cochin China cock, 2 years old, ........ 79

Cochin China stag, 2 years old, ....... 8

Cochin China hen, moulting, ....... 5

Cochin China stag, moulting, ....... 52

Malay hen, moulting, ......... 56

Malay pullet, moulting, .........4 5

Dorking hen, full-grown, ..........6 2

Dorking pullet, full-grown, .........4 6 
I refer your readers to Mr. Dixon's treatise for a more extended list of weights, who will still further confirm the assertion, that, in point of weight, our fowls are superior.

POULTRY WEIGHED THIS DAY IN MY OWN YARD.

Cochin China cock, 13 months old, ....... lbs. oz. 4

Cochin China stag, 8 months old, . . . . . . 912

Cochin China pullet, 7 months old, ...... 610

Cochin China pullet, 8 months old, .......7 2

Chittagong stag, $8 \frac{1}{2}$ months old, ....... 106

Chittagong pullet, 7 months old, ....... 87

Chittagong pullet, 8 months old, ....... 92

Chittagong pullet, 6 months old, ........ 612

Chittagong hen, 2 years old, ........ 106

I have a Chittagong hen, three years and three months old, which last spring weighed thirteen and one fourth pounds; she being, however, a rara avis, should not be regarded as a fair sample.

[She is now owned by Mr. Joseph A. Sampson, of Duxbury.]

The English fowls were weighed about seven weeks since, when scarcely over the effects of moulting. This might make a difference of a pound or a pound and a half, in their favor, over fowls weighed now ; but even then, the balance is still heavily in our favor. And so I think every breeder or fancier who breeds judiciously, pure fowls, will find, at least, in the question of weight, a balance in his favor over the best and most reliable results of the English breeder. To what this superiority is owing, - whether to our drier climate, or a better selection of stock, - I pretend not to say ; but knowing the facts, I have thought proper to record them, with the view of encouraging at once our breeders in a proper use of their own material, and preventing the young and ardent fancier expending money in sending for large transatlantic fowls, only to be dis- 
appointed, or find that he could have procured as good if not better, nearer home, at much less delay and expense.

Notwithstanding Mr. Rugg's general accuracy, I consider him decidedly in error in confounding the Royal Cochins with the Shanghaes. This point is fully settled in the body of this work.

It will be observed that the descriptions in the work begin with Mr. Burnham's Imperial Chittagong; and it is deemed suitable and graceful to conclude it with the splendid specimen in Mr. Sampson's possession.

Subsequent editions of this work will be embellished with portraits from life, by the same distinguished and excellent artist, F. A. Durivage, Esq., of my Pride of India fowl, from my own stock; my South American Eagle fowl, (a very rare and singular bird,) from the stock of J. Jacob Bower, Esq., of Baltimore, and now in possession of Mr. William Nickerson, of Plymouth; the Java Game Fowl, from the stock of Mr. George C. Peirce, of Danvers; and numerous other rare and choice breeds, (a full history of sixty different breeds and varieties being promised by Mr. Bower alone;) and will contain an additional fund of practical matter from some of the best breeders in this and foreign countries, with whom the author is in correspondence. 


\title{
ADVERTISEMENT.
}

\section{JOHN C. BENNETT, M. D.,}

\author{
PHYSICIAN AND SURGEON, PLYMOUTH, MASS.;
}

FORMERLY PROFESSOR OF OBSTETRIC MEDICINE AND SURGERY, AND
THE DISEASES OF WOMEN AND CHILDREN; AND

\section{LECTURER ON MEDICO-LEGAL SCIENCE}

IN THE

\section{"Willoughby University of Lake Erie," and in the Cincinnat "Lit. and Bot. Med. College of Ohio,"}

Continues the practice of his profession in all its various departments. He received his first medical diploma A. D. 1825 , aince which to the present time he has been continuously engaged in the practice of medicine nnd surgery, (embracing a period of twenty-five consecutive years, having enjoyed the most extensive opportunities in medicine, in various climates, both in private practice and in public institutions; and the most ample means, from the nature of his official position, in field-military surgery.

He takes this opportunity, therefore, to offer to the public a fow choice compound for the alleviation of human suffering, which cunnot be procured elsewhere, and which long and extensive experience has proved to be both aafe and efficacious.

COUGH DROPS. - This invaluable compound is equally applicable to colds, coughs; consumptions, and all kindred aftections, and has effected the most astonishing cures. The reputation of these drops is co-extensive with the American Union, and they are now extengively used in most of the States of the Republic.

Directions. - For an adult, the medium dose is 100 drops in four table-spoonfuls of cold water, or warm tea, morning and evening - once in twelve hours - but the morning dose is not to be taken, uaually, untî after breakfast. If this does not control the cough, increase the dose to 200 drops, and some will even bear 300 , and require the dose to be repeated once in eight hours, or three timea a day, but such cases are rare. Should the medium dose produce vertigo, or nausea, diminish the quantity to 50 drops, or even less. The medicine should be well shaken every time it is used, and it is best to commence with one half of the medium dose, and gradually increase as the patient will hear it. The proper dose for infant: and children may be reckoned at the following rates: One drop for a child fifteen days old ; two drops for one a month old ; four drops for one three months old; eight drops for one eight months old; sixteen drops for one a year old; twenty-five drops for one two years old; thirty drops for one three years old; forty drops for one four years old; fifty-five drops for one ten years old; and so on; in a litcle cold water or warm tea. Theae doses are prescribed for children who are altogether unused to this medicine; the power of bearing more may be rapidly increased by habit. The same is true of adults.

Price. - Thirteen cents an ounce; one dollar and fifty cents a pound; two dollars and eiglity cents a quart; five dollars for two quarts; and nine dollars a gallon, for the medicine only - phials or bottle to be charged extra.

RHEUMATIC DROPS, - This preparation is unsurpassed in the speedy cure of rheumntism, gout, or pain of any description. Its virtues have only to be known to be appreciated; but, for the satisfaction of strangers, we append one of the many voluntary certificates of its salutary effects :-

"To whom it may concern :-

"Plymouth, Mass., Dec. 13th, 1849.

"About the lat of Sept., 1847, I returned home from the Quereau Banks, severely afflicted with rbeumatism, and from the 5 th of that month, to the 28 th of March, 1848, I was entirely incapable of performing ordinary laber on account of said affiction, all the remedial agenis 
to which I had resortad having utterly failed to effect a cure, or even to procure relief. On the last day named, I heard of Dr. Bennett's Rheumatic Drops, and immediately procured some of them, and took a tea-spoonful in some cold water, about 1 o'clock, P. M., but without any perceptible efiect; and about $60^{\prime} \mathrm{clock}$, on the same day, 1 applied to br. Bennett, in person, who informed me that 1 was not easily impressible, and administered to me two teaspoonfuls more, which relieved me of all pain whatever, in less than an hour, and the swelling soon began to subside, and $I$ have not had the least eymptom of rheumatism from that day to the present, and never enjoyed better health in my life, though I have been exposed to all weathers as heretofore.

\section{BENJAMIN N. PIRCE,"}

Directions, Price, etc. - The same, in all respects, as for the Cough Drops. The use of the drops to be continued until a oure is effected. In cascs of severe jain, one dose (a large tea-spoonful) will, frequently, be all sufficient.

DYSENTERIC DROPS. - These drops ara admirably adapted to the radical cure of cholera, dysentery, diarrhcea, etc., either in an acute or chronic form. They seldom fail to cure, even where other patent remedies signally fail.

Directions, price, etc. - The same as for the Cough Drops. The drops to be given thrae times a day, until thare is no further necessity for their use.

HEALTH RESTORATIVE. - This medicine is exceedingly pleasant to the taste ; and, at the same time, most potent in its curative properties. Through the agency of this sanative compound, accompanied by appropriate adjuvants, a young lady of this town, who had been afflicted from her youth with a very troublesome cutaneous affection, of a leprous character, has been restored to health and vigor. Mr. Little, in a letter to Dr. Erland, dated "Boston, Jan. 31, 1849," in speaking of this article, 6ays :-

"It is undoubtedly one of the very best innocuous and sanative preparations ever compounded for humors, skin diseases, general debility and visceral derangements, acting as a powerful corrector of the secretions, (Detter understood by the people as a purifier of the blood,) and wherever used, ite virtues will evidently be highly appreciated. Yours, with respect,

WM. B. LITTLE, Chemist, 104 Hanover st."

James Thurber, Esq., Editor of "The Old Colony Memorial," in his paper of Feb. 3, 1849 , in an article on this medicine, says:-

"This article, Mr. Little, an eminent Boston chemist, pronounces one of the best compeunds for the purification of the blood ever prepared. We can testify, having tried it, to its pleasant taste, and its revivifying effect upon the system. If the compound possessed no medicinal qualities, it would be a drink much gought after as a beverage, being extremely pleasant to take. We rather suspect that Dr. Bennett will have his hands full in supplyins the demand for this innocuous and valuable medicine."

Directions. - The dose of this "Restorative" is from a tea-spoonful to two table spoonfuls three times a day - once in eight hours - without mixing it with any other article at the time of ita administration. To be well shaken when used; and its use continued, as the case may require, to effect the object intended.

Price. - Four cents an ounce ; forty-eight cents a pint; eighty cents a quart; and three dollars a gallon; for the medicine only - phials and bottles to be charged extra.

CATHARTIC POWDER, - This is decidedly the best general purgative, or family physic, that is now known. It acts upon the whole alimentary canal, and is a powerful promoter ol the secretions. It may be given to any age or sex, and is indicated in bilious and febrile diseases, and in all cases where laxatives or purgatives are required; and it does not, like most cathartic substances, leave the bowels in a constipated condition.

Directions. - Take a heaping tea-spoonful of the powder, and an ounce or two of loaf (or other fine) sugar, and add to them about a gill of bolling water: when cool, atir it up, and drink dregs and all. Repeat the dose in three hours, if necessary. It is better to take it on an empty stomach.

Price. - Fifteen cents an ounce; and one dollar and fifty cents a pound.

EMETIC DROPS. - This emetic, though extremely unpleasant to the taste, is unsurpassed for promptness and efficiency of action, but mostly valued for its sanative influences. It neither cramps nor prostrates the system, like most other emetics, but is always safe and efficacious, and should be administered in all cases where an emetic is indicated.

Directzons. - An adult should take two large tea-spoonfuls of the emetic drops, in about a gill of luke-warm composition tea, and repeat the dose every fifteen or twenty minutes, until copious vomiting takes place. During the operation the patient should drink very freely of quite hot composition tea. If it should not be convenient to use composition tea, boneset, chamomile, or other common articles will answer. Some persons will require double the abovenamed doses.

Price. - Eight centa an ounce ; ninety-six cents a pint ; and a dollar and fifty cents a quart ; for the medicine only - phials and bottles to be an additional charge.

COMPOSITION POWD́ERS. - These powders are compounded of the most potent and pure diaphoretic articles of the Materia Medica, differing essentially from the article usually sold at the shops under the same name, and composed of refuse drugs. They answer the general purposes of an alterative, establish perspiration, equalize the circulation, and $r \epsilon-$ move plstructions arising from colds, atmospheric vicissitudes, or other causes. 
Directions. - Take one or two heaping tea-spoonfuls of the powder to three gilla of boiling water ; mix well, and add cream and loaf (or other fine) sugar, to suit the taste of the patient. This makea a very pleasant stimulating tea, and should be liberally used in colds and all similar affections.

Price. - Eight cents an ounce, and a dollar a pound.

CATHARTIC SYRUP. - This medicine is prepared expressly for young children, and is recommended to mothers and nursee as a safe and gentle laxative and carminative, operating in small doses, without nausea or griping. It is applicable in all cases where a cathartic or laxative is indicated.

Directions. - An infant from three to twelve months old can take from 20 drops to one tea-spoonful, in a little cold water, or luke-warm tea. A child from one to three years old can take from one to two tea-apoonfuls. A child from three to aix years of age can take from two to four tea-spoonfula ; from six to twelve yeara, a table-spoonful will be a aufficient dose. An adult can take two table-spoonfula.

Price. - Eight cents an ounce; one dollar a pound; and one dollar and fifty cente a quart - phiala and bottles to be an extra charge.

AGUE POWDERS. - These powders are equally applicable to all cases wherein the lawe of periodicity are fully established, as in Fever and Ague, periodical headache, etc., etc. It is an unrivalled remedy in auch aflections.

Directione. - Take one of the powders, in a little molasses, or water, or other convenient article, six hours before the acceasion of the chill or atage of depression, and if it fails to cure take another powder six hours before the next chill is expected, and oo on; though one dose will generally be found sufficient.

There is no difficulty in calculating the exact period of the chill's return, for if the firat chill ahould accede on Monday, at 10 o'clock, A. M., and the aecond on Werinesday, at 10 o'clock, A. M., the third may be expected on Friday at the same hour - in that event, the powder should be taken on that day (Friday) at 4 o'clock, A. M.; but if the chill ahould appear on Monday, at 10 o'clock, A. M.., and on the aucceeding Wednesday, at 1 o'clock, P. M., the chill on Friday would be at 40 'clock, P. M. - and in that event, the powder should be taken at 10 o'clock, A. M., on Friday; or if the chill should come on on Monday, at 10 o'clock, A. M., and on Wednesday, at 9 o'clock, A. M., the Friday's chill would be at 8 o'clock, A. M. - and the powder ahould be taken at $20^{\prime}$ clock, A. M.; and so on. The same rule appliea invariably, when the periodicity is well defined, in any disease of a periodical character; and that rule is, to administer the powder six hours before the depressed stage is expected, and a cure is almost universally the inevitable result.

Price. - Twenty-fiva cents a powder.

Of the purity of the articles of which the above medicines are compounded, my manufacturing chemist observes:-

"Dr. J. C. Bennett, $-\bar{W}_{\text {e }}$ are much pleased with the formulas which you have sent us to prepare - their combination shows a chemical knowledge highly creditablo to you, which could only have been attained by the deepeat reaearch.

We have bestowed great care in selecting the medicines and chemicals of which your pre. parations are made, as you requeated, and their use we think cannot but be attended with beneficial effects. Yours respectfully, W'M. B. LITTLE \& Co."

The above medicines can be forwarded to any part of the United States, to order.

For the satiafaction of strangera, the following testimnnials of professional ability are ap. pended :-

From Samuel Preacott Hildreth, M. D., President of the Medical Convention of the State of Ohio, Jan. Itt, A. D. 1838 ; and John Cotton, M. D., Preaident of the General Medical Society of the State of Ohio, Jan. 5th, A. D. $18 \% 9$.

"To whom it may concern :"Marietta, Ohio, May 25th, 1831.

"The undersigned with pleasure state that they have, for several years past, been acquainted with Doctor John C. Bennett, and have known bim to be a very ingenious and auccessful practitioner of Medicine and Surgery, as well as an able writer in the Western Medical Journal, edited by Professor Daniel Drake, M. D. His moral character has ever been fair and unexceptionable.

\section{S. P. HILDRETH,}

From the Medical Class of the Willongluby Univeraty of Lake Erie.

"Willoughby, Ohio, February 21st, A. D. 1825.

"At a meeting of the Medical Class of the Willoughby University of Lake Erie, convened at the College Edifice, on Saturday, the 2lst inst., the following Resolution was unanimously adopted :

Resolved, That we, the members of the Medical Class of the Willoughby University of Lake Erie, present our thanks to John C. Bennett, M. D., Preaident of our Medical Faculty, and Professor of the Principles and Practice of Midwifery and the Diseases of Women and 
Children, for the very ahle, interesting, and scientific Course of Leetures, hy him delivered during the present session, and as a feeble testimonial of our high regard for the interest he has evinced in our welfare and improvenent, and for his splendid talents as a teacher.

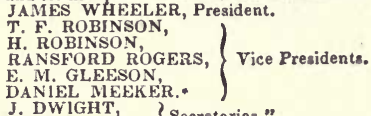

From Rev. John Stewart, Presiding Elder in the Methodist Episcopal Church.

"Hocking City, Ohio, April 29, 1838.

"To whom it may concern :-

"This is to certify that I have been, for many years, intimately acquainted with John C. Bennett M. D., who was, in 1825, my family physician. His advantages for acquiring correct medical knowledge have been very great, far superior to those of most physicians in thie country ; and I consider him one of the most able ad accomplished physicians and surgeona.

Appointment by the Governor. - "Brigadier-General John C. Bennett, of the First Brigada of Dramoons, (and formerly Surgeon-in-Chief of the Second Division of Infantry,) to be Quarter-Master-Ganeral of the Militia of the State of Illinois, from the 20th day of July, 1840 .

"In maling the above sppointment, Governor Carlin has selected an able, energetic, and efficient officer. The duties that will devolve on him perhaps no man in the State is better qualified to fill, and we have no doubt he will render due justice to the office which he has been selected to euperintend." - Wabash (Illinois) Republican.

CHLOROFORM. - We are permitted by $\mathbf{M r}$. Wm. R. Little, the able manufacturing chemist, of Boston, to publish the following extract of a letter from him to Dr. Bennett, of Plymouth, in relation to the entire safety of pure chloroform in all cases in which it has been correctly spplied. We procured for Dr. Bennett some of the first chloroform manufactured in this country, after the diacovery of its anzathetic properties, and it will be recollected by our renders that the Dr. has maintained from the beginning, that " pure chloroform, appropriately administered, is, fron. its very nature, as harmless aa water," and the following corroboratory stntement from one of the most able chemists of our country must be highly satisfactory to all persons interested in its use. The important question, as to the safety ani utility of this agent, appears to be, "Is the chloroform pure?"

"Boston, Jan. 11, 1849.

"Doct. J. C. Bennet! Dear Sir:by "Prof. Simpson," we have manufactured and sold upwards of five thousand pounds. This immense quantity has, been distributed throughout the world, snd must necessarily have been used by all classes of persons, both competent and incompetent, and we have never heard of a aingle instance where it las produced injurious effects. You can judge, from your great experience in its use, whether we speak correctly as regards the safety of its administrntion. We believe you had the first, ounce we sold out of Boston, and we find, by referring to our books, that you have had rearly twenty pounds.

"One great reason why the use of our chloroform has been attended with such happy results is, that we never sell any but what we know to be pure. All the chloroform of our manufacture is chemically tested before being sold, and can be depended upon for safety and $\mathrm{e}$ ficiency.

"We have had numerous samples of impure chloroform sent to us for examination from variou parts of the country, particularly from the Weatern States, anil we do not wonder at the aceidents which have arisen from the use of such vile compounds, prepared probstily by persona totally ignorant of the first principles of chemistry.

"Yours respectfully

Old Colony Memorial of Jan. 20, 1849.

WM. B. LITTLE \& Co."

Doctor Bennett recently extracted thrty teeth for a larly of this town, under the influence of chloroform, thirteen of which were removed at one sitting, without pain. This is the second entire set he has extracted within a few days. The doctor has certainly had most nmple experience in the use of chloroform, with uniform auccess.-Old Colony Memoricl of Mareh I7, 1849.

Chloroform and its uses. - We have receiver from Wm. B. Little \& Co., Chemists and Druggista, of this city, a treatise by J. Y. Simpson, M. D., a very able author, upon the " Suverioduction of Anasthesia, in Natural and Morbid Parturition;" a work which may be read by everybody with interest. The discovery of any agent possessing the power to annul the aesse of pain in the midst of surcicnl operations, is not only an important achievement in medical science, but is a blessing to mankind which eannot be over appreciated.

- Dr. Meeker is now Professor of Anafomy and Stirgery in J.a Porte University. 
If wo remenber rightly, Dr. Charles T. Jackson cluinu the original discovery here, that Sulphuric ether, with a proper adnixture of atmospherie air, might be safely inhalad; producing upon the patiens a temporary insensibility, not injurious to the system afterwards; and, nnder the influence of which, very many experiments and rucceswul operations in surgery have been performed, from time to time, which havo already been made public. With the deaign of improving upon thia agent, however, Profeseor Simpaon (of Edinburgh) introduced the use of Chloroform; and his success with this article has been very great, in cases where the other has been found objectionable. The author contends that the latter posesses many advantages over the other, and the almost general use into which it has now come, in preference to the former, shows ita great value to the profession and to the world.

Messra. Little \& Co. have here compiled a variety of authenticated inatances of the auccess of this great agent, in cases of intricate and painful surgical operation, the principal ones relating to the subject of "natural and morbid parturition." Other inatancea are quoted, however, supported by the lighest medical authority, that professor Simpson affirms that, in his whole experience, no single case has he known where the slightest bad effects have resulted from the employment of chloroform. In its application during amputations, the removal of cancers or tuinors, and a variety of other surgical operations, it is latterly used almost universally; and our best dentists in America have found it incomparably the most acceptable, least offensive, and safestagent of ita class, ever yet adopted in their practice.

In the appendix attached to this treatise, we find the arguments of Professor Simpson ably supported by the best medical and surgical men in this country - among whoun ia Dr. J. C. Warren, who ays, "Without qualification, this article, so happily introduced by Professor Simpson, is the most valuable improvement on etherization hitherto made." Walter Channing, M. D., of Harvard College, Drs. Jackson, and J. W. Warren, Dr. Hitchcock, Lyman, and others who have used it extensively, all join in praiae of its excellence and preference. Out of Boaton, Dr. J. C. Bennett, of Plymouth, Mass., was the first to adopt its use ; and, in his extended practice, has probably administered more chloroform than any surgeon out of the city.

This article is now manufactured by some few chemists in this country, hut we learn that Messra. Little \& Co. have made up some three thousand pounds of it in the last year, which has found a ready market. They make it in its purity, and we are informed that Dr. Bennett alone has uaed some forty pounda of it, in private practice - more than has ever been used by any single physician in the United States. His opinion accords with those of other medical gentlemen above named, and the character of so useful an agent as this, in destroying the pains which humanity has hitherto been subjected to, in cases of surgery, should be more generally understood and inquired into by the community.

We have been led into the above remarks from witnessing, latterly, a painful operation, which was performed upon a near friend, while under the infuence of cliloroform, and from meeting with the work now spoken of, which we have perused with a deep interest. We have no acquaintance with Messrs. Little \& Co., and speak of them only froin the very high commendationa we have heard of them, through the medical gentlemen above alluded to but we commend the work of Professor Simpson to general notice, most cordially. - Boston American Union.

Dr. Bennett has administered upwards of fifty pounds of chloroform since its first introduction as an anasthetic agent, for the extraction of teeth, the extirpation of tumors, the amputation of limbs, and in obatetrics, with uniform success; and is prepared to forward pure chloroform to any part of the United States.

The doctrine bas recently heen promulgated that the use of chloroform involves danger, and is so often attended with fatal eflects, that it should be dispensed with in medical practice. From the same source chloric ether is recommended as a safer and better anæsthetic agent. This opinion would be entitled to greater respect if the composition of chloric ether were unknown. Accurate analysia, however, shows that "concentrated chloric ether con. tains 33 1-3 per cent. pure chloroform, the remainder being nearly absolute alcohol (containing but about 4 or 5 per cent. of water)." It is difficult, therefore, to understand in what its superiority over pure chloroform consista. The fuct is, that chloric ether is less volatile than chloroform, and, therefore, it produces its original effects more tardily, and its gubsequent influence on the system is prolonged. The alcohol contained in it tends to the induration of the surfaces of the delicate membranes of the lungs, with which it comes in contact in inhalation, and on this grave account, if on no other, its use is objectionable, where chloroform is admissible. The secondary effects of sulphuric ether are also to be deprecated, while pure chloroform is one of the most innocuous preparations in the materia medica. At all events, on the theory of the most decided enemies of chloroform, its use has not produced worse consequences than have ensued from the exhibition of calomel, antimony, and opium, and yet these, by the same parties, are constantly lauded as the chief reliancea of the heal. ing art.

Plymouth, Mass., Feb. 26th, A. D., 1850.

We take pleasure in stating that we have used chloroform extenaively in our practice, and fully concur with Dr. Bennett, in his foregoing opinion, as to the comparative merits of pure chloroform, chloric ether, and sulphuric ether. The safety of either depends upon the purity of the articlc, and its appropriate administration.

F. B. BREWER, M. D.

B. HUBBARD, M. D

F. A. FULLER, Surgeon Dentrat. 


\section{6}

Francis Gurney Smith, M. D., editor of the Medical Examiner, of Philadelphia, in a review of the Transactions of the American Medical Association, vol. 2, says :-

"The superiority of chloroform over ether is sustained by the testimony of a number of eminent American surgeons, of large experience, whose views were solicited, and altogether form a strong array in favor of this powerful agent." 


\section{parker $\mathfrak{w h i t e ' s ~} \mathfrak{A} d \mathfrak{v e r t i s e m e n t . ~}$}

\section{DOMESTIC POULTRY.}

We have engaged in the Breeding and Importation of the most va.uable kinds of Domestic Fowls, for Sale, taking the utmost pains to have them of perfectly pure blood. Orders are solicited, and letters of inquiry will be promptly answered.

Several gentlemen, amateur breeders, who have valuable stocks, and raise more than they use for their tables, or desire to keep in their yards, have allowed us to sell from their collections, thus adding to our previous facilities everything needed to prepare us to furnish to those who desire it, any variety of Fowls, in their purity.

Also, for Sale, Artificial Nest-eggs, Straw Nests and Feeders.

PARKER \& WHITE,

No. 10 Gerrish Block, Blackstone St., Boston.

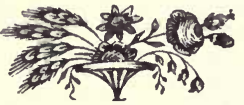

\section{SEEDS \& TREES.}

\section{PARKER \& WHITE, SEEDSMEN,}

NO. 10 GERRISH BLOCK, BLACKSTONE ST., BOSTON,

Continue their unanimously approved system for procuring the purest and best Garden and Field Seeds of each variety, employing only such growers as are of established reputation, and, as far as may be, those who raise only one variety of each kind of seeds, as by this mode the possibility of a mixture of different varieties, similar in appearance, is entirely avoided. Among their choicest varieties are found, Long Blood and Early Turnip-rooted Beet, very fine; Early York and Drumbead Cabbage; Long Orange and Whíte Carrots; White Spine Cucumber; Early Frame and Long Prickly do.; best varieties of Onions, Squashes, Melons, Turnips, Tomatoes, and all sorts of Herb Seeds ; Beans from the Early Yellow to the Large Late Lima; Early Peas; Marrowfat do ; Field do.

Also, Prime Timothy, Red Top, Clover, Fowl-meadow, and other Northern Grass Seeds.

Seeds of the best varieties of Spring and Winter Wheat, Oats, Barley, Buckwheat, Rye, Millet, Early Sweet and Field Corn, and Early Potatoes.

\section{Trees, Shrubs, Roots and Vines,}

for Fruit or Ornament, of the most approved sorts - among them, all the recently introduced varieties - for sale, at the lowest prices, and every article sold warranted to prove genuine, and accord with the description. 


\section{PARKER \& WHITE'S}

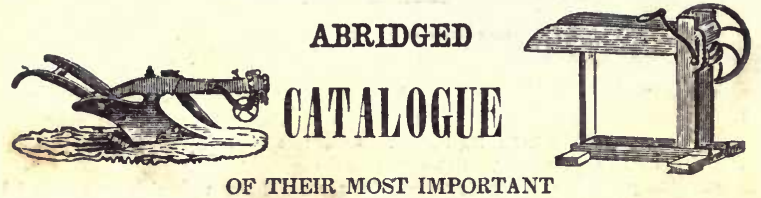

\section{Agricultural Machines and Implements.}

The Subscribers manufacture and deal in every kind of Farm and Garden Tools and Machines, viz.:

Improved Greensward, Stubhle, Horse and Road Ploughs.

Gedde's and Common Harrows and Cultivators.

Prenium Hay, Straw and Cornstalk Cutters, with spiral or straight

Knives; prices $\$ 3$ to $\$ 30$.

Improved Seed-sowers and Corn-planters.

Thermometer, Cylinder and Dash Churns.

Clinton's and Yankee Corn-shellers.

Butter-moulds, Cheese-presses, and Cheese-hoops.

Ox-yokes, complete, with patent Bow-pins, and Ox-bows.

Traces; Back, Draft, and Fence Chains.

Whippletrees, and Hook and Ring Hames.

Nason's, Hunt's, and White's warranted Axes.

Superior Walnut and Oak Patent Axe-handles.

Ames', White's, and Stone's Cast-steel Shovels and Spades.

Morse's Superior Manure Forks, 4, 6, 8 and 10 prongs.

Pope \& Parsons', King's, Partridge's, and Gaylord's ditto.

Tuttle's and Plympton's Cast-steel Concave Hoes.

Nason's, Tower's and Morse's Common and Eyed Hoes.

Roby \& Sawyer's warranted Scythes ; also, Common Scythes.

Clapp's, Lamson's, Aiken's and other Scythe Sinaths.

Haven's, Hall's, Dame's, and other Hay Rakes.

Revolving and Wire-tooth Horse Rakes.

Austin's Scythe Rifles. (P. \& W. are the agents for New England.)

Quinebaug and Indian Pond Scythe Stones.

Beals' Patent Corn and Cob Crushers for power.

Hand Corn Mills, Coffee Mills, Sugar Mills.

Grafiing and Pruning Saws and Cbisels.

Pruning and Budding Knives; Tree-scrapers.

Hatchets, Hammers, Cards, Cúrry-combs, Brushes.

Handles for Hoes, Shovels, Hay and Manure Forks and Rakes, in large quantities, for manufacturers of such Tools.

Cast-steel Garden Trowels, Weeding Forks, \&c. \&c.

These articles are offered for sale, in large lots, or at retail, at low prices, by PARKER \& WHI'TE, No. 10 Gerrish Block, Blackstone Street, Boston, Mass. 
Phillips, Sampson \&. Company's Publications.

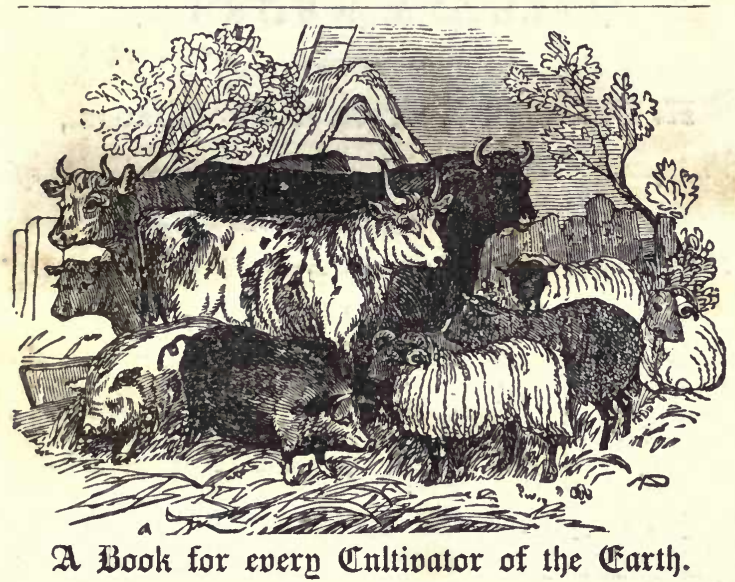

\section{VALUABLE AGRICULTURAL WORK. EUROPEAN AGRICULTURE AND RURAL ECONOMY, FOR FARMERS AND AGRICULTURALISTS. \\ FROM PERSONAL OBSERVATIONS, BY HENRY COLMAN, \\ Late Commissioner of Agriculture in Massachusetta. \\ Containing observations on}

Pairing, Burning, Drainage and Improvements of Lands ; Rules for Ploughing, subsoil Plnughing, Crops, Soils, Manures, Live Stock, Dairy, Husbandry, Narkets, Farm-Houses, Harvesting, Farming Implements, Application of Cheinistry to Agriculture, Labor, Theory of Agriculture, Moral Considerations, Agricultural Education, \&c. \&c. \&c. In two volumes, octavo,

Embellished with Fifty-four fine Engravings,

from steel plates and wood cuts, representing Farming Implements, Sheep, Cattle, Horses, \&c. \&c.

The above work is considered indispensable to any person following agricultural pursuits, and should be in the hands of every farmer throughout the country.

"There is no prinluctior, of the day, on rural affairs, that we read with more pleasure and profit." $-\boldsymbol{N}$. Y. Farmer und Mechanic.

"We know Mr. Colman, and his character warrants us in pronouncing him eminently qualifieil to execute the work he has begun." - Neio Eng. Farmur. 


\section{VALUABIE FOWLS.}

\section{H. B. Coffin, Newton Corner, Mass.,}

Will pay particular attention to the raising of

FIRST-RATE STOCK, FOR SALE.

Now on hand, among other varieties, the

\section{SHANGHAE FOWL,}

from stock originally imported by R. B. Forbes, Esq. They are very quiet, and easily kept within an enclosure four feet high. Thickly feathered upon the legs. At maturity weigh from seven to nine pounds - cocks from ten to twelve and one half pounds.

\section{COCHIN CHINA,}

similar in many respects to the ahove, with the exception of feathers upon the legs. The old cock weighs eleven and one half pounds - a very handsome bird.

\section{WHITE SHANGHAE,}

a first-rate fowl in every respect, and by many preferred to the White Dorking.

Also, POLAND, GUELDERLAND, DORKING, and other Fowls.

\section{Eggs for Hatching,}

safely packed in boxes, will be supplied from any of the above breeds.

Having twenty coops upon his premises, enables him to keep each variety entirely separate and distinct, at all seasons; and it is his determination to keep up with the times in any improvement which can be made in his stock, by importing or otherwise.

Persons not having the opportunity of seeing the fowls before purchasing may have the privilege of returning any which are not satisfactory.

Orders to be directed to

\section{No. 5 Congress Square,}




\section{LIBRARY EDITION}

OF

\section{STANDARD POETICAL WORKS.}

\section{IN UNIFORM STYLE.}

TUPPER'S POETICAL WORKS; embracing Proverbial Philosophy, Thousand Lines, Geraldine, Hactenus, and Miscellaneous Poems. Complete in 1 rol., $12 \mathrm{mo}$, muslin, fine portrait, Price $\$ 1,00$.

COWPER'S POETICAL WORKS; with Life; a new edition, 1 vol., $12 \mathrm{mo}$, with portrait. Price $\$ 1,00$.

POPE'S POETICAL WORKS; new edition, containing a Life of the Author. Price $\$ 1,00$.

BYRON'S POETICAL WORKS; with a Sketch of his Life, in 1 vol., $12 \mathrm{mo}$, and embellished with a portrait. Price $\$ 1,00$.

MOORE'S POETICAL WORKS; an entirely new edition, in 1 vol., with portrait. Price $\$ 1,00$.

BURNS'S POETICAL WORKS ; embracing a Life of the Au. thor, Glossary, and Notes. A new edition, 1 vol., $12 \mathrm{mo}$, with fine portrait. Price $\$ 1,00$.

SCOTT'S POETICAL WORKS; with a Memoir of the Author, embellished with a portrait. Price $\$ 1,00$.

LIFE, GEMS, AND BEAUTIES OF SHAKSPEARE; all embraced in 1 vol., $12 \mathrm{mo}$, containing six fine engravings and portrait. Price $\$ 1,00$.

POETICAL REMAINS OF HENRY KIRKE WHITE; containing a Memoir of the Author, with an introductory chapter on his religious and poetical development, by Rev. John Todd. Price \$1,00. 


\section{LIBRARY EDITION}

\section{OF \\ STANDARD POETICAL WORKS.}

\section{IN UNIFORM STYLE.}

HEMANS'S POETJCAL WORKS ; an entire new edition, in 1 vol., and illustrated with steel engravings. Price $\$ 1,00$.

HOWITT, COOK AND LANGDON'S POETICAL WORKS; a new edition, 1 vol., $12 \mathrm{mo}$, neat muslin. Price $\$ 1,00$.

MILTON AND YOUNG; containing Paradise Lost, and Young's Night Thoughts, a new edition, complete in 1 vol., $12 \mathrm{mo}$, with portrait. Price $\$ 1,0$ J

CROLY'S BRITISH POETS; combining the beauties of the British Poets, with introductory observations by Rev. George Croly, 1 vol., embellished with fine steel engravings. Price $\$ 1,00$.

THE POEMS OF OSSIAN; a new edition, containing ten steel engravings, and printed on fine paper, 1 vol., $12 \mathrm{mo}$. Price $\$ 1,00$.

THOMSON AND POLLOK; containing the Seasons, by James Thomson, and Course of Time, by Robert Pollok, com plete in 1 vol., $12 \mathrm{mo}$, with portrait. Price $\$ 1,00$.

WORDSWORTH'S POETICAL WORKS; an entirely new edition, from plates just stereotyped, complete in 1 vol., $12 \mathrm{mo}$, with portrait. Price $\$ 1,00$.

CAMPBELL'S POETICAL WORKS; including his Pleasures of Hope, Theodoric, and Miscellaneous Poems, many of which are not contained in the former editions. Complete in 1 rol., $12 \mathrm{mo}$, with portrait. Price $\$ 1,00$.

The above poetical works are uniform in size and binding, and are sold separately, or together. Their size and style considered, they are the cheapest library editions of the same authors before the American public. 


\section{BIOGRAPHIES, \&c.}

\section{Life of George Washington,}

Commander-in-Chief of the American Army through the Revolutionary War, and the first President of the United States.

BY AARON BANCROFT, D. D.

Illustrated with Engravings. 12mo., Muslin, $\$ 100$.

\section{LIFE AND CAMPAIGNS OF NAPOLEON BONAPARTE;}

Giving an account of all his engagements, from the Siege of Toulon to the Battle of Wuterloo; also, embracing accounts of the daring exploits of his marshals, together with his public and private life, from the commence ment of his career to his final imprisonment and death on the rock of St. Helena.

Translated from the French of

M. A. ARNAULT AND C. L. F. PANCKOUCKE. Numerous Engravings. 12mo., Muslin, $\$ 1,00$.

\section{HEROES OF THE AMERICAN REVOLUTION;}

Comprising the Lives of Washington, and his generals and officers who were the niost distinguished in the War of the Independence of the United States; also embracing the Declaration of Independence, and Signers' Names, the Constitution of the United States, and Amendments ; together with the Inaugural, First Annual, and Farewell Addresses of Washington. Four Portraits, 12mo, Muslin, $\$ 1,00$.

\section{PICTORIAL IIISTORY OF ENGLAND,}

BY HUME AND SMOLLETT.

Abridged and continued to the accession of Vicrosis.

BY JOHN ROBINSON, D. D.

Engravings, 12mo., Muslin, $\$ 1,00$.

The Life of our Blessed Lord and Saviour Jesus Christ;

To which is added, the Lives and Sufferings of his Holy Evangelists, Apostles, and other primitive Martyrs.

BY THE REV. JOHN FLEETWOOD, D. D.

Numerous Engravings, 12mo, Muslin, $\$ 1,00$.

PILGRIM'S PROGRESS,

FROM THIS WORLD TO THAT WHICH IS TO COME. BY JOHN BUNYAN.

With Notes, and a Life of the Author,

BY THE REY. THOMAS SCOTT,

Late Chaplain to the Lock Hospital.

Illustrated, 12mo, Musiin, $\$ 1,00$. 


\section{Advice to Young Ladies}

\section{ON THEIR \\ DUTIES AND CONDUCT IN LIFE.}

BY T. S. ARTHUR.

Right modes of thinking are the basis of all correct action. It is from this cause that we shall, in addressing our young friends on their duties and conduct in life, appesl at once to their rational faculty. To learn to think right is, therefore, a matter of primary concern. If there be right modes of thinking, right actions will follow as a natural consequence. - Extraot from the Author's Introduction.

Price 75 Cents.

\section{Advice to Young Men}

\section{DUTIES A ND CONDUCT IN LIFE.}

BY T. S. ARTHUR.

The aim of the author of this volume has been to lead young men to just concluslons, from reflections upon whst they are, and what are their duties in society, as integral parts of the common body. Satisfied that those who read it as it should be read cannot fill to have their good purposes strengthened, and their minds elevated into sounder views of life than usually prevail, the writer dismisses it from his hands, and tnrns to other matters demsnding his attention. - Author's Preface.

Price 75 Cento

\section{The Young Lady's Offering; OR, GEMS OF PROSE AND POETRY.}

The above is prepared especially as a gift book for young ladies, embracing a choice arrangement of prose and poetic comhination, adapting it particu?arly; as its title indicates, as an ecceptable offering to young ladies. Price $\$ 1,00$.

\section{The Young Man's Offering;}

\section{COMPRISING \\ PROSE AND POETICAL WRITINGS}

OF THE MOST EMINENT AUTHORS.

This work is intended to be, as its title indicates, a useful and entertaining companion to young men, which may cheel tliem in hours of languor and of sickness, and when the mind, exhausted by its efforts, seeks, in amusement, for the restoration of its wonted powers. Illustrated with numerous engravings. Price $\$ 1,00$. 







\section{CIRCULATION DEPARTMENT 198 Main Stacks}

\section{LOAN PERIOD 1 HOME USE}

$\overline{4}$

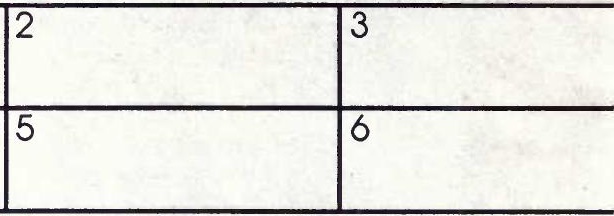

ALL BOOKS MAY BE RECALLED AFTER 7 DAYS.

Renewls and Recharges may be made 4 days prior to the due date. Books may be Renewed by calling 642-3405.

SENFOAHL

\section{DUE AS STAMPED BELOW}

U. C. BERKELEY 


\section{$17 \%$}

27,002

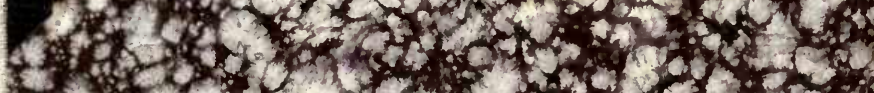

2.

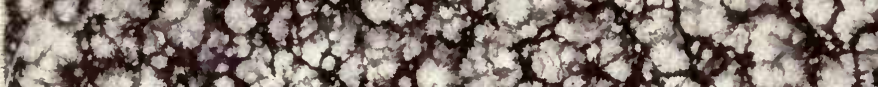

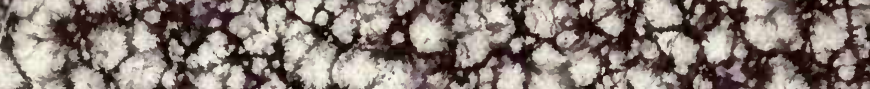

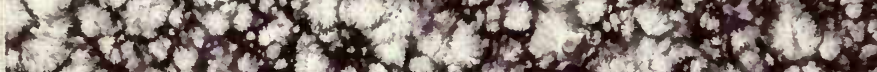
$100000 \times 100$

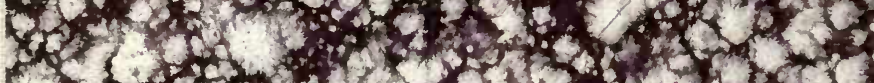
12070100001 $1 \times 2101$

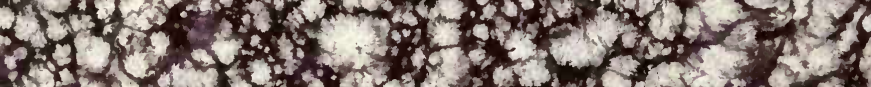

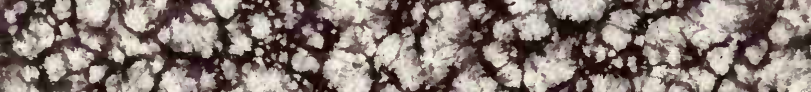

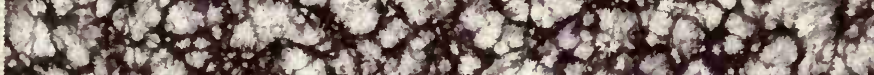

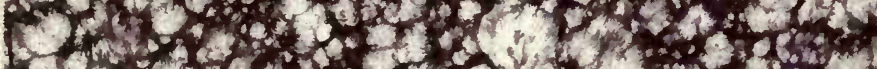

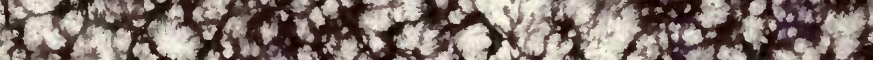

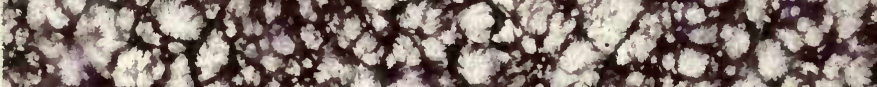

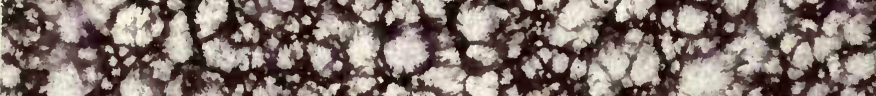

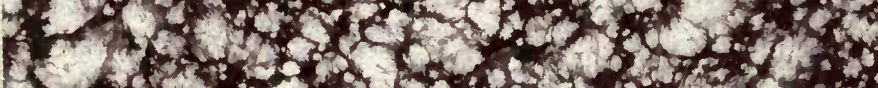

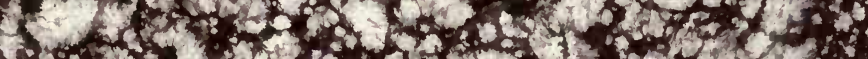

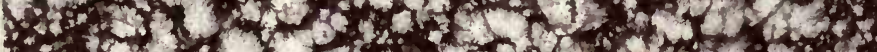

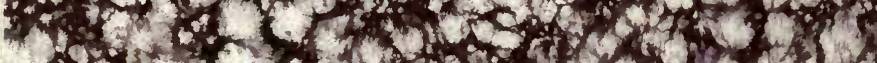

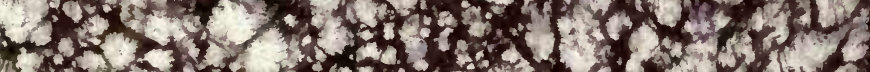

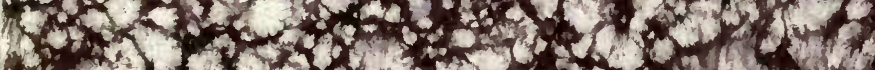

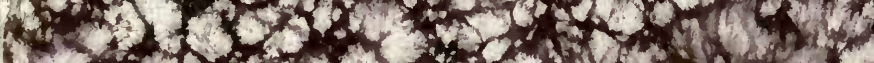

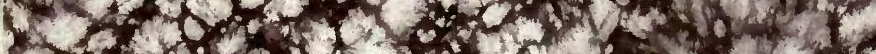
C chen 20 .

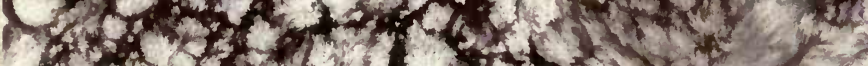
If

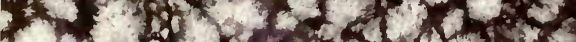

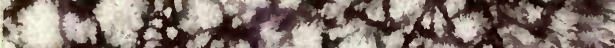

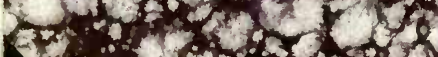




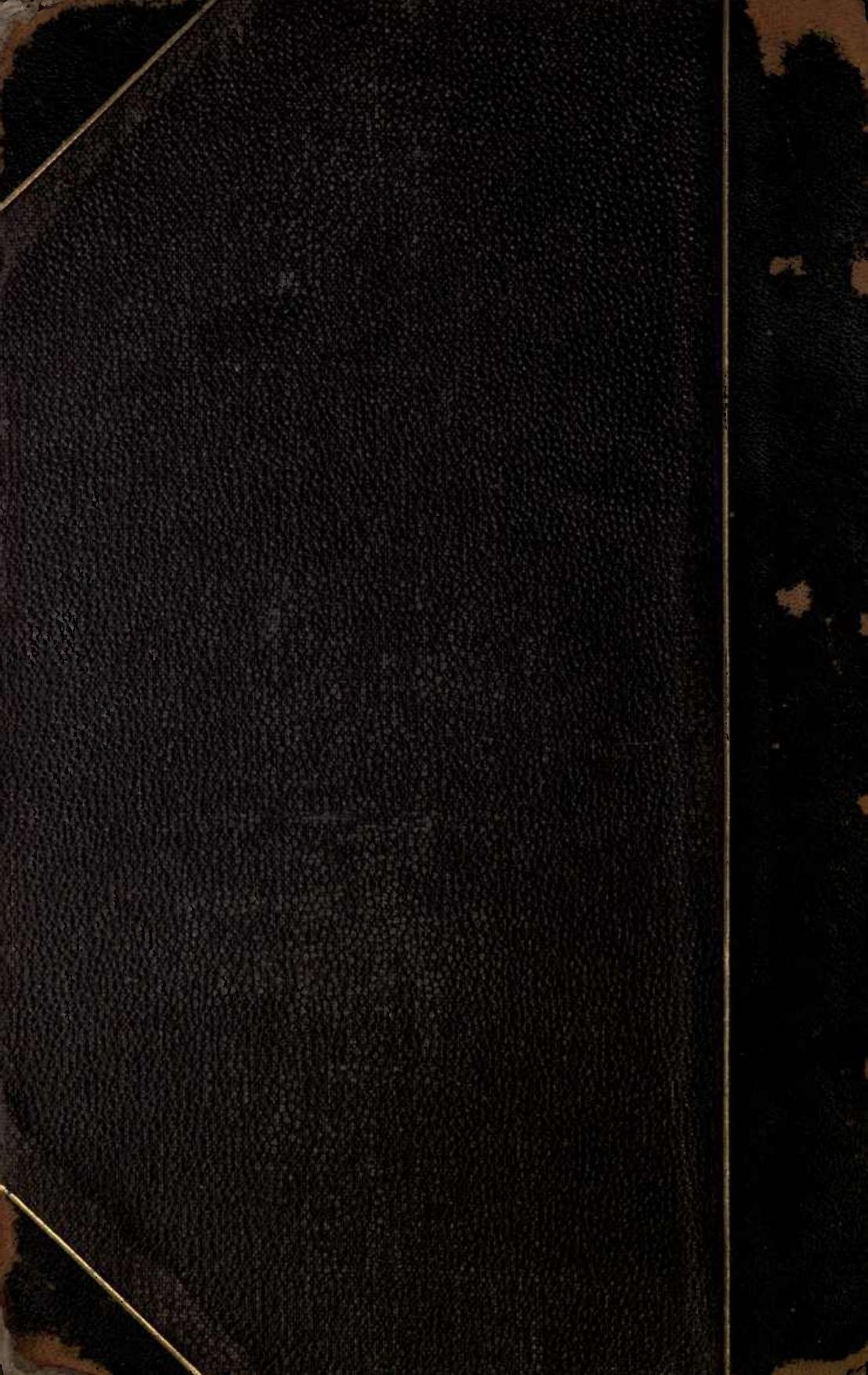

